Numerical Analysis of Thermal Stratification in Large Horizontal Thermal Energy Storage Tanks 


\title{
NUMERICAL ANALYSIS OF THERMAL STRATIFICATION IN LARGE HORIZONTAL THERMAL ENERGY STORAGE TANKS
}

BY

MAIKEL SHAARAWY, B.Sc.

\author{
A THESIS \\ Submitted to the DePARtMent of MeChanicAl Engineering \\ AND THE SCHOOL OF GRADUATE STUDIES \\ of MCMaster University \\ IN PARTIAL FULFILLMENT OF THE REQUIREMENTS \\ FOR THE DEGREE OF \\ Master of Applied Science
}

(c) Copyright by Maikel Shaarawy, September 2014

All Rights Reserved 
TITLE: Numerical Analysis of Thermal Stratification in Large Horizontal Thermal Energy Storage Tanks
AUTHOR:
Maikel Shaarawy
B. Eng., (Mechanical Engineering)
McMaster University, Hamilton, Canada
SUPERVISOR:
Dr. Marilyn Lightstone

NUMBER OF PAGES: xxiv, 171 


\section{Abstract}

In order to enhance the performance of a large horizontal thermal energy storage, a numerical model was generated and validated using measurements obtained from Drake Landing Solar Community (DLSC). A total of nine different baffle configurations were tested in order to enhance the thermal stratification. The designs were tested for a total of six different cases of charging, discharging and simultaneous charging and discharging in an attempt to better identify key features that mix the tank under realistic conditions. Characterization of the tank performance was done by monitoring the tank outlet temperature and computing Huhn's efficiency $\left(2^{\text {nd }}\right.$ Law characterization index).

Results show that the current tanks at DLSC experience excessive mixing due to plume entrainment that occurs during the spreading of the inlet jet. The introduction of a baffle into the middle of the tank was found to have no impact on the level of stratification. In addition, most designs tested have a relatively high level of stratification during charging, discharging and simultaneous charging and discharging, but fail to sustain the level of stratification when a positive buoyant jet is introduced.

It was demonstrated that the inlets and outlets should be moved to the top and bottom of the tank to eliminate stagnant fluid that is not easily discharged. Horizontal baffles are effective in allowing the inlet jet to spread horizontally but not vertically, thus reducing the mixing. Alternatively, a simple solution would be to increase the size of the inlet, which has a comparable performance to the best baffle configurations. 


\section{Acknowledgements}

I wish to express my gratitude to my supervisor, Dr. Marilyn F. Lightstone of the Department of Mechanical Engineering at McMaster University, for her support and guidance. Her expertise in this area was invaluable.

Thanks are also due to Dr. Stephen Harrison of the Department of Mechanical and Materials Engineering at Queen's University for his helpful insight for this project.

I also would like to thank Mr. Bruce Sibbitt from Natural Resources Canada for providing data of the Drake Landing Solar Community project.

The financial support by Natural Sciences and Engineering Research Council (NSERC), Smart Net-Zero Energy Buildings Strategic Research Network is acknowledged with gratitude.

The CFD simulation code provided by ANSYS CFX and the high performance computing cluster SHARCNET, without which this work would not have been possible.

I thank my parents, sister, cousin, and my wonderful niece for their support and encouragement. Without their help, this thesis would not have been possible.

Last but not least, to my colleagues at the CFD lab, I would like to thank them for their assistance and encouragement. 


\section{Glossary of Terms}

\section{Acronyms and Abbreviations}

\begin{tabular}{ll} 
Symbol & Definition \\
\hline \hline BTES & Borehole Thermal Energy Storage \\
CFD & Computational Fluid Dynamics \\
DLSC & Drake Landing Solar Community \\
STTS & Short Term Thermal Storage \\
TES & Thermal Energy Store/Thermal Energy Storage \\
TST & Thermal Storage Tank
\end{tabular}

\section{Physical Properties}

\begin{tabular}{ll} 
Symbol & Definition \\
\hline \hline$c_{p}$ & Specific heat $(J / k g K)$ \\
$D$ & Diameter $(m)$ \\
$E$ & Thermal Energy $(J)$ \\
$\mathrm{f}$ & Distance between baffle and bottom of the tank $(m)$ \\
$g$ & Gravitational acceleration $\left(\mathrm{m} / \mathrm{s}^{2}\right)$
\end{tabular}




\begin{tabular}{|c|c|}
\hline Symbol & Definition \\
\hline g & Diameter of the center hole $(m)$ \\
\hline$H$ & $\begin{array}{l}\text { Height of tank/vertical distance between inlet and outlet } \\
(m)\end{array}$ \\
\hline$h$ & Heat transfer coefficient $\left(W /\left(m^{2} K\right)\right.$ \\
\hline$k$ & Thermal conductivity $(W /(m K))$ \\
\hline$L$ & Length of tank $(m)$ \\
\hline$m_{\text {store }}$ & Mass of fluid within the tank $(k g)$ \\
\hline$\dot{m}$ & Mass flow rate in or out of tank $(\mathrm{kg} / \mathrm{s})$ \\
\hline$M_{E}$ & Moment of Energy $(\mathrm{Jm})$ \\
\hline$M I X_{D a v}$ & MIX number \\
\hline $\operatorname{Pr}$ & Prandtl number \\
\hline$\dot{Q}$ & Rate of heat transfer $(W)$ \\
\hline$S T_{W U}$ & Stratification coefficient $\left(K^{2}\right)$ \\
\hline$T$ & Temperature $(K)$ \\
\hline$t$ & Time $(s)$ \\
\hline$t_{d}$ & $\begin{array}{l}\text { Time at which temperature difference degrades more } \\
\text { than } 20 \%(s)\end{array}$ \\
\hline$u$ & Velocity $(m / s)$ \\
\hline$\xi$ & Exergy/Available energy/Potential for work $(J)$ \\
\hline$\eta$ & Efficiency \\
\hline$\Delta t$ & Time-step size $(s)$ \\
\hline$\beta$ & Thermal Expansion Coefficient $(1 / K)$ \\
\hline$v$ & Kinematic viscosity $\left(m^{2} / s\right)$ \\
\hline
\end{tabular}




\section{Subscripts}

\begin{tabular}{|c|c|}
\hline Symbol & Definition \\
\hline Accumulated & Value stored in the tank \\
\hline ambient & Value of the environment surrounding the tank \\
\hline $\operatorname{avg}$ & Average value of fluid within the tank \\
\hline cylinder & Value lost from the cylindrical surface of the tank \\
\hline Destruction or Dest & Value destroyed in the tank \\
\hline$f$ & Value at film \\
\hline final & Final value of fluid within the tank \\
\hline$h l$ & Value including heat loss from the tank \\
\hline$i$ & Value contained within a fluid element, i \\
\hline ideal & $\begin{array}{l}\text { Value for a TES operating under perfectly stratified con- } \\
\text { dition }\end{array}$ \\
\hline in & Value of inlet fluid \\
\hline initial & Initial value within the tank \\
\hline lost & Losses due to irreversible processes \\
\hline mixed & Value for a TES operating under a fully mixed condition \\
\hline out & Value leaving the tank \\
\hline real & Value for the simulated or experimental TES \\
\hline$s$ & Value at the surface \\
\hline sides & Value lost from the sides of the tank \\
\hline Simulated & Value obtained from numerical simulation \\
\hline Surface & Value at the surface of the tank \\
\hline stored & Value stored within the tank \\
\hline
\end{tabular}




\begin{tabular}{|c|c|}
\hline Symbol & Definition \\
\hline$Z G$ & First law recoverable heat efficiency \\
\hline 0 & Value at reference/dead-state \\
\hline $2, C h$ & First law charging and discharging efficiency \\
\hline$\xi, H u$ & Second law Huhn's stratification efficiency \\
\hline$\xi, S h$ & Second law exergy or entropy efficiency \\
\hline$\xi, V B$ & Second law van Berkel's stratification efficiency \\
\hline$\infty$ & Value at infinity \\
\hline \multicolumn{2}{|c|}{ Dimensionless Groups } \\
\hline Symbol & Definition \\
\hline$F r$ & Froude Number(1/sqrtRi) \\
\hline$G r$ & Grashof Number $\left(g \beta\left(T_{i n}-T-i n i\right) / v^{2}\right)$ \\
\hline$N u$ & Nusselt Number $(h L / k)$ \\
\hline$R a$ & Raleight number $(G r P r)$ \\
\hline$R e$ & Reynolds Number $\left(u_{i n} D / \beta\right)$ \\
\hline$R i$ & Richardson Number $\left(g \beta\left(T_{i n}-T_{\text {initial }}\right) H / u_{\text {in }}^{2}\right)$ \\
\hline $\operatorname{Pr}$ & Prandtl Number \\
\hline
\end{tabular}




\section{Contents}

Abstract $\quad$ iii

Acknowledgements $\quad$ iv

Glossary of Terms $\quad$ v

1 Introduction 1

1.1 Solar Thermal Systems . . . . . . . . . . . . . . . . 2

1.2 Stratification . . . . . . . . . . . . . . . 3

1.3 Drake Landing Solar Community . . . . . . . . . . . . . . . . 3

1.4 Short Term Thermal Storage (STTS) Tanks . . . . . . . . . . . . . 5

1.5 Problem ............................. 8

1.6 Objectives and Approach . . . . . . . . . . . . . . . 8

1.7 Outline of Thesis . . . . . . . . . . . . . . . . 9

2 Literature Review $\quad 10$

2.1 Stratification . . . . . . . . . . . . . . . . 10

2.1.1 Inlet Jet Mixing . . . . . . . . . . . . . . . . . . . 11

2.1.2 Plume Entrainment . . . . . . . . . . . . . . 13 
2.1.3 Key Dimensionless Groups . . . . . . . . . . . . . . . . . . . 14

2.2 Methods to Enhance Stratification . . . . . . . . . . . . . . 16

2.2 .1 Baffles ........................... 16

2.2.2 Diffusers ........................ 25

2.2 .3 Stratifiers . . . . . . . . . . . . . . . . 27

2.3 Methods of Assessing Stratification . . . . . . . . . . . . . . . . 32

2.3.1 Graphical .................... 33

2.3.2 First Law Efficiencies . . . . . . . . . . . . . . . . . . 34

2.3.3 Second Law Efficiencies . . . . . . . . . . . . . . . . . . 35

2.4 System Simulation Models . . . . . . . . . . . . . . . . . 37

2.5 Computational Fluid Dynamics Modelling of TST . . . . . . . . . . . 40

2.6 Summary . . . . . . . . . . . . . . . . . . . 42

\section{Development and Validation of CFD Simulation Model for STTS} tanks at DLSC 43

3.1 Geometry and Boundary Conditions . . . . . . . . . . . . 43

3.2 Grid Development . . . . . . . . . . . . . . . . . . . 45

3.3 Simulation Methodology . . . . . . . . . . . . . . 46

3.3.1 Solver Settings . . . . . . . . . . . . . . . 46

3.3.2 Timestep Independence Tests . . . . . . . . . . . . . . . . . 47

3.3.3 Grid Independence: Axial Direction . . . . . . . . . . . . . . . 48

3.3.4 Grid Independence: Tank Cross Section _. . . . . . . . . . . 51

3.4 Validation Against DLSC Measurements . . . . . . . . . . . 53

3.5 Summary . . . . . . . . . . . . . . . . . 58 
4 Tank Design and CFD Analysis $\quad 59$

4.1 Existing Designs . . . . . . . . . . . . . . . 61

4.2 New Designs. . . . . . . . . . . . . . . . . 62

4.3 Mesh Summary . . . . . . . . . . . . . . . . . 67

4.4 Results \& Discussion . . . . . . . . . . . . . . . . . . . . . . 69

4.4.1 Case 1: Discharging of a Fully Mixed Hot Tank with Constant Discharging Inlet Temperature . . . . . . . . . . . . 70

4.4.2 Case 2: Charging of a Fully Mixed Cold Tank with Constant Charging Inlet Temperature . . . . . . . . . . . . . . 81

4.4.3 Case 3: Discharging of a Pre-stratified Tank with Constant Discharging Inlet Temperature . . . . . . . . . . . . . . . . . 90

4.4.4 Case 4: Simultaneous Charging and Discharging of a Pre-stratified Tank with Constant Charging Inlet Temperature . . . . . . . 97

4.4.5 Case 5: Charge a Pre-stratified Tank with Decreasing Charging Inlet Temperature . . . . . . . . . . . . . . . . 106

4.4.6 Case 6: Simultaneous Charging and Discharging a Pre-stratified Tank with Decreasing Charging Inlet Temperature . . . . . . 115

4.5 Conclusion . . . . . . . . . . . . . . . . . 126

5 Conclusion and Future Work $\quad 129$

5.1 Performance of the Large Horizontal STTS Tank Designs . . . . . . . 129

5.2 Analysis of the Cases Utilize to Test the STTS Tank Designs . . . . . 131

5.3 Recommendations for Future Work . . . . . . . . . . . . . . 133

A Justification of Assumptions used in the Numerical Solution 142 
A.1 Heat Loss from Tank by Natural Convection . . . . . . . . . . . . . . 142

A.1.1 Heat Loss From the Horizontal Cylinder . . . . . . . . . . . . 142

A.1.2 Heat Loss Through the Sides of the Tank . . . . . . . . . . . . 145

A.1.3 Total Energy Loss Through Tank . . . . . . . . . . . . . . . . 146

A.1.4 Energy Leaving the Tank During Discharging . . . . . . . . . 147

A.1.5 Error Introduced by Assuming No Heat Loss from Tank .. . 147

A.2 Heat Conduction Through Tank Wall . . . . . . . . . . . . . . . . . 148

A.3 Heat conduction Through Baffles . . . . . . . . . . . . . . . . 148

B TES Analysis $\quad 150$

B.1 Fully Mixed Tank Temperature . . . . . . . . . . . . . . . . . . 150

B.2 Energy . . . . . . . . . . . . . . . . . . 152

B.3 Exergy . . . . . . . . . . . . . . . . . . . 152

B.3.1 TES Charging ..................... 153

B.3.2 TES Discharging . . . . . . . . . . . . 153

B.4 Huhn's Efficiency . . . . . . . . . . . . . . . . . 154

B.5 Tank Turn Over Time . . . . . . . . . . . . . . . . . . 154

C Detailed Drawings and Meshes of Nine Designs Tested 155

C.1 Design 1: Tank Without Baffles . . . . . . . . . . . . . . . 155

C.2 Design 2: Current Tank at DLSC . . . . . . . . . . . . . . 157

C.3 Design 3: Rysanek's Best Performing Tank . . . . . . . . . . . . . . . 158

C.4 Design 4: Rysanek's Tank with Middle Baffle . . . . . . . . . . . . 159

C.5 Design 5: Rysanek's Tank with Redirecting Baffles . . . . . . . . . 160

C.6 Design 6: Tank with Top and Bottom Inlet and Outlet . . . . . . . . 161 
C.7 Design 7: Tank with Vertical Baffles . . . . . . . . . . . . 163

C.8 Design 8: Tank Without Baffles and a Discharge Inlet of $200 \mathrm{~mm}$. . 164

C.9 Design 9: Tank Without Baffles and a Discharge Inlet of $400 \mathrm{~mm}$. . 165

$\begin{array}{ll}\text { D Grid Independence Test for Tank } 6 & 167\end{array}$

$\begin{array}{ll}\text { E Tank } 3 \text { without Buoyancy } & 170\end{array}$ 


\section{List of Tables}

3.1 Accuracy of the different grid intensities in the axial direction . . . . 50

3.2 Accuracy of the different grid intensities in the radial direction . . . . 52

3.3 Maximum deviation between different turbulence models and measured results in degrees . . . . . . . . . . . . . . . . . 57

4.1 Summary of initial and boundary conditions used for the six different test cases . . . . . . . . . . . . . . . . . . . 60

4.2 Richardson number for the tank without baffles during discharging at different tank diameters . . . . . . . . . . . . . . 66

4.3 Detailed information of the grids used to resolve the different tank designs . . . . . . . . . . . . . . . . . . . . . 68

4.4 Summary of results of the performance of nine different design undergoing six different test cases . . . . . . . . . . . . . . . . 126 


\section{List of Figures}

1.1 Typical Canadian household energy use in 2009 [2] . . . . . . . . . . 2

1.2 A simplified solar thermal system [5] . . . . . . . . . . . . . 3

1.3 Simplified illustration of the current system in use at DLSC [3] . . . . 5

1.4 Design of the DLSC STTS tanks $[6] \ldots \ldots \ldots$. . . . . . . 6

1.5 Location of inlet/outlet ports on the STTS tanks (not to scale) [6] . . 6

1.6 Location of the temperature sensors in the STTS tanks (identical on both tanks) $[6] \ldots \ldots \ldots \ldots$. . . . . . . . . . . . . . 7

2.1 Discharging of a fully charged horizontal tank with a horizontal inlet [9] 11

2.2 Discharging of a fully charged horizontal tank with a horizontal inlet and penetration through all hot fluid layers due to impingement on side wall $[9] \ldots \ldots \ldots$

2.3 Discharging of a fully charged vertical tank with a vertical inlet [10] . 12

2.4 Plume Entrainment into a vertical tank while charging [5] . . . . . . 14

2.5 Temperature distribution in the tank center plane after 5 min of 10 1/min inlet flow, Left: raw pipe Center: pipe with a small hemispherical baffle plate. Right: pipe with a large flat baffle plate [10] (top hot fluid is at $318.15 \mathrm{~K}$ and bottom cold fluid is at $283.15 \mathrm{~K}$ ). . . . . . . . 18 
2.6 Configuration of Design 11 tested by Altuntop et al [20] and Arslan et al. $[21] \ldots \ldots \ldots \ldots$

2.7 Detailed view of the different obstacles tested $[20] \ldots \ldots$

2.8 Temperature contour plots of the simulation of designs 1 to $6[20]$. . 20

2.9 Temperature contour plots of the simulation of designs 7 to 12 [20] . . 21

2.10 Schematic of tanks being studied by Aviv et al. [9], left: tank without deflectors, right: tank with a deflector at the bottom inlet . . . . .

2.11 Mixing in horizontal tank, a) excess mixing due to the discharging inlet jet, b) reduced mixing after adding a deflector at the entrance of the inlet $[9] \ldots \ldots \ldots \ldots \ldots$

2.12 Different baffle configurations investigated by Rysanek in order to enhance the performance of the STTS at DLSC [6] . . . . . . . . . . 24

2.13 Diffuser configurations studied by Hegazy [22] . . . . . . . . . . . 26

2.14 Diffuser configuration studied by Chung et al. Left: the layout of the diffuser within the tank. Right: a) radial plate, b) radial adjusted plate, and c) H-beam diffuser [23] . . . . . . . . . . . . . . . 27

2.15 Layout of the rigid stratifier tested by Shah et al. [25] . . . . . . . 28

2.16 Two fabric stratifiers during a heating experiment. Upper right corner: cross section of the expanded fabric where hot water leaves the pipe, lower right corner: cross section of the collapsed fabric in order to prevent outside water from entering the pipe $[27]$. . . . . . . . . . . 29

2.17 Left: illustration of the patent idea presented by Lorenz, right: illustration of the fluid flow around the channels in order to spread and achieve the correct fluid level $[30] \ldots \ldots$. . . . . . . . . . 
2.18 An illustration of the vertical parallet plates that help stratify the tank

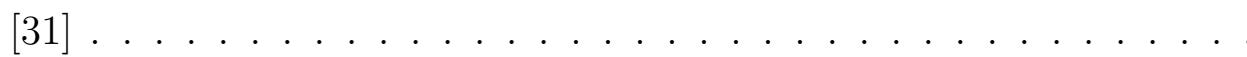

2.19 Comparison of different degrees of stratification using a temperature versus height graph where a) left, highly stratified, b) center, moderately stratified, c) right, fully mixed [32] . . . . . . . . . . . . . . 33

2.20 Illustration of the difference in the value of $t_{d}$ between fully mixed and perfectly stratified tank . . . . . . . . . . . . . . . 35

2.21 Schematic of the node distribution inside a one dimensional tank [11] 39

3.1 Schematic of the current horizontal tank at DLSC (Not to scale) . . 44

3.2 A coarsened mesh of the STTS tank at DLSC . . . . . . . . . . 45

3.3 Temperature profile within the tank at 30 minutes, 1 hours, and 1.5 hours into discharging showing the results using $0.75 \mathrm{~s}$ and $1.5 \mathrm{~s}$ timestep in order to prove timestep independence . . . . . . . . . . . . . . . 48

3.4 The mesh of the chosen cross section and the three axial grid intensities

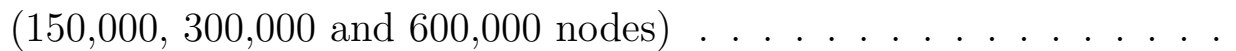

3.5 Temperature profile within the tank at 30 minutes, 1 hour and 1.5 hours into discharging showing the results using different axial grid intensities for a total of 150,000, 300,000, and 600,000 nodes. . . . .

3.6 The mesh of the chosen axial grid and the three cross sectional grid intensities $(150,000,300,000$ and 1,200,000 nodes $) \ldots . . . . .$.

3.7 Temperature profile within the tank at 30 minutes, 1 hour and 1.5 hours into discharging showing the results using different cross sectional grid intensities for a total of 150,000,300,000, and 1,200,000 nodes. . . . 
3.8 Transient profile of inlet temperature during charging (Data for: October 23,2007$)[7] \ldots \ldots \ldots \ldots$

3.9 Transient profile of inlet velocity during charging (Data for: October

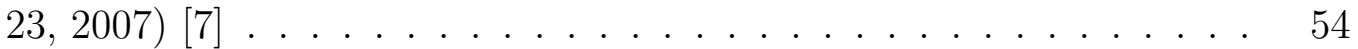

3.10 Location of temperature sensors in STTS tanks at DLSC (Not to scale) 55

3.11 Transient simulated and actual temperature at the top sensor of the hot tank showing the predictions using the $k-\omega \mathrm{SST}$ and $k-\omega$ turbulence

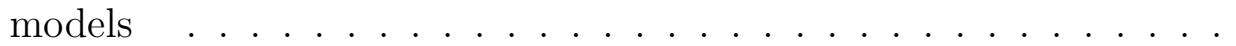

3.12 Transient simulated and actual temperature at the middle sensor of the hot tank showing the predictions using the $k-\omega$ SST and $k-\omega$ turbulence models . . . . . . . . . . . . . . . . . . 56

3.13 Transient simulated and actual temperature at the bottom sensor of the hot tank showing the predictions using the the $k-\omega \mathrm{SST}$ and $k-\omega$ turbulence models . . . . . . . . . . . . . . . . 57

4.1 Tank 1, horizontal tank without baffles (Not to scale) . . . . . . . 61

4.2 Tank 2, current DLSC horizontal tank (Not to scale) . . . . . . . . 62

4.3 Tank 3, Rysanek's recommended tank (Not to scale) . . . . . . . . . 62

4.4 Tank 4, addition of a middle baffle to Tank 3 (Not to scale) . . . . . 63

4.5 Tank 5, addition of two redirecting baffles to Tank 3 (Not to scale) . 63

4.6 Tank 6, horizontal tank with top and bottom baffles with inlet and outlet moved to the center of the tank (Not to scale) . . . . . . . . . 64

4.7 Tank 7, horizontal tank with vertical baffles (Not to scale) . . . . . 65

4.8 Plot showing the length of the mixing region compared to the length of the tank as a function of Richardson number [13] . . . . . . . . . . 66 
4.9 Tank 8, horizontal tank without baffles with a discharging inlet diameter of $200 \mathrm{~mm}$ (Not to scale) . . . . . . . . . . . . . 67

4.10 Tank 9, horizontal tank without baffles with a discharging inlet diameter of $400 \mathrm{~mm}$ (Not to scale) . . . . . . . . . . . . . 67

4.11 Schematic of the different loops at DLSC under discharging showing the configurations of the inlets and outlets of the STTS tanks. The simulated discharging case is focused on the cold tank. . . . . . . . . 71

4.12 Transient temperature of fluid leaving the top of the tank for 9 different designs during simulation of Case 1 . . . . . . . . . . . . . . . . 72

4.13 Huhn's efficiency for 9 different designs during simulation of Case 1 . 73

4.14 Temperature contour plot of 9 different designs 15 minutes into simulation of Case 1. Cold inlet jet causes significant mixing at the bottom of the tank. . . . . . . . . . . . . . . . . .

4.15 Temperature contour plot of 9 different designs 3.5 hours into simulation of Case 1. Essentially stagnant pocket of fluid below the middle baffle of Tanks 2 and 4 that contributes into the destratification of the tank. . . . . . . . . . . . . . . . .

4.16 Temperature contour plot of 9 different designs 7 hours into simulation of Case 1. Stagnant fluid at the top of all tanks except for Tank 6 that is not easily accessed that contributes into the destratification of the tank. . . . . . . . . . . . . . . . .

4.17 Schematic of the different loops at DLSC under charging showing the configurations of the inlets and outlets of the STTS tanks. The simulated charging case is focused on the hot tank. . . . . . . . . . . 
4.18 Transient temperature of fluid leaving the bottom of the tank for 5

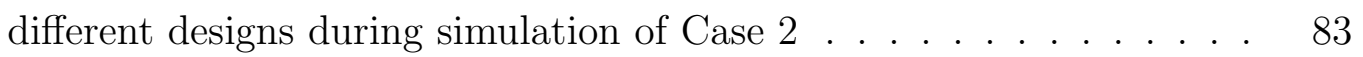

4.19 Huhn's efficiency for 5 different designs during simulation of Case 2 . 84

4.20 Temperature contour plot of 5 different designs 5 minutes into simulation of Case 2. Hot inlet jet causes significant mixing at the top of the tank. . . . . . . . . . . . . . . . .

4.21 Temperature contour plot of 5 different designs 1.25 hours into simulation of Case 2. Essentially stagnant pocket of fluid above the middle baffle of Tank 4 contributes to the tank destratification. . . . . . . .

4.22 Temperature contour plot of 5 different designs 2.4 hours into simulation of Case 2. Essentially stagnant pocket of fluid above the bottom baffles contributes to the tank destratification. . . . . . . . . . .

4.23 Temperature contour plot of 5 different designs 3 hours into simulation of Case 2. Stagnant cold fluid at the bottom of the Tanks 3, 4, 5, and 8 is not accessible and degrades tank performance. . . . . . . . . .

4.24 Transient temperature of fluid leaving the top of the tank for 5 different designs during simulation of Case $3 \ldots \ldots \ldots$

4.25 Huhn's efficiency for 5 different designs during simulation of Case 3. Huhn's efficiency of Tanks 3 and 5 overlap. . . . . . . . . . . .

4.26 Temperature contour plot of 5 different designs 15 minutes into simulation of Case 3. Cold inlet jet causes significant mixing at the bottom of the tank. . . . . . . . . . . . . . . . 
4.27 Temperature contour plot of 5 different designs 2.9 hours into simulation of Case 3. Essentially stagnant pocket of fluid below the middle baffle of Tank 4 that contributes into the destratification of the tank.

4.28 Temperature contour plot of 5 different designs 7 hours into simulation of Case 3. Stagnant fluid at the top of all tanks except for Tank 6 that is not easily accessed that contributes into the destratification of the tank. . . . . . . . . . . . . . . . . .

4.29 Schematic of the tanks at Drake Landing Solar Community showing that the hot tank has multiple outlets but only one inlet for our specific case of simultaneous charging and discharging from the solar collector to space heating . . . . . . . . . . . . . .

4.30 Transient temperature of fluid leaving the top of the tank for 5 different designs during simulation of Case 4. Note: the transient outlet temperature curves for Tanks 3 to 5 overlap. . . . . . . . . . .

4.31 Transient temperature of fluid leaving the bottom of the tank for 5 different designs during simulation of Case 4. Note: the transient outlet temperature curves for Tanks 3 and 5 overlap. . . . . . . . . . 100

4.32 Huhn's efficiency for 5 different designs during simulation of Case 4 . 101

4.33 Temperature contour plot of 5 different designs 5 minutes into simulation of Case 4. Inlet jet mixing taking place at the top of the tank degrading the level of stratification. . . . . . . . . . . . . . . . . 102

4.34 Temperature contour plot of 5 different designs 2 hours into simulation of Case 4. Essentially stagnant pocket of fluid above the middle baffle of Tank 4 contributes to the tank destratification. . . . . . . . . . . 103 
4.35 Temperature contour plot of 5 different designs 5 hours into simulation of Case 4. Stagnant cold fluid at the bottom of the tank that is not accessible and degrades tank performance. . . . . . . . . . . . . . 104

4.36 Transient temperature of fluid leaving the bottom of the tank for 6 different designs during simulation of Case 5 . . . . . . . . . . 108

4.37 Huhn's efficiency for 6 different designs during simulation of Case 5 . 109

4.38 Temperature contour plot of 6 different designs 15 minutes into simulation of Case 5. Inlet jet mixing taking place at the top of the tank degrading the level of stratification. . . . . . . . . . . . . . . . 110

4.39 Temperature contour plot of 6 different designs 55 minutes into simulation of Case 5. Plume entrainment resulting in excessive mixing. . . 111

4.40 Temperature contour plot of 6 different designs 1.25 hours into simulation of Case 5. The inability for the middle baffle to reduce the damage generate from plume entrainment. . . . . . . . . . . . .

4.41 Temperature contour plot of 6 different designs 3 hours into simulation of Case 5. Plume entrainment completely mixes the tank. . . . . . . . 113

4.42 Transient temperature of fluid leaving top of the tank for 6 different designs during simulation of Case $6 \ldots \ldots$. . . . . . . . . 116

4.43 Transient temperature of fluid leaving bottom of the tank for 6 different designs during simulation of Case $6 \ldots$. . . . . . . . . . . . . 117

4.44 Huhn's efficiency for 6 different designs during simulation of Case $6 \quad 118$ 
4.45 Temperature contour plot of 6 different designs 15 minutes into simulation of Case 6. Inlet jet mixing taking place at the top of the tank which contributes to the destratification of the tank. The curves for Tank 3 and 4 overlap. . . . . . . . . . . . . . . . . . . . 119

4.46 Temperature contour plot of 6 different designs 1 hour into simulation of Case 6. Plume entrainment resulting in excessive mixing at the top of the tank. . . . . . . . . . . . . . . . . 120

4.47 Temperature contour plot of 6 different designs 1.5 hours into simulation of Case 6 . The middle baffle of Tank 2 is ineffective in reducing the damaging effect of plume entrainment. . . . . . . . . . . . . 121

4.48 Temperature contour plot of 6 different designs 5 hours into simulation of Case 6. The tanks are all completely mixed by the end of the simulation. . . . . . . . . . . . . . . . . 122

5.1 Summary of all tanks investigated (Not to scale) . . . . . . . . . . 131

A.1 Speed of the thermocline within a tank during a discharging cycle similar to Case 1 . . . . . . . . . . . . . . . . . . . . . . . 149

B.1 Illustration of a fully mixed tank . . . . . . . . . . . . . . . . . . 151

C.1 Detailed drawing of Design 1 (tank without baffles) . . . . . . . . . 155

C.2 Mesh for Design 1 (tank without baffles) . . . . . . . . . . . . 156

C.3 Detailed drawing of Design 2 (current tank at DLSC) . . . . . . . . . 157

C.4 Mesh for Design 2 (current tank at DLSC) . . . . . . . . . . . . . 157

C.5 Detailed drawing of Design 3 (Rysanek's best performing tank) . . . . 158

C.6 Mesh for Design 3 (Rysanek's best performing tank) . . . . . . . . . . 158

C.7 Detailed drawing of Design 4 (Rysanek's tank with a middle baffle) . 159 
C.8 Mesh for Design 4 (Rysanek's tank with a middle baffle) $\ldots \ldots$. . . 159

C.9 Detailed drawing of Design 5 (Rysanek's tank with redirecting baffles) 160

C.10 Mesh for Design 5 (Rysanek's tank with redirecting baffles) . . . . . . 160

C.11 Detailed drawing of Design 6 (tank with top and bottom inlet and outlet)161

C.12 Mesh for Design 6 (tank with top and bottom inlet and outlet) . . . . 162

C.13 Detailed drawing of Design 7 (tank with vertical baffles) $\ldots . . . .163$

C.14 Mesh for Design 7 (tank with vertical baffles) . . . . . . . . . 163

C.15 Detailed drawing of Design 8 (tank without baffles and a discharge inlet of $200 \mathrm{~mm}) \ldots \ldots \ldots \ldots$. . . . . . . . . . . 164

C.16 Mesh for Design 8 (tank without baffles and a discharge inlet of 200

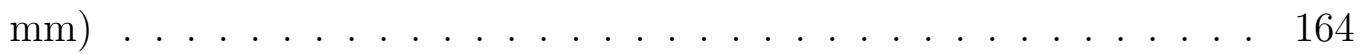

C.17 Detailed drawing of Design 9 (tank without baffles and a discharge inlet of $400 \mathrm{~mm}) \ldots \ldots \ldots \ldots \ldots \ldots \ldots$

C.18 Mesh for Design 9 (tank without baffles and a discharge inlet of 400

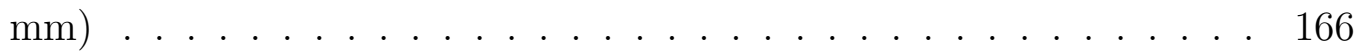

D.1 Transient top outlet temperature of an initial hot tank during discharging showing the difference between a 300,000, 1,200,000 nodes grids . 168

D.2 Huhn's efficiency of an initially hot tank during discharging showing the difference between a $300,000,1,200,000$ nodes grids $\ldots \ldots \ldots$

E.1 Transient temperature contour plots of Tank 3. Left: tank with buoyancy activated, Right: tank without buoyancy The tank inlet is located at the bottom right of the tank while the outlet is located at the top

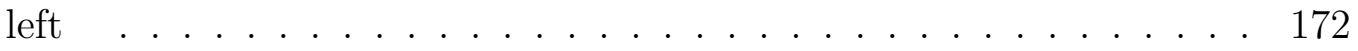




\section{Chapter 1}

\section{Introduction}

The continuously rising cost of energy, which is primarily related to the scarcity of resources used to produce power, has a huge impact on today's economy. Moreover, the combustion of fossil fuels with the associated greenhouse gas production has been linked with climate change. Solar energy is a promising alternative source of energy because it is abundant and has minimal greenhouse gases associated with its collection. In fact, solar energy is the most abundant source of energy on earth [1].

Solar energy can be harnessed using either photovoltaic or solar thermal conversion devices. Solar thermal systems are ideally suited to offset heating loads which compose $80 \%$ of a typical Canadian household energy consumption [2] (space heating and water heating combined) as shown in Figure 1.1 ${ }^{1}$. Indeed, most Canadian cities receive about $5.3 \mathrm{GJ} / \mathrm{m}^{2}$ of yearly solar radiation (on a south facing surface with slope equal to the latitude) [3], and the typical Canadian house yearly energy consumption is about 105 GJ [4], as a result five solar panels $\left(3 \mathrm{~m}^{2}\right)$ per house will provide enough

\footnotetext{
${ }^{1}$ The household energy consumption takes into consideration the consumption of natural gas, electricity, wood, heating oil and propane.
} 
energy to offset the heating load.

There is a mismatch, however, between the availability of solar energy and the demand of energy since solar energy is plentiful during the summer while the heating load increases during the winter. This mismatch proves to be the main obstacle that has to be overcome in order to make solar thermal systems a viable option to balance the heating loads. This problem can be solved by employing a thermal storage.

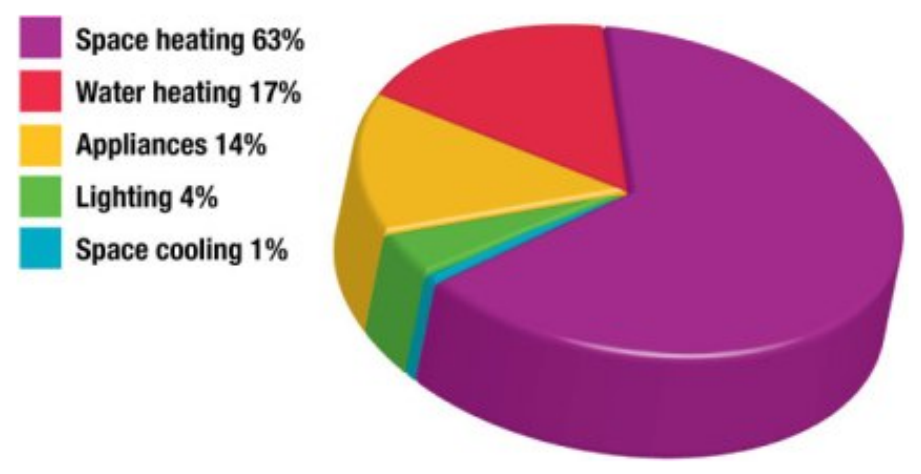

Figure 1.1: Typical Canadian household energy use in 2009 [2]

\subsection{Solar Thermal Systems}

A simple solar thermal system consists of three main components: solar collector, thermal storage tank (TST) and auxiliary heater, as shown in Figure 1.2. If the fluid within the TST is cold and there is solar radiation incident on the solar collector, then cold water is pumped out of the TST into the solar collector. Hot water leaves the solar collector entering the top of the TST. If there is a heat load that needs to be met, cold water is added to the TST and hot water is pumped out of it. The hot water goes into the auxiliary tank for additional heating if required. 


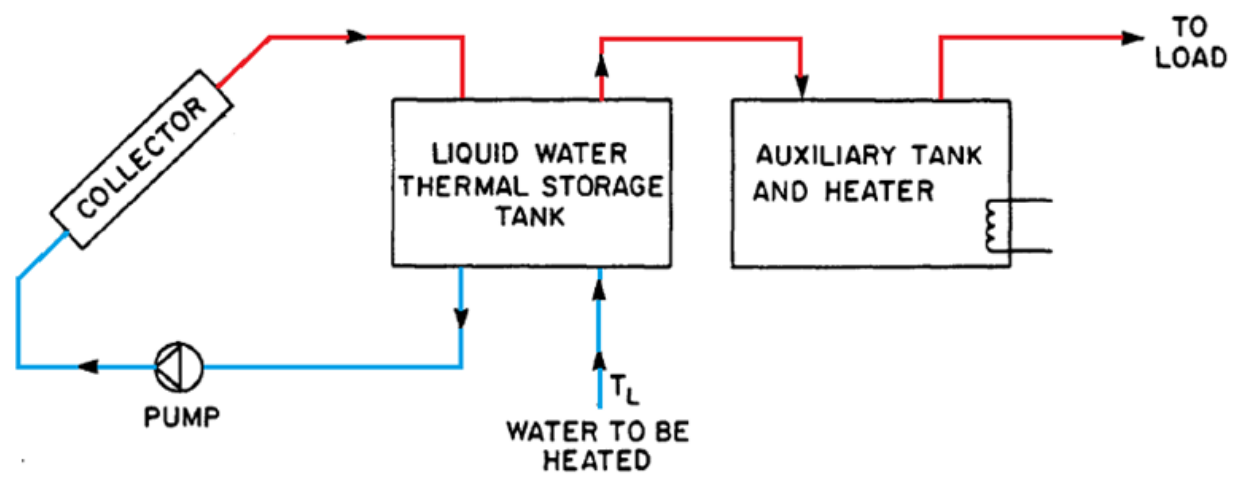

Figure 1.2: A simplified solar thermal system [5]

\subsection{Stratification}

The performance of the entire system can be improved through thermal stratification of the storage tank. Stratification is the vertical layering of water due to density difference, so cold water sinks to the bottom of the tank and hot water floats to the top of the tank. Improving the thermal stratification within a TST can improve the entire system performance by up to $37 \%$ when compared to a fully mixed tank [5]. This is due to the increase in solar collector efficiency since cooler fluid from the bottom of the tank enters the collector which reduces collector heat losses to the environment. Moreover, a well stratified tank will retain warmer fluid at the top and will eventually discharge it to the user, thus reducing the need for auxiliary heating.

\subsection{Drake Landing Solar Community}

The Drake Landing Solar Community (DLSC) is located in the town of Okotoks, Alberta, Canada and it is the first of its kind in North America. The community contributes to a reduction of 5 tonnes of greenhouse gas emissions per home per 
year. The community consists of 52 houses that receive $97 \%$ of their annual space heating demand from solar thermal energy [3]. This was achieved by using a seasonal storage system to store the thermal energy during the summer for later use during the winter. The system shown in Figure 1.3, is comprised of three major components: solar collectors, short term thermal storage (STTS) tanks and a borehole field, also known as borehole thermal energy storage (BTES).

A BTES uses a large volume of soil for seasonal storage of thermal energy. The soil is heated through a series of boreholes that are each $35 \mathrm{~m}$ deep and contain a pipes bent in a U-shape. During the summer season, hot fluid exits the STTS tanks and runs through the pipe to charge the field, while cold fluid from the field is recirculated back to the STTS tanks. During the winter season, cold fluid exits the STTS tanks and runs through the pipe to absorb the heat back from the ground, and hot fluid from the field is re-circulated back to the STTS tanks.

The solar collector loop extracts cold water from the STTS tanks, which is then run through the solar collector for heating. The hot fluid from the collector is returned to the top of the STTS tanks.

In order to meet the space heating load, hot water is extracted from the STTS tanks and is sent to heat the houses, and cold water from the space heating loop is re-circulated back into the STTS tanks. It should be noted that all three separate loops can run simultaneously. 


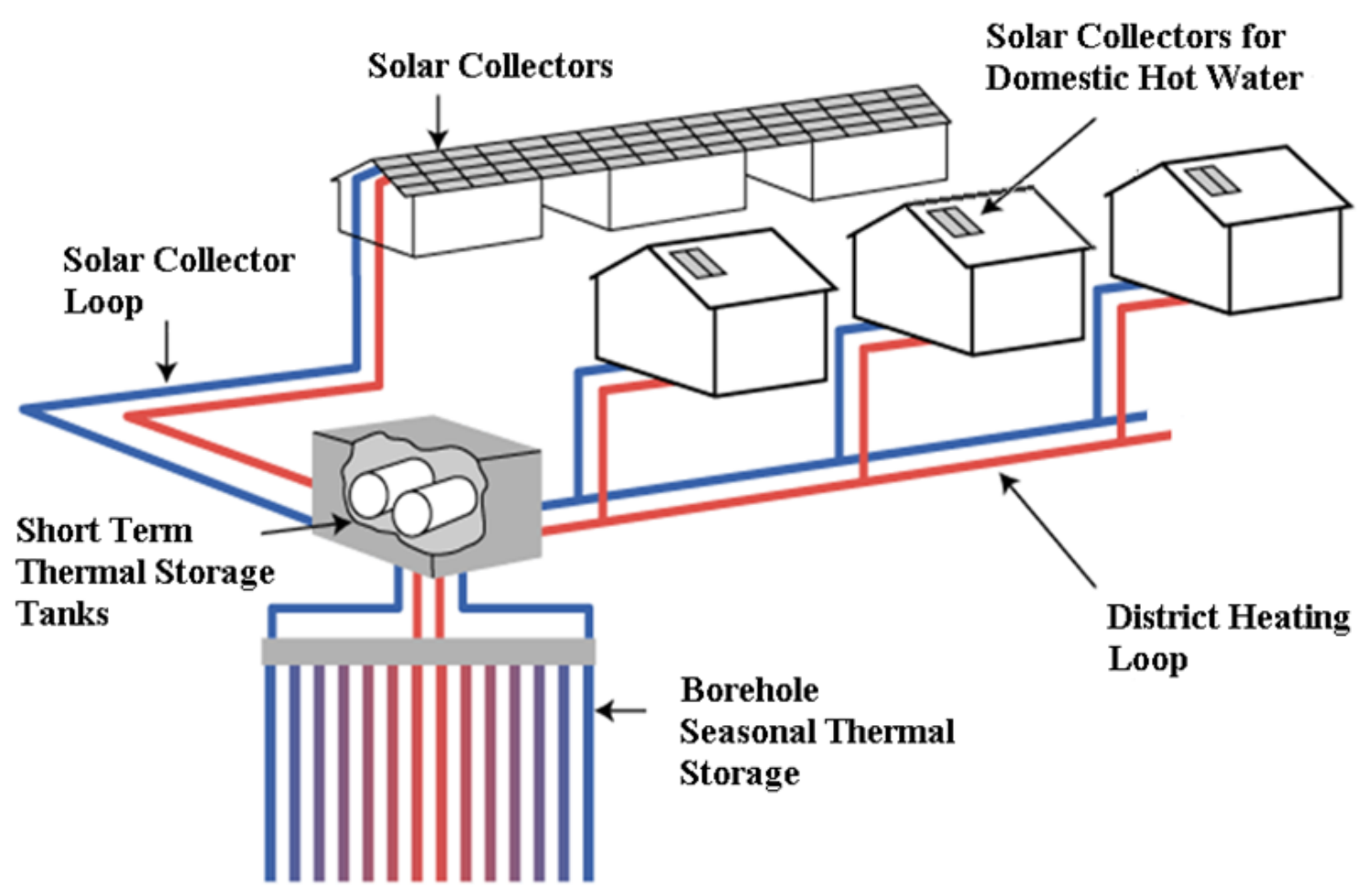

Figure 1.3: Simplified illustration of the current system in use at DLSC [3]

\subsection{Short Term Thermal Storage (STTS) Tanks}

The STTS consists of two large horizontal tanks that are approximately the size of railway cars. Each tank stores about 130,000 L of water. Since the tanks need to be enclosed in a building, it was chosen to orient the tanks horizontally because it is more economical. The two tanks are connected in series in order to provide sequential stratification, as presented in Figure 1.4. In order to help enhance the level of stratification, the tanks are equipped with a horizontal baffle located in the middle of the tank that spans about $85 \%$ of the total tank length. The tanks have one inlet and outlet per loop and a connector pipe that connects the hot tank to the cold 
tank and the port configuration is presented in Figure 1.5. Each tank is equipped with three temperature sensors as shown in Figure 1.6. A temperature reading is recorded every ten minutes, and the error associated with the reading is $+/-2^{\circ} \mathrm{C}[6]$

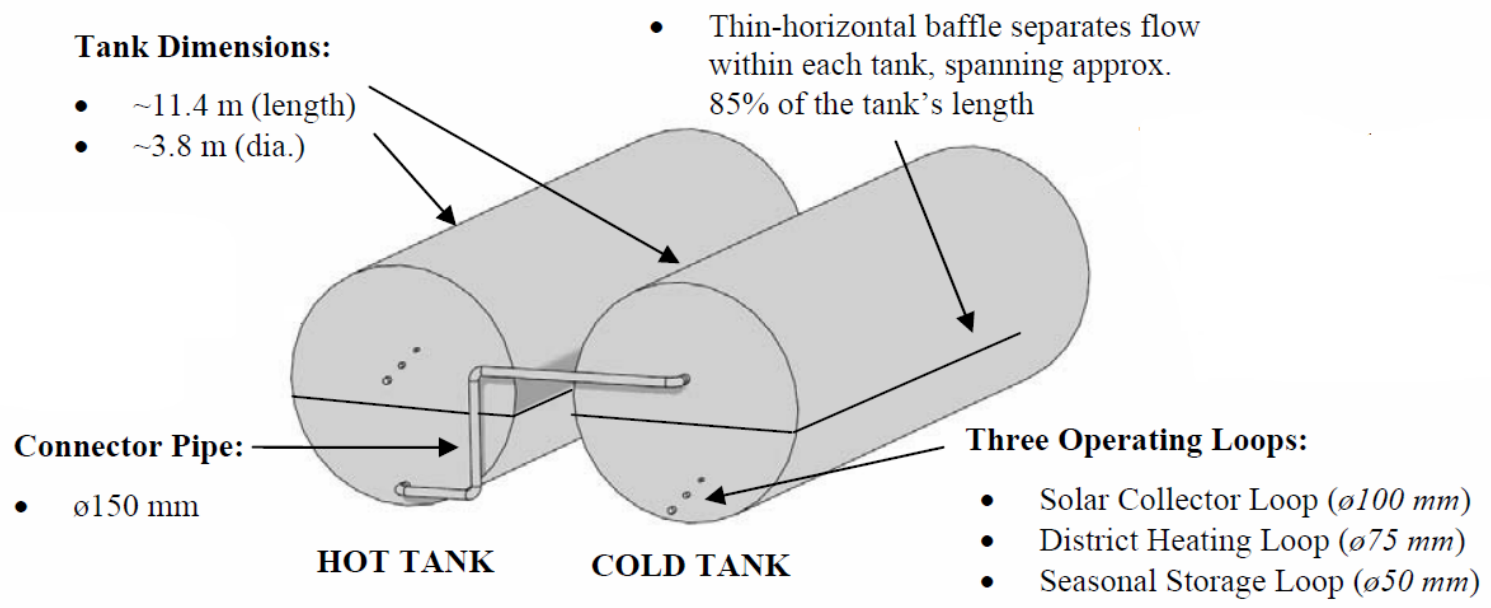

Figure 1.4: Design of the DLSC STTS tanks [6]
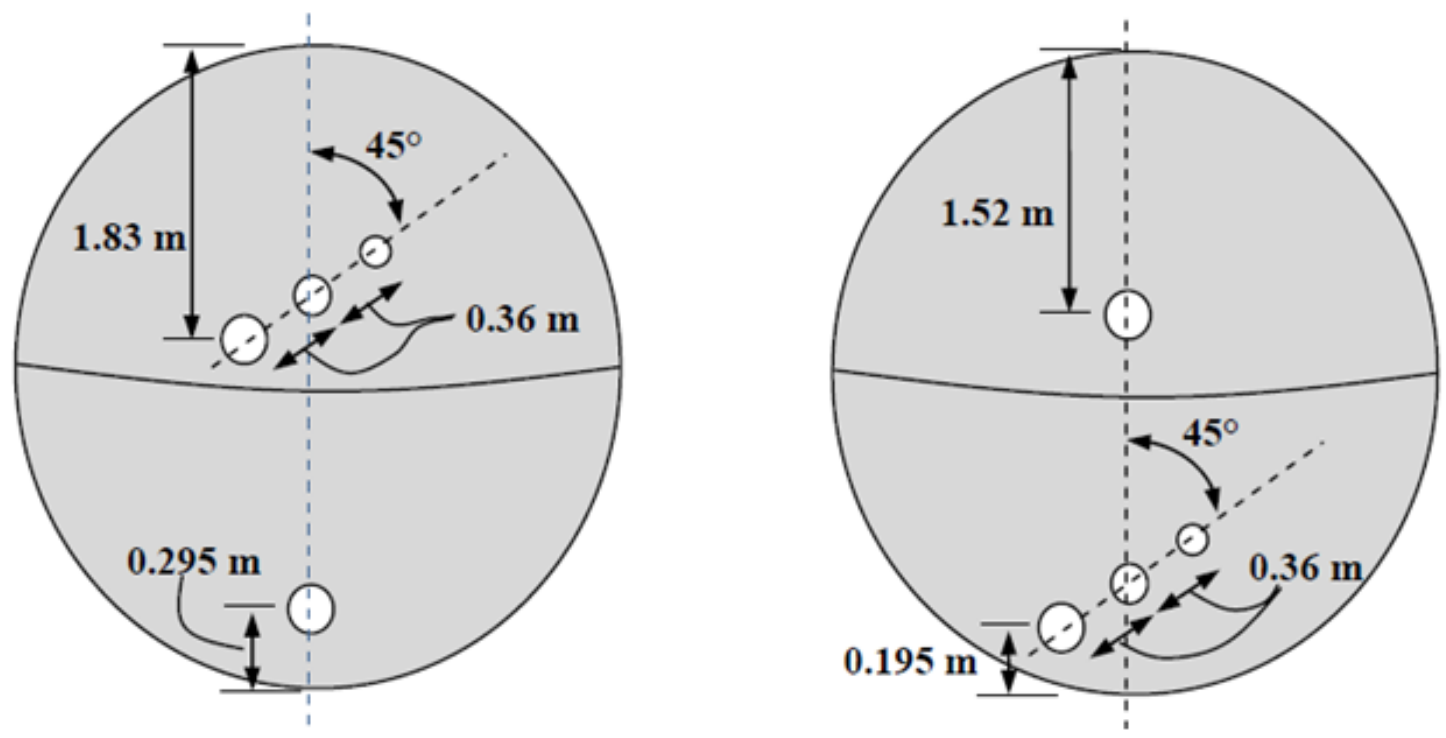

Figure 1.5: Location of inlet/outlet ports on the STTS tanks (not to scale) [6] 


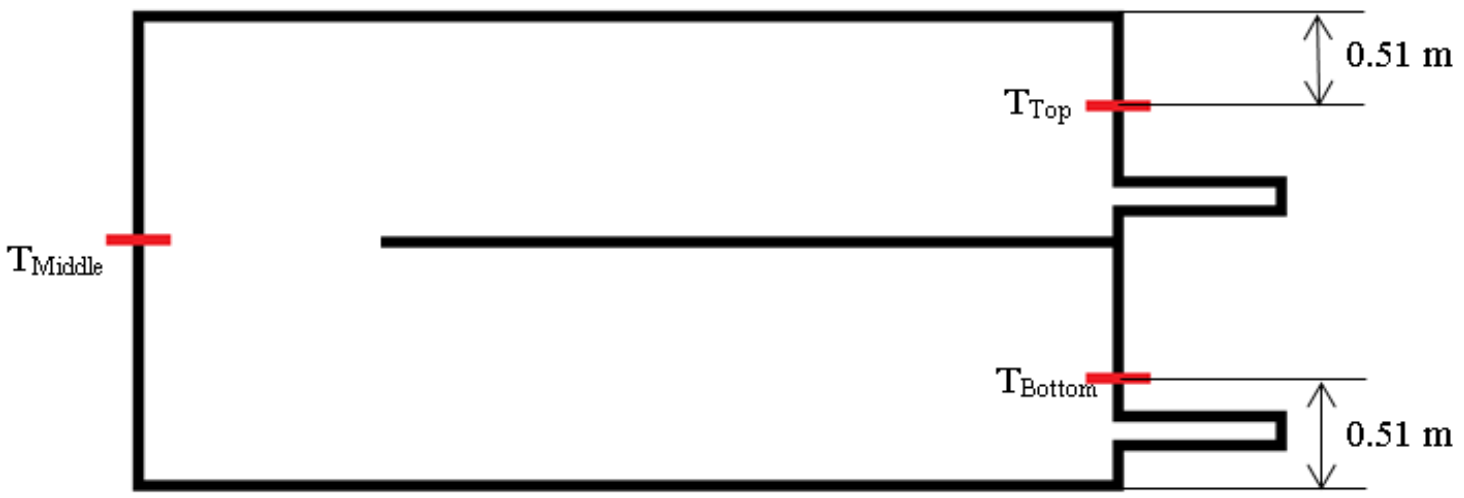

Figure 1.6: Location of the temperature sensors in the STTS tanks (identical on both tanks) [6]

The STTS tanks have a relatively small capacity compared to the BTES, allowing them to charge and discharge much faster than the BTES. As a result they act as a buffer zone between the solar collector loop, the space heating loop and the BTES loop [3]. Charging occurs when hot water is added to the top of the tank and cold water is extracted from the bottom, and discharging occurs when cold water is added to the bottom of the tank and hot water is extracted from the top. Due to the quick charge and discharge of the STTS tanks (5 hours to turnover the total volume of both tanks at maximum flow rates), all the solar energy collected by the solar collector during the day can be quickly stored in the STTS tanks whereas it takes about 24 hours for the energy to be transferred to the BTES [7]. 


\subsection{Problem}

Shortly after the DLSC system started full operation, it was found that the hot fluid within the tanks was not easily accessed and the tanks experienced significant mixing. This hindered the performance of the solar community system. Due to the size of the tanks, it was impractical to perform experiments in order to find the primary cause of the mixing and inability to extract the hot water. As a result, three dimensional Computational Fluid Dynamics (CFD) simulations were performed by Rysanek from Queen's University in order to better understand the problem [6]. The tank was extensively studied during charging and multiple tank designs were proposed to enhance the stratification within the tank. Rysanek was able to recommend a better design that reduces the mixing during charging. However, the performance of this design was not assessed for a wide range of realistic operating conditions.

\subsection{Objectives and Approach}

The objective of this thesis is to explore the thermal performance of the STTS tank at DLSC under a range of operating conditions. Mechanisms to promote stratification such as the use of baffles and modifications to the inlet geometries are considered. In addition, this thesis provides recommendations for the design large horizontal STTS tanks.

In order to gain confidence in the CFD model generated, the results of the model are compared to measured data from DLSC. The current tank at DLSC along with eight other designs are tested for six sets of operating conditions. The eight designs are alterations of the baffle configuration within the tank in order to enhance the 
thermal stratification. The six cases consider a range of charging and discharging conditions.

\subsection{Outline of Thesis}

This thesis is divided into three main sections: a review of the literature, validation of the CFD model, and analysis of the results obtained for the different geometries and operating conditions.

Chapter 2 is a review of the literature and it studies the main sources of mixing within the tank and the means that can be used in order to enhance the level of stratification within the tank. The chapter also presents a thorough review of the different methods that can be used in order to quantify the level of stratification within a tank.

Chapter 3 shows the steps in the construction of the geometry of the current tank at DLSC. It also demonstrates the steps used to assess grid and time-step independence. Sensitivity of the predictions to the turbulence model is also explored.

Chapter 4 introduces the nine designs that will be tested throughout the thesis. The designs are tested using six different initial and boundary conditions that try to simulate realistic conditions at DLSC in order to help select the best design.

The final chapter, chapter 5, presents recommendations for the design of large horizontal STTS tanks in order to promote stratification. Suggestions for future work are also given. 


\section{Chapter 2}

\section{Literature Review}

Thermal energy storage tanks are key components that play a significant role in determining the efficiency of an entire solar energy system. Indeed, a perfectly stratified storage can deliver up to $37 \%$ more energy than a fully mixed storage [8]. This enhancement of the system performance is due to the increase in the solar collector efficiency since cooler fluid from the bottom of the tank enters the collector which reduces the heat lost from the collector to the environment. Moreover, a well stratified tank will retain warmer fluid at the top and will eventually discharge it to the user, thus reducing the need for auxiliary heating. This chapter presents an overview of various experimental and numerical studies pertaining to stratification in thermal energy storage tanks.

\section{$2.1 \quad$ Stratification}

The factors that affect stratification are inlet jet mixing, plume entrainment, heat conduction within the water, heat conduction within the tank wall, and heat loss 
to the environment. Inlet jet mixing and plume entrainment are considered to be the most dominant factors that affect stratification during charging or discharging. However, all the other factors play a crucial role when the tank is idling [5]. Since the focus of this study is either charging or discharging, the intensity of inlet jet mixing and plume entrainment will dictate the level of stratification within the tank.

\subsubsection{Inlet Jet Mixing}

Mixing occurs when fluid exits from a small pipe with a very high momentum and is introduced into a tank containing quiescent fluid. Shear forces between the moving and stagnant fluid causes the inlet jet to spread and slow down while entraining stagnant fluid into the jet leading to turbulent mixing. The mixing usually occurs within the vicinity of the inlet port.

For conditions under which the tank charging inlet temperature is higher than the temperature at the top or when the tank discharging inlet temperature is below the temperature at the bottom of the tank, buoyancy forces act to promote stratification. As a result, inlet jet mixing dictates the level of stratification within the tank.

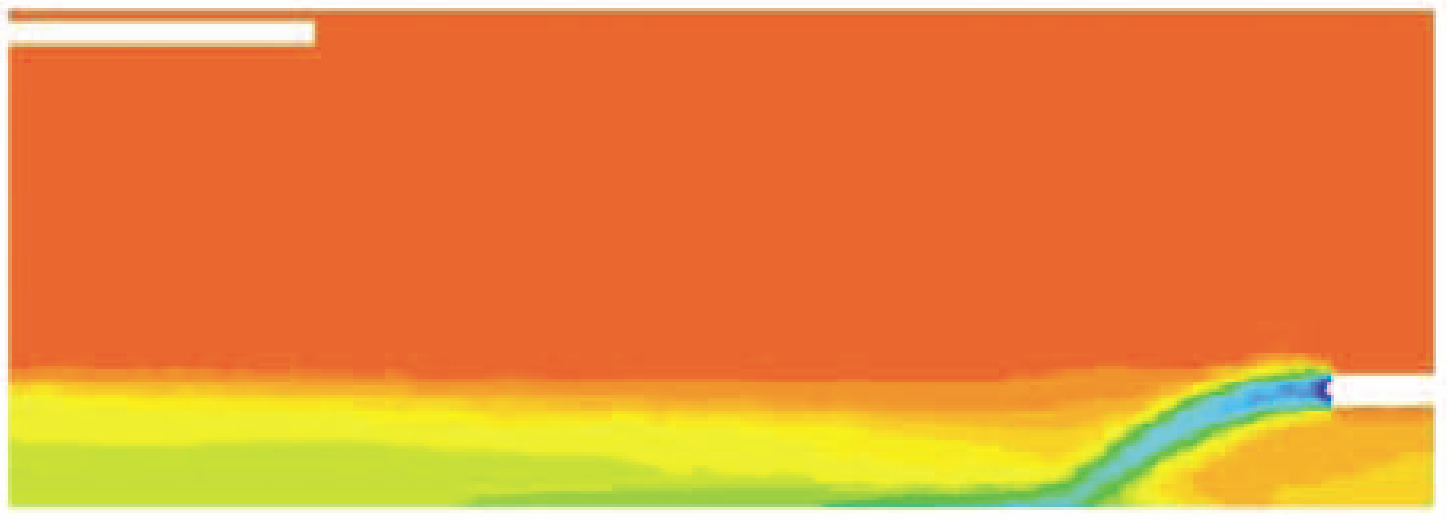

Figure 2.1: Discharging of a fully charged horizontal tank with a horizontal inlet [9] 


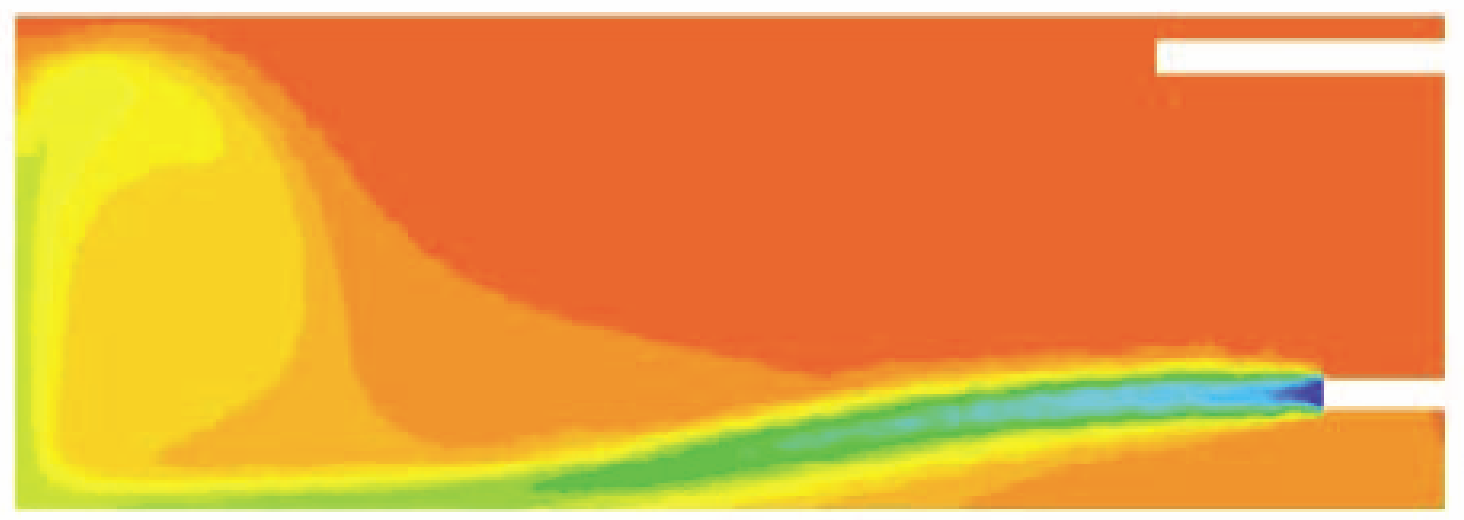

Figure 2.2: Discharging of a fully charged horizontal tank with a horizontal inlet and penetration through all hot fluid layers due to impingement on side wall [9]

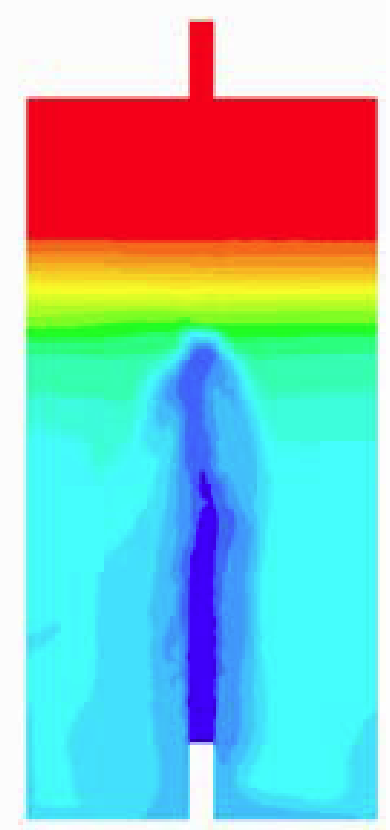

Figure 2.3: Discharging of a fully charged vertical tank with a vertical inlet [10]

Inlet jets are typically oriented either horizontally or vertically. The horizontal inlet jet presented in Figure 2.1 [9] shows that the mixing occurs because the inlet jet 
spreads vertically within the tank which entrains more hot fluid into the jet. If the jet does not spread enough before it reaches the side wall, it impinges on the vertical wall and penetrates through all the hot fluid layers as shown in Figure 2.2 [9]. The vertical inlet jet displayed in Figure 2.3 [10] shows that the mixing is due to the very high momentum of the inlet jet that penetrates through the hot fluid layers.

\subsubsection{Plume Entrainment}

Buoyant plumes can be described as positive or negative. A positive buoyant plume is when momentum of the jet and buoyancy force act in the same direction, while a negative buoyant plume is when momentum of the jet and the buoyancy act in opposite directions. Nizami [11] extensively studied negative buoyant plumes numerically for vertical thermal storage tanks. A simple integral model was developed in order to simulate the fluid flow within the tank during a negative buoyant plume. Generally, a positive buoyant plume is more destructive to the level of stratification than a negative buoyant plume for vertical inlets.

Plume entrainment is a common problem for STTS tanks because in the afternoon, the solar radiation incident on the solar collector decreases and as a result the charging inlet temperature entering the tank decreases. Consequently, the charging inlet temperature is lower than the fluid temperature at the top of the tank creating a positive buoyant plume. This plume sinks inside the tank until it reaches a fluid of the same temperature as shown in Figure 2.4 [5]. During the process, hot fluid entrains into the cold plume and significant mixing occurs. 


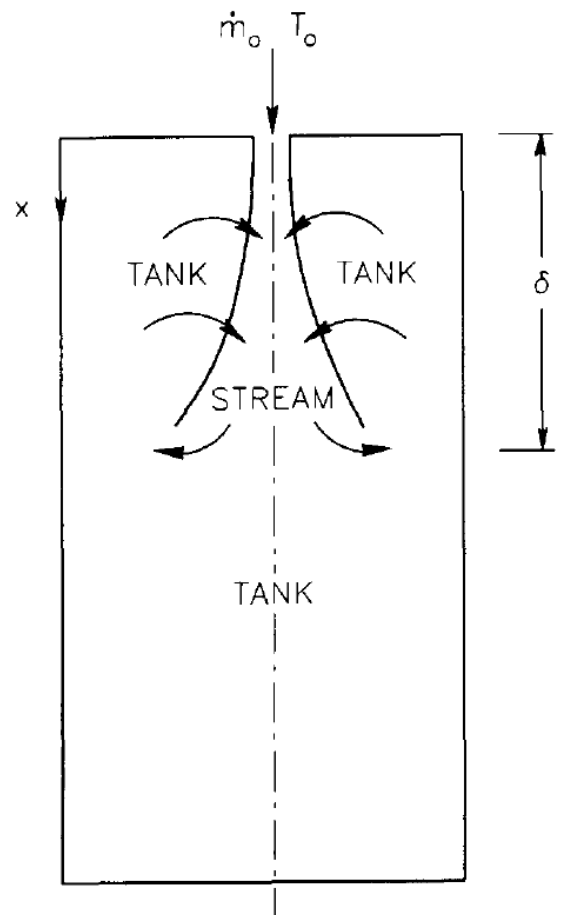

Figure 2.4: Plume Entrainment into a vertical tank while charging [5]

\subsubsection{Key Dimensionless Groups}

As noted by Lavan and Thompson [12], the important dimensionless group that influences stratification is the Richardson number. It represents the ratio between buoyancy and inertial forces as defined below. A higher Richardson number indicates better stratification. The important dimensionless groups are given below:

$$
\begin{gathered}
G r=\frac{\text { Buoyancy Forces }}{\text { Viscous Forces }}=\frac{g \beta\left(T_{\text {in }}-T_{\text {initial }}\right) H^{3}}{v^{2}} \\
R e=\frac{\text { Inertial Forces }}{\text { Viscous Forces }}=\frac{\left|u_{\text {in }}\right| D}{v} \\
R i=\frac{\text { Buoyancy Forces }}{\text { Inertial Forces }}=\frac{g \beta\left(T_{\text {in }}-T_{\text {initial }}\right) H}{\left|u_{\text {in }}\right|^{2}}
\end{gathered}
$$




$$
F r=\frac{\text { Inertial Forces }}{\text { Gravitational Forces }}=\frac{1}{\sqrt{R i}}
$$

where $H$ is sometimes defined as the height of the tank or the vertical distance between the inlet and outlet ports. Generally, the height of the tank is almost equal to the vertical distance between the inlet and outlet because the inlet is usually located at the top of the tank while the outlet is located at the bottom of the tank. However, if the inlet and outlet are located elsewhere within the tank, it is more accurate to describe Richardson number using the vertical distance between the inlet and outlet. In these equations the symbol $D$ is the diameter of the inlet pipe, $u_{i n}$ is the inlet fluid velocity, $T_{i n}$ is the temperature of the inlet fluid, $T_{\text {initial }}$ is the initial temperature of the stored fluid, $\beta$ is the thermal expansion of the fluid, $v$ is the kinematic viscosity. One of the important factors that has a noteworthy effect on stratification is the inlet geometry. Sliwinski et al. [13] performed experiments on a vertical tank initially at $42^{\circ} \mathrm{C}$ with a charging inlet temperature of $72^{\circ} \mathrm{C}$ and was able to predict that the height within the tank that will experience the turbulent mixing is below $5 \%$ of the total tank height when the Richardson number is greater than 0.5. Richardson number is defined using the length of the vertical tank. However, if the inlet configuration is changed such as the experiments performed by Loehrke and Holzer [14], a high degree of stratification was not achievable with a Richardson number of 4.7 due to turbulent incoming flow. Zurigat [15] studied horizontal tanks and found that if the Richardson number is below 3.6, then the inlet geometry has a significant effect on stratification. Later, Ghajar [16] was able to refine the previous statement by showing that the inlet effect can be neglected for a Richardson number greater than 10 .

In general it can be concluded that in order to enhance stratification, the Richardson number must be high. Since, Richardson number is very sensitive to the inlet 
speed; as a result, inlet diameter could be increased in order to reduce the inlet speed.

\subsection{Methods to Enhance Stratification}

There are several ways to enhance stratification, through careful design of the tank geometry, the location of inlets and outlets, the number of inlets or outlets, the baffle configuration, and through the use of stratifiers. The best location for inlets and outlets are at the very top of the tank and the very bottom of the tank respectively in order to maximize the vertical distance between the inlet and outlet yielding the maximum Richardson number. Additionally, stratification can be enhanced by the use of tank walls with a low thermal conductivity [17]. In this study, the tank geometry is considered to be fixed; as a result, the only options to enhance the stratification are through the use of baffles, diffusers and stratifiers.

\subsubsection{Baffles}

Baffles can be a very effective way to enhance stratification and their main role is to redirect the inlet jet or act as an obstacle in order to hinder mixing. However, baffles are ineffective in controlling plume entrainment. A baffle can be parallel or perpendicular to the inlet jet. A baffle that is parallel to a horizontal inlet jet will constrain the jet from spreading vertically while allowing it to spread horizontally. This will slow down the inlet jet while minimizing the mixing that takes place within the tank. A baffle that is perpendicular to the inlet jet will force the jet to impinge on the baffle surface, which will allow it to spread while not penetrating deep into the tank. 
Zurigat [18] performed experiments to study multiple inlet baffle configurations on vertical tanks. The configurations studied included a radial diffuser, side inlet, perforated inlet and impingement inlet. The perforated baffle near the inlet performed the best in comparison to all other configurations tested. Shah and Furbo [10] noticed that discharging has a notable effect on stratification. The authors studied stratification in vertical TST theoretically and experimentally using different baffle configurations. The tank was initially fully charged at $318 \mathrm{~K}$ and inlet temperature is $291 \mathrm{~K}$. Figure 2.5 [10] depicts the different baffle configurations that were explored: a raw pipe, a pipe with a small hemispherical baffle plate and a pipe with a large flat baffle plate. The tank with a raw pipe clearly shows the damaging effect of the inlet jet where it penetrates deep into the hot fluid and creates considerable mixing. The pipe with a small hemispherical baffle plate successfully enhances stratification by redirecting the flow back to the bottom of the tank allowing it to spread. The best configuration was determined to be a pipe with a large flat baffle plate because it allowed the jet to impinge on the baffle surface, while not penetrating deep into the tank.

Zachar [19] improved the design proposed by Shah and Furbo by studying different horizontal plate sizes that are located at different heights in the vertical storage tank. The tank employed vertical inlets for both charging and discharging. This horizontal baffle proved to be important at high flow rates $(10 \mathrm{l} / \mathrm{min}$ or $R i=0.22)$. The best results using the horizontal plate were obtained when the plate diameter was more than $95 \%$ of the tank diameter and the distance between the plate and the top/bottom of the tank was no more than $3 \%$ of the height of the tank. 

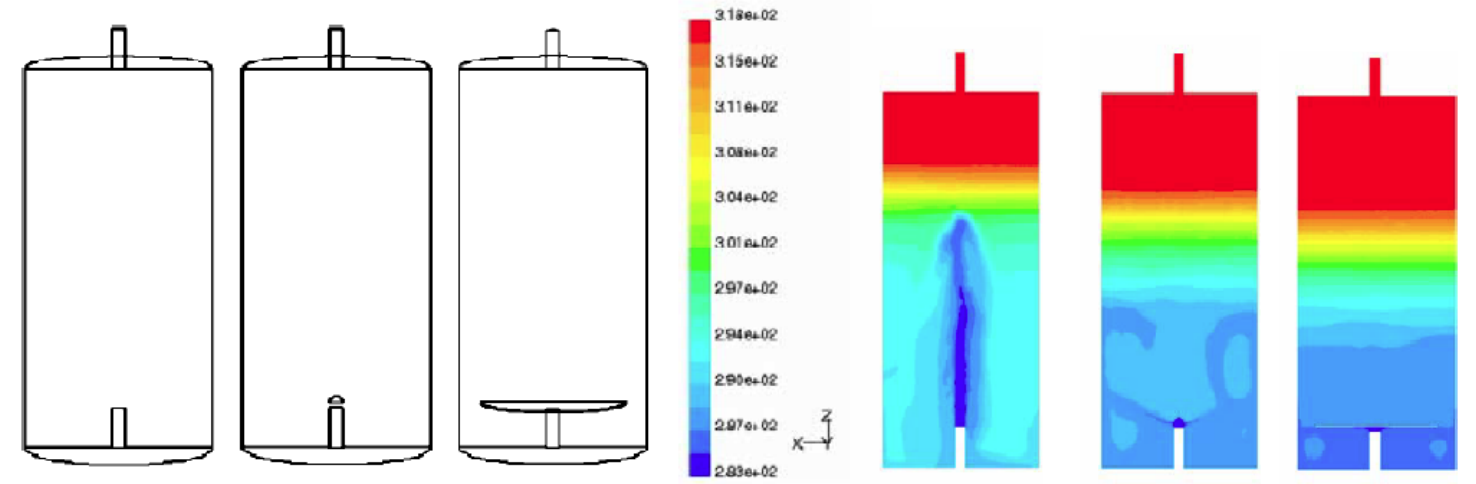

Figure 2.5: Temperature distribution in the tank center plane after $5 \mathrm{~min}$ of $10 \mathrm{l} / \mathrm{min}$ inlet flow, Left: raw pipe Center: pipe with a small hemispherical baffle plate. Right: pipe with a large flat baffle plate [10] (top hot fluid is at $318.15 \mathrm{~K}$ and bottom cold fluid is at $283.15 \mathrm{~K}$ ).

Altuntop et al. [20] studied numerically 12 different baffle configurations for vertical storage tanks during simultaneous charging and discharging. The baffle geometries are shown in Figure 2.6 [20]. The tank is initially at $320 \mathrm{~K}$, the cold bottom inlet $\left(T_{4}\right)$ is at $285 \mathrm{~K}$ and $1 \mathrm{~m} / \mathrm{s}$ and the hot top inlet $\left(T_{2}\right)$ is at $333 \mathrm{~K}$ and $0.02 \mathrm{~m} / \mathrm{s}$. The 12 different tank designs are displayed in Figures 2.8 and 2.9, and the obstacles are shown in more details in Figure 2.7 [20]. Although not discussed in the paper, designs $1,2,8,10$, and 12 have very poor performance because the inlet jet reaches the tank wall making a very sharp turn and penetrates through the hot fluid layers causing excessive mixing. Designs 3 to 6 , have a slightly better performance because the baffle effectively spreads the inlet jet reducing its speed and ultimately reducing the mixing within the tank. However, when the inlet jet exits the baffle, it is forced to turn and penetrate through the hot fluid layers. Lastly, designs 7, 9, and 11 seem to have the best results because the opening in the middle of the baffle is very effective at redirecting the inlet jet into the tank while maintaining a relatively even velocity 


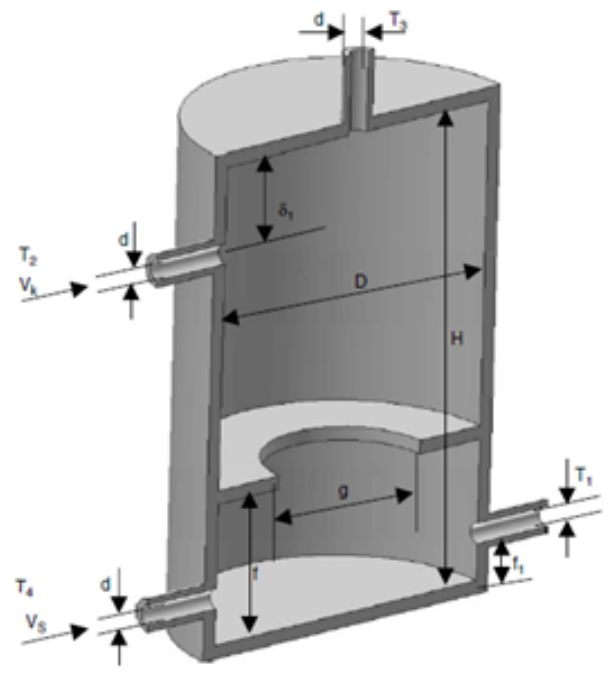

Figure 2.6: Configuration of Design 11 tested by Altuntop et al [20] and Arslan et al. $[21]$

out of the middle opening.

Therefore, it was concluded that placing obstacles with a gap in the center provides better thermal stratification than those having gap near the tank wall. In addition, employing horizontal baffles can spread the inlet jet and reduce the mixing within the tank.

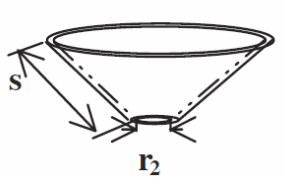

A

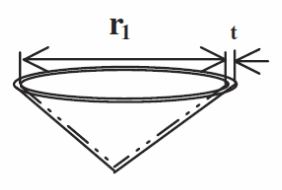

B

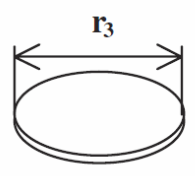

C

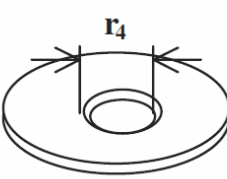

D

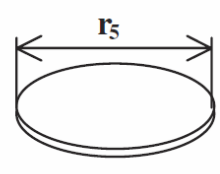

$\mathbf{E}$

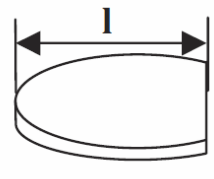

F

Figure 2.7: Detailed view of the different obstacles tested [20] 

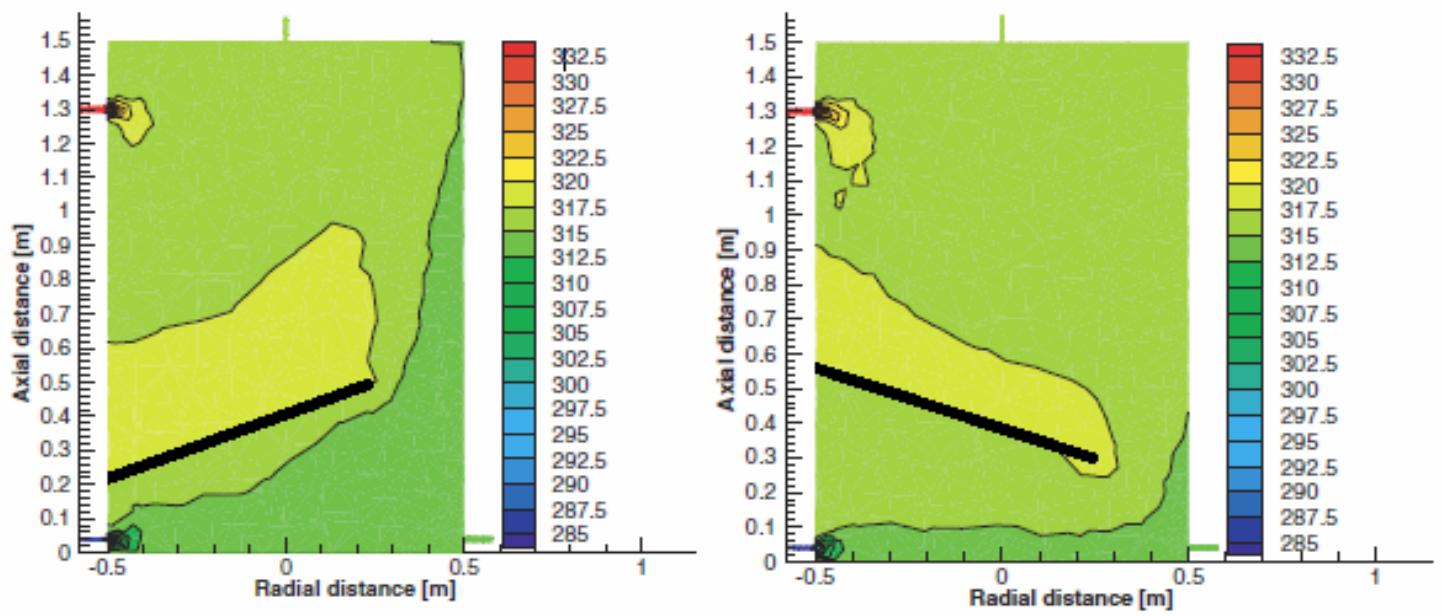

(1)
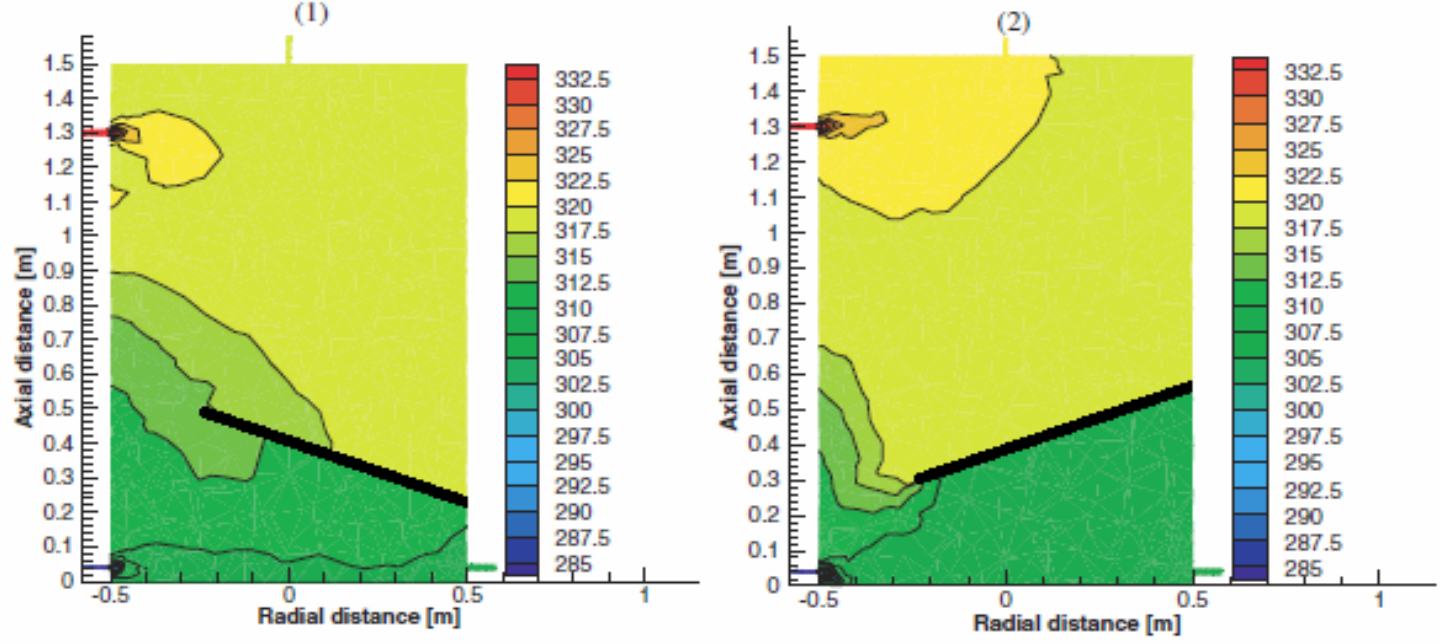

(3)

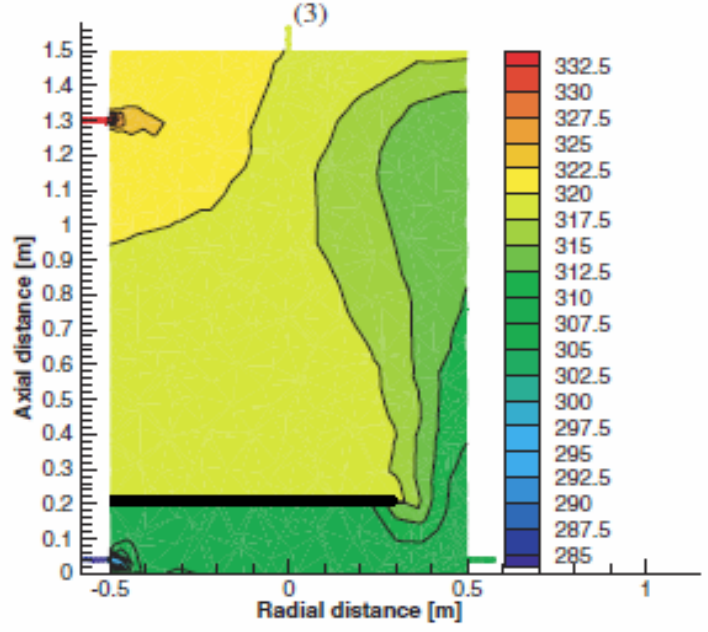

(5)

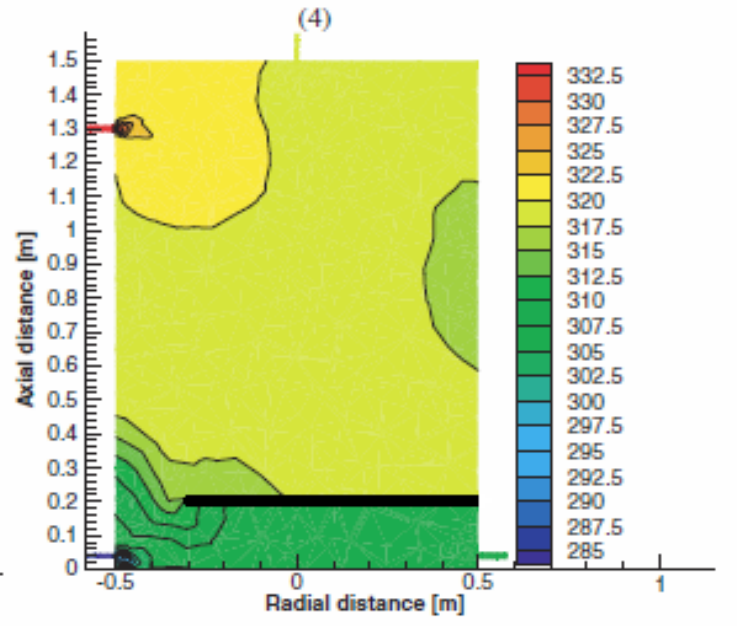

(6)

Figure 2.8: Temperature contour plots of the simulation of designs 1 to 6 [20] 


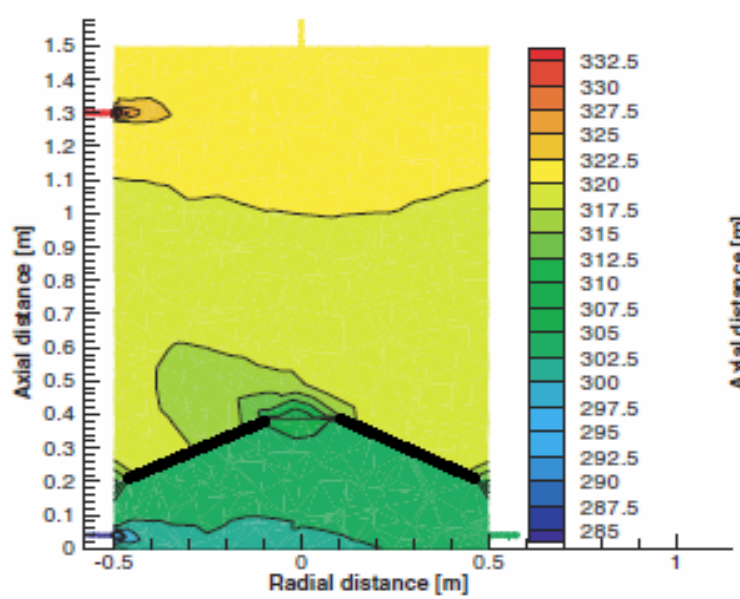

(7)

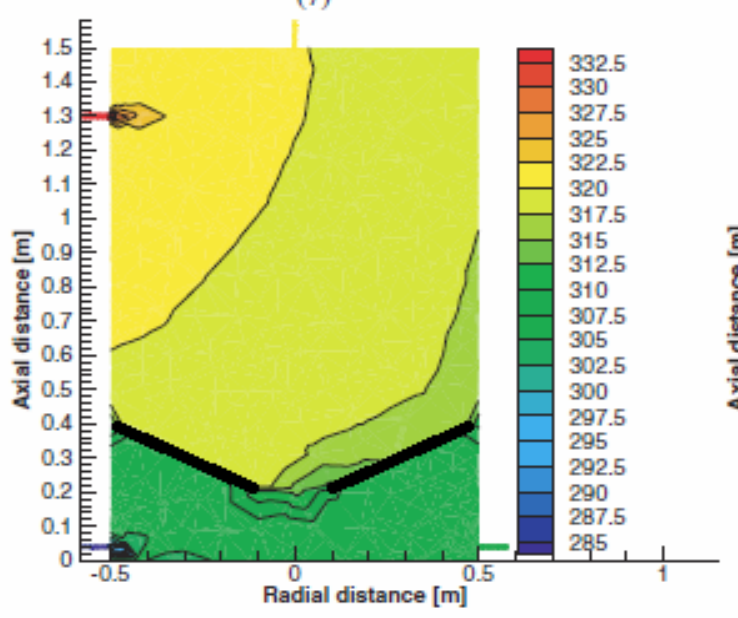

(9)

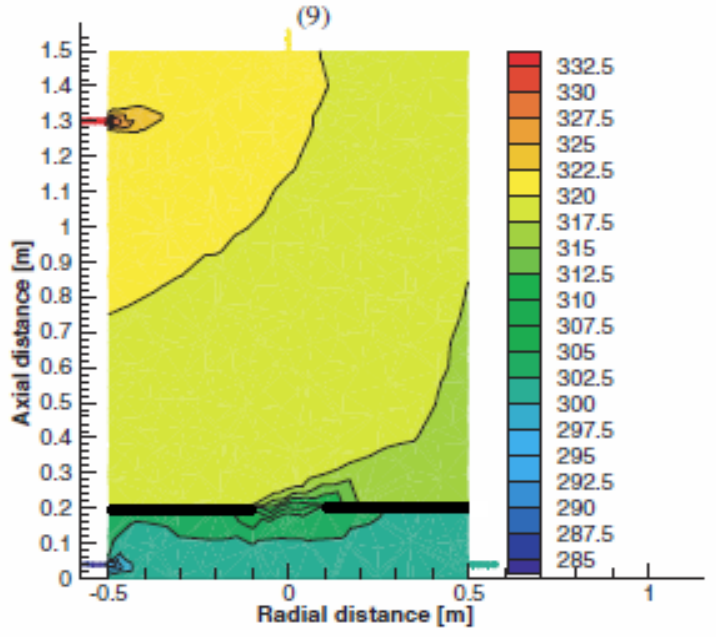

(11)

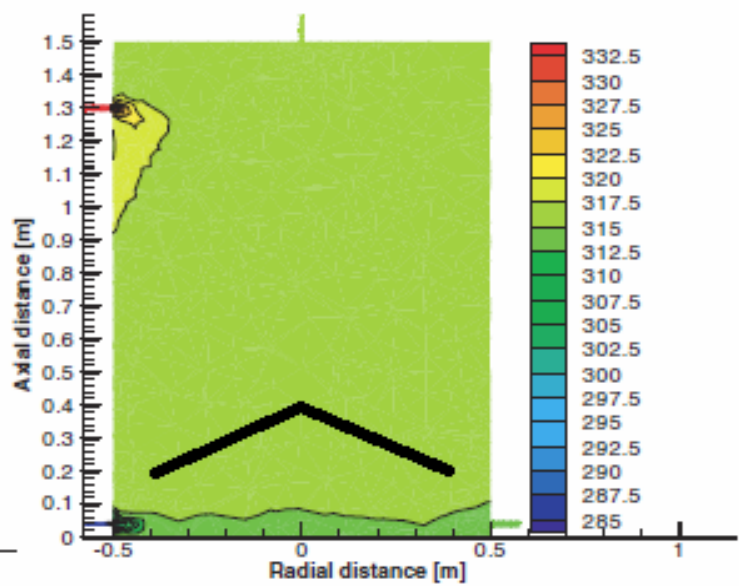

(8)

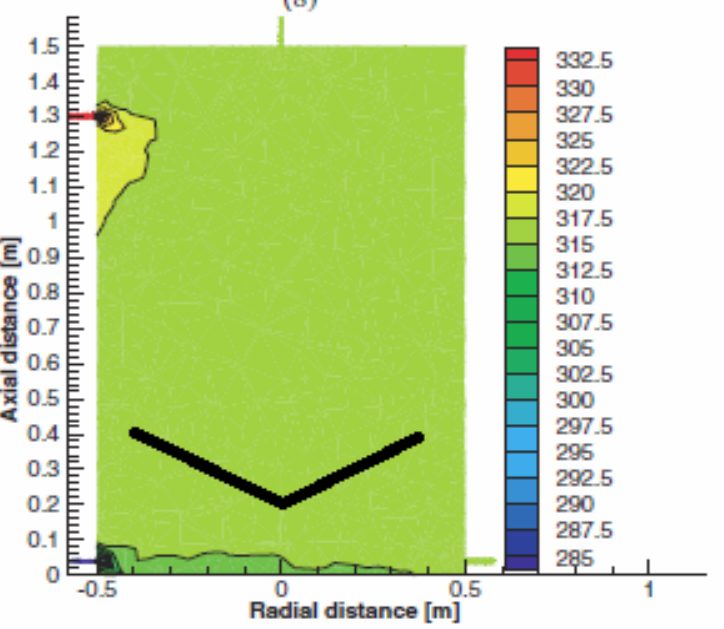

(10)

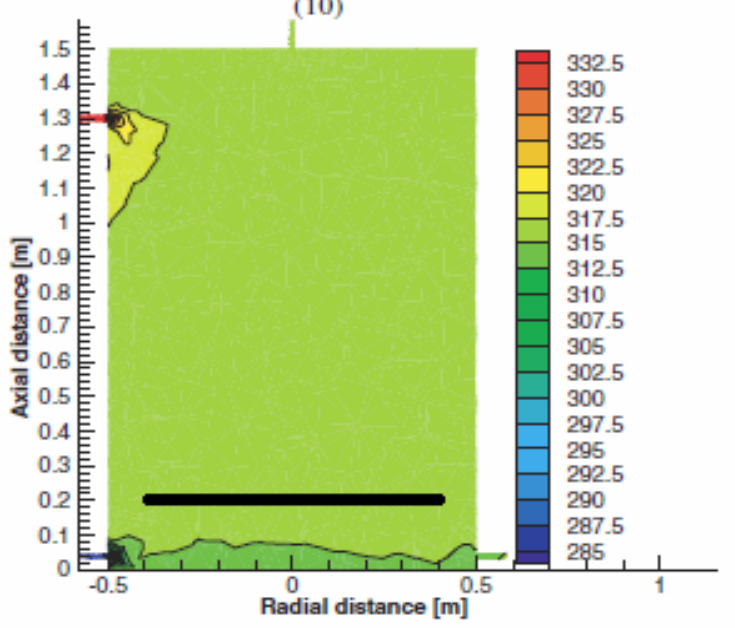

(12)

Figure 2.9: Temperature contour plots of the simulation of designs 7 to 12 [20] 
Arslan et al. [21] numerically studied the baffle configuration of design 11, shown in Figure 2.6 [21] for simultaneous charging and discharging. The tank was initally set to $320 \mathrm{~K}$, the hot inlet temperature $\left(T_{3}\right)$ is $333 \mathrm{~K}$ at $1 \mathrm{~m} / \mathrm{s}$, and the cold inlet temperature $\left(T_{1}\right)$ is $285 \mathrm{~K}$ at $1 \mathrm{~m} / \mathrm{s}$. The optimization was done by varying the diameter of the hole in the center of the baffle and the location of the baffle. It was discovered that as the baffle was raised, the temperature of the stratified region increases, while the volume of the region is decreased. The best thermal stratification is obtained for obstacle dimensions corresponding to $\mathrm{g} / \mathrm{D}$ ratio of 0.2 and $\mathrm{f} / \mathrm{H}$ ratio of 0.13 . In these equations the symbol g represents the diameter of the hole, $\mathrm{D}$ is the diameter of the tank, $\mathrm{f}$ is the distance between the baffle and the bottom of the tank, and $\mathrm{H}$ is the tank height as demonstrated in Figure 2.6.

Stratification in horizontal tanks has not been studied in as much detail as vertical tanks since vertical tanks are more widely used. Discharging was studied numerically and experimentally by Aviv et al. [9] and it was concluded that at high flow rates (7 $\mathrm{L} / \mathrm{min}$ or $\mathrm{Ri}=0.17$ and turn over time of 4.57 minutes), a baffle must be installed at the entrance in order to achieve better stratification. This baffle redirects the inlet jet to the bottom of the tank and this prevents the jet from spreading vertically within the tank as demonstrated by Figures 2.10 and 2.11 [9].

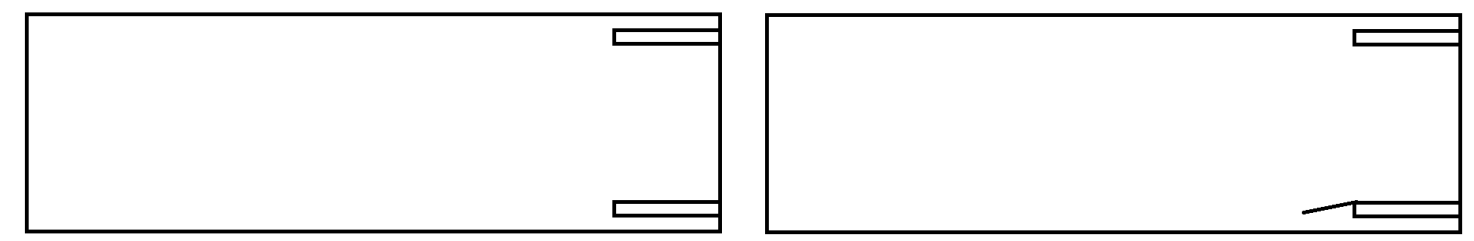

Figure 2.10: Schematic of tanks being studied by Aviv et al. [9], left: tank without deflectors, right: tank with a deflector at the bottom inlet 


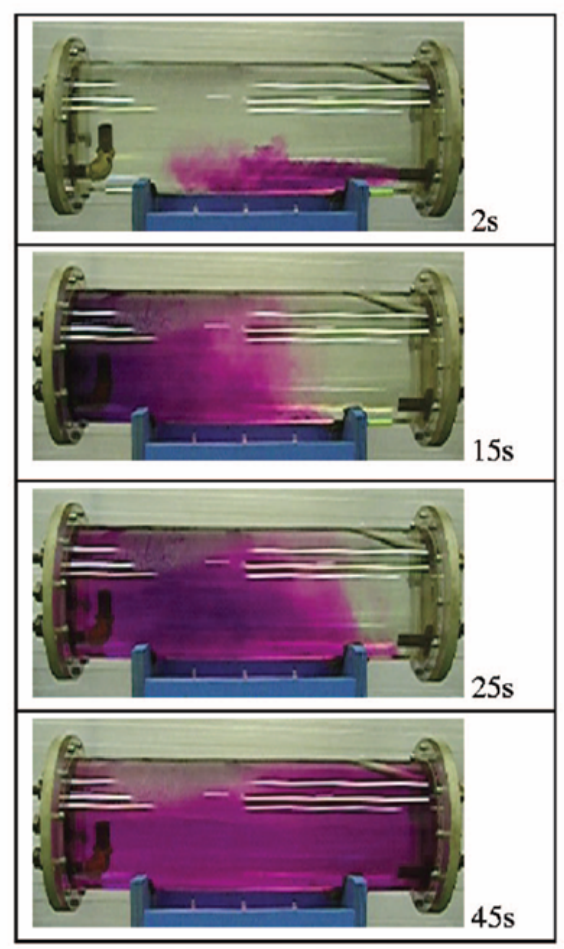

(a)

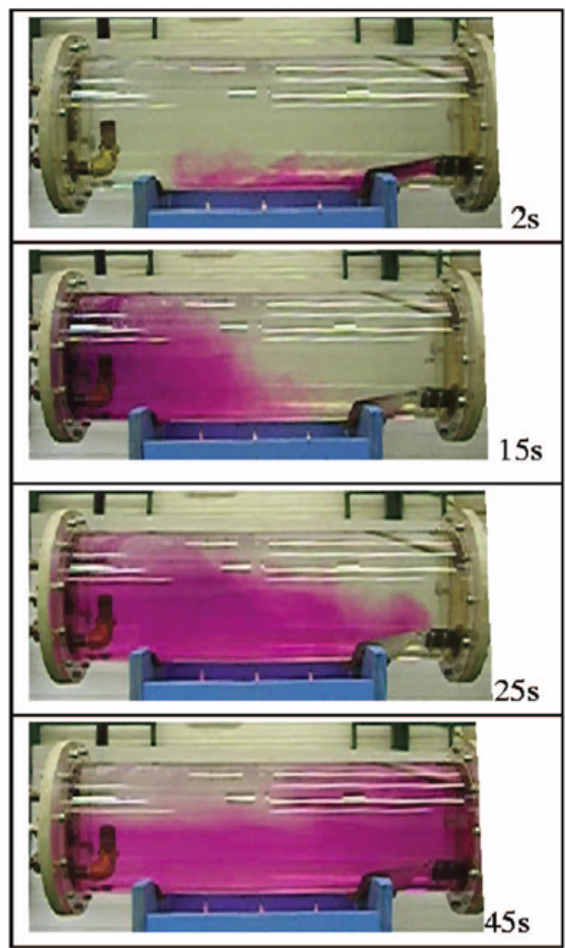

(b)

Figure 2.11: Mixing in horizontal tank, a) excess mixing due to the discharging inlet jet, b) reduced mixing after adding a deflector at the entrance of the inlet [9]

Rysanek [6] investigated numerically the STTS tanks at Drake Landing Solar Community (DLSC). Rysanek's study was motivated by the poor performance of the tanks in the field. Figure $2.12[6]$ presents the seven different baffle configurations that were tested under typical charging conditions and compared to the existing configuration at DLSC presented in Tank 1. The three charging conditions were charging at constant inlet temperature, charging at increasing inlet temperature and charging at decreasing inlet temperature. Tank 1 had the worst performance because the charging inlet was located in the middle of the tank, which allows the buoyant inlet jet to propagate into a large mixing plume. Tanks 2 and 3 can reach a better level of 
stratification than Tank 1, but the inlet jet is allowed to spread vertically which mixes the top of the tank. Tank 5 has poor performance because the first chamber can be considered almost fully mixed. Tanks 4, 6, and 7 have the best performance due to their ability to effectively control the entrainment of the inlet jet. They all produced almost the same level of stratification during charging at constant temperature and increasing charging temperature. When the charging inlet temperature is decreasing, Tank 7 performed the best because it employs two inlets which help the inlet jet reach its correct level. However, the improvement in performance is not of great significance, and does not justify the complex geometry. It was concluded since Tank 4 has a similar performance to Tank 6 and Tank 7 , then Tank 4 is the most economical, least complicated solution.
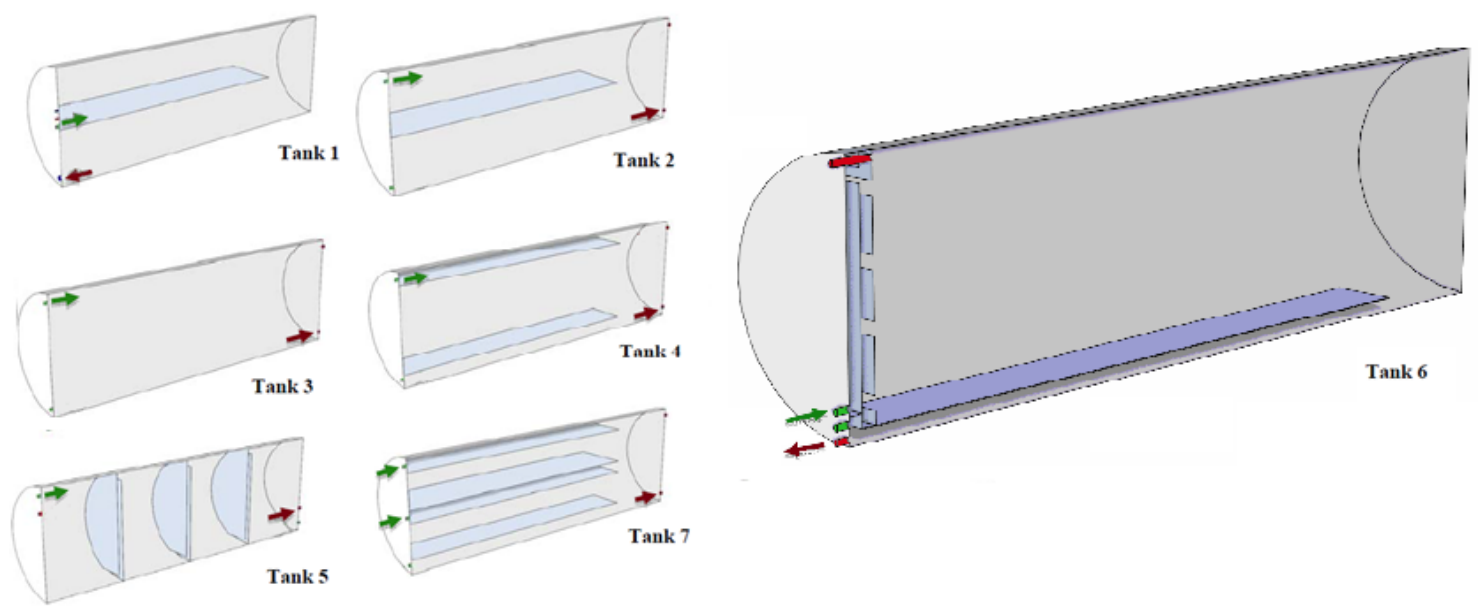

Figure 2.12: Different baffle configurations investigated by Rysanek in order to enhance the performance of the STTS at DLSC [6] 


\subsubsection{Diffusers}

Diffusers are another important tool to enhance stratification. A diffuser is a device that forces the inlet jet to flow through a large area, which reduces the fluid speed, ultimately reducing mixing within the tank. Diffusers can be effective for reducing inlet jet mixing, but may not help in reducing plume entrainment. Three different side-inlet geometries were studied experimentally by Hegazy [22] for vertical tanks during discharging shown in Figure 2.13 [22]; namely wedged, perforated, and slotted pipe-inlets. These diffusers were oriented horizontally and all the opening were directed to the bottom of the tank. Hegazy concluded that the perforated inlet performed the best, however the slotted inlet is the more economical choice, despite providing a slightly poorer stratification. Therefore, it was decided that the slotted inlet is the recommended design.

Chung et al. [23] numerically studied radial plate, radial adjusted plate, and Hbeam diffuser depicted in Figure 2.14 [23]. The fluid enters vertically upward into the tank, impinges on the radial plate diffuser, which slows it down and helps reduce the mixing in the tank. This diffuser works better for circular tanks. The radial adjusted plate type is a modified radial plate diffuser for better performance in rectangular tanks. It helps spread the fluid uniformly along the top of the tank by modifying the shape of the radial diffuser. This modification allows the fluid to spread in one direction more than the other, allowing it spread the fluid evenly in a rectangular tank. The H-beam diffuser forces the fluid to flow through multiple slots along the H-shaped pipes that help spread the fluid more evenly in a rectangular tank. The performance of the different diffusers was evaluated for Reynolds number equal to 400, 800, and 1200 and Froude number equal to 0.5, 1.0, and 2.0. Froude number 
$\underline{\text { M.A.Sc. Thesis - Maikel Shaarawy } \quad \text { McMaster - Mechanical Engineering }}$
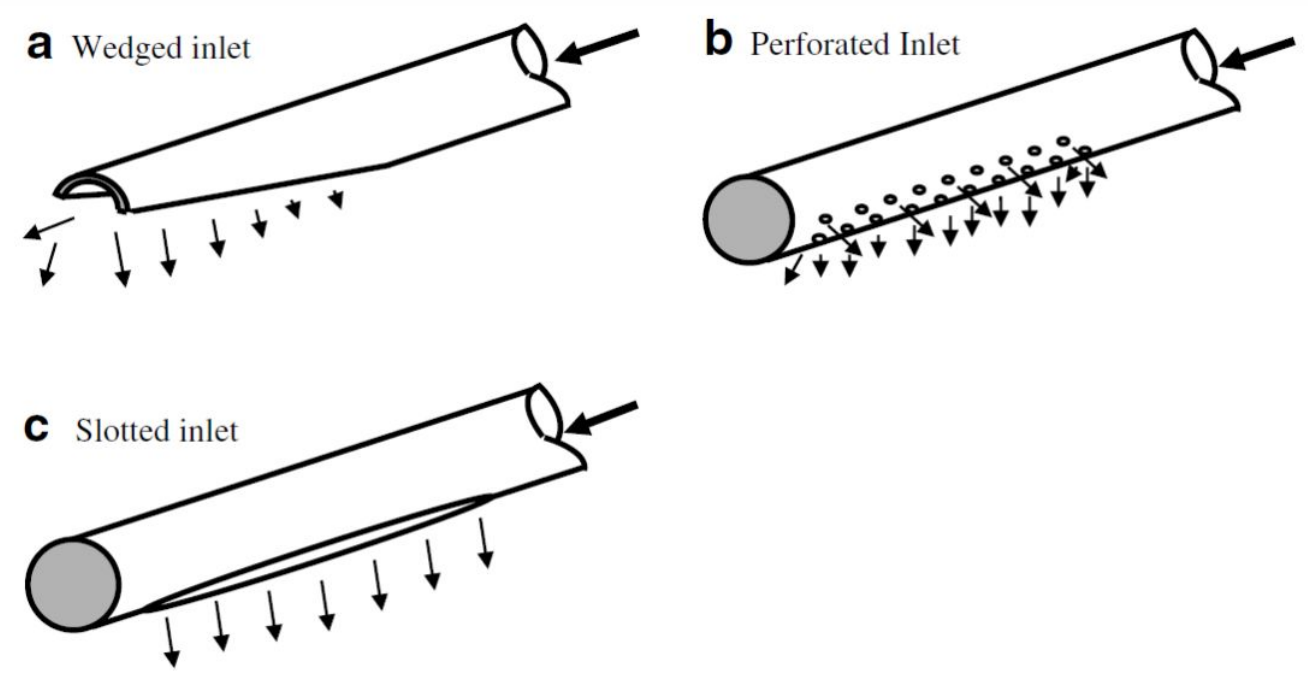

Figure 2.13: Diffuser configurations studied by Hegazy [22]

was varied by changing the gap between the diffuser plates. Reynolds number was varied by changing the flow rate into the tank. The results show that Froude number has negligible contribution while Reynolds number is a more dominant parameter. It should be noted that the Froude number considered in these simulations are within the recommended region (explained in section 2.1.3), which means that changes in the Froude number should not have an effect on the level of stratification within the tank. The authors found that radial adjusted plate to be the best performing diffuser due to its ability to effectively spread the fluid in the rectangular tank. 

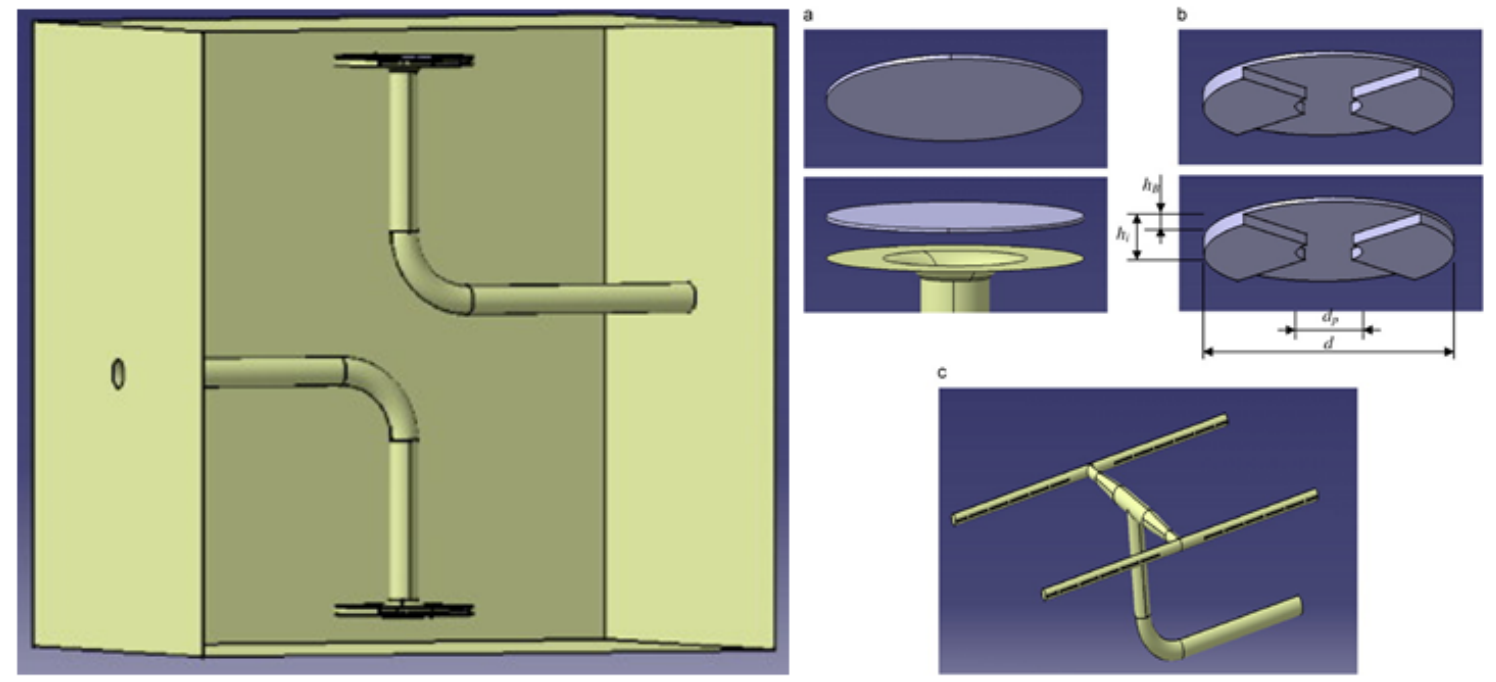

Figure 2.14: Diffuser configuration studied by Chung et al. Left: the layout of the diffuser within the tank. Right: a) radial plate, b) radial adjusted plate, and c) H-beam diffuser [23]

\subsubsection{Stratifiers}

Placing inlet stratifiers inside STTS tanks can significantly improve the degree of stratification. Stratifiers are developed in order to allow the thermal storage to be able to handle variable flow rates and inlet temperatures. They are an effective mean of reducing the mixing due to inlet jet and plume entrainment. Stratifiers make use of the density difference between the hot and cold fluid in order to try to deliver the incoming fluid into the layer with the same temperature. The first stratifier was developed by Van Koppen et al. [24]. It was flexible light rubber hose that was able to float by buoyancy difference in order to deliver the incoming fluid into the fluid layer with the same temperature. However, this solution did not perform as expected in practice due to problems with dirt accumulating inside the hose. Later, two types of vertical stratifiers were investigated by Loehrke et al. [14], where the charging fluid enters the top of the stratifier and is released to the correct fluid layer. One stratifier 
was a rigid perforated $10 \mathrm{~cm}$ PVC drain pipe and the other was a $10 \mathrm{~cm}$ diameter sleeve made of polyester cloth. The polyester cloth was found to outperform the PVC drain pipe.

Highly perforated side and top inlet rigid tubes were investigated by Abu-Hamdan et al. [26]. They found no advantages over conventional side and top inlets. Shah et al. [25] studied another vertical rigid stratification device with only 3 side holes with hot water being introduced at the bottom of the tank as shown in Figure 2.15 [25]. This stratifier works using buoyancy difference, hot water is introduced from the bottom of the rigid stratifier, while the water around the bottom of the stratifier is cold. Since hot water is lighter in weight than cold water, then this will drive the cold water surrounding the stratifier to enter the stratifier and mix with the hot water. This is confirmed by their finding that the stratifier works more as a mixing device. In the same paper, flaps were installed in front of

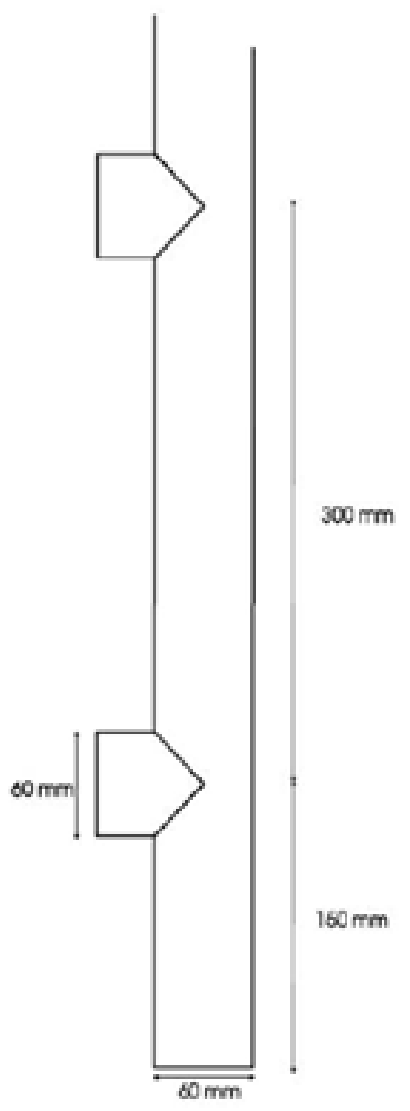
the 3 side holes. It was found that the flaps act as a non-return valve, which reduced the undesirable flow at the bottom of the stratifier. It was noted that the stratifier with flaps has an outstanding performance when the flow rate is between $5 \mathrm{~L} / \mathrm{min}(\mathrm{Ri}=82)$ and $8 \mathrm{~L} / \mathrm{min}(\mathrm{Ri}=32)$. A disadvantage 
of rigid stratifiers occurs when the correct temperature layer is located between two rigid holes. This will drive the stratifier to let fluid escape from two holes, one below the correct temperature layer and another above it. This destroys the stratification within the tank, while a fabric stratifier does not have that limitation.

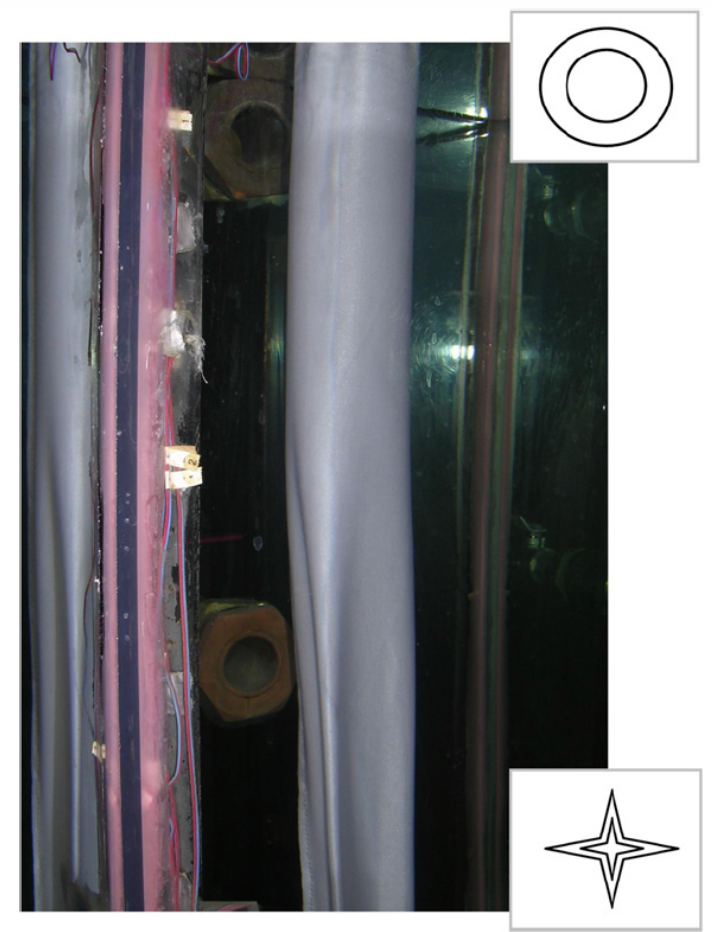

Figure 2.16: Two fabric stratifiers during a heating experiment. Upper right corner: cross section of the expanded fabric where hot water leaves the pipe, lower right corner: cross section of the collapsed fabric in order to prevent outside water from entering the pipe [27]

Flexible stratifiers are porous fabrics that have the advantage that the inlet pipe can expand or contract to equalize the pressure between the fluid inside the pipe and the tank. If the pipe has warmer fluid than the surrounding, then the outside colder fluid will build pressure on the pipe which will make it collapse. This will prevent water from the tank entering into the stratifier. When the fluid within the pipe is 
colder than the surrounding, then the fluid inside the pipe will have a higher pressure than the surrounding and as a result, the porous fabric will expand allowing the fluid inside the pipe to escape as shown in Figure 2.16 [27]. It should be noted that for this stratifier, the inlet is always at the bottom of the pipe. Davidson and Adams [28] studied flexible stratifiers, and found that synthetic fabrics that stretch easily in one direction are better than natural fibers. They compared the different stratifiers using the MIX-number and they found that the flexible stratifier is only about $4 \%$ more effective than a rigid stratifier and $48 \%$ more effective than a traditional drop-tube inlet. Andersen et al. [27] noted that since the fabric is very thin, this can lead to a high heat transfer rate horizontally between the hot fluid inside the pipe and the cold fluid inside the tank. In order to reduce this undesirable heat transfer, it is better to use two fabric layers instead of one that are $10 \mathrm{~mm}$ apart.

Andersen and Furbo [29] compared fabric stratifiers to rigid stratifiers. Rigid stratification pipes can provide better stratification for low flow rates $(6 \mathrm{~L} / \mathrm{min}, \mathrm{Ri}=113$ ) while fabric stratifiers can provide better stratification for high flow rates $(10 \mathrm{~L} / \mathrm{min}$, $\mathrm{Ri}=40$ ). One main disadvantage of stratifiers is that the knowledge of the long term durability is still unknown.

Lorenz [30] introduced a stratification device where the inlet fluid goes through stratification channels in a way that reduces the momentum of the fluid, making buoyancy a more dominant force which leads the incoming fluid to the fluid layer with the same temperature as presented in Figure 2.17 [30]. The benefit of this stratification device is that it has no moving parts, unlike the rigid and fabric stratifiers, while being able to maintain stratification. Although not discussed in the paper, the pressure drop and the size of this stratifier might be a concern. 

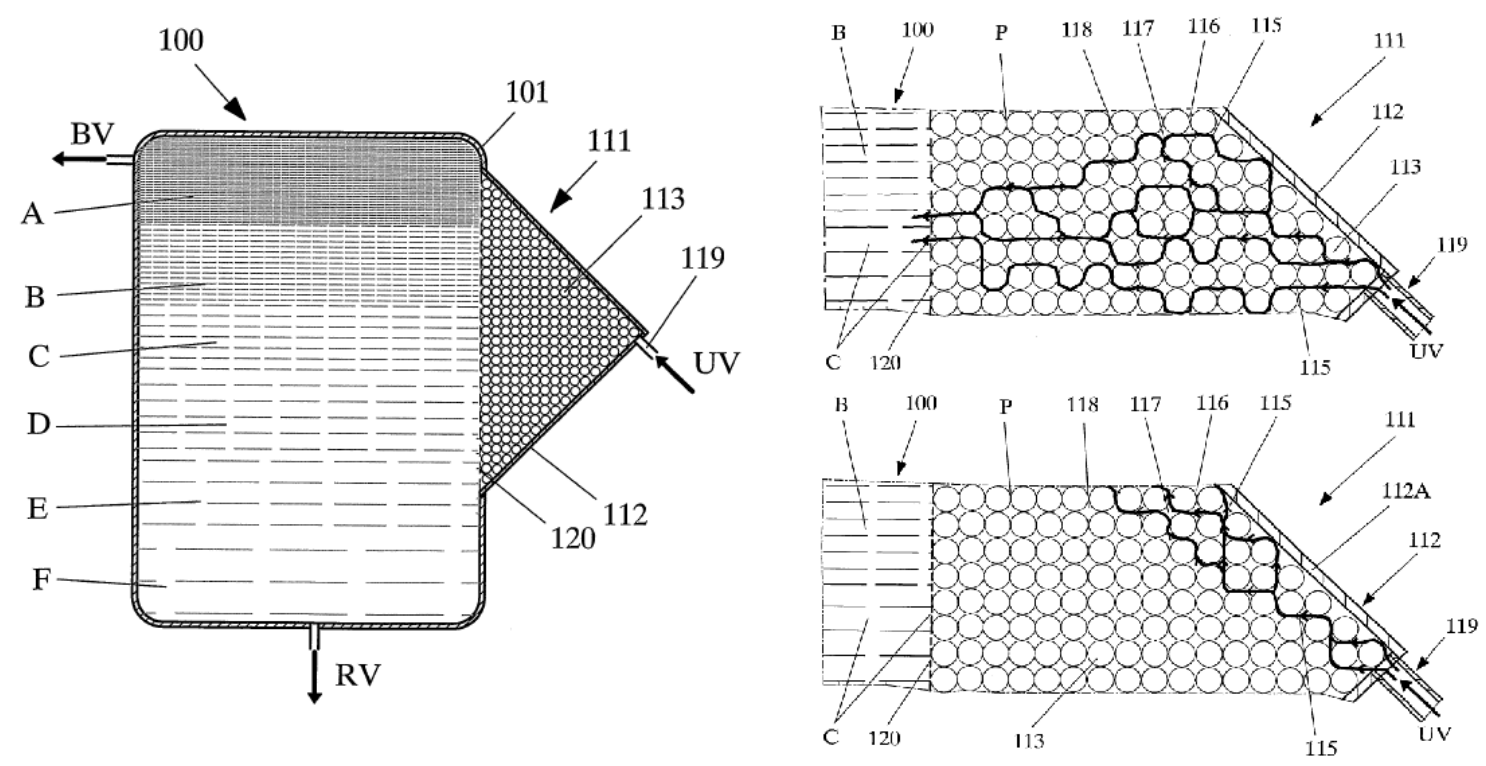

Figure 2.17: Left: illustration of the patent idea presented by Lorenz, right: illustration of the fluid flow around the channels in order to spread and achieve the correct fluid level [30]

Vogelsanger et al. [31] introduced a new type of stratifier using vertical baffles in vertical tanks presented in Figure 2.18 [31]. The idea is to place two parallel vertical plates that are rectangular in shape with the inlet located in the middle of the plate, very close to the tank wall. It was found that these vertical baffles are successful at delivering the inlet fluid to the correct fluid layer. When the inlet jet enters the gap between the two vertical plates, the inlet jet is forced to spread within a very small volume. This reduces the jet momentum and allows buoyancy to dominate, which helps deliver the fluid to the correct fluid layer. It was discovered that if the gap between the two vertical baffles is carefully tuned, the thermal stratification within the tank can be boosted. This type of baffle has the ability to prevent mixing within the tank due to plume entrainment. It should be noted that the flow rates used in these experiments are very small $(70-100 \mathrm{l} / \mathrm{hr})$ or in the laminar regime for the 
dimensions considered.
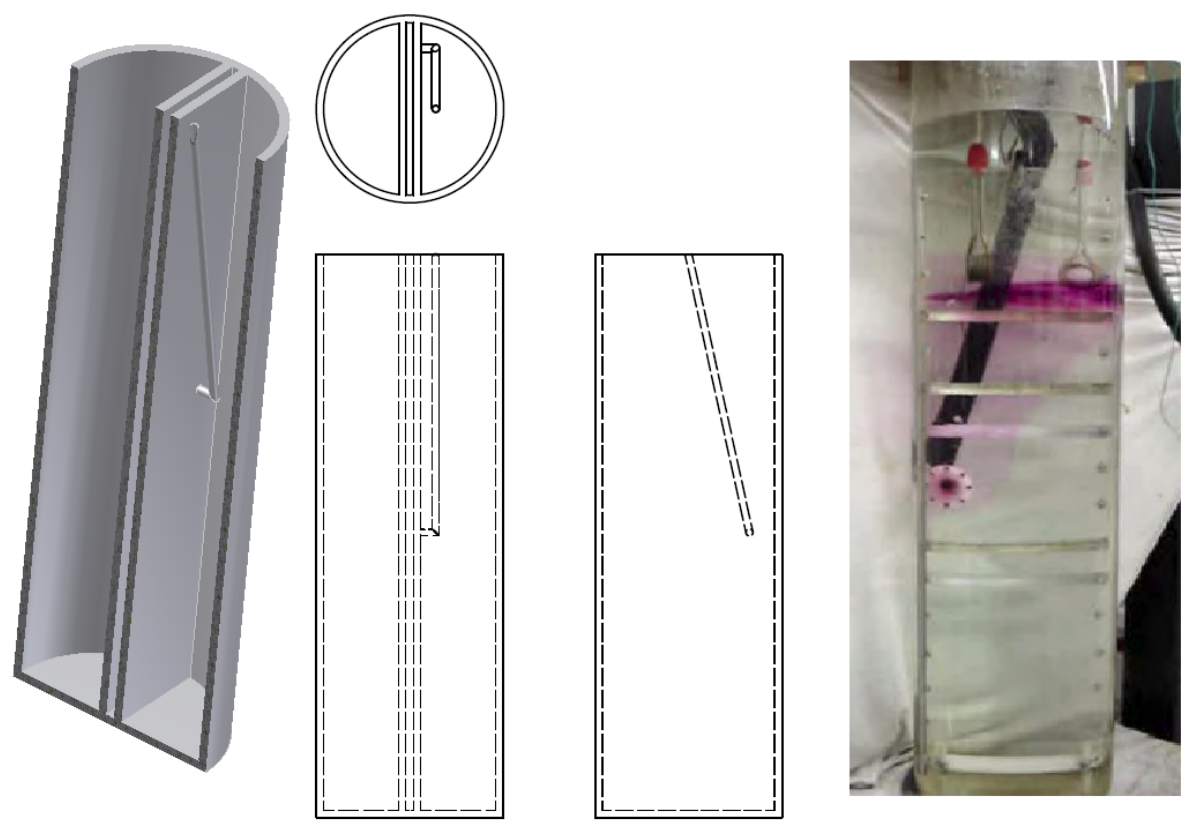

Figure 2.18: An illustration of the vertical parallet plates that help stratify the tank [31]

In summary, stratifiers have a noticeable advantage over baffles and diffusers in that they can deliver the inlet fluid to the correct level within the tank while introducing less mixing. Questions as to the long term durability and performance of these devices do remain.

\subsection{Methods of Assessing Stratification}

In order to conduct a fair comparison between different designs that help improve the stratification within the tank, it is important to create a measure that is able to quantify the amount of mixing that takes place. There are multiple measures available that vary in simplicity and accuracy. There are graphical methods, efficiencies 
based on the first law of thermodynamics, and efficiencies based on the second law of thermodynamics.

\subsubsection{Graphical}

The simplest technique to assess stratification is by plotting a temperature versus storage height graph at different instances as depicted in Figure 2.19 [32] and comparing the thermocline thickness [33], thermocline gradient [13], or the thermocline gradient decay [34]. However, these methods cannot be used if the inlet temperature is changing throughout the experiment [35].

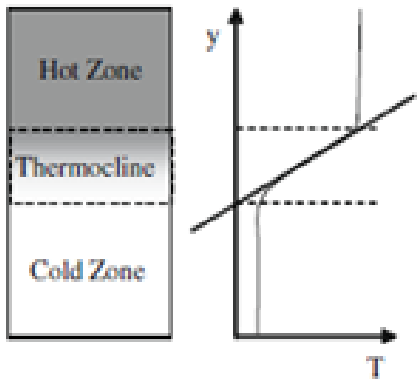

(a)

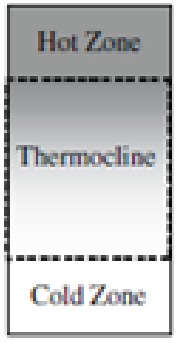

(b)

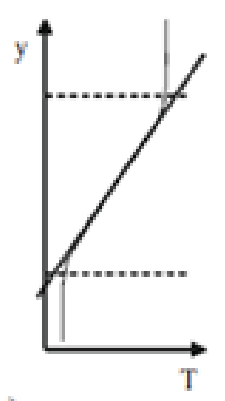

)

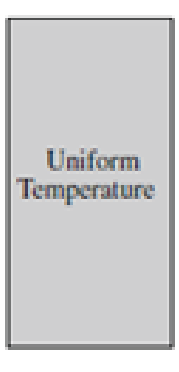

(c)

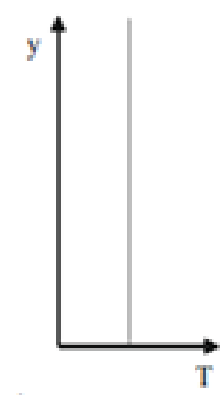

Figure 2.19: Comparison of different degrees of stratification using a temperature versus height graph where a) left, highly stratified, b) center, moderately stratified, c) right, fully mixed [32]

$\mathrm{Wu}$ and Bannerot [36] introduced an index for the degree of stratification called the stratification coefficient. It is based on the variance of temperatures in the storage from the mean storage temperature. A large stratification coefficient indicates a high level of stratification.

$$
S T_{W u}=\frac{1}{m_{\text {store }}} \cdot \sum_{i} m_{i}\left[T_{i}-T_{\text {avg }}\right]^{2}
$$




\subsubsection{First Law Efficiencies}

Stratification can be assessed using the first law of thermodynamics by finding the recoverable heat efficiency [37], charging and discharging efficiencies [38] and figure of merit [39]. Recoverable heat efficiency is a fraction of recoverable heat as a measure of thermocline degradation during storing and considers the temperature at the outlet during charging or discharging. This efficiency is defined in Equation 2.6 below, where $t_{d}$ is the time at which the temperature difference degrades more than $20 \%$. In other words, it measures the amount of energy that can be extracted from the tank before the outlet temperature drops by $20 \%$.

$$
\eta_{Z G}=\frac{\int_{0}^{t_{d}} \dot{m} \cdot c_{p}\left|T_{\text {out }}-T_{\text {in }}\right| d t}{m_{\text {store }} \cdot c_{p}\left|T_{\text {in }}-T_{\text {initial }}\right|}
$$

An example of a fully mixed cold tank being charged is presented in Figure 2.20 in order to better illustrate the difference of the value of $t_{d}$ between a fully mixed and a perfectly stratified tank .

$$
\frac{\left|T_{\text {out }}-T_{\text {in }}\right|}{\left|T_{\text {in }}-T_{\text {initial }}\right|}<0.8
$$

The charging and discharging efficiencies represent the actual energy change at time $t$ divided by the maximum energy change of ideal plug flow in the same experiment.

$$
\eta_{2, C h}(t)=\frac{m_{\text {store }} \cdot c_{p} \cdot\left|T_{\text {avg }}(t)-T_{\text {initial }}\right|}{t \cdot \dot{m} \cdot c_{p}\left|T_{\text {in }}-T_{\text {initial }}\right|}
$$

These methods calculate a fraction of energy recovered. However, they cannot determine the degree of stratification during standby, differentiate mixing from heat 


\section{Outlet Temperature}

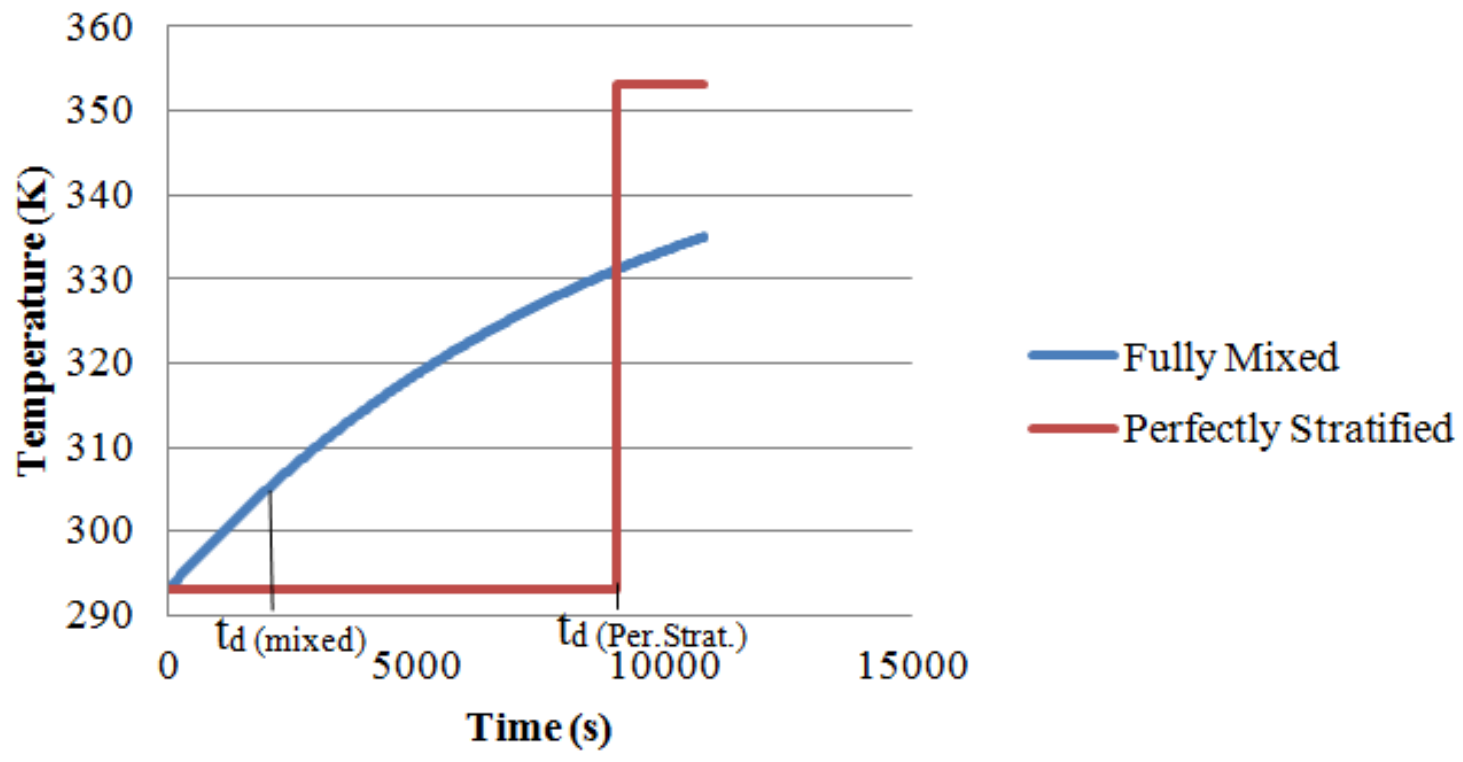

Figure 2.20: Illustration of the difference in the value of $t_{d}$ between fully mixed and perfectly stratified tank

loss, and are inapplicable for variable inlet temperature and mass flow rates [32].

\subsubsection{Second Law Efficiencies}

The method that captures most of the stratification details is the second law of thermodynamics because the exergy stored in a tank is the thermodynamic limit of the work that can be produced [32]. Examples of second law efficiencies are exergy efficiency [40], exergy or entropy efficiency [10], entropy generation ratio [41], and stratification efficiency $[42,43]$. Exergy or entropy efficiency proposed by Shah and Furbo is ratio between total exergy stored in a real TES and a TES with plug flow.

$$
\eta_{\xi, S h}(t)=\frac{\xi_{\text {stored,real }}(t)}{\xi_{\text {stored,ideal }}(t)}
$$


It is an index that suggests that the worst case scenario for a TES is one that does not store more exergy. However, this index does not distinguish between a stratified tank and a fully mixed tank [6] . Stratification efficiency is introduced by Van Berkel, who proposed an index that is based on a ratio of the exergy destroyed in a real TES in comparison to a fully mixed and ideal tank.

$$
\eta_{\xi, V B}(t)=\frac{\xi_{\text {lost }, \text { mixed }}(t)-\xi_{\text {lost }, \text { real }}(t)}{\xi_{\text {lost }, \text { mixed }}(t)-\xi_{\text {lost }, \text { ideal }}(t)}
$$

Huhn [43] simplified Berkels equation and obtained another stratification efficiency.

$$
\eta_{\xi, H U}(t)=1-\frac{\xi_{\text {lost }, \text { real }}(t)}{\xi_{\text {lost }, \text { mixed }}(t)}
$$

This efficiency states that the total exergy destroyed in a real tank must be less than the total exergy destroyed in a fully mixed tank. The methods based on the second law of thermodynamics are more complicated to use due to the requirement to quantitatively assess the complete temperature distribution inside the thermal storage tank. These methods became feasible through the use of three-dimensional CFD analyses.

MIX-number is another important method to assess the degree of mixing, and it was introduced by Davidson et al. [44], and improved by Anderson et al. [27]. The MIX-number is based on the "moment of energy" $\left(M_{E}\right)$, which is an integration of the sensible energy content along its vertical axis, weighted with the height of its location along the vertical axis.

$$
M_{E}=\sum_{i=1}^{N} y_{i} \cdot E_{i}
$$




$$
M I X_{\text {Dav }}=\frac{M_{E, \text { ideal }, h l}-M_{E, \text { real }}}{M_{E, \text { ideal }, h l}-M_{E, \text { mix }, h l}}
$$

Values of $M_{E}$ for a perfectly stratified and a fully mixed tank are calculated from the beginning of the experiment while taking heat loss to the environment into consideration. Anderson subsequently simplified the expression by neglecting the heat loss to the surroundings by calculating the stratified and fully mixed conditions at each instant.

According to Haller et al., the best method is the stratification efficiency proposed by Huhn because it is in qualitative agreement with entropy production and is applicable to variable inlet temperatures and mass flows. The only drawback of this method is that it lacks the ability to distinguish if the entropy generation is due to heat losses or internal mixing and heat conduction through the water [32]. Since, the simulations being considered for this thesis assume that heat loss to the ambient to be negligible and is eliminated from the simulation, then all entropy generation within the tank will be due to internal mixing and heat conduction through the water, thus making Huhn's efficiency a perfect candidate for this study.

\subsection{System Simulation Models}

System simulation codes are mainly used to predict the long term performance of the entire system including all components such as the solar collector, thermal storage tanks, and auxiliary heaters (i.e. yearly performance of the entire system). Detailed simulation of the flow cannot be performed using three dimensional codes because they are too computationally expensive. In order to reduce the computational expense, 
most of the tank models try to simplify the problem by assuming that the horizontal temperature variation through the tank is very minimal and as a result, the tank temperature is modeled in one dimension.

Several models were developed such as the one proposed by Close [45], which over simplified the thermal storage tank by splitting it into multiple fully mixed layers while assuming that the inlet fluid settles into the correct section of the tank without mixing with any other layer. Duffie and Beckman [46] improved the model by allowing the tank to have a fixed or variable inlet model, representing complete or zero plume entrainment respectively. The fixed inlet model, considers the fluid entering at the top of the tank. If the water coming in is hotter than the water at the top layer of the tank, then a new layer is formed at the top and the previous layers in the tank will be pushed downward, and an equal volume will exit the tank from the bottom. If the water coming in is cooler than the water at the top of the tank, then water coming in will mix with the top layer and any adjacent layers until the layer below the mixed layers is lower in temperature.

In order to better assess the turbulent mixing taking place inside the tank, Cole and Bellinger [47] presented an inlet mixing parameter that was a function of the Fourier number and the Richardson number. Oppel [48] was able to produce a one dimensional finite difference model that can deal with turbulent mixing. This was done using a thermal eddy conductivity factor. Oppel was also able to model charging and discharging at variable flow rates by introducing a conceptual buffer tank. Later, Oppel [49] noticed that the inlet eddy conductivity is dependent on the Reynolds number and the Richardson number. Also, it was shown that the inlet eddy conductivity decreases along the length of the tank as a hyperbolic function with the 
maximum value at the top. After experimental study of different inlet configurations, these models were used to try to predict the mixing within the tank for the different inlets.

A general weak point with some of the proposed techniques is that they are developed while ignoring the actual physics that takes place inside the thermal storage tank. To improve on this, Pate [50] and Csordas et al. [51] used the mass entrainment formulation in the jet affected region. This was done in order to better model the real effects of plume entrainment. Nizami [11] successfully modeled a negative buoyant plume inside a vertical storage tank. He defined a penetration depth of the inlet jet which is the length extending from the inlet to the point where the jet changes its direction along the centerline of the tank. He achieved this model by dividing the tank into four different regions as shown in Figure 2.21 [11].

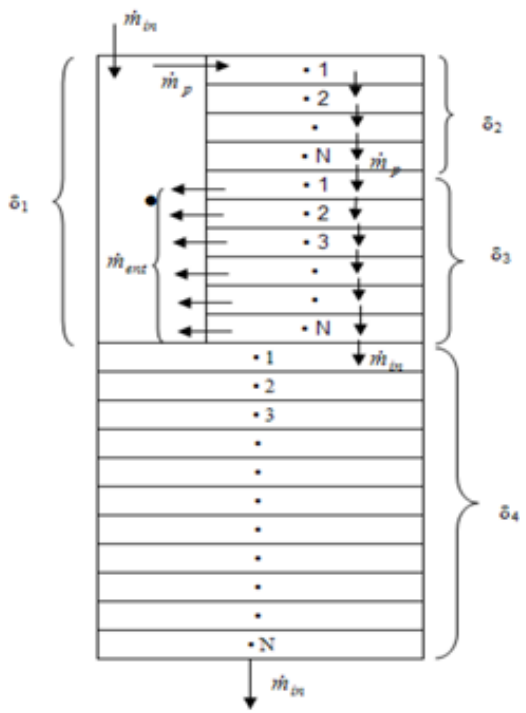

Figure 2.21: Schematic of the node distribution inside a one dimensional tank [11]

Currently TRNSYS has four different thermal storage simulation models that are 
inspired by Duffie and Beckman [46], Kuhn [52], and Newton [53]. The most basic tank model is "Type 4"; it splits the tank into $\mathrm{N}(N \leq 15)$ fully-mixed equal volume segments. The degree of stratification is dependent on the number of segments, if $\mathrm{N}$ is equal to one, then the tank is fully mixed. The code can also model unequal size nodes, and incremental heat loss coefficients. A more detailed simulation code is Type 60, which uses the same concept as Type 4 but allows the tank to be split into up to 100 volume segments. It allows non uniform number of inlets and outlets, accounts for the conduction along the tank wall, and destratification due to mixing at node interface. Type 38 is a more efficient simulation model because it utilizes a non uniform grid. It splits the tank into constant temperature segments, where there are small segments at the thermocline and larger segments away from the thermocline.

The models are unable to correctly predict the heat transfer and the fluid flow in horizontal tanks containing baffles. This is due to the complexity of the problem since the flow is generally three dimensional. As a result, simulations should be performed using a three dimensional CFD simulation program.

\subsection{Computational Fluid Dynamics Modelling of TST}

CFD solves fluid flow and heat transfer problems through numerical discretization of the differential equations of mass, momentum, and energy. The process of solving the governing equations in order to obtain accurate solutions is very complex, and requires the use of turbulence models. Care must also be taken to ensure that predictions do not depend on the grid spacing and time-step. 
There is an extensive effort to ensure that solutions obtained from turbulence models are consistent with experimental results of STTS tanks. Radial diffusers were studied by Shin et al. [54] using standard k- $\varepsilon$ and the ReNormalized Group (RNG) $\mathrm{k}-\varepsilon$ turbulence model, and found that the results of the different models is almost identical. However, there was some deviation from the experimental measurements and this was suggested to be due to experimental uncertainties. Also, the results of the $k-\varepsilon$ model were in good agreement with the experimental values when the buoyancy term in the production and dissipation equations were added by Oliveski et al. [55].

Panthalookaran [56] suggested that the default RNG $\mathrm{k}-\varepsilon$ and the realizable $\mathrm{k}-\varepsilon$ turbulence models cannot correctly simulate stratified flows because they overestimated the turbulence mixing. As a result, Panthalookaran decided to recalibrate the dissipation coefficients in order to get a better agreement. After numerous simulations and comparison with experimental results, the $C_{\varepsilon 2}$ coefficient for RNG k- $\varepsilon$ model was changed from 1.68 to 3.40 and the $C_{2}$ coefficient in the realizable k- $\varepsilon$ model was changed from 1.9 to 2.9. Rysanek [6] tested different turbulence models ( $\mathrm{k}-\varepsilon, \mathrm{k}-\varepsilon \mathrm{RNG}, \mathrm{k}-\varepsilon$ realizable, and $\mathrm{k}-\omega \mathrm{SST}$ ) on the hot and cold tanks available at Drake Landing. All turbulence models produced similar results. However, the default k- $\varepsilon$ realizable model was able to achieve the solution closest to the experimental values. In addition, Rysanek suggested that all the models used over-predict turbulence mixing which confirms Panthalookaran's observation. 


\subsection{Summary}

In summary, STTS tanks are key components in thermal storage systems. Thermal stratification impacts the system performance and a perfectly stratified storage can deliver $37 \%$ more energy than a fully mixed storage. It was understood that the mechanisms that affect stratification are inlet jet mixing, and plume entrainment. Stratification can be enhanced through the use of baffles, diffusers and stratifiers. Baffles are a very effective way to enhance stratification and their main role is to redirect the inlet jet or act as an obstacle in order to hinder mixing. However, baffles are ineffective in controlling plume entrainment. Diffusers are devices that force the fluid to go through a large area in order to reduce its speed ultimately reducing the mixing within the tank, but diffusers cannot deliver the fluid to the correct fluid layer, meaning that they are ineffective in hindering the mixing resulting from plume entrainment. Lastly, stratifiers are very effective in delivering the fluid to the correct temperature layer and reduce mixing due to inlet jet. Most of the previous research focused on vertical tanks because they are more widely used. Performance of horizontal tanks has been studied under charging condition. The question of the tank's performance under discharging conditions has not been previously explored. Moreover, the impact of simultaneous charging and discharging on thermal stratification should also be considered. 


\section{Chapter 3}

\section{Development and Validation of}

\section{CFD Simulation Model for STTS tanks at DLSC}

In order to gain confidence in the numerical model, predictions should be validated against experimental data. Moreover, grid independence and timestep independence tests must be performed. This chapter explains all the steps that were involved in the generation of the CFD model of the Drake Landing STTS tanks. A validation study using experimental data from DLSC is also presented.

\subsection{Geometry and Boundary Conditions}

The validation compared model predictions of the tank temperature in the cold STTS tank at the DLSC to those obtained experimentally. The simulated tank is $3.8 \mathrm{~m}$ in diameter and $11.42 \mathrm{~m}$ in length. Fluid enters the bottom through an inlet diameter of 
$101.6 \mathrm{~mm}$ and exits through an outlet diameter of $152.4 \mathrm{~mm}$. The tank has a middle baffle that extends about $85 \%$ of the entire tank length. This geometry is shown in Figure 3.1.

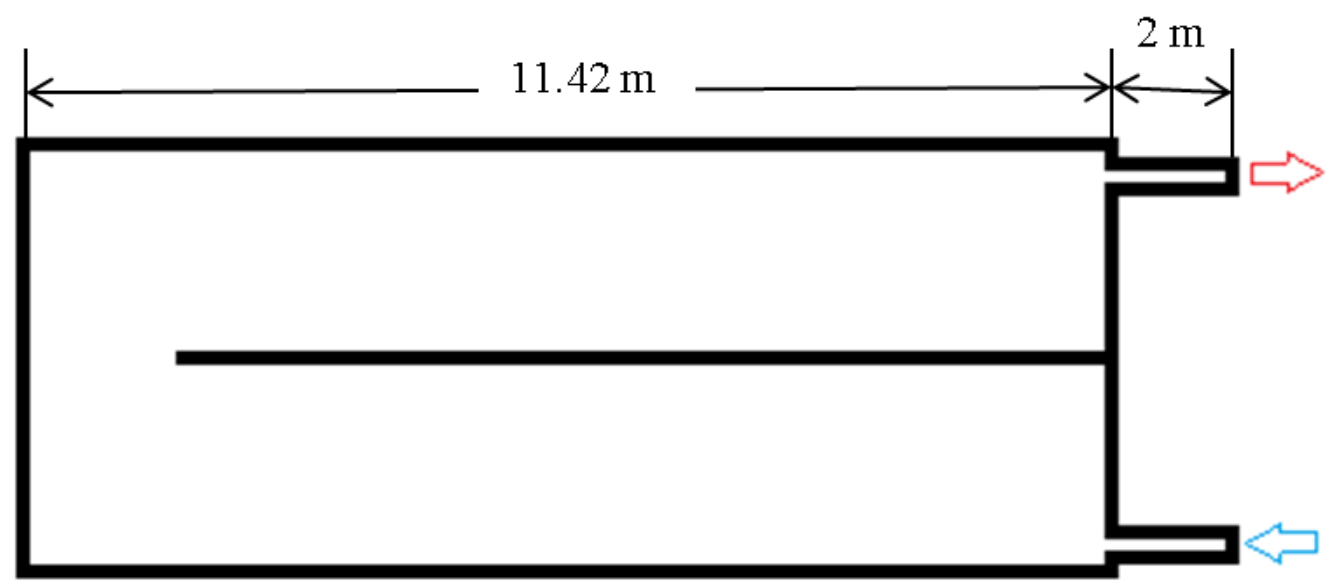

Figure 3.1: Schematic of the current horizontal tank at DLSC (Not to scale)

The tank was at an initial uniform fluid temperature of $60^{\circ} \mathrm{C}$. This represents a typical fully charged STTS tank at DLSC. The tank has a discharging inlet mass flow rate of $6 \mathrm{~L} / \mathrm{s}$ which is the maximum achievable mass flow rate of the discharging loop, resulting in the largest amount of mixing. The tank discharging inlet temperature is $30^{\circ} \mathrm{C}$. The inlet temperature does not vary widely during a normal discharging cycle and this represents a typical discharging inlet temperature [7]. Heat losses from the tank walls are neglected. In order to allow for flow development at the inlet and outlet, the domain was extended to include $2 \mathrm{~m}$ long pipe sections in those regions. Although not to scale, the extended inlet and outlet are shown in Figure 3.1. 


\subsection{Grid Development}

The validation study is performed based on the geometry of the existing STTS tanks at Drake Landing Solar Community. Since the location of the inlets and the outlets are very close to the center of the tank, symmetry is applied and only half of the tank is simulated. This reduces the computational time significantly. The hexahedral volume mesh is generated using the commercial code ICEM CFD 12.1. The minimum boundary layer thickness is $3 \mathrm{~mm}$ at the walls of the tank. The smallest mesh element is $3 \mathrm{~mm} \times 3 \mathrm{~mm} \times 5 \mathrm{~mm}$, and the largest mesh element is $61 \mathrm{~mm} \times 61 \mathrm{~mm} \times 400 \mathrm{~mm}$. This is dictated by the gradients inside the tank; the larger the gradients, the finer the mesh and vice versa.

A total of five different grids were generated in order to assess the number of nodes required to maintain an accurate solution. Three different grids were used to study grid independence in the axial direction, and two to study grid independence in the radial direction. The number of grid points used ranged from 150,000 to 1,200,000. Figure 3.2 shows a sample grid.
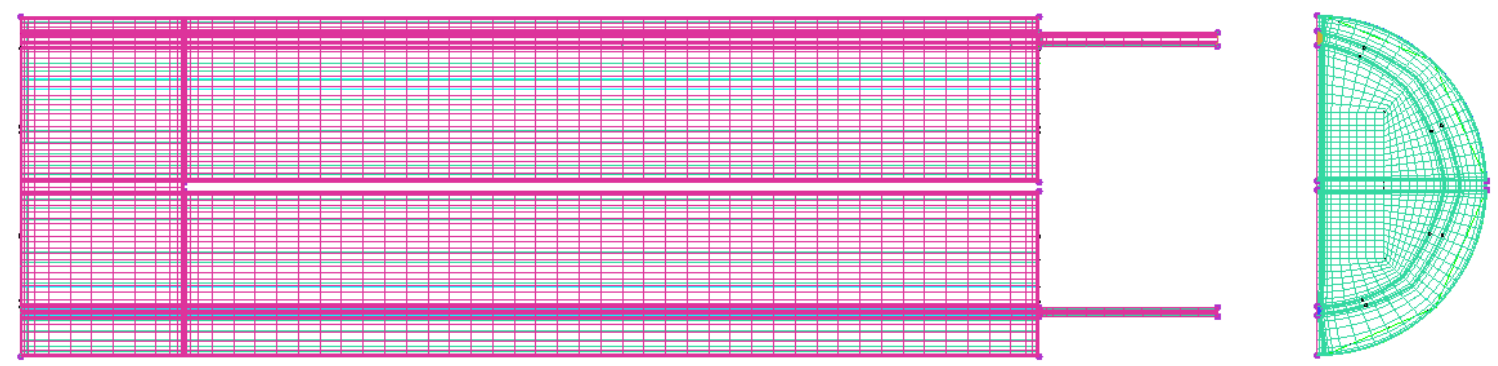

Figure 3.2: A coarsened mesh of the STTS tank at DLSC 


\subsection{Simulation Methodology}

This section summarizes the procedure used to assess grid and timestep independence as well as to explore the effects of various turbulence models. A baseline grid (600,000 nodes) was first created using ICEM CFD 12.1 and the mesh exported to ANSYSCFX 14. Two simulations were performed using different timesteps to assess timestep independence. Grid independence was studied by separately exploring the effects of grid density in the tank cross-section and in the axial direction. The effect of the selection of the turbulence model was assessed by comparing predictions from the code to experimental data and is presented in the validation section.

\subsubsection{Solver Settings}

The commercial CFD code used for this simulation is ANSYS CFX 14.0. All simulations were performed using either a personal computer with a $3.4 \mathrm{GHz}$ quad core processor or the high performance computer SHARCNET with 12 cores running in parallel. The solver settings are as follows:

- The simulation is transient, and a timestep of $1.5 \mathrm{~s}$. Sensitivity to time-step was tested and is described in Section 3.3.2

- The fluid is water with constant properties

- Buoyancy is activated, gravity direction is identified and reference temperature is set to $25^{\circ} \mathrm{C}$

- Heat transfer model is thermal energy 
- Turbulence model is $k-\omega$. Sensitivity to turbulence model was tested by analyzing the performance of the $k-\omega$ and $k-\omega$ SST turbulence model against experimental data from DLSC. This is described in Section 3.4

- Advection scheme is High Resolution

- Maximum number of loops is 20

- Convergence criteria of RMS residual of $10^{-5}$ and conservation target of $10^{-2}$

- Transient simulation files are saved every 5 minutes of simulation time

\subsubsection{Timestep Independence Tests}

This is a very important test in order to ensure that the values obtained from the simulation are accurate while not consuming excessive computation time. This test is performed by doubling the value of the timestep from 0.75 to $1.5 \mathrm{~s}$ and examining the results of the different simulations.

The profiles shown in Figure 3.3 indicate that the solution is independent of the timestep used. If the timestep is increased above $1.5 \mathrm{~s}$, however, the simulation result starts to fluctuate and does not converge to the desired converging criteria. Therefore, the largest allowable timestep while obtaining convergence is $1.5 \mathrm{~s}$. The discontinuity in the curves coincides with the location of the horizontal plate. 


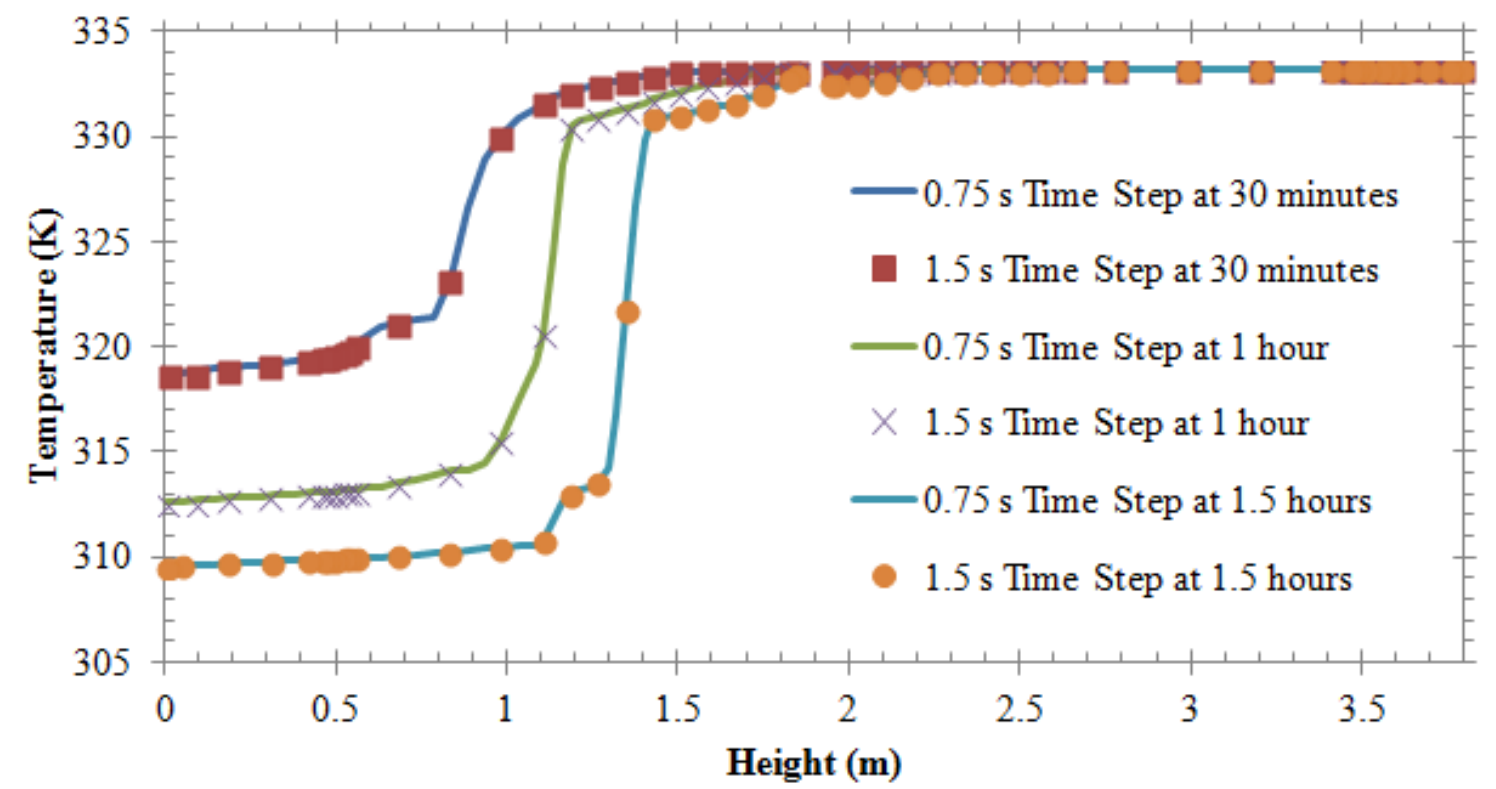

Figure 3.3: Temperature profile within the tank at 30 minutes, 1 hours, and 1.5 hours into discharging showing the results using $0.75 \mathrm{~s}$ and $1.5 \mathrm{~s}$ timestep in order to prove timestep independence

\subsubsection{Grid Independence: Axial Direction}

In order to confirm that solution does not depend on the density of the grid, a grid independence test was performed. Five different grids were generated. Three to prove grid independence in the axial direction and two for the radial direction. The goal of this process is to ensure that the grid is fine enough for the level of detail that is required to be captured, while maintaining a reasonable CPU time. A baseline cross section grid was chosen and the grid intensity in the axial direction was changed. The grids that were used had 4644 nodes in the cross section. The number of nodes in the axial direction was set to 34,68 , and 136 for three cases. This resulted in a total number of nodes of 150,000,300,000 and 600,000 respectively. These grids are shown in Figure 3.4. 


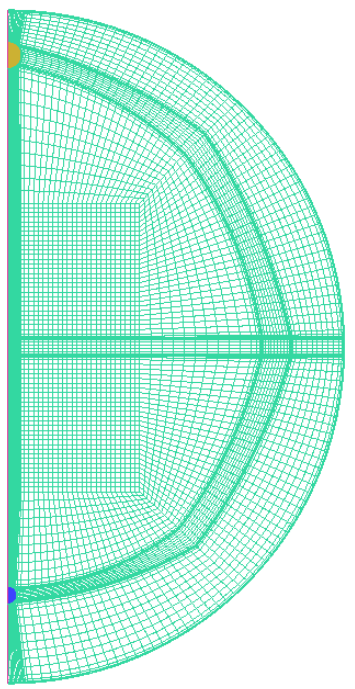

Cross Section

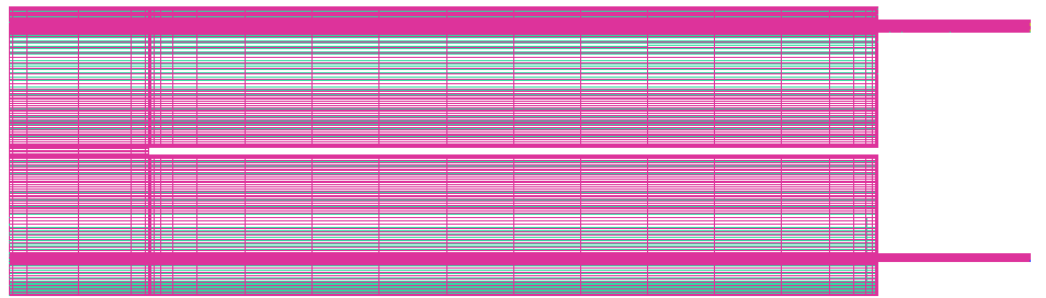

Axial Coarse $(150,000$ Nodes $)$

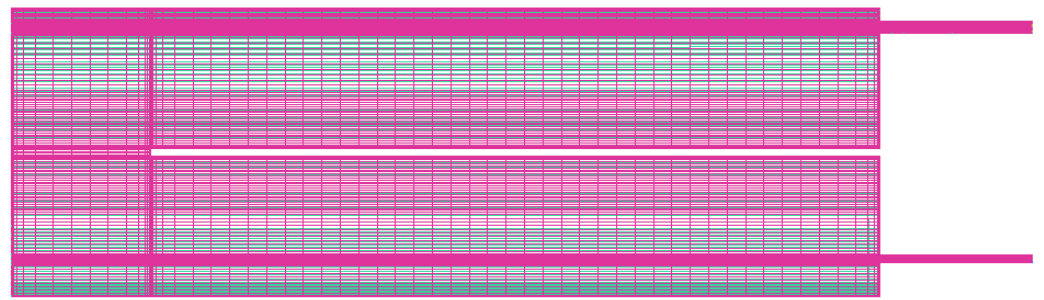

Axial Medium (300,000 Nodes)

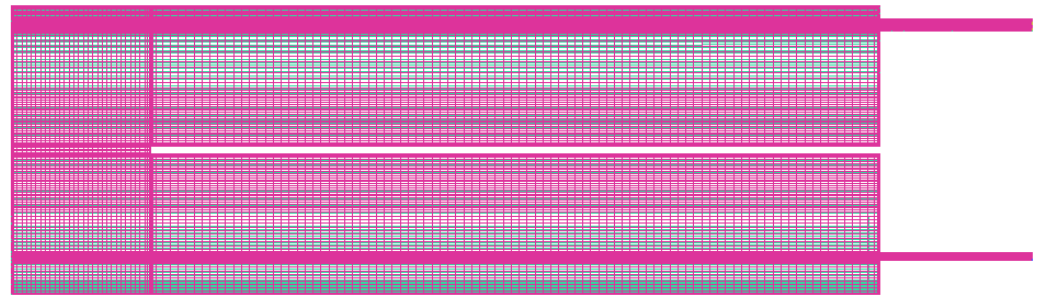

Axial Fine $(600,000$ Nodes $)$

Figure 3.4: The mesh of the chosen cross section and the three axial grid intensities $(150,000,300,000$ and 600,000 nodes)

Figure 3.5 shows the predicted temperature profiles from three different grids. The discontinuity in the curves coincides with the location of the horizontal plate. The results indicate that the solutions is grid independent in the axial direction. This is confirmed by Table 3.1 which indicated that as the grid is coarsened, there is very little impact on the accuracy of the simulation. As a result, it was decided that the best grid density is 150,000 which coincides with 34 nodes in the axial direction. It can predict results close to the other grid intensities while consuming the least computational power. The grid could not be coarsened further because the simulation does not meet the desired convergence criteria. 


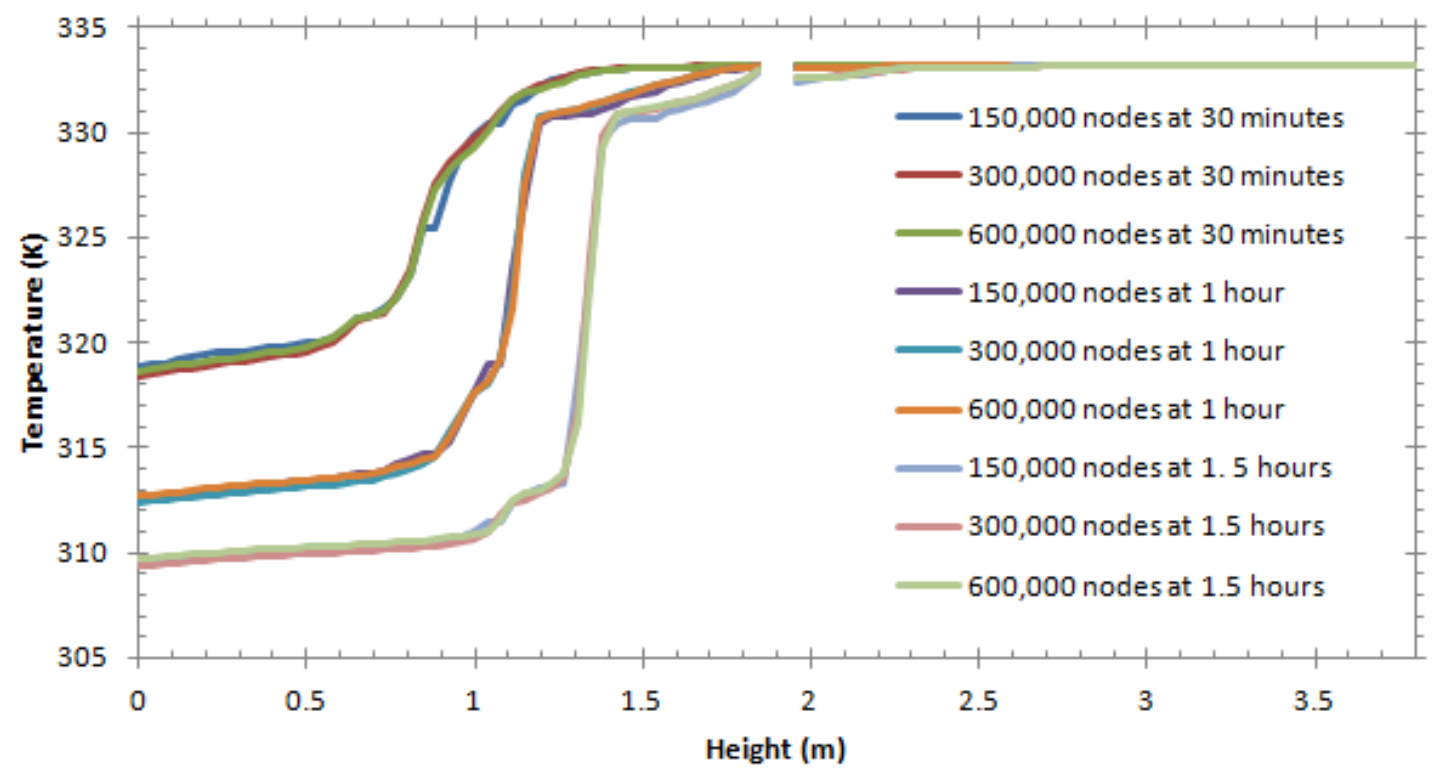

Figure 3.5: Temperature profile within the tank at 30 minutes, 1 hour and 1.5 hours into discharging showing the results using different axial grid intensities for a total of $150,000,300,000$, and 600,000 nodes.

\begin{tabular}{|c|l|l|l|}
\hline \multirow{2}{*}{ 1800s } & $\begin{array}{l}\text { Compares } \\
300,000 \\
600,000\end{array}$ & to & $\begin{array}{l}\text { Compares } \\
150,000 \\
600,000\end{array}$ \\
\cline { 2 - 5 } & Maximum Difference $\left({ }^{\circ} \mathrm{C}\right)$ & 0.25 & 0.47 \\
\hline \multirow{3}{*}{$3600 \mathrm{~s}$} & Root Mean Square Difference $\left({ }^{\circ} \mathrm{C}\right)$ & 0.11 & 0.13 \\
\hline \multirow{3}{*}{$5400 \mathrm{~s}$} & Maximum Difference $\left({ }^{\circ} \mathrm{C}\right)$ & 0.32 & 0.72 \\
\cline { 2 - 5 } & Root Mean Square Difference $\left({ }^{\circ} \mathrm{C}\right)$ & 0.16 & 0.13 \\
\cline { 2 - 5 } & Maximum Difference $\left({ }^{\circ} \mathrm{C}\right)$ & 0.36 & 0.49 \\
\hline
\end{tabular}

Table 3.1: Accuracy of the different grid intensities in the axial direction 


\subsubsection{Grid Independence: Tank Cross Section}

In order to gain confidence that the results are independent of the mesh intensity, then a grid independence test must be carried out for the tank cross section as well. The grid used had 34 nodes applied in the axial direction, and the grid intensity in the cross section was varied. The cross sectional grids considered had 4644, 9717, and 35350 nodes. This resulted in the total number of nodes in the domain of 150,000, 300,000, and 1,200,000, respectively. The grids are shown in Figure 3.6.

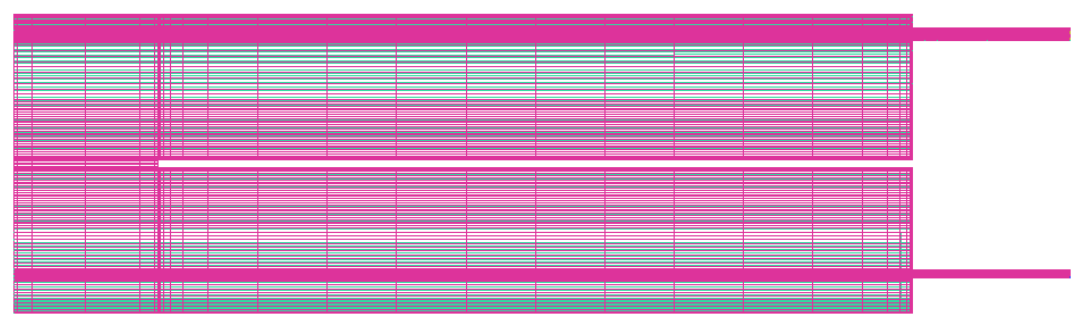

Axial Grid

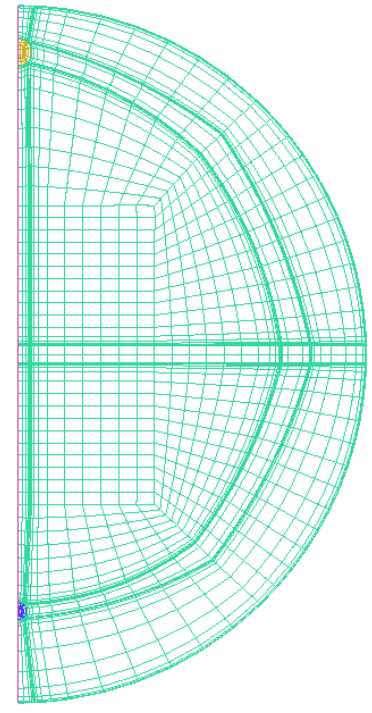

Cross Section Coarse (150,000 Nodes)

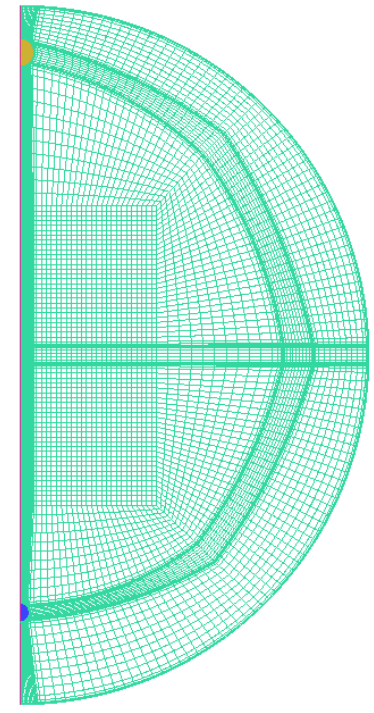

Cross Section Medium (300,000 Nodes)

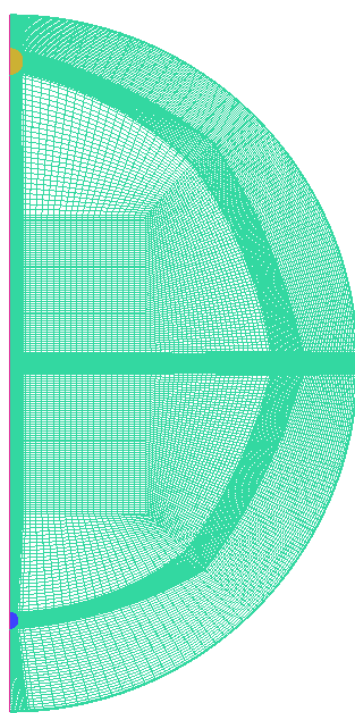

Cross Section Fine (1,200,000 Nodes)

Figure 3.6: The mesh of the chosen axial grid and the three cross sectional grid intensities (150,000, 300,000 and 1,200,000 nodes) 


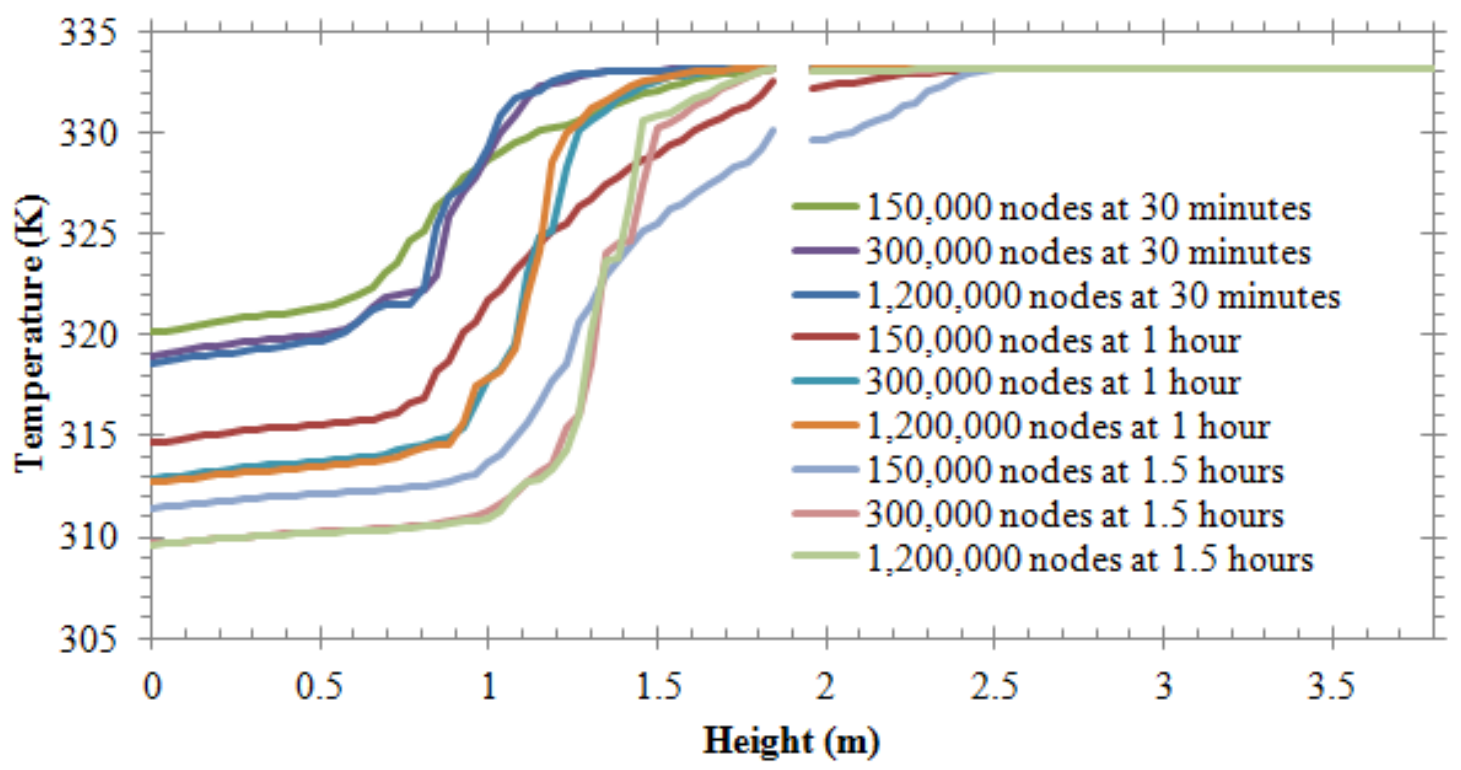

Figure 3.7: Temperature profile within the tank at 30 minutes, 1 hour and 1.5 hours into discharging showing the results using different cross sectional grid intensities for a total of $150,000,300,000$, and 1,200,000 nodes.

\begin{tabular}{|c|c|c|c|}
\hline & & $\begin{array}{l}\text { Compares } \\
300,000 \quad \text { to } \\
1,200,000\end{array}$ & $\begin{array}{l}\text { Compares } \\
150,000 \quad \text { to } \\
1,200,000\end{array}$ \\
\hline \multirow{2}{*}{$1800 \mathrm{~s}$} & Maximum Difference $\left({ }^{\circ} \mathrm{C}\right)$ & 0.84 & 3.15 \\
\hline & Root Mean Square Difference $\left({ }^{\circ} \mathrm{C}\right)$ & 0.22 & 1.10 \\
\hline \multirow{2}{*}{$3600 \mathrm{~s}$} & Maximum Difference $\left({ }^{\circ} \mathrm{C}\right)$ & 1.11 & 4.47 \\
\hline & Root Mean Square Difference $\left({ }^{\circ} \mathrm{C}\right)$ & 0.23 & 2.00 \\
\hline \multirow{2}{*}{$5400 \mathrm{~s}$} & Maximum Difference $\left({ }^{o} \mathrm{C}\right)$ & 1.63 & 5.31 \\
\hline & Root Mean Square Difference $\left({ }^{\circ} \mathrm{C}\right)$ & 0.25 & 2.10 \\
\hline
\end{tabular}

Table 3.2: Accuracy of the different grid intensities in the radial direction 
Figure 3.7 shows the predicted temperature profiles from the three different grids. The discontinuity in the curves coincides with the location of the horizontal plate. The results indicate the grid containing 150,000 nodes has the poorest accuracy compared to the other two grids. In contrast, the 300,000 nodes grid almost overlaps the 1,200,000 nodes grid. This is confirmed by the Table 3.2 since all the maximum difference for the 300,000 node grid is within the $+/-2^{\circ} \mathrm{C}$ error of the experiment while the 150,000 node grid is far outside these error bounds. As a result, the 300,000 nodes grid was selected to be used for later simulations because it delivers the best accuracy with the least number of nodes.

\subsection{Validation Against DLSC Measurements}

A series of simulations were completed to assess the performance of different turbulence models by comparing predictions to experimental measurements obtained from the STTS tanks at DLSC. The data for this study was gathered on October 23, 2007 [7]. The conditions for that day are well suited for a validation study because the tank is continuously charged by the solar collector loop. The tank was also at a fully discharged uniform temperature of $51^{\circ} \mathrm{C}$ at the start of the experiment. This eliminates any uncertainty in the initial temperature distribution in the tank. The mass flow rates were between 3 to $15 \mathrm{~L} / \mathrm{s}$ which is representative of the typical flow rates that are experienced by the tanks. The total charging time is about six hours which is long enough in order to turn over the tank. The tank inlet temperature and velocity are shown in Figures 3.8 and 3.9 respectively. 


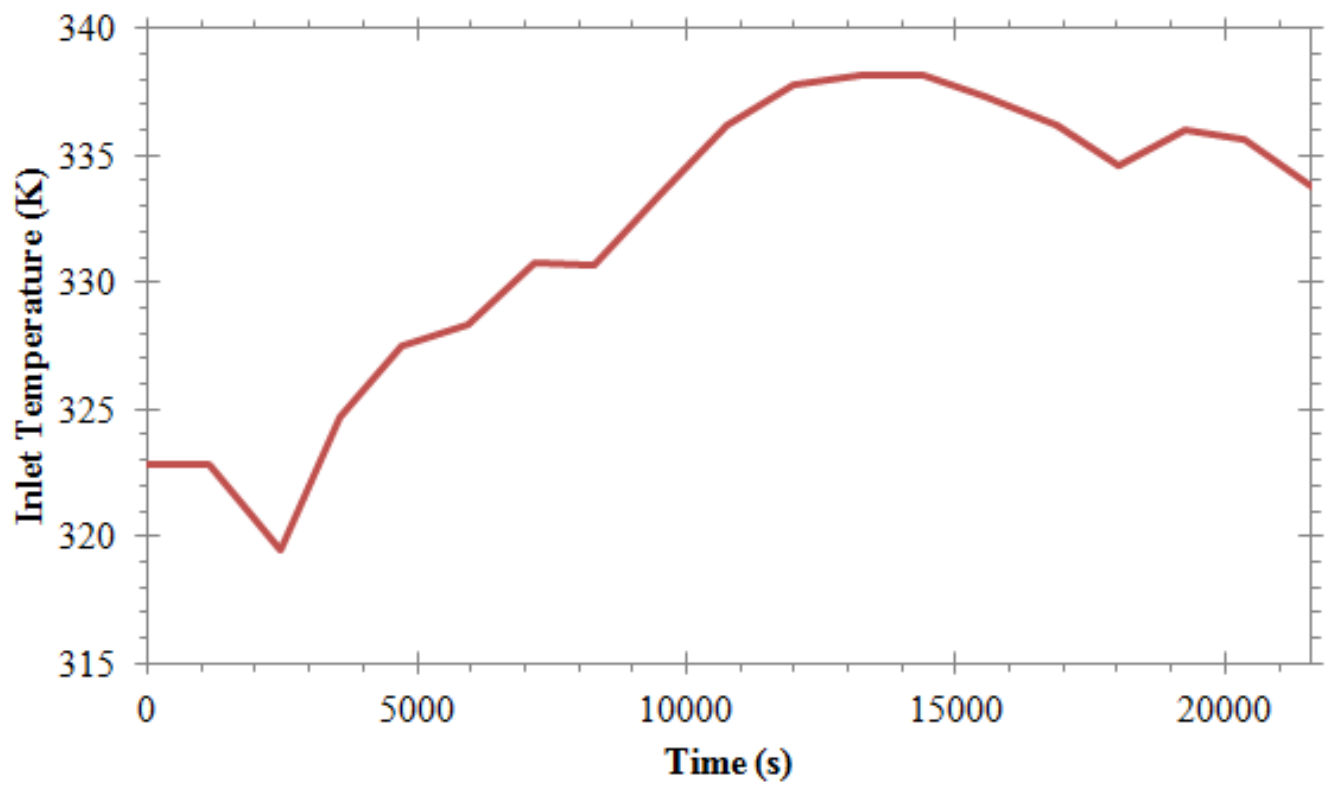

Figure 3.8: Transient profile of inlet temperature during charging (Data for: October $23,2007)[7]$

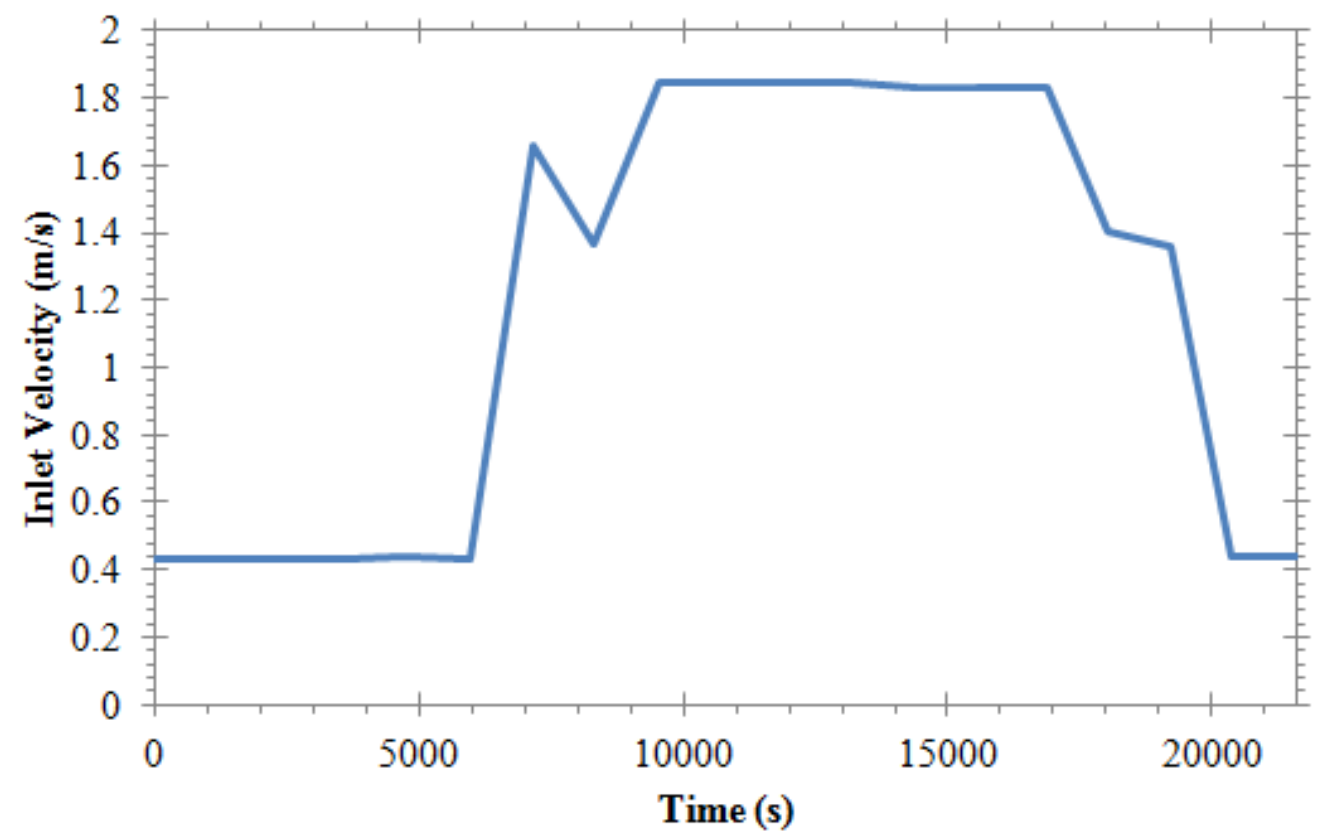

Figure 3.9: Transient profile of inlet velocity during charging (Data for: October 23, 2007) [7] 
The STTS tank at DLSC is equipped with three interior thermocouples in order to measure the fluid temperature within the tank at different levels. The location of the thermocouples within the tank is depicted in Figure 3.10. A temperature reading is recorded every ten minutes, and the error associated with the reading is $+/-2^{\circ} \mathrm{C}[6]$. The two turbulence models are assessed using temporal predictions of temperature at the three locations in the tank are shown in Figure 3.10.

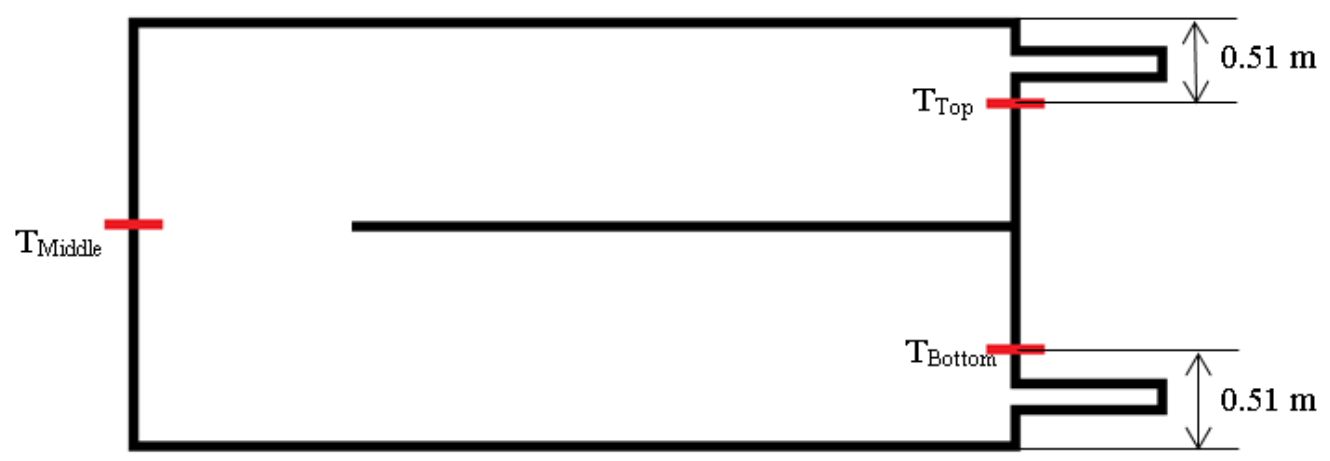

Figure 3.10: Location of temperature sensors in STTS tanks at DLSC (Not to scale)

The turbulence models that were tested in this section are $k-\omega$ and $k-\omega$ SST. The $k-\omega$ model is able to model round jets and has a better treatment of the viscous region than the standard $k-\varepsilon$ model. The $k-\omega$ SST model is a model that incorporates a blending function that allows the model to use $k-\omega$ turbulence model in the near wall regions while using $k-\varepsilon$ model in areas away from the surface. This makes the $k-\omega$ SST model provide a more accurate answer for a wider variety of flows [15]. The $k-\varepsilon$ model is considered to be an engineering standard because it is easy to use, numerically robust, and very well documented. It can model flows such as flat plate boundary layer, plane jet, and plane mixing layer. However, it cannot model swirling and rotating flows, flows with strong separation, axisymmetric jets, 
and fully developed flows in non-circular ducts. This model does not seem to be a good candidate for our geometry because the STTS tank has a round inlet, and as soon as the inlet fluid exits the inlet nozzle, some flow separation is expected.

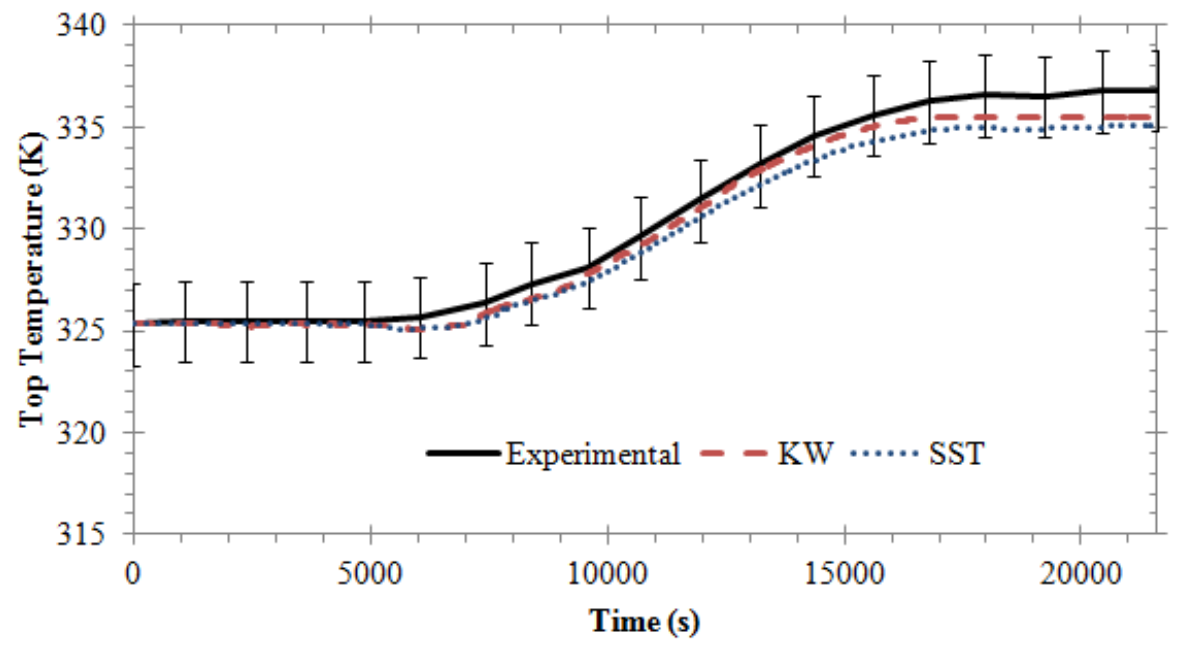

Figure 3.11: Transient simulated and actual temperature at the top sensor of the hot tank showing the predictions using the $k-\omega \mathrm{SST}$ and $k-\omega$ turbulence models

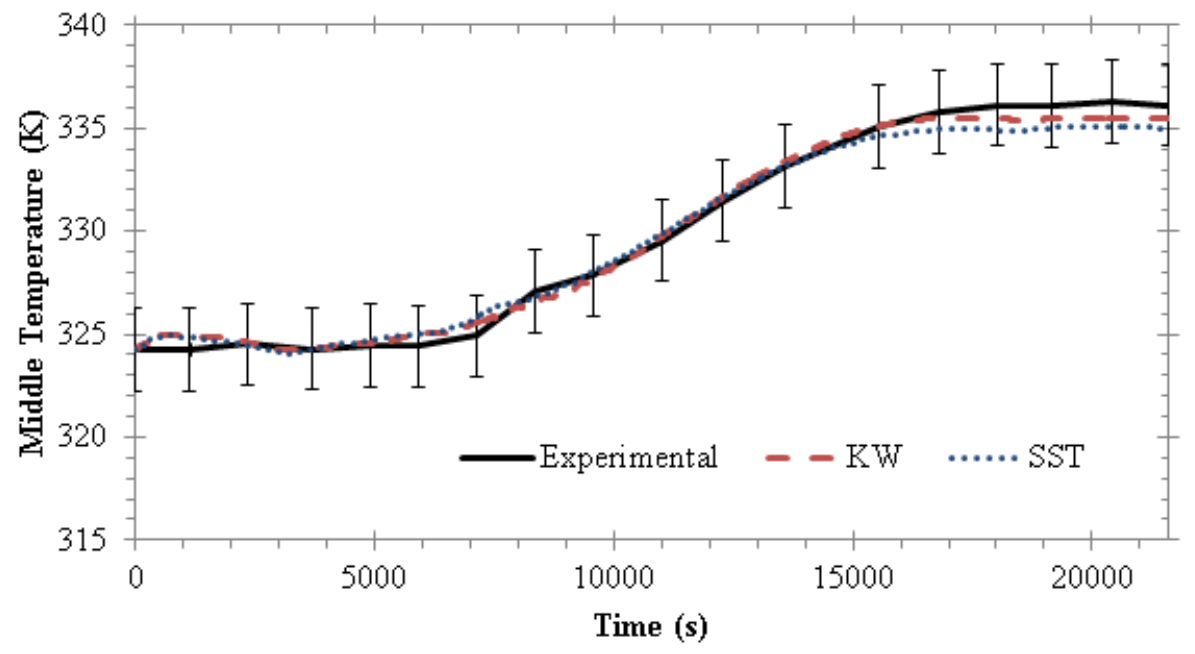

Figure 3.12: Transient simulated and actual temperature at the middle sensor of the hot tank showing the predictions using the $k-\omega$ SST and $k-\omega$ turbulence models 


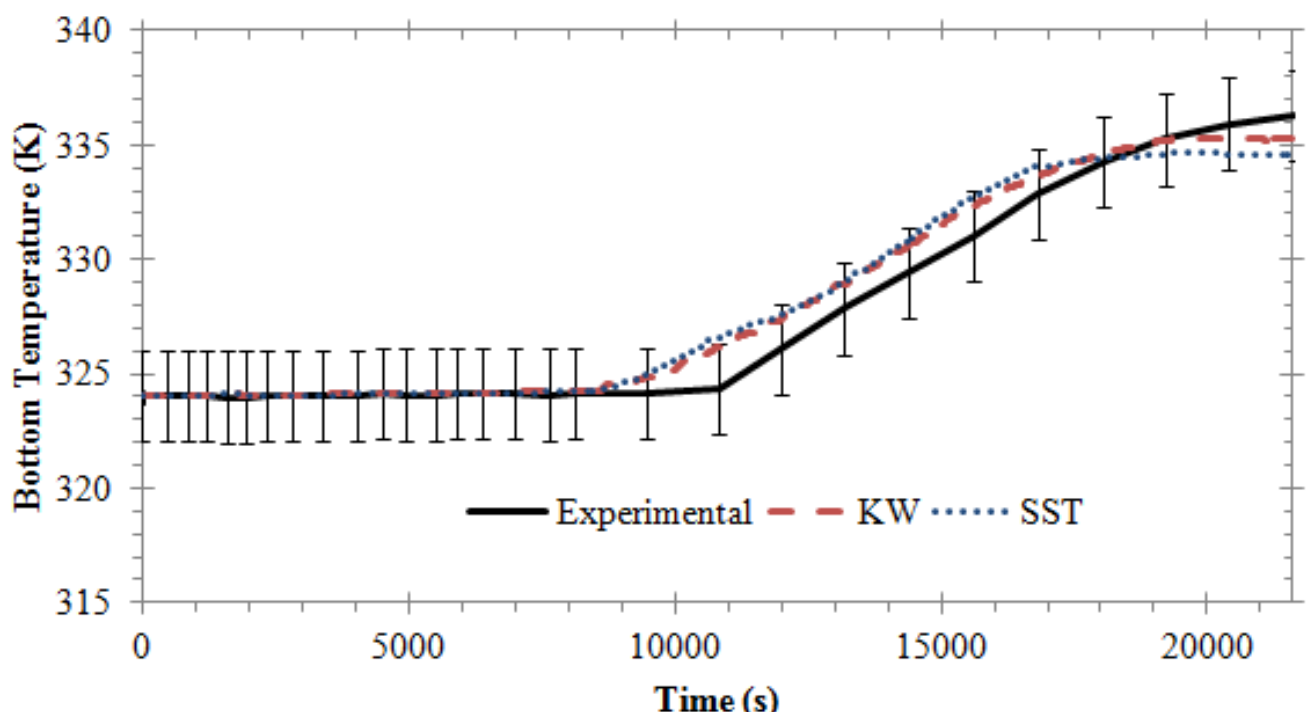

Figure 3.13: Transient simulated and actual temperature at the bottom sensor of the hot tank showing the predictions using the the $k-\omega$ SST and $k-\omega$ turbulence models

\begin{tabular}{|l|l|l|l|l|}
\hline & \multicolumn{2}{|c|}{$k-\omega$} & \multicolumn{2}{c|}{$k-\omega$ SST } \\
\hline $\begin{array}{l}\text { Maximum } \\
\text { Difference } \\
\left({ }^{\circ} \mathrm{C}\right)\end{array}$ & $\begin{array}{l}\text { Root Mean Square } \\
\text { Difference }\left({ }^{\circ} \mathrm{C}\right)\end{array}$ & $\begin{array}{l}\text { Maximum } \\
\text { Difference } \\
\left({ }^{\circ} \mathrm{C}\right)\end{array}$ & $\begin{array}{l}\text { Root Mean Square } \\
\text { Difference }\left({ }^{\circ} \mathrm{C}\right)\end{array}$ \\
\hline Top & 1.30 & 0.65 & 1.76 & 1.02 \\
\hline Middle & 0.81 & 0.42 & 1.24 & 0.62 \\
\hline Top & 1.86 & 0.79 & 2.24 & 1.02 \\
\hline
\end{tabular}

Table 3.3: Maximum deviation between different turbulence models and measured results in degrees

Figures 3.11, 3.12, and 3.13 present the transient predicted temperature profiles of $k-\omega \mathrm{SST}, k-\omega$ turbulence models and the experimental temperature profile at the top, middle and bottom of the tank. The results indicate that the $k-\omega$ SST, and the 
$k-\omega$ turbulence models predict similar results. In addition, Table 3.3 clearly shows that all turbulence models lie within the experimental error range, which suggests that all results are acceptable. Closer examination of the results show that the $k-\omega$ model outperform the $k-\omega$ SST turbulence model. This is expected because $k-\omega$ turbulence model has the ability to predict free shear flows like the inlet jet, and low Reynolds number flows while SST has the same abilities but only near the wall where $k-\omega$ is activated. As a result, the $k-\omega$ turbulence model was selected to be used for later simulations because it delivers the best accuracy.

\subsection{Summary}

The geometry of the tank was generated, and grid and timestep independence tests were conducted. The simulation was found to be timestep independent at $1.5 \mathrm{~s}$. The grid was shown to be independent in the axial direction at an intensity of 150,000 nodes and independent of the cross sectional intensity when the grid is composed of 300,000 nodes. Lastly, the final grid was tested with different turbulence models against experimental data and it was found that the $k-\omega$ turbulence model has the best performance. 


\section{Chapter 4}

\section{Tank Design and CFD Analysis}

The previous review of the literature has indicated that the thermal performance of large horizontal tanks has not been extensively studied. This chapter will use CFD to assess the performance of a range of tank designs under realistic conditions. The dominant factors that effect stratification during charging, discharging and simultaneous charging and discharging will be assessed.

This study attempts to simulate the closest conditions experienced by the STTS tanks at the DLSC in order to determine the location where the mixing is occurring. Moreover, the goal is to also explore alternative baffle designs in order to decrease

fluid mixing. As such, a total of nine designs were tested: three previously proposed designs (which had been studied by Rysanek for charging conditions) and six new designs. The operating conditions studied are given in Table 4.1. Analysis of results is discussed within. 


\begin{tabular}{|c|c|c|c|}
\hline Case \# & $\begin{array}{l}\text { Operating } \\
\text { Conditions }\end{array}$ & Initial Conditions & Inlet Conditions \\
\hline 1 & Discharging & Fully mixed at $60^{\circ} \mathrm{C}$ & $\begin{array}{l}\text { Temperature of } 30^{\circ} \mathrm{C} \text { and } 6 \mathrm{~L} / \mathrm{s} \\
\text { mass flow rate }\end{array}$ \\
\hline 2 & Charging & Fully mixed at $20^{\circ} \mathrm{C}$ & $\begin{array}{l}\text { Temperature of } 80^{\circ} \mathrm{C} \text { and } 14 \mathrm{~L} / \mathrm{s} \\
\text { mass flow rate }\end{array}$ \\
\hline 3 & Discharging & $\begin{array}{l}\text { Linearly decreasing } \\
\text { temperature of } 50^{\circ} \mathrm{C} \\
\text { at the top and } 40^{\circ} \mathrm{C} \\
\text { at the bottom }\end{array}$ & $\begin{array}{l}\text { Temperature of } 30^{\circ} \mathrm{C} \text { and } 6 \mathrm{~L} / \mathrm{s} \\
\text { mass flow rate }\end{array}$ \\
\hline 4 & $\begin{array}{l}\text { Simultaneous } \\
\text { Charging and } \\
\text { Discharging }\end{array}$ & $\begin{array}{l}\text { Linearly decreasing } \\
\text { temperature of } 70^{\circ} \mathrm{C} \\
\text { at the top and } 55^{\circ} \mathrm{C} \\
\text { at the bottom }\end{array}$ & $\begin{array}{l}\text { Charging inlet temperature of } \\
80^{\circ} \mathrm{C} \text { and } 14 \mathrm{~L} / \mathrm{s} \text { mass flow rate } \\
\text { and discharging outlet mass flow } \\
\text { rate is } 6 \mathrm{~L} / \mathrm{s}\end{array}$ \\
\hline 5 & Charging & $\begin{array}{l}\text { Linearly decreasing } \\
\text { temperature of } 70^{\circ} \mathrm{C} \\
\text { at the top and } 55^{\circ} \mathrm{C} \\
\text { at the bottom }\end{array}$ & $\begin{array}{l}\text { Linearly decreasing charging inlet } \\
\text { temperature from } 80^{\circ} \mathrm{C} \text { to } 60^{\circ} \mathrm{C} \\
\text { within the first } 2 \text { hours and } 14 \mathrm{~L} / \mathrm{s} \\
\text { mass flow rate }\end{array}$ \\
\hline 6 & $\begin{array}{l}\text { Simultaneous } \\
\text { Charging and } \\
\text { Discharging }\end{array}$ & $\begin{array}{l}\text { Linearly decreasing } \\
\text { temperature of } 70^{\circ} \mathrm{C} \\
\text { at the top and } 55^{\circ} \mathrm{C} \\
\text { at the bottom }\end{array}$ & $\begin{array}{l}\text { Linearly decreasing charging inlet } \\
\text { temperature from } 80^{\circ} \mathrm{C} \text { to } 60^{\circ} \mathrm{C} \\
\text { within the first } 2 \text { hours and } 14 \mathrm{~L} / \mathrm{s} \\
\text { mass flow rate and discharging } \\
\text { outlet mass flow rate is } 6 \mathrm{~L} / \mathrm{s}\end{array}$ \\
\hline
\end{tabular}

Table 4.1: Summary of initial and boundary conditions used for the six different test cases 


\subsection{Existing Designs}

The designs introduced below were either investigated previously or used at the DLSC. Figure 4.1 depicts a tank without baffles (Tank 1), which allows for the study of fluid flow and jet spreading inside the tank without obstacles that could alter the fluid motion. This study will allow for a better understanding of areas within the tank that experience the highest level of mixing and its main driver. It also provides a benchmark to which other results can be compared. Note that the direction of the arrows on all the tanks shows the flow direction for discharging.

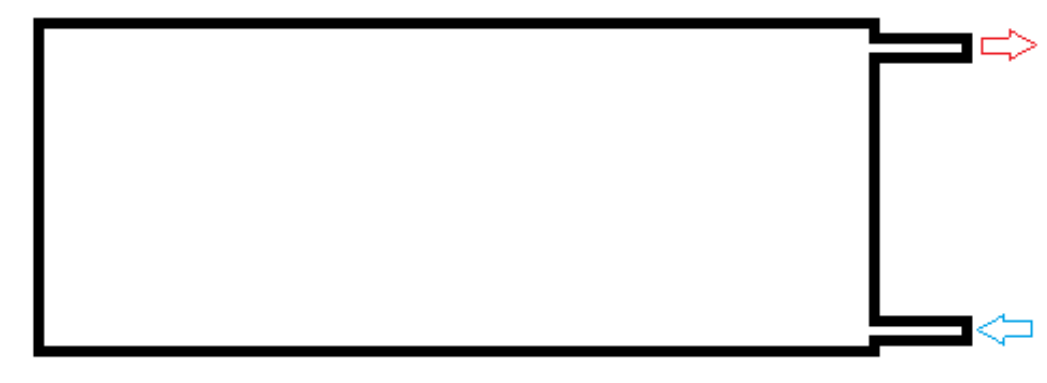

Figure 4.1: Tank 1, horizontal tank without baffles (Not to scale)

Consideration of the current tank at DLSC (Tank 2), Figure 4.2, allows for the study of the changes in the level of stratification resulting from adding a baffle in the middle of the tank. This study helps to understand the current tank behaviour over a broader range of operating conditions. 


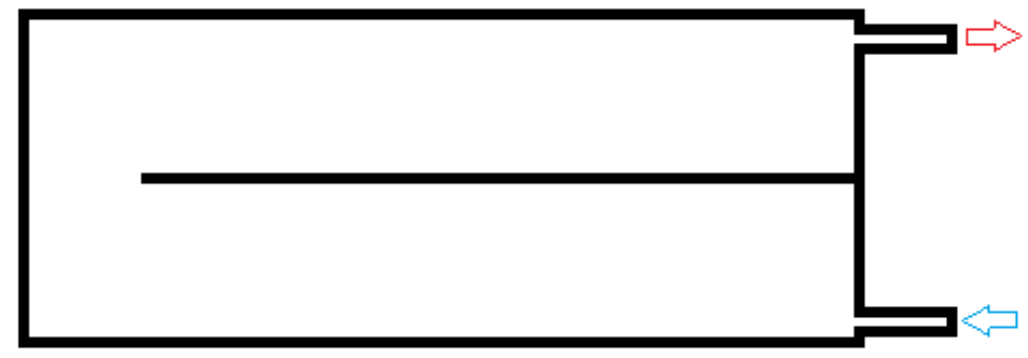

Figure 4.2: Tank 2, current DLSC horizontal tank (Not to scale)

Adam Rysanek's recommended tank (Tank 3), Figure 4.3, is simulated to obtain a better understanding of its performance for a broader range of operating conditions.

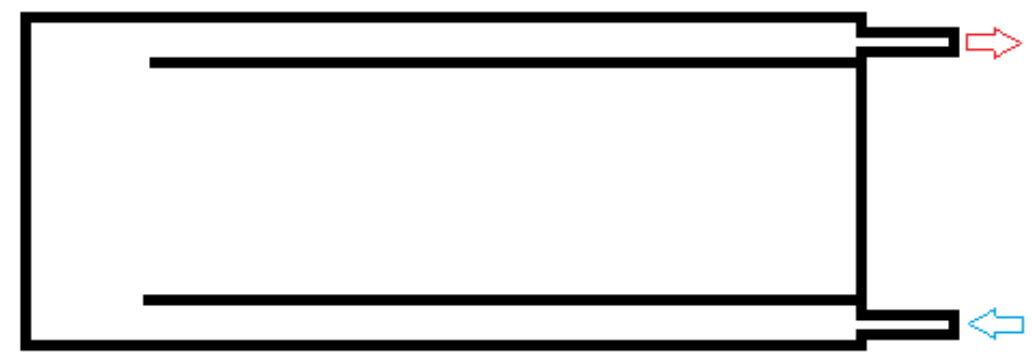

Figure 4.3: Tank 3, Rysanek's recommended tank (Not to scale)

\subsection{New Designs}

In order to further improve stratification, a number of alternative designs were also considered. The new tanks were carefully designed after a detailed analysis of all its preceding configurations. Tank 4, shown in Figure 4.4, enhances Tank 3 by adding an extra baffle in the middle of the tank. This baffle may help to restrict the mixing to fewer temperature layers and is motivated by the current DLSC tank design. 


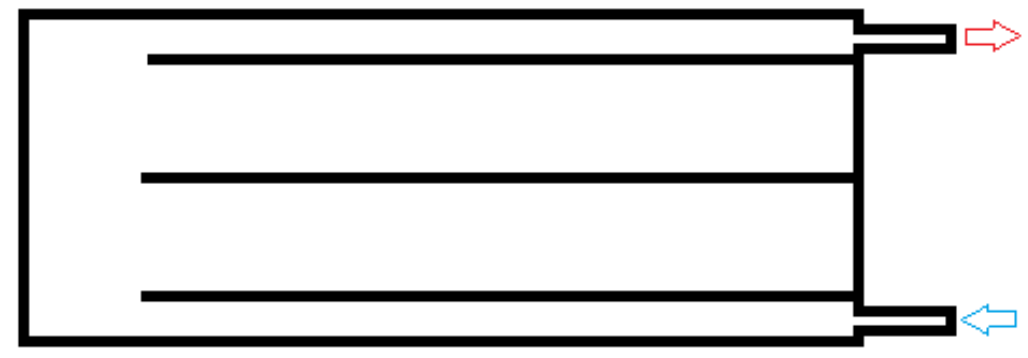

Figure 4.4: Tank 4, addition of a middle baffle to Tank 3 (Not to scale)

It is noted that in Tank 3, the fluid at the end of the bottom baffle is forced to turn upwards. This may result in fluid mixing since the upward moving fluid penetrates through the warm fluid layers above. Figure 4.5 shows Tank 5 which modifies Tank 3 by adding two baffles. These baffles are used in order to help the fluid turn inside the tank, which is expected to reduce the penetration of the cold inlet water into the warm stored water.

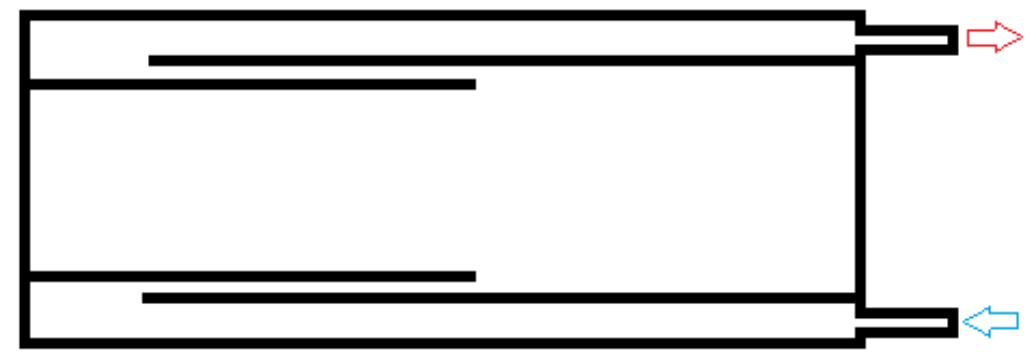

Figure 4.5: Tank 5, addition of two redirecting baffles to Tank 3 (Not to scale)

Tank 6, presented in Figure 4.6 is motivated by the work of Shah and Furbo [10] which recommended the use of a vertical inlet with a large flat plate. This allows the fluid to impinge onto the baffle surface, allowing the jet to spread within the tank. Tank 6 changes the locations of the inlet and outlet to the center of the bottom and the top of the tank respectively. Moreover, two large baffles are added to the top 
and bottom of the tank. The baffles allow for a gap on only two sides of the tank which are expected to help confine the jet and reduce its velocity when it enters the regions above the plate. The introduction of two gaps does not double the area that inlet fluid goes through because the plate is located closer to the ports. However, the baffle length was increased from $85 \%$ of the total tank length to $95 \%$ of the total tank length in order to replicate the tank tested by Zachar [19]. Zachar stated that when the baffles are $95 \%$ of the tank length, they help the tank stratify when it experiences a decreasing charging inlet temperature.

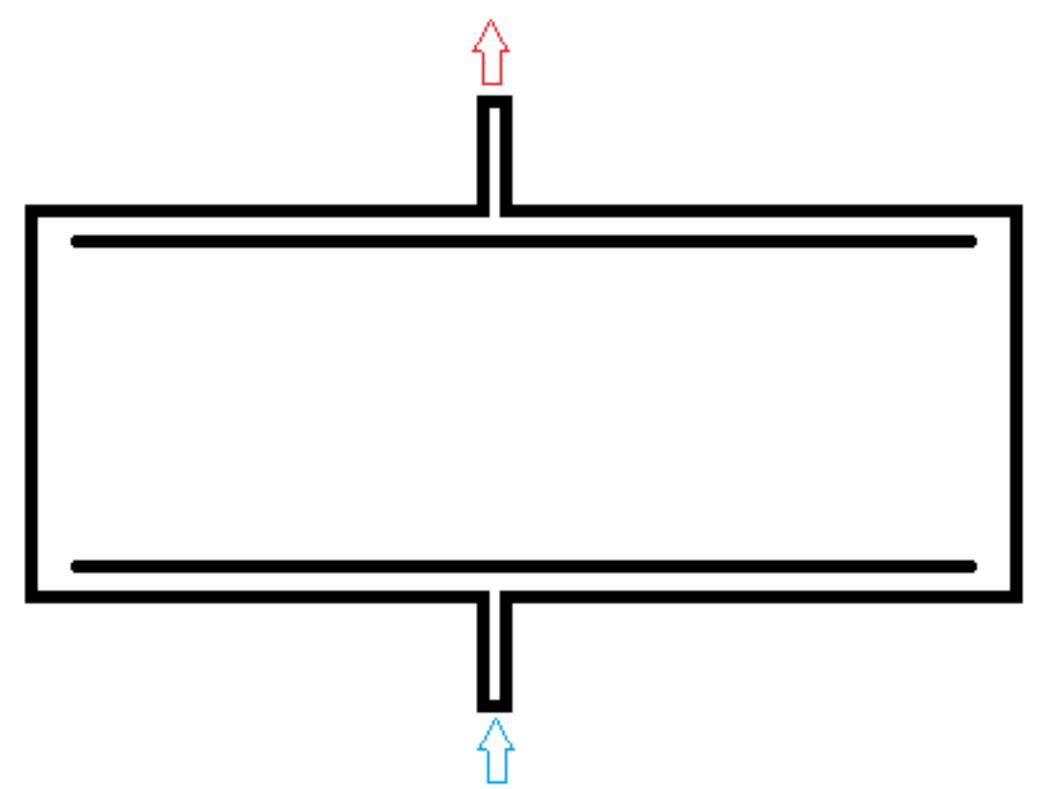

Figure 4.6: Tank 6, horizontal tank with top and bottom baffles with inlet and outlet moved to the center of the tank (Not to scale)

Tank 7 shown in Figure 4.7 employs two vertical baffles in order to spread the inlet jet over a larger area. This will reduce the fluid speed, resulting in better stratification while mixing a smaller volume inside the tank. The tank also employs a baffle near the inlet that helps spread the fluid along the baffle. 


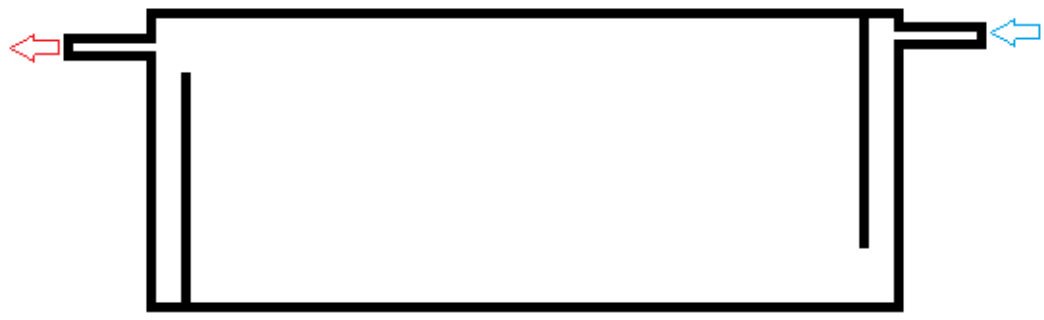

Figure 4.7: Tank 7, horizontal tank with vertical baffles (Not to scale)

As previously noted in the literature, an effective way to enhance stratification is to increase the Richardson number. The Richardson number represents the ratio of buoyancy forces to the inertial forces. The Richardson number can be increased in multiple ways: increasing the height of the tank, increasing the temperature difference between the fluid introduced and the fluid within the tank, and decreasing the inlet velocity. Since the tank geometry and the inlet conditions cannot be changed, the only option remaining is to decrease the inlet velocity, by increasing the flow area at the inlet. According to Sliwinski et al. [13], the level of mixing decreases as the Richardson number increases. There is a sharp drop in the level of mixing as the Richardson number increases from 0 to 0.4 . If the Richardson number is greater than 0.5 , there is little or no change to the level of mixing within the tank, as shown in Figure 4.8. The level of mixing within the tank is found by measuring the height $L^{*}$ of the mixing region and non-dimensionalize it by dividing by the tank height $\mathrm{L}$. 


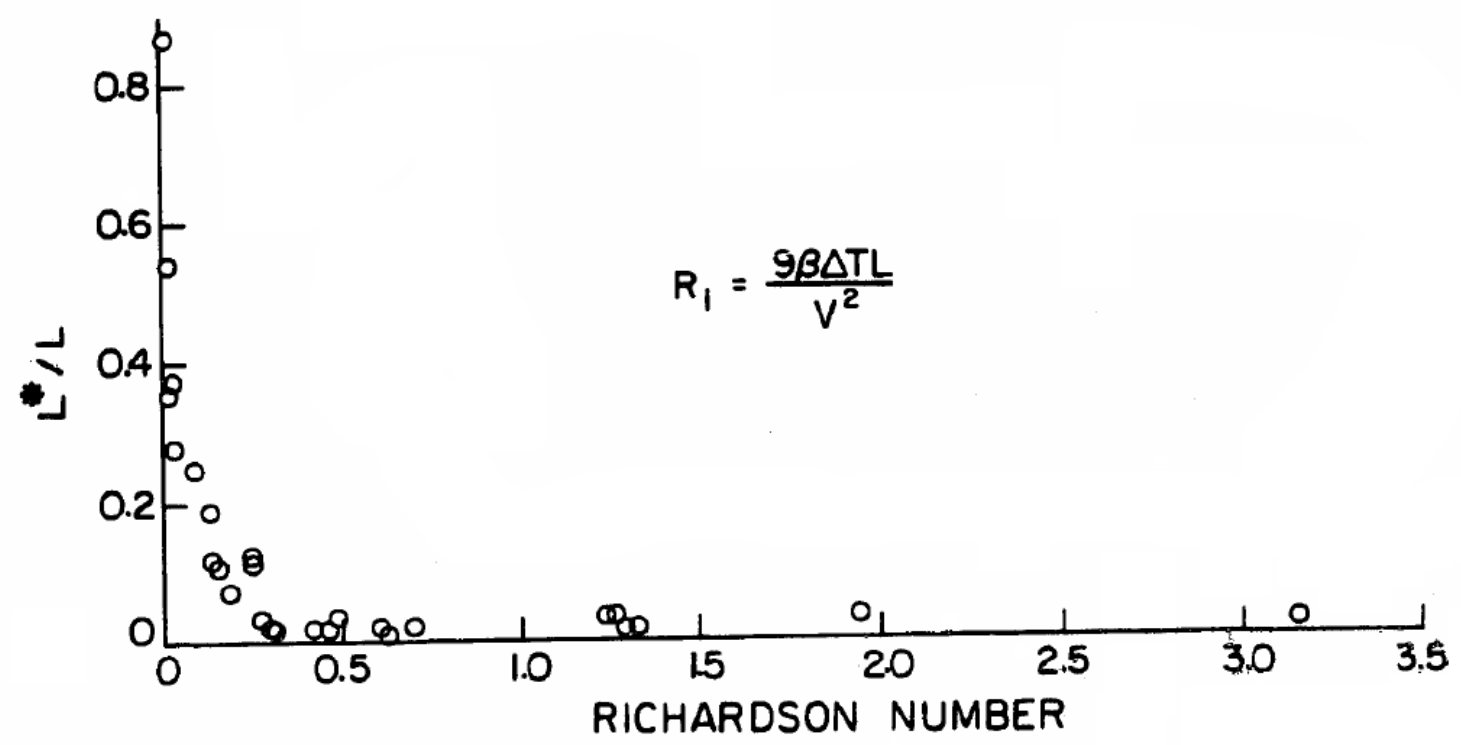

Figure 4.8: Plot showing the length of the mixing region compared to the length of the tank as a function of Richardson number [13].

Table 4.2 provides the estimated Richardson number for a tank without baffles with an initial uniform temperature of $60^{\circ} \mathrm{C}$ being discharged with an inlet flow rate of $6 \mathrm{~L} / \mathrm{s}$ at a temperature of $30^{\circ} \mathrm{C}$. Tanks 8 and 9 are two tanks without baffles, similar to Tank 1 . The discharging inlet diameter of Tank 8 is $200 \mathrm{~mm}$ and Tank 9 is $400 \mathrm{~mm}$ presented in Figure 4.9 and 4.10 respectively.

\begin{tabular}{|l|l|l|}
\hline & Inlet Diameter $(\mathrm{mm})$ & Richardson Number \\
\hline Tank 1 & 101.6 & 0.894 \\
\hline Tank 8 & 200 & 13.4 \\
\hline Tank 9 & 400 & 215 \\
\hline
\end{tabular}

Table 4.2: Richardson number for the tank without baffles during discharging at different tank diameters

It should be noted that some of these inlet diameters seem impractical and operate 
beyond the range where a change in the level of stratification is expected to occur according to Sliwinski et al. [13]. However, since they provide a simple solution to enhance stratification, it is valuable to investigate its effect on the stratification within the tank. Detailed drawings of all nine designs are available in Appendix C

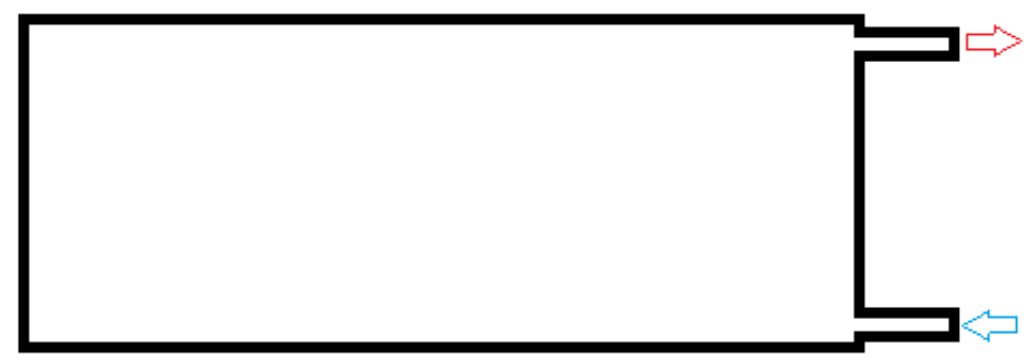

Figure 4.9: Tank 8, horizontal tank without baffles with a discharging inlet diameter of $200 \mathrm{~mm}$ (Not to scale)

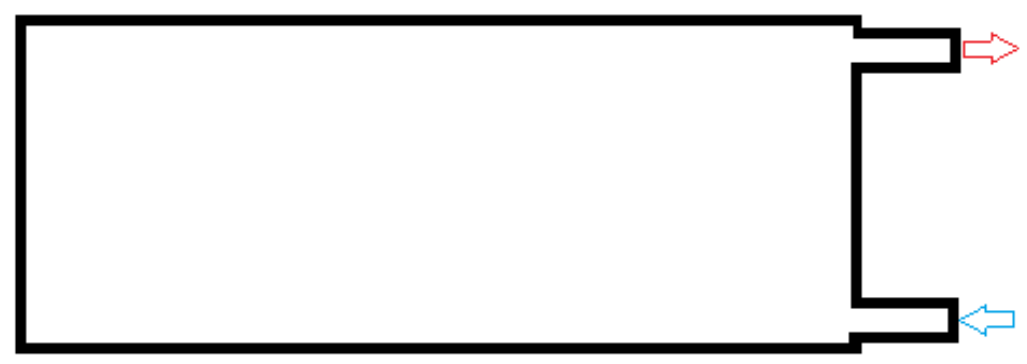

Figure 4.10: Tank 9, horizontal tank without baffles with a discharging inlet diameter of $400 \mathrm{~mm}$ (Not to scale)

\subsection{Mesh Summary}

The details of the proposed above design are presented in Table 4.3. This table shows the total number of nodes employed in each mesh, the mesh dimensions and the mesh quality. Grid independence studies were performed and the mesh details are provided in Appendix C 


\begin{tabular}{|l|l|l|l|}
\hline Mesh ID & Number of Cells & $\begin{array}{l}\text { Grid Dimensions (\# of nodes } \\
\text { along cylinder's length) } \times \text { (\# of } \\
\text { faces at cylinder end cap) }\end{array}$ & Mesh Quality \\
\hline Tank 1 & 346240 & $40 \times 8656$ & 0.75 \\
\hline Tank 2 & 330404 & $34 \times 9717$ & 0.7 \\
\hline Tank 3 & 291098 & $48 \times 6064$ & 0.6 \\
\hline Tank 4 & 376628 & $51 \times 7384$ & 0.6 \\
\hline Tank 5 & 457253 & $61 \times 7496$ & 0.55 \\
\hline Tank 6 & 273732 & $70 \times 3910$ & 0.55 \\
\hline Tank 7 & 568872 & $67 \times 8490$ & 0.6 \\
\hline Tank 8 & 400603 & $35 \times 11446$ & 0.7 \\
\hline Tank 9 & 512844 & $40 \times 12821$ & 0.7 \\
\hline
\end{tabular}

Table 4.3: Detailed information of the grids used to resolve the different tank designs

According to the manual of ICEM [57], the quality of the mesh is a diagnostic of the determinant, orthogonality, and warpage of the elements in the mesh. The minimum of the three normalized diagnostics will be used. A value of 0 represents the worst quality while 1 is the best quality. The minimum acceptable value of quality by CFX is 0.3 . The determinant checks the deformation of the element by calculating the Jacobian of each element and normalizing the determinant of the matrix. The orthogonality checks the maximum internal angle deviation from 90 degrees for each element. Lastly, warpage checks the degree of twist or distortion of the elements.

The grids generated have an acceptable quality because the minimum mesh quality is 0.55 , while the acceptable quality for ANSYS CFX is 0.3 . The grid is composed of 
hexahedral elements, the minimum boundary layer thickness is $3 \mathrm{~mm}$ at the walls of the tank. The smallest mesh element is $3 \mathrm{~mm} \times 3 \mathrm{~mm} \times 5 \mathrm{~mm}$, and the largest mesh element is $61 \mathrm{~mm} \times 61 \mathrm{~mm} \times 400 \mathrm{~mm}$. This is dictated by the gradients inside the tank; the larger the gradients, the finer the mesh and vice versa.

\subsection{Results \& Discussion}

Simulation results from six different cases are presented and discussed in this section. The study considers the effect of discharging, charging and simultaneous charging and discharging on thermal stratification within a STTS tank for DLSC. The nine different designs introduced earlier are closely examined in order to determine the best design.

The fluid enters the tank through a pipe that extends outside the tank in order to avoid applying the boundary conditions on the tank itself. In addition, the fluid exits the tank through a pipe that extends outside of the tank in order to avoid backflows.

As a general note, most contour plots displayed have two inlets and two outlets. However, some of the inlets and outlets are hidden in order to avoid confusion. This results in some baffles that look to have no purpose in the charging case, but play an important role during discharging and vice versa. The unused inlets and outlets were set to adiabatic walls. 


\subsubsection{Case 1: Discharging of a Fully Mixed Hot Tank with Constant Discharging Inlet Temperature}

Previous work focused on charging conditions only and developed Tank 4 that is capable of maintaining stratification for a range of tank charging conditions. However, another essential process in thermal storage tanks is discharging. As such, it is very important to verify that a tank can maintain stratification while discharging. This motivates investigating a tank that experiences only discharging in order to gain a better understanding of the sources and extent of mixing.

Figure 4.11 shows the DLSC system where the STTS tanks are used to offset the space heating load. The DLSC utilizes two STTS tanks that are connected in series (hot and cold tank) in order to promote sequential stratification. The hot fluid exits the top of the hot tank is used to meet the space heating load and cold fluid is returned to the bottom of the cold tank, and warmer fluid exits the top of the cold tank and enters the bottom of the hot tank. As shown in Figure 4.11, the discharging simulation is focused on the cold tank. Simulations used an initial uniform fluid temperature of $60^{\circ} \mathrm{C}$. This represents a typical fully charged cold STTS tank at DLSC. The tank has a discharging inlet flow rate of $6 \mathrm{~L} / \mathrm{s}$. The flow rate chosen is the maximum achievable flow rate of the discharging loop which will result in the largest amount of mixing. The tank discharging inlet temperature is $30^{\circ} \mathrm{C}$. The inlet temperature does not vary widely during a normal discharging cycle, so it is set to a typical discharging inlet temperature. The total simulation time was 7 hours, and the tank turn over time is 5.8 hours.

For this case, all nine designs are tested in order to gain an understanding on the level of stratification that is expected to be maintained by each tank. This 
simulation is expected to also help determine the dominant factors that causes mixing and provide insight into methods that could reduce mixing.

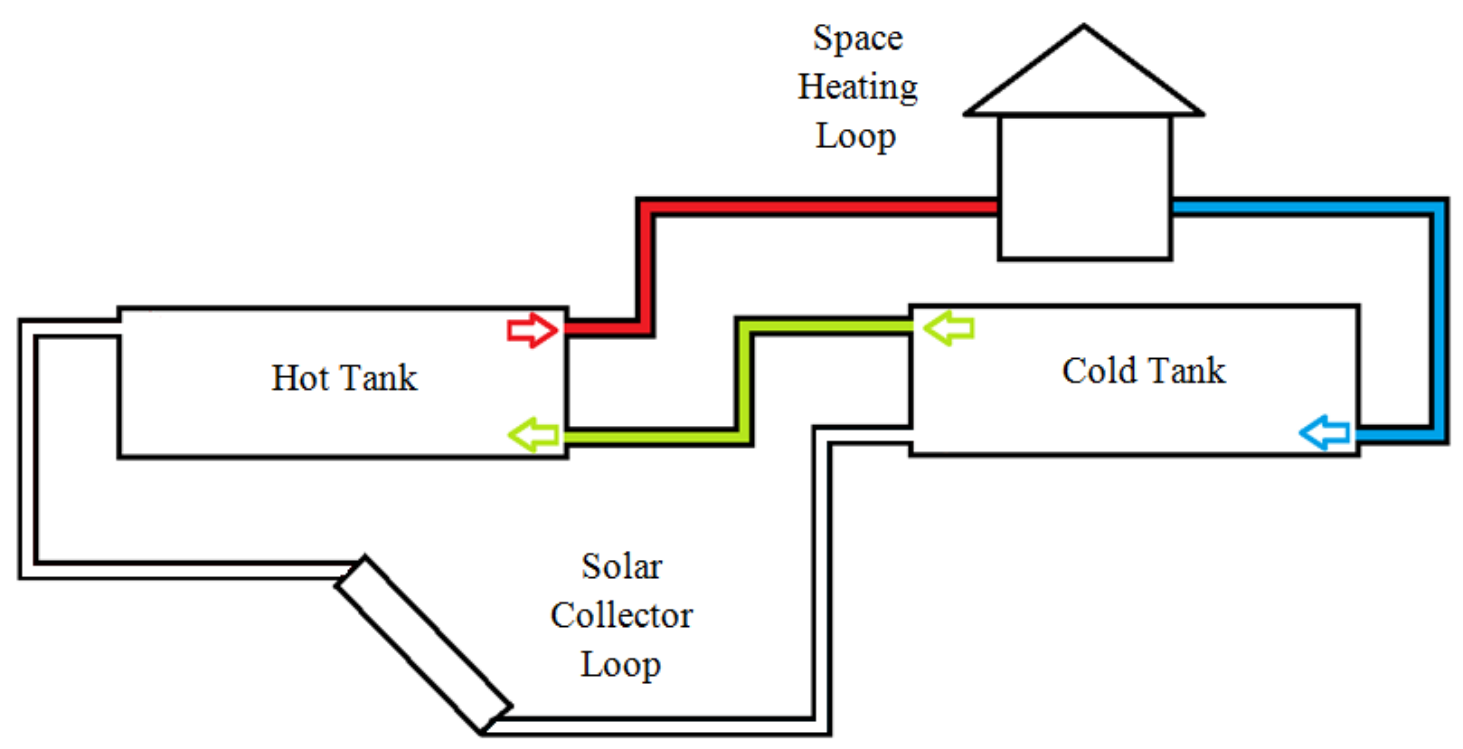

Figure 4.11: Schematic of the different loops at DLSC under discharging showing the configurations of the inlets and outlets of the STTS tanks. The simulated discharging case is focused on the cold tank. 


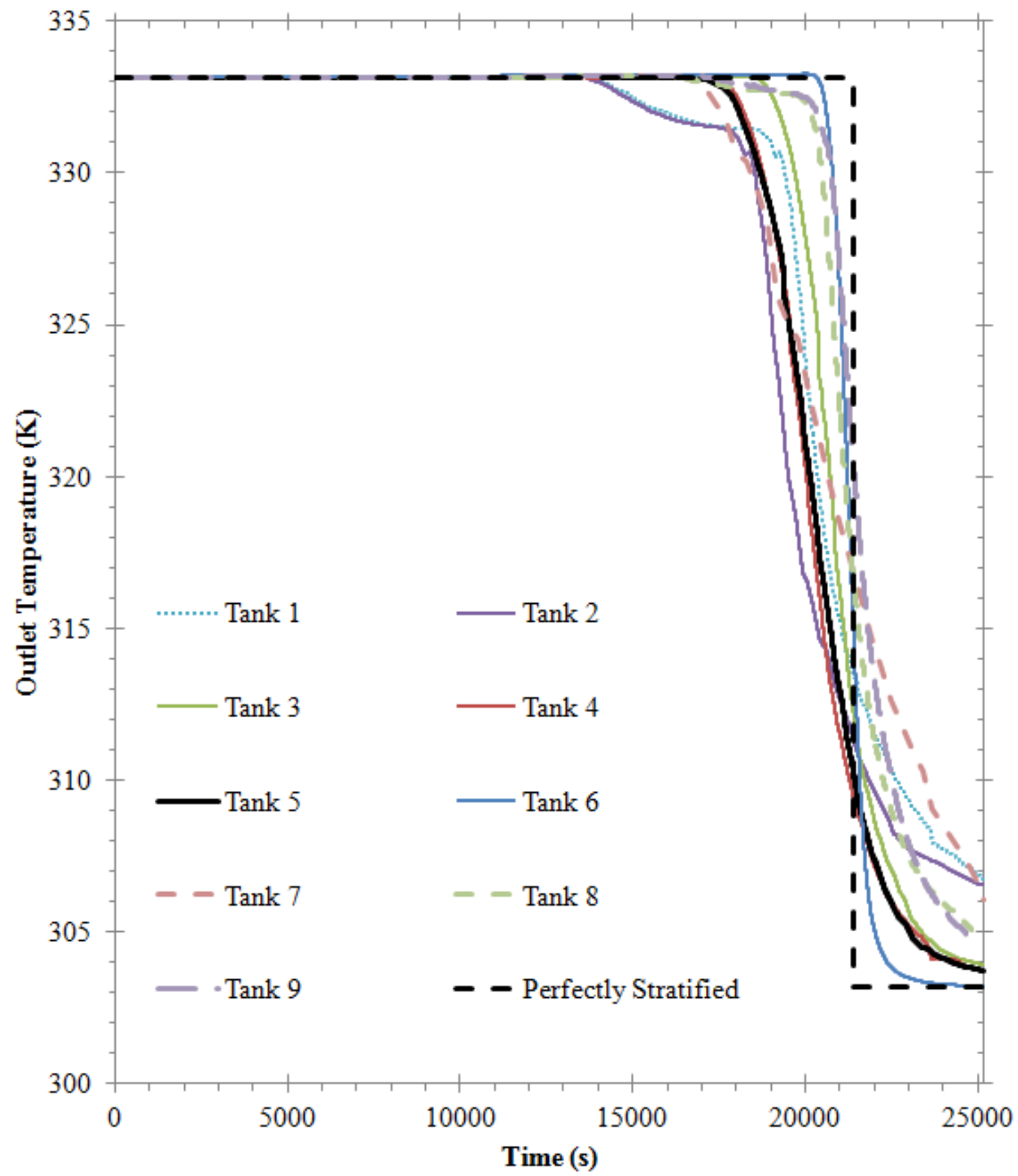

Figure 4.12: Transient temperature of fluid leaving the top of the tank for 9 different designs during simulation of Case 1 


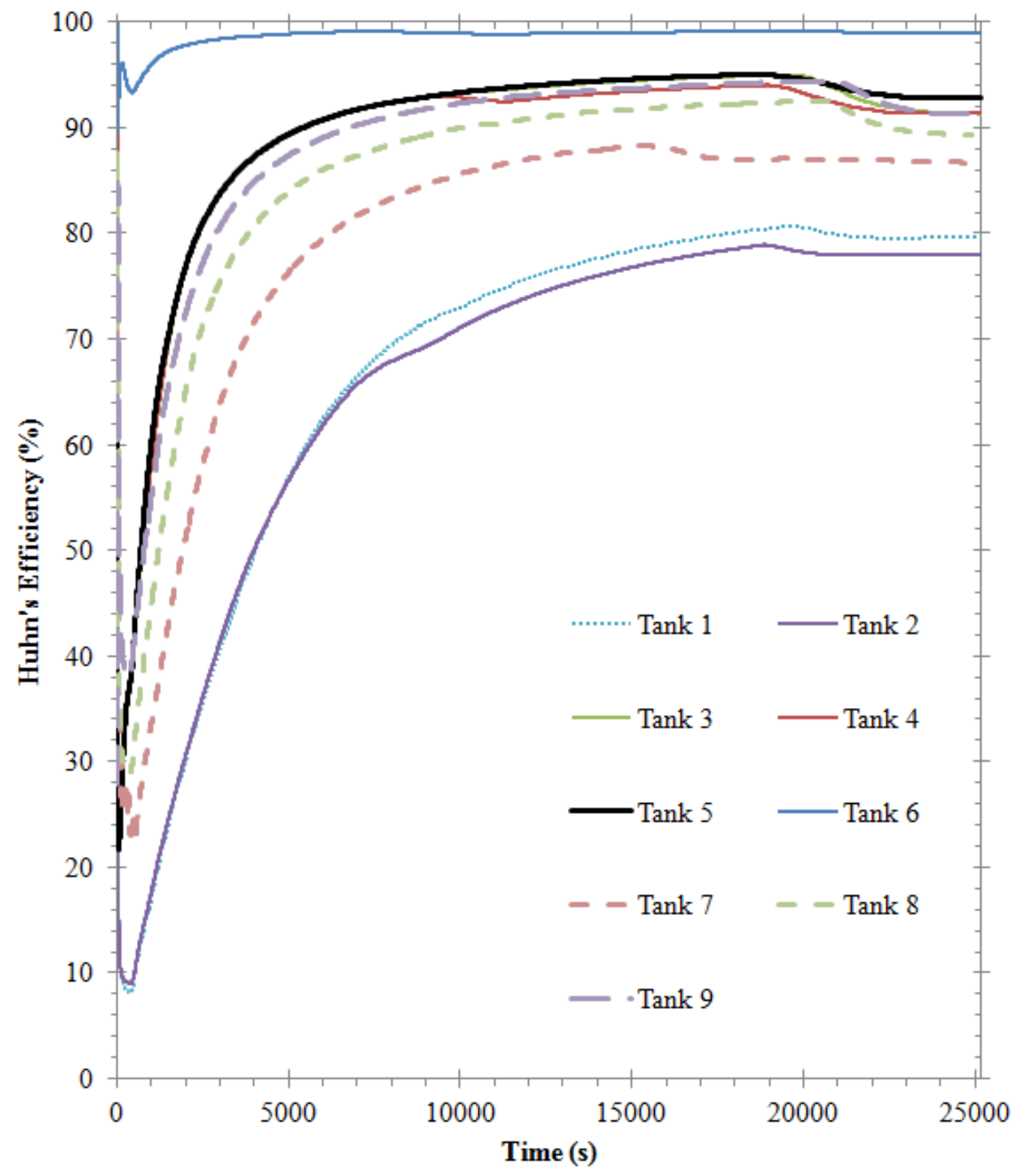

Figure 4.13: Huhn's efficiency for 9 different designs during simulation of Case 1 
Temperature

Contour

$[\mathrm{K}]$

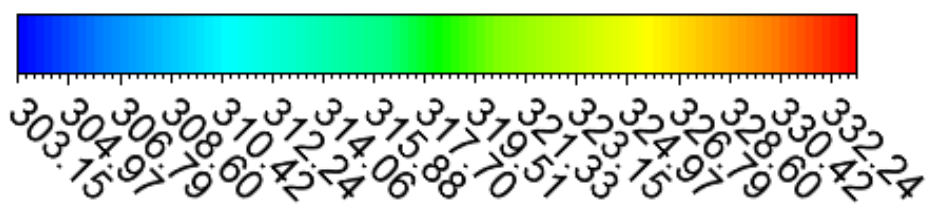

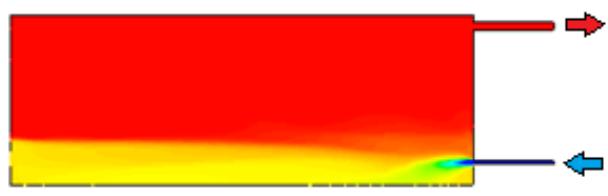

Tank 1

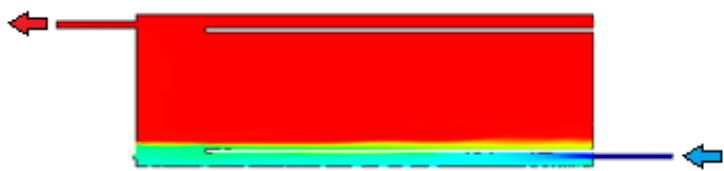

Tank 3

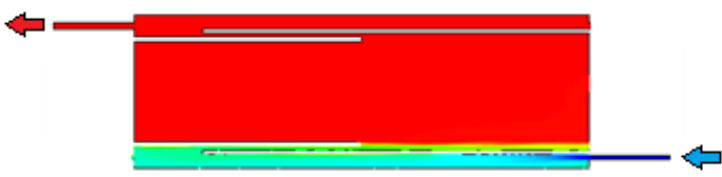

Tank 5

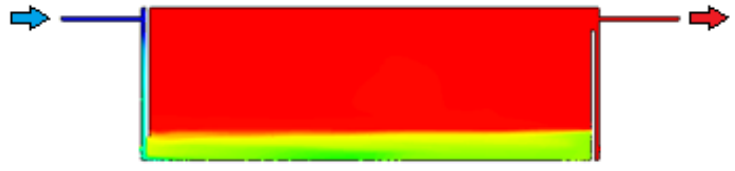

Tank 7

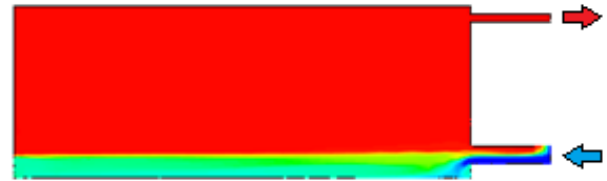

Tank 9

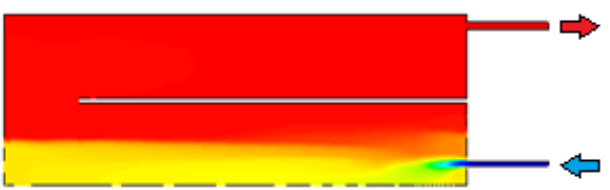

Tank 2

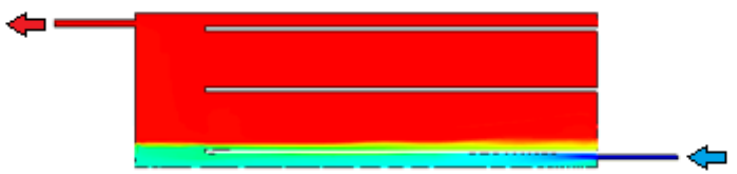

Tank 4

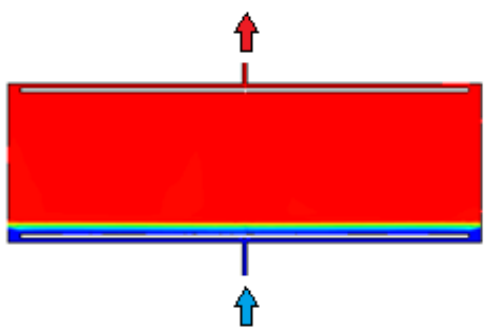

Tank 6

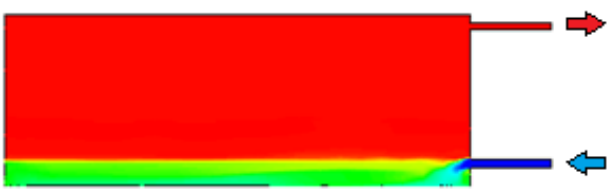

Tank 8

Figure 4.14: Temperature contour plot of 9 different designs 15 minutes into simulation of Case 1. Cold inlet jet causes significant mixing at the bottom of the tank. 


\section{Temperature \\ Contour}

[K]

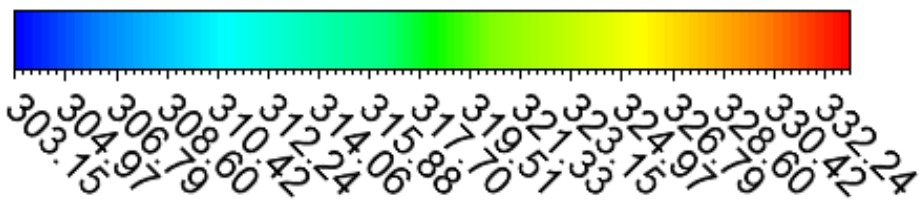

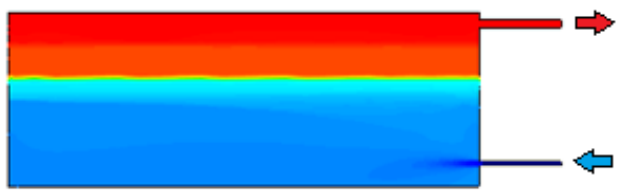

Tank 1

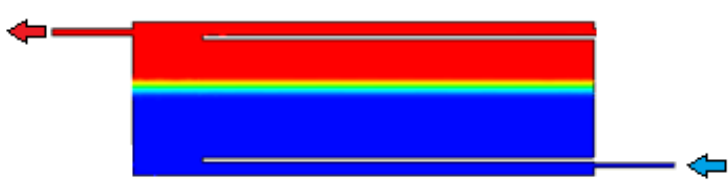

Tank 3

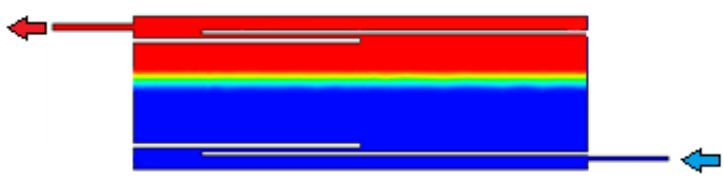

Tank 5

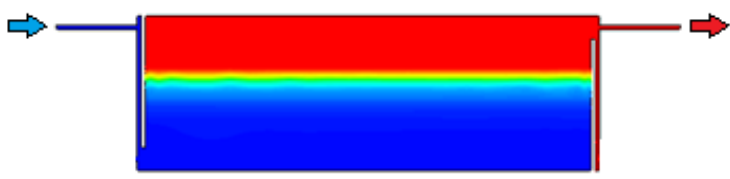

Tank 7

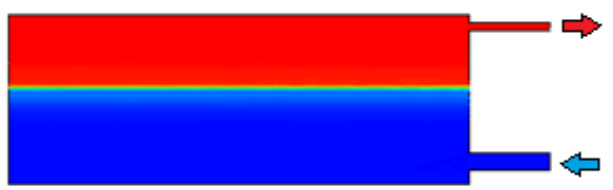

Tank 9

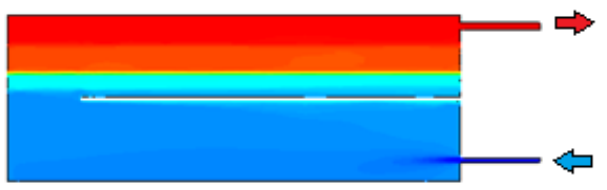

Tank 2

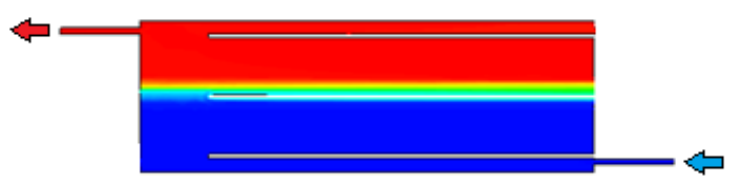

Tank 4

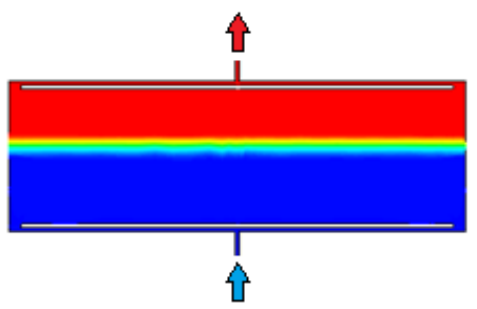

Tank 6

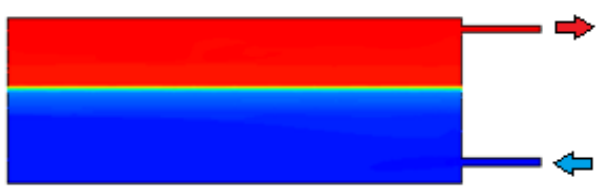

Tank 8

Figure 4.15: Temperature contour plot of 9 different designs 3.5 hours into simulation of Case 1. Essentially stagnant pocket of fluid below the middle baffle of Tanks 2 and 4 that contributes into the destratification of the tank. 


\section{Temperature}

Contour $\quad[\mathrm{K}]$

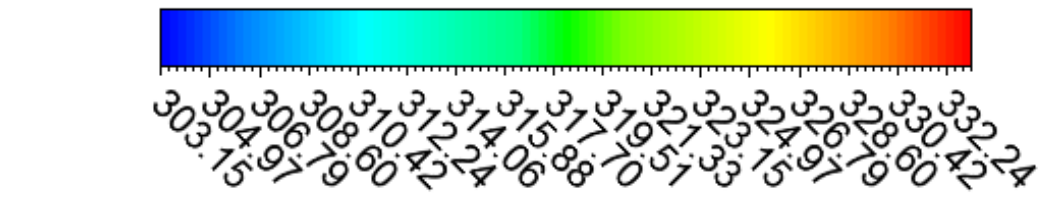

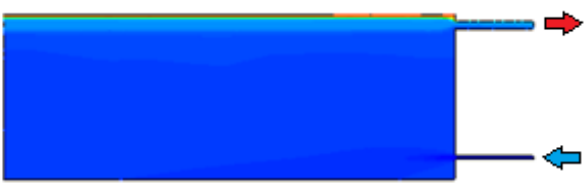

Tank 1

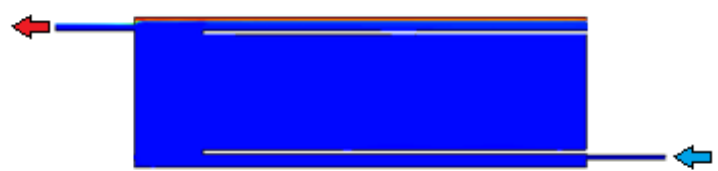

Tank 3

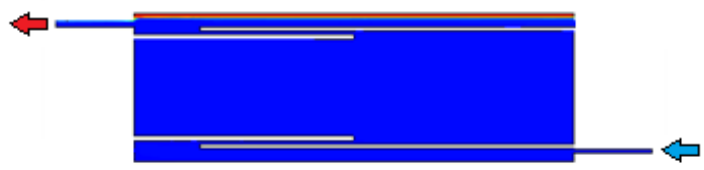

Tank 5

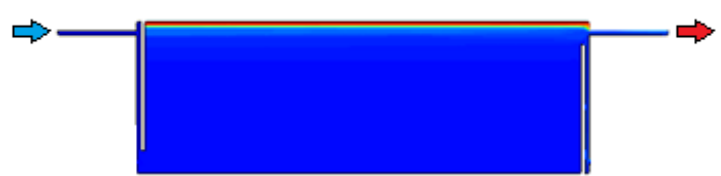

Tank 7

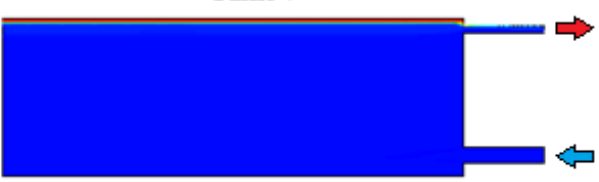

Tank 9

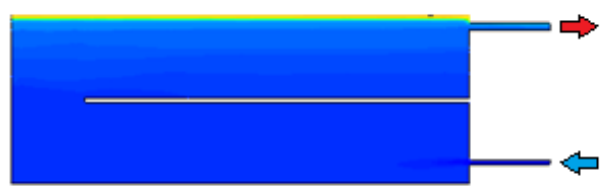

Tank 2
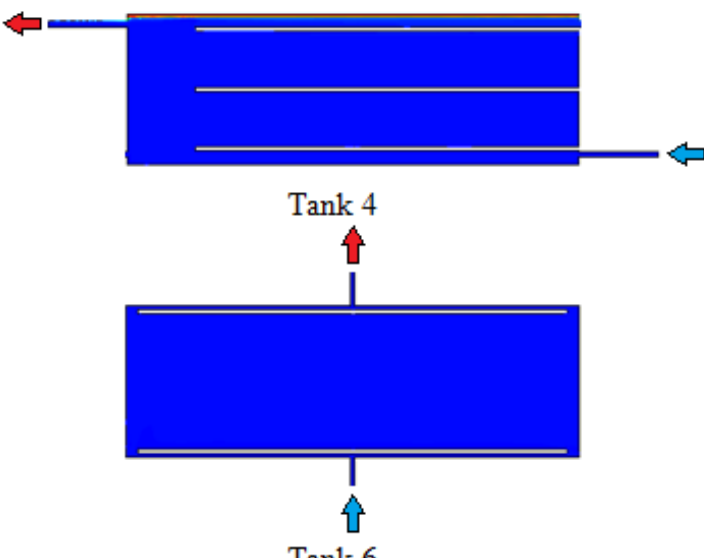

Tank 6

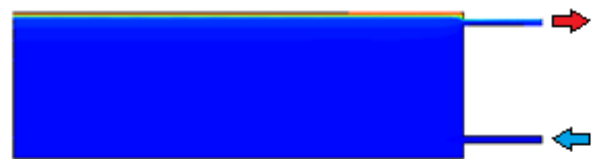

Tank 8

Figure 4.16: Temperature contour plot of 9 different designs 7 hours into simulation of Case 1. Stagnant fluid at the top of all tanks except for Tank 6 that is not easily accessed that contributes into the destratification of the tank.

Figure 4.12 and Figure 4.13 presents the top outlet temperature of the fluid leaving the tank and Huhn's efficiency respectively for the nine different designs during discharging. The results shows that the best performing tank is Tank 6 because it 
was able to sustain the hot outlet temperature for the longest duration and has the sharpest thermocline. This is confirmed by Huhn's efficiency, shown in Figure 4.13, which clearly shows that Tank 6 outperforms all other designs over the entire simulation time. Huhn's efficiency shows that all tanks are initially perfectly stratified and within the first couple of seconds all tanks experience a sharp drop in Huhn's efficiency. This occurs because of the cold inlet jet entering the hot tank which induces a significant amount of mixing at the bottom of the tank. This is seen in Figure 4.14 that displays the temperature contour plot of the different designs 15 minutes into the simulation, which shows that most of the tanks experience excessive mixing at the bottom tank layers. As a result, the main source of the initial mixing within the tank is the inlet jet. As time progresses, the inlet jet mixes with colder fluid resulting in less destruction of the exergy within the tank. It should be noted in Figure 4.14 that there is a difference in the mixing mechanism depending on the orientation of the inlet jet and baffle. Tank 3 has a horizontal inlet and it is clear that all the fluid underneath the bottom baffle is almost fully mixed. This mixing occurs as the cold inlet jet entrains hot fluid in order to spread and slow down. However, Tank 6 is fully mixed under the bottom baffle but the mixing is confined to a smaller region. The mixing is attributed to the inlet jet impingement on the baffle and mixing with the fluid under the baffle as it spreads. It should be noted that by moving the bottom baffle of Tank 6 closer to the ports, the volume under the baffle decreased dramatically from $5.72 \mathrm{~m}^{3}$ to $0.93 \mathrm{~m}^{3}$ which reduced the volume of fluid that becomes fully mixed within the tank.

Tank 2 and Tank 4 appear to have a sudden drop in Huhn's efficiency around 2.2 hours to 2.5 hours from the start of discharging. These two designs have a baffle 
in the middle of the tank, and this dip represents the time when the thermocline has reached the middle baffle. As shown in Figure 4.15, the middle baffle stagnates a pocket of fluid underneath it. This stagnant hot fluid cannot be recovered easily, destroying the layering of the fluid and thus reducing the level of stratification.

The hot fluid located above the top outlet is not easily recovered, because the fluid is stagnant as shown in Figure 4.16. The energy is eventually recovered through conduction within the water, which is a slow process that destroys an excessive amount of exergy thus reducing the Huhn's efficiency.

It is noted that Tank 1 and Tank 2 have a similar performance. These two designs have the poorest performance in comparison to all nine tanks. This suggests that adding a baffle in the middle of the tank does not contribute to the improvement in the tank performance because the middle baffle has little to no interaction with the inlet jet in order to help reduce mixing. As discussed earlier, the middle baffle stagnates a pocket of fluid underneath it which degrades the level of stratification. It is apparent that Tank 3 outperforms all the existing designs (i.e Tanks 1 and 2) because of the placement of the bottom baffle, which allows the inlet jet to spread in the horizontal direction while constraining the spread in the vertical direction. As a result, the bottom baffle helps to slow down the inlet jet without mixing a large volume of the hot water within the tank.

Tank 4 and Tank 5 showed very similar performance to Tank 3 . The difference in performance between the tanks is very small and is likely to be within the simulation error range (based on experimental error of $+/-2^{\circ} \mathrm{C}$ ). Figure 4.15 showed that Tank 4 trapped hot fluid under the middle baffle as the thermocline was moving through it. Tank 5 appears to have been able to slightly reduce the fluid speed when turning 
and penetrating through the hot temperature layers, resulting in less mixing, but not resulting in a significant change in performance compared to Tank 3.

The attempt to use vertical baffles to help stratify the tank was expected to perform well, because by orienting the baffles vertically and moving them closer to the ports, the volume of the fluid between the baffle and the ports decreases from $5.72 \mathrm{~m}^{3}$ to $1.13 \mathrm{~m}^{3}$ compared to Tank 3 . This reduces the volume of the fluid that becomes fully mixed within the tank. The baffle also extends about $85 \%$ of the total tank height doubling the flow area at the bottom of the tank in comparison to Tank 6. However, the tank did not outperform alternatives. As shown in Figure 4.14, the vertical baffles were not able to successfully spread the inlet jet in order to avoid high velocity fluid mixing.

It is evident that Tank 6 is the best performing tank of the nine geometries studied. This is expected because the outlet was relocated to the top of the tank, which eliminates stagnant hot fluid that used to settle at the top of the tank. Additionally, the bottom baffles was lowered to be closer to the inlet which allows the inlet jet to spread effectively while not mixing with a large volume of hot fluid. In addition, the tank has two gaps on both sides of the tank instead of one to help spread the inlet fluid evenly within the tank.

Tanks 8 and 9 have larger inlet diameters and do not employ baffles. As such, these designs would be the easiest to implement in practice. The increase in the inlet diameter allows for a decrease in the inlet jet momentum which should reduce the fluid mixing. The simulation results show that Tank 8 outperforms Tank 1 by about $10 \%$ according to Huhn's efficiency. However, Tank 9 outperforms Tank 8 by only $5 \%$. This agrees with the expectations that are based on Richardson number provided 
by Sliwinski et al. [13] because as the Richardson number increases, the mixing is reduced at an exponentially decreasing rate. It should be noted that according to Huhn's efficiency, Tank 8 underperforms the best performing design (Tank 6) by about $10 \%$ and underperforms Tank 5 by about $6 \%$. However, the design of Tank 8 is the simplest out of all top performing designs.

Simulations of the discharging of a fully charged tank confirm that the current tank at the DLSC (Tank 2) experiences excessive mixing during discharging. This is mainly caused by the inlet jet spreading vertically and entraining hot fluid into the cold inlet jet. Moreover, it is found that Tank 6 and Tank 5 provide the best performance. Tank 5 utilizes the bottom baffle in order to help the inlet jet spread horizontally and confines the mixing to the region below the baffle. It also employs a baffle that helps the fluid turn inside the tank which reduces cold fluid penetration into the hot fluid layers. Tank 6 eliminates stagnant hot fluid at the top of the tank by placing the outlet at the top. Moving the bottom baffle closer to the inlet also reduces the volume of fluid mixed within the tank. Lastly, increasing the inlet diameter of a tank without baffles from $101.6 \mathrm{~mm}$ to $200 \mathrm{~mm}$ (i.e Tank 8) resulted in an increase in Huhn's efficiency by $10 \%$ which still underperforms the best design by $10 \%$. However, it should be noted that the design of Tank 6 is much more complicated that Tank 8 . 


\subsubsection{Case 2: Charging of a Fully Mixed Cold Tank with Constant Charging Inlet Temperature}

In order to provide a more complete assessment of the tank performance, it is valuable to also study charging conditions.

Figure 4.17 shows a schematic of the fluid circuit at DLSC under charging. Cold fluid is extracted from the bottom of the cold STTS tank and passes through the solar collector to gain a significant amount of energy and returned to the top of the hot STTS tank. During this process, warm fluid exits the bottom of the hot STTS tank and enters the top of the cold STTS tanks. The charging simulation is focused on the hot STTS tank where the tank is initially at $20^{\circ} \mathrm{C}$ and is charged by hot fluid entering at $14 \mathrm{~L} / \mathrm{s}$ and a temperature of $80^{\circ} \mathrm{C}$. The flow rate chosen is the maximum achievable flow rate of the charging loop which will result in the largest amount of mixing. The total simulation time is 3 hours; tank turn over time is about 2.5 hours. This simulation is adapted from Rysanek [6] case 1 .

Since the difference between the Richardson number of the two cases is relatively small (charging 1.67 and discharging 0.87), as a result it is expected that the fluid will have a similar behaviour during charging and discharging. According to Sliwinski et al. [13], the level of mixing decreases sharply for a Richardson number between 0 and 0.4, if Richardson number is greater than 0.5 , there is little or no change to the level of mixing within the tank, as shown in Figure 4.8.

The tanks chosen to be tested in this case are Tanks 3, 4, 5, 6 and 8. The goal of this case is to rigorously test the top performing tanks in order to obtain the best performing design. Since, Tanks 1, 2, and 7 were found to be the lowest performing

designs in Case 1, this led to their elimination. Tank 9 is not investigated because 
as seen in Case 1, the difference in the performance between Tank 8 and Tank 9 is relatively small. Tanks 3,4 , and 5 were considered in order to ensure that the conclusions made for discharging case are also valid under charging conditions.

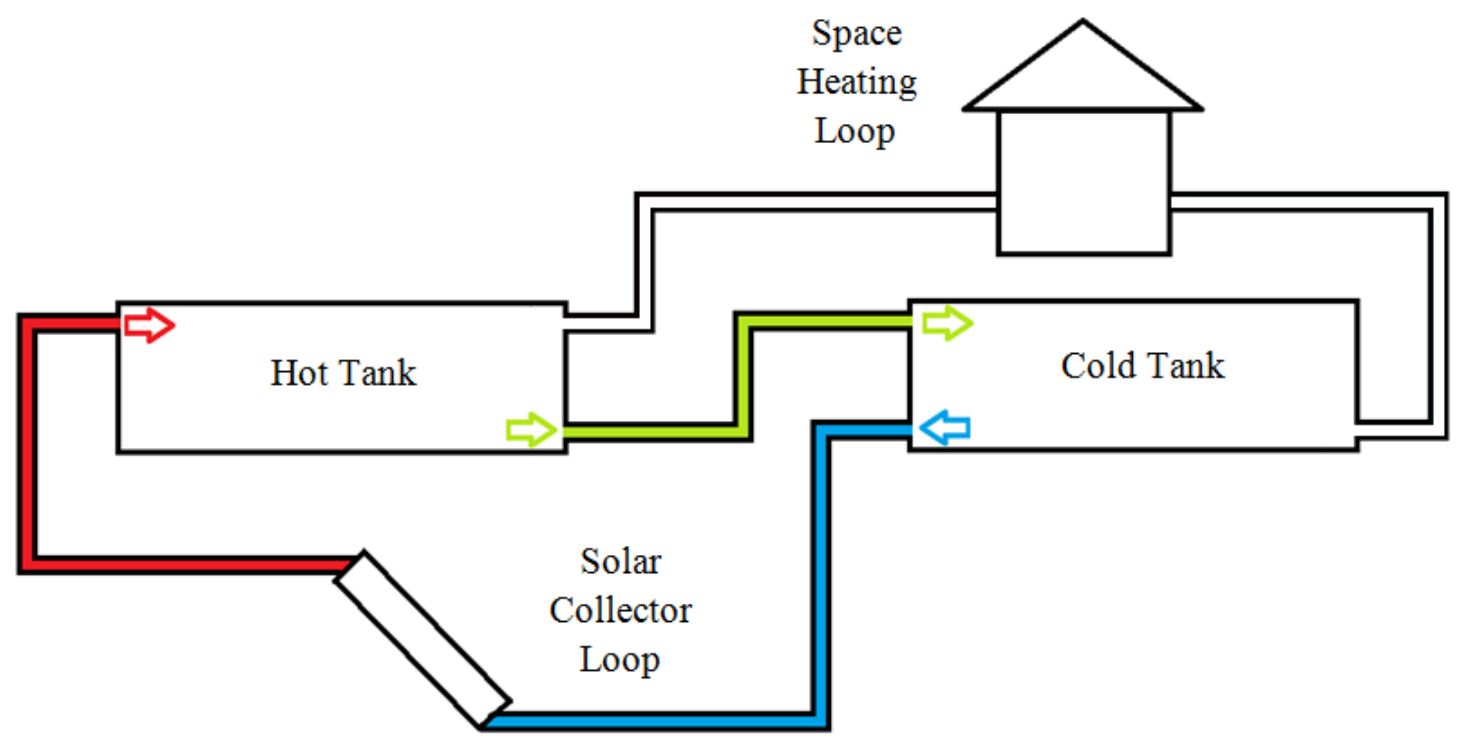

Figure 4.17: Schematic of the different loops at DLSC under charging showing the configurations of the inlets and outlets of the STTS tanks. The simulated charging case is focused on the hot tank. 


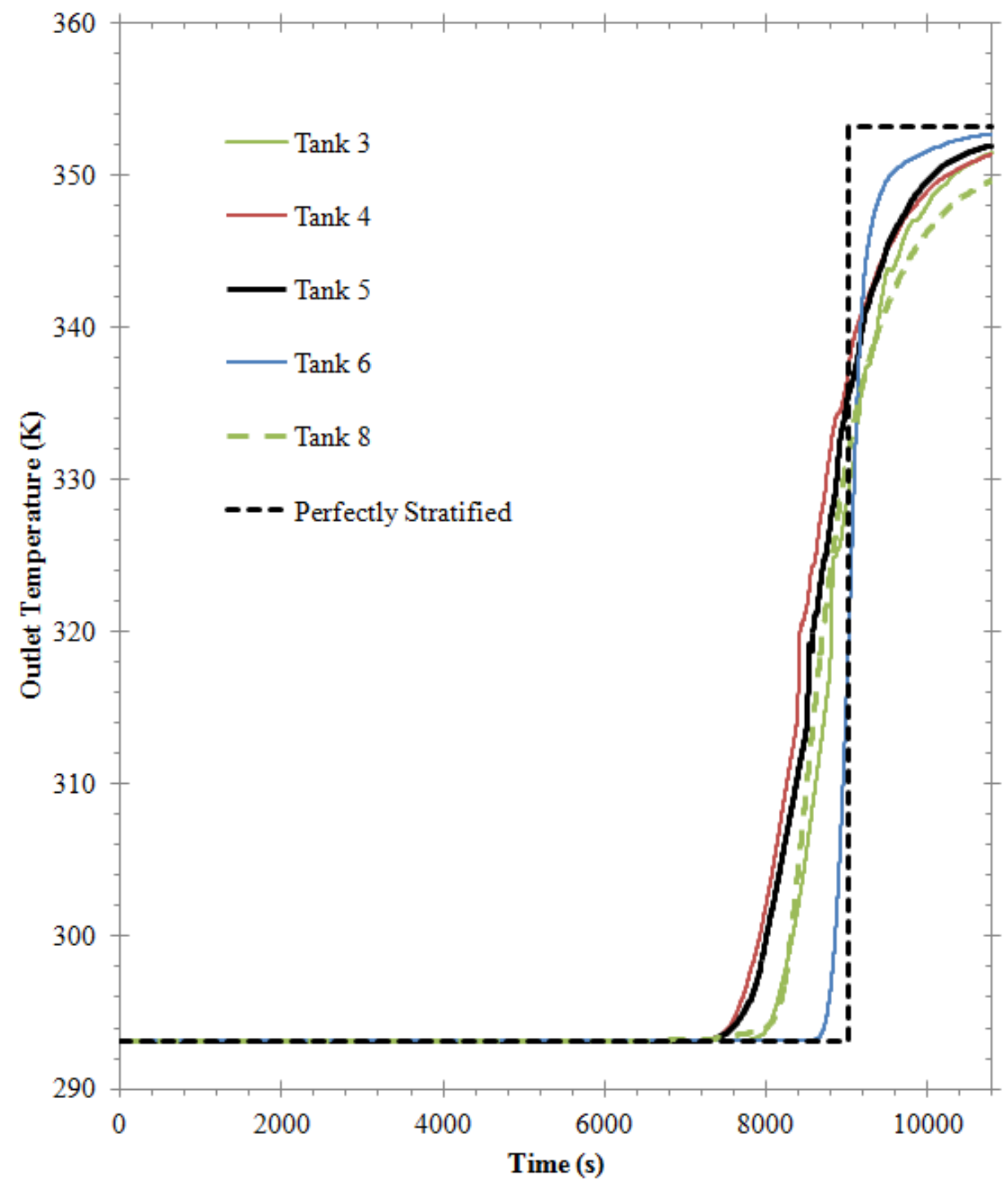

Figure 4.18: Transient temperature of fluid leaving the bottom of the tank for 5 different designs during simulation of Case 2 


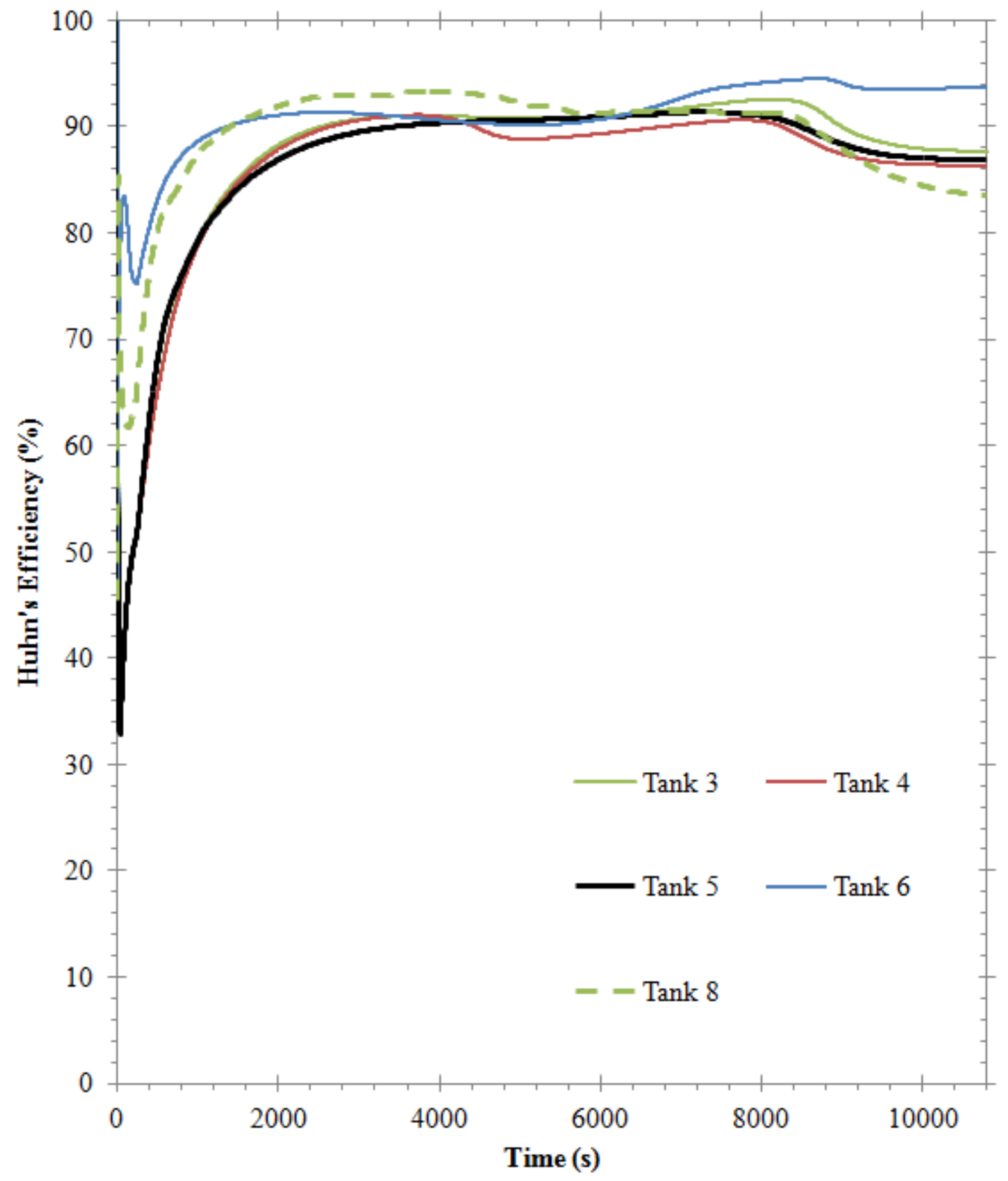

Figure 4.19: Huhn's efficiency for 5 different designs during simulation of Case 2 


\section{Temperature}

Contour

$[\mathrm{K}]$

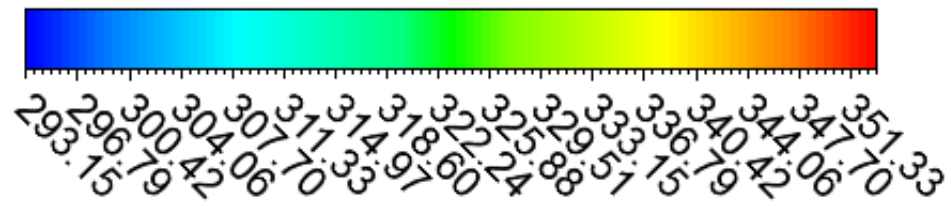

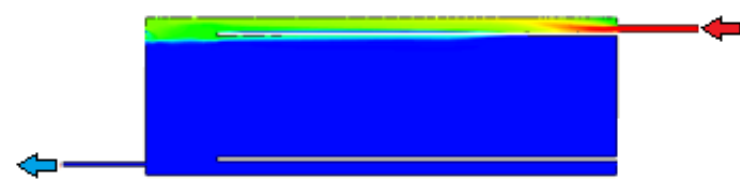

Tank 3

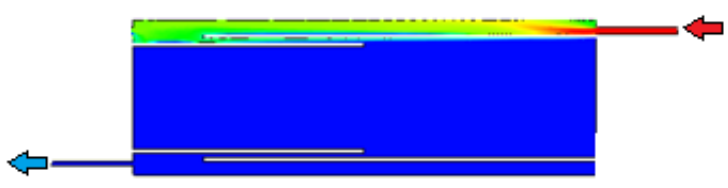

Tank 5

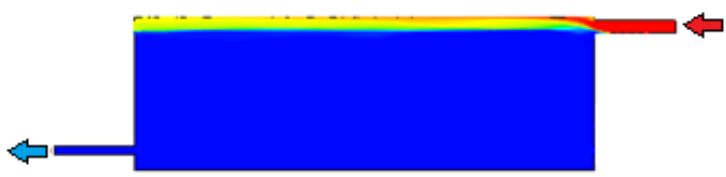

Tank 8

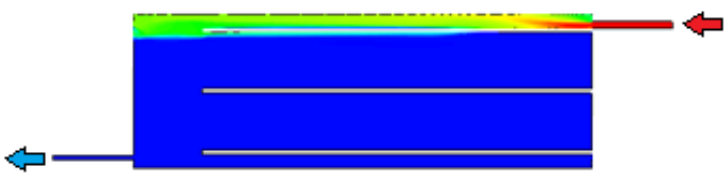

Tank 4

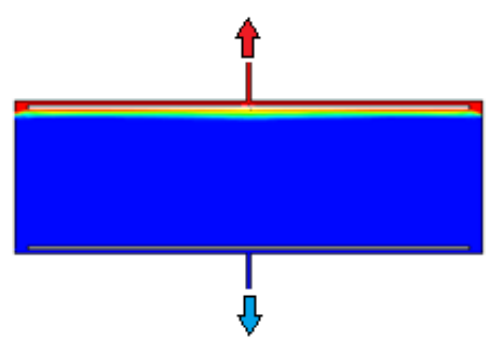

Tank 6

Figure 4.20: Temperature contour plot of 5 different designs 5 minutes into simulation of Case 2. Hot inlet jet causes significant mixing at the top of the tank. 
Temperature

Contour

$[\mathrm{K}]$

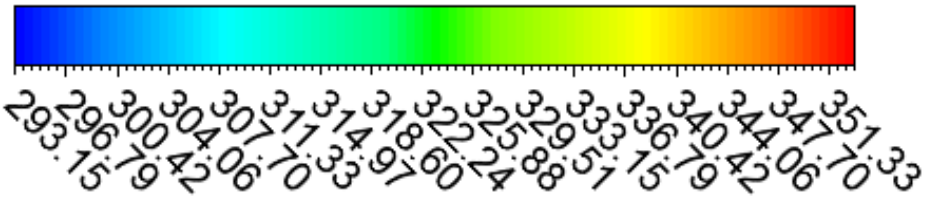

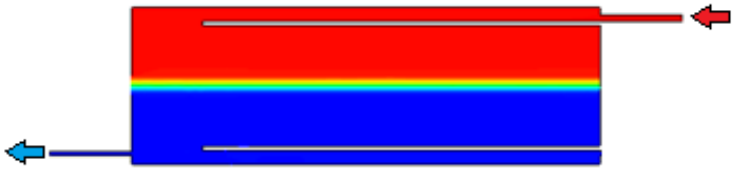

Tank 3

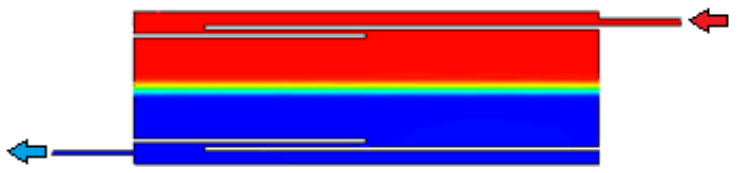

Tank 5

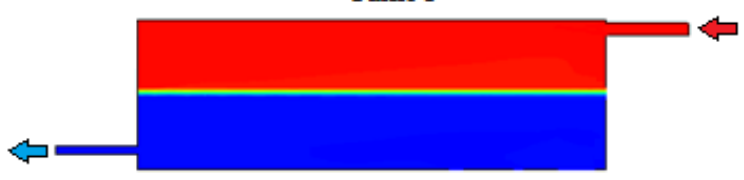

Tank 8

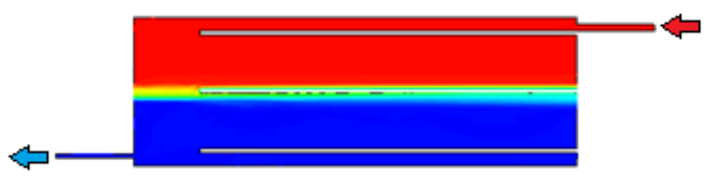

Tank 4

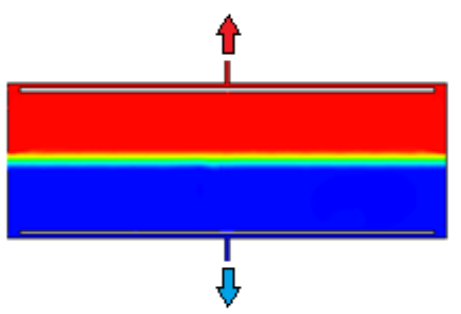

Tank 6

Figure 4.21: Temperature contour plot of 5 different designs 1.25 hours into simulation of Case 2. Essentially stagnant pocket of fluid above the middle baffle of Tank 4 contributes to the tank destratification. 


\section{Temperature}

Contour

$[\mathrm{K}]$

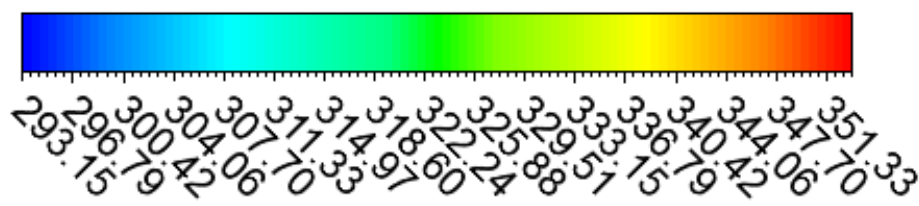

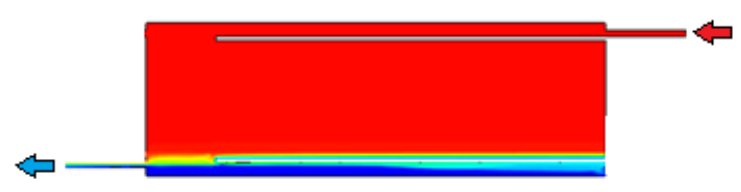

Tank 3

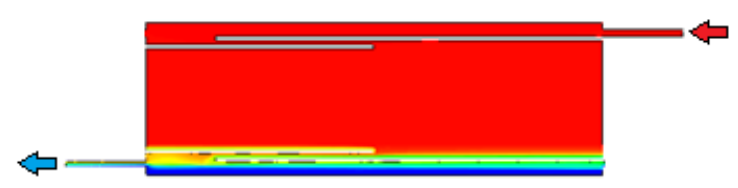

Tank 5

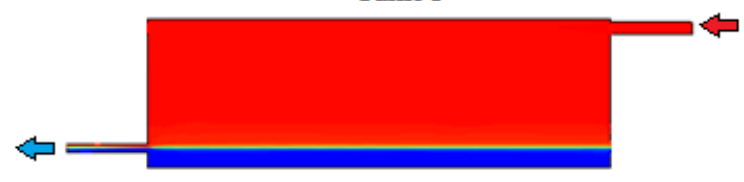

Tank 8

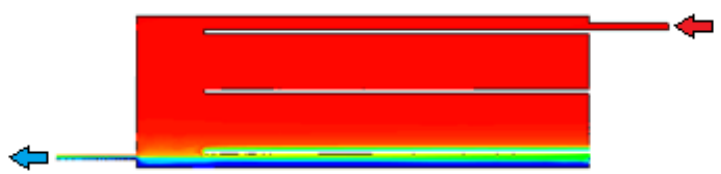

Tank 4

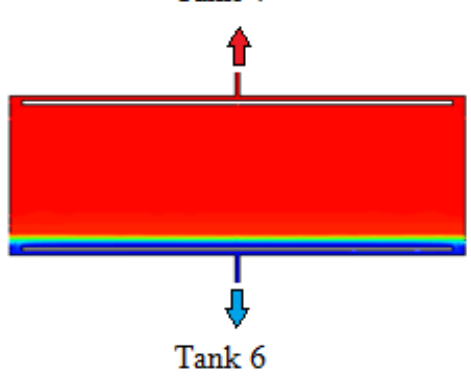

Tank 6

Figure 4.22: Temperature contour plot of 5 different designs 2.4 hours into simulation of Case 2. Essentially stagnant pocket of fluid above the bottom baffles contributes to the tank destratification. 


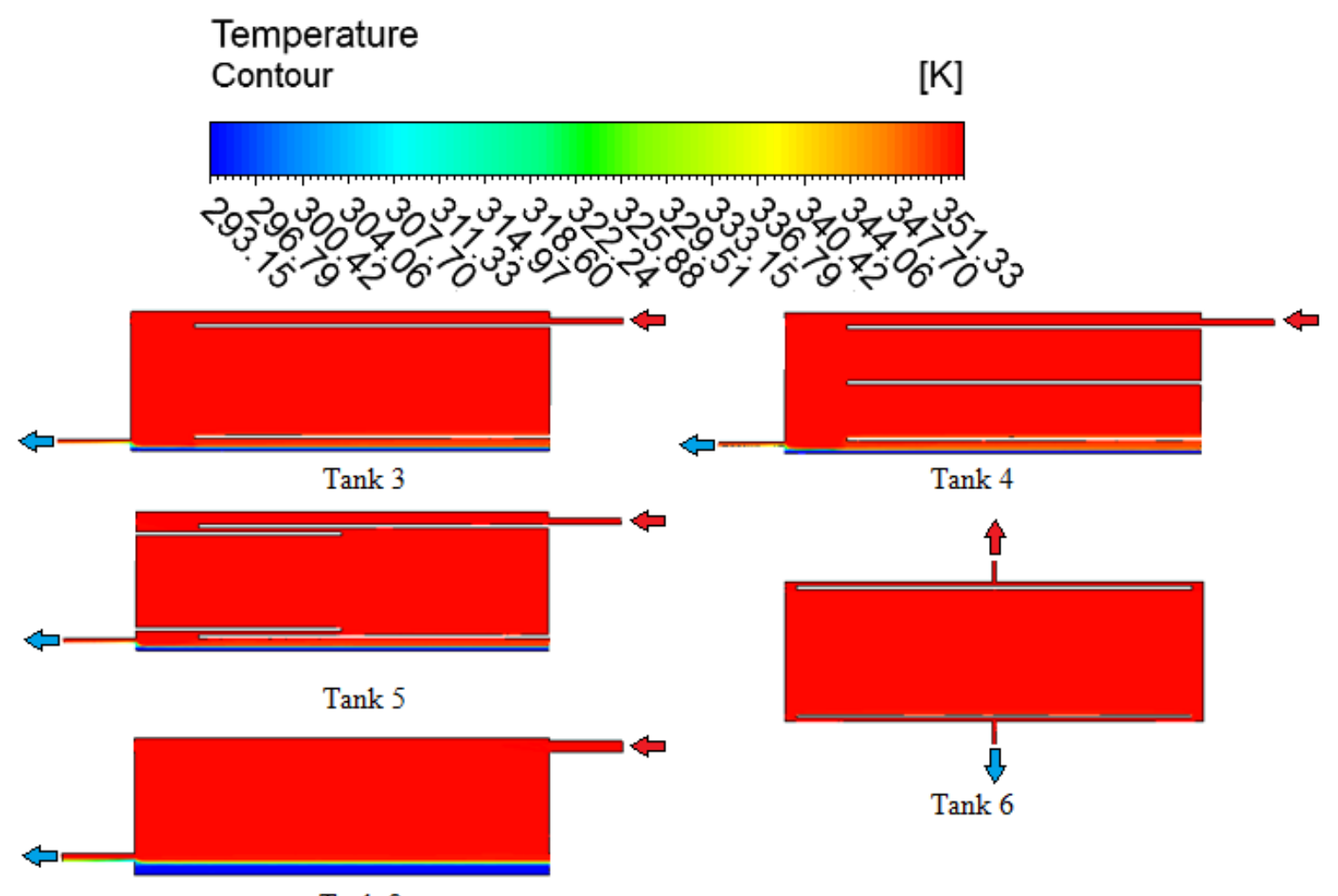

Tank 8

Figure 4.23: Temperature contour plot of 5 different designs 3 hours into simulation of Case 2. Stagnant cold fluid at the bottom of the Tanks 3, 4, 5, and 8 is not accessible and degrades tank performance.

It is apparent in Figure 4.18 that Tank 6 outperforms all the other designs because of its delayed sharp rise in temperature at the outlet. This is confirmed by Huhn's efficiency in Figure 4.19 where Tank 6 slightly outperforms all the other designs. As discussed before, all the attempted improvements of Tank 3 (i.e Tanks 4 and 5 ) do not have a significant effect on stratification and the difference in the tank performances is likely within the simulation error range.

Figures 4.20 to 4.23 show temperature contour plots of the five different designs that were investigated during charging. Under charging conditions the inlet is located 
at the top of the tank while the outlet is at the bottom. These contours provide important information on key locations where destratification takes place within the tank. As seen in Figure 4.20, significant mixing takes place at the top of the tank, this is caused by the cold fluid entrainment into the hot inlet jet. In addition, the middle baffle in Tank 4 clearly degrades the level of stratification within the tank and this can be seen in the dip in Huhn's efficiency around 1.53 hours. Figure 4.21 shows the presence of stagnant pocket of fluid above the middle baffle of Tank 4 which degrades tank performance because it destroys the layering of fluid within the tank. The redirecting baffles for Tank 5 help the fluid turn inside the tank which reduces the hot fluid penetration into the cold region, resulting in a reduction in the mixing. Tank 6 experience less mixing through the charging cycle. This is mainly a result of the baffle being located closer to the inlet which reduces the volume of the fluid that mixes with the inlet jet while spreading. Furthermore, the relocation of the outlet to the bottom of the tank eliminates the stagnant fluid located at the bottom of the tank. About two hours into the simulation, it is clear that most tanks experience another slight drop in Huhn's efficiency; this is a result of the stagnant pocket of fluid that accumulates above the bottom baffles, shown in Figure 4.22. In addition, as displayed in Figure 4.23, Tank 3 to 5 and Tank 8 show stagnant cold fluid at the bottom of the tank that is not easily discharged. In summary, Tank 8 has a similar performance to Tanks 3 to 5 but has the benefit of a simple design without the use of interior baffles.

As expected, the conclusions drawn from the analysis of charging are consistent with those for discharging. This is a result of the value of the Richardson number for charging and discharging to be relatively close (1.67 and 0.87 respectively), thus there 
is a little effect on the stratification. According to Sliwinski et al. [13], if Richardson number is greater than 0.5 , there is little or no change to the level of mixing within the tank, as shown in Figure 4.8. This shows that the factors that mix the tank do not change as the flow rate varies during charging or discharging. Therefore, it can be safely assumed that the tank enhanced for discharging will be enhanced for charging and vice versa.

\subsubsection{Case 3: Discharging of a Pre-stratified Tank with Con- stant Discharging Inlet Temperature}

The tanks are always in a pre-stratified condition when either charging or discharging. This is expected to change the way the fluid moves and mixes within the tank because the buoyancy force acting on the fluid particle will not be as strong as in the previous cases owing to the smaller temperature difference between inlet jet and fluid at the bottom of the tank. As a result, it is very important to study the impact of a prestratified tank on the level of stratification during discharging.

As previously shown in Figure 4.11, the discharging simulation is focused on the cold tank. The tank being studied is initially pre-stratified with a linearly decreasing temperature of $50^{\circ} \mathrm{C}$ at the top of the tank and $40^{\circ} \mathrm{C}$ at the bottom of the tank. The gradient is an approximation of the gradient experienced by the cold STTS tank at DLSC based on the three temperature sensors. The initial conditions are typical average temperatures experienced by the cold STTS tanks at the DLSC. The inlet

discharging temperature is $30^{\circ} \mathrm{C}$ with a flow rate of $6 \mathrm{~L} / \mathrm{s}$. The total simulation time is 7 hours; tank turn over time is about 6 hours.

Since, Tanks 3 to 6 and 8 were found to be the best performing tanks in Case 1, 
they are chosen to be investigated for this case.

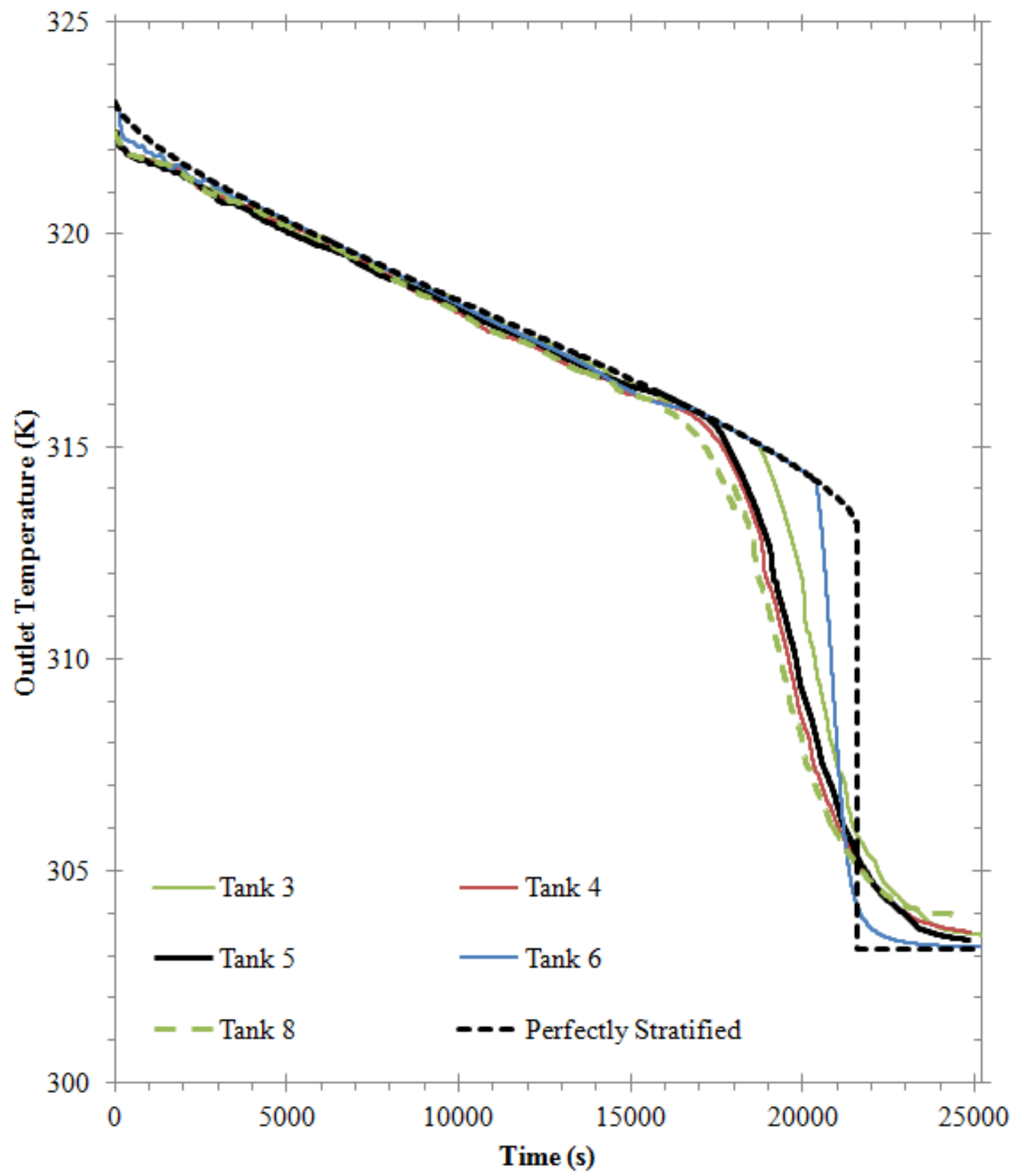

Figure 4.24: Transient temperature of fluid leaving the top of the tank for 5 different designs during simulation of Case 3 


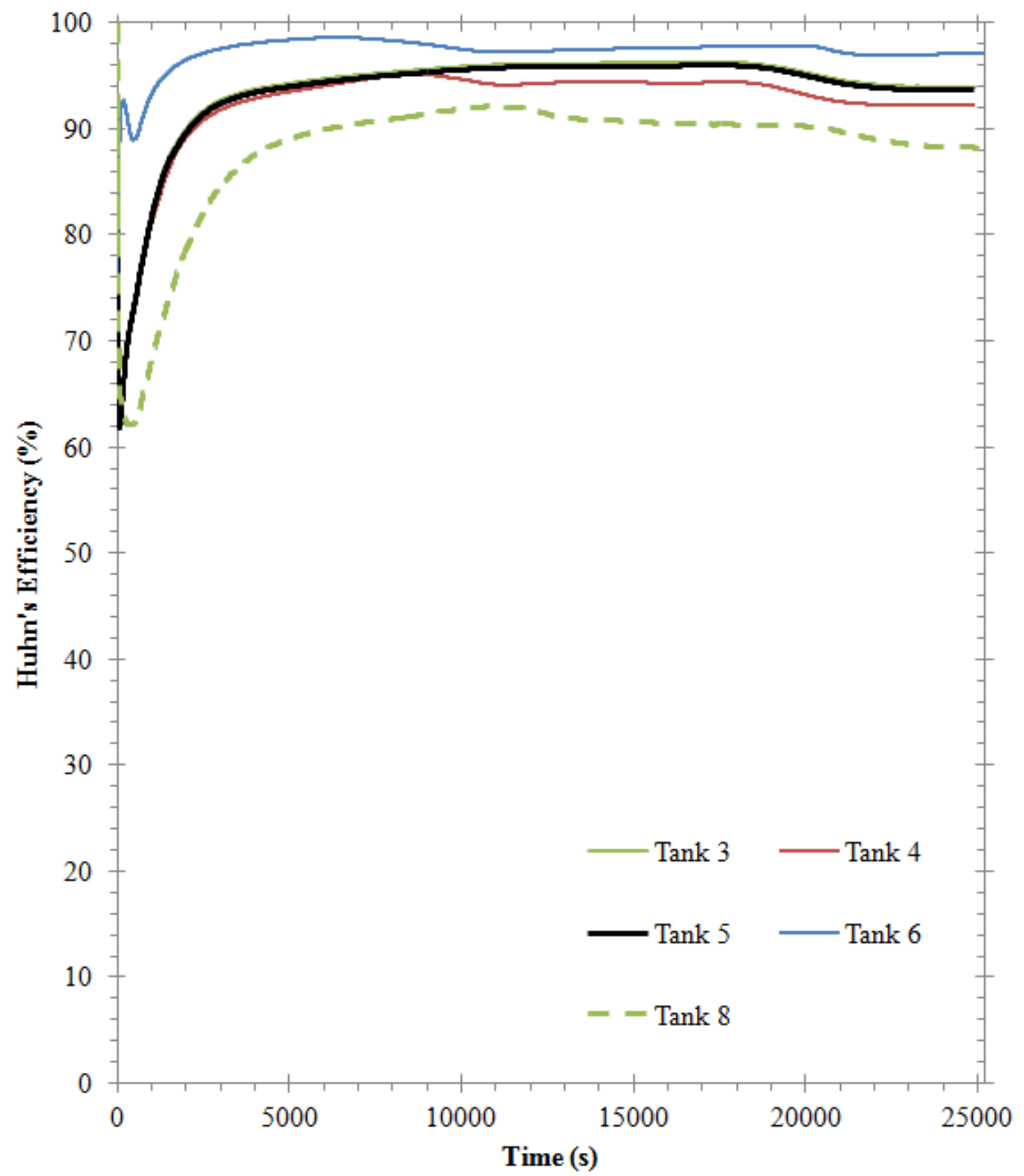

Figure 4.25: Huhn's efficiency for 5 different designs during simulation of Case 3. Huhn's efficiency of Tanks 3 and 5 overlap. 


\section{Temperature}

Contour

$[\mathrm{K}]$
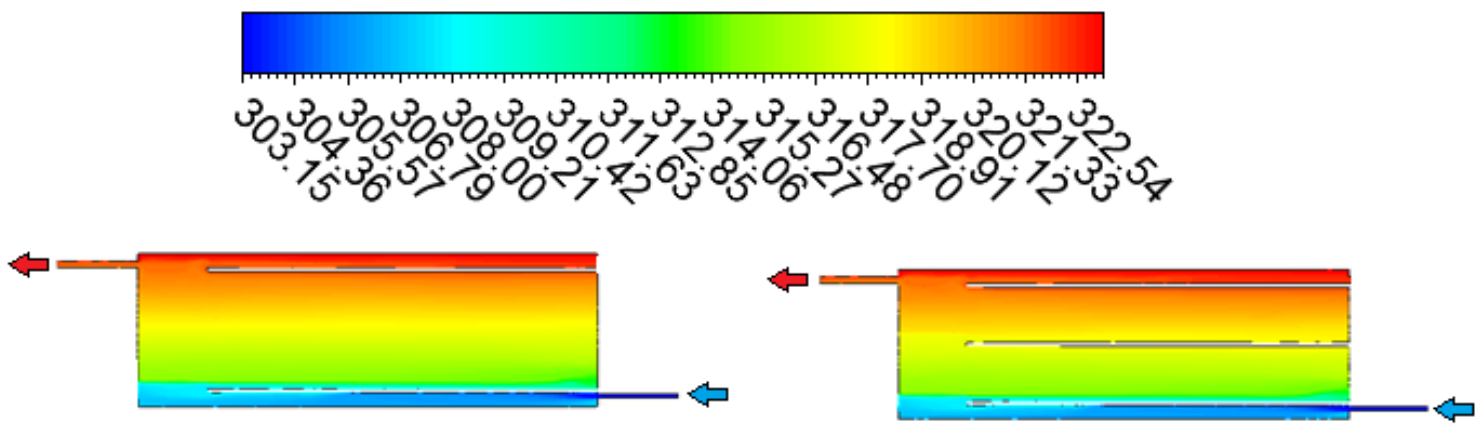

Tank 3
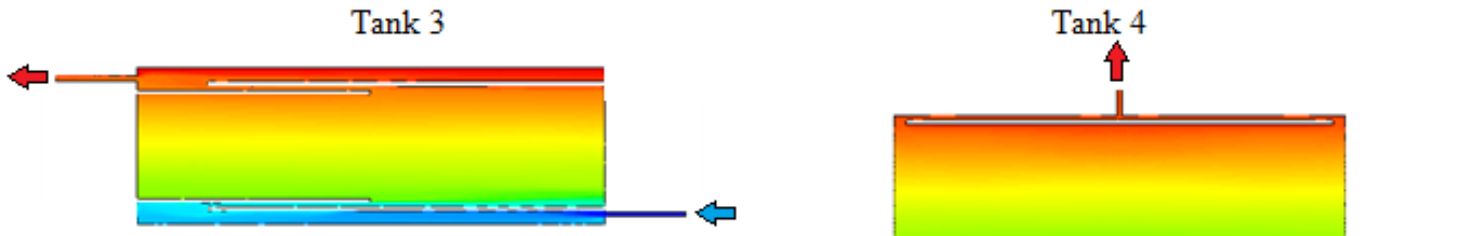

Tank 5
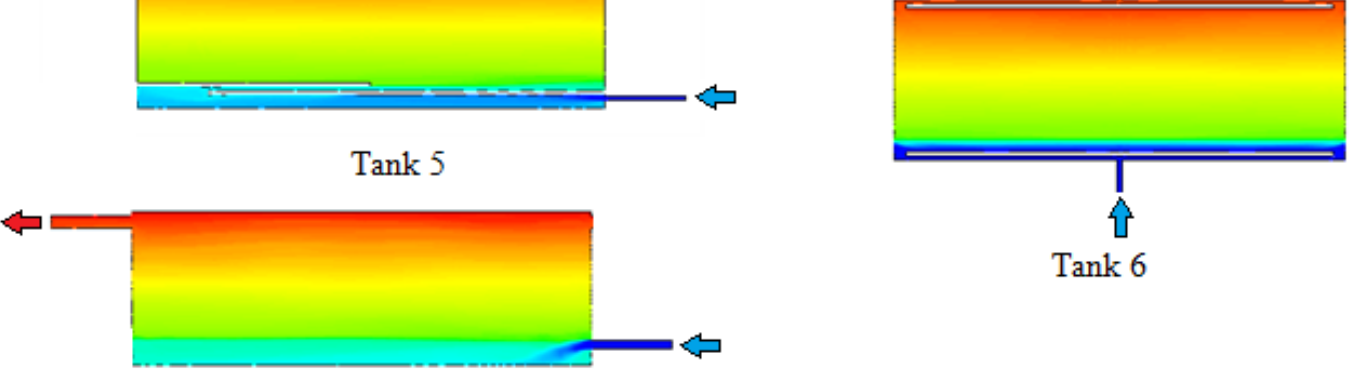

Tank 6

Tank 8

Figure 4.26: Temperature contour plot of 5 different designs 15 minutes into simulation of Case 3. Cold inlet jet causes significant mixing at the bottom of the tank. 


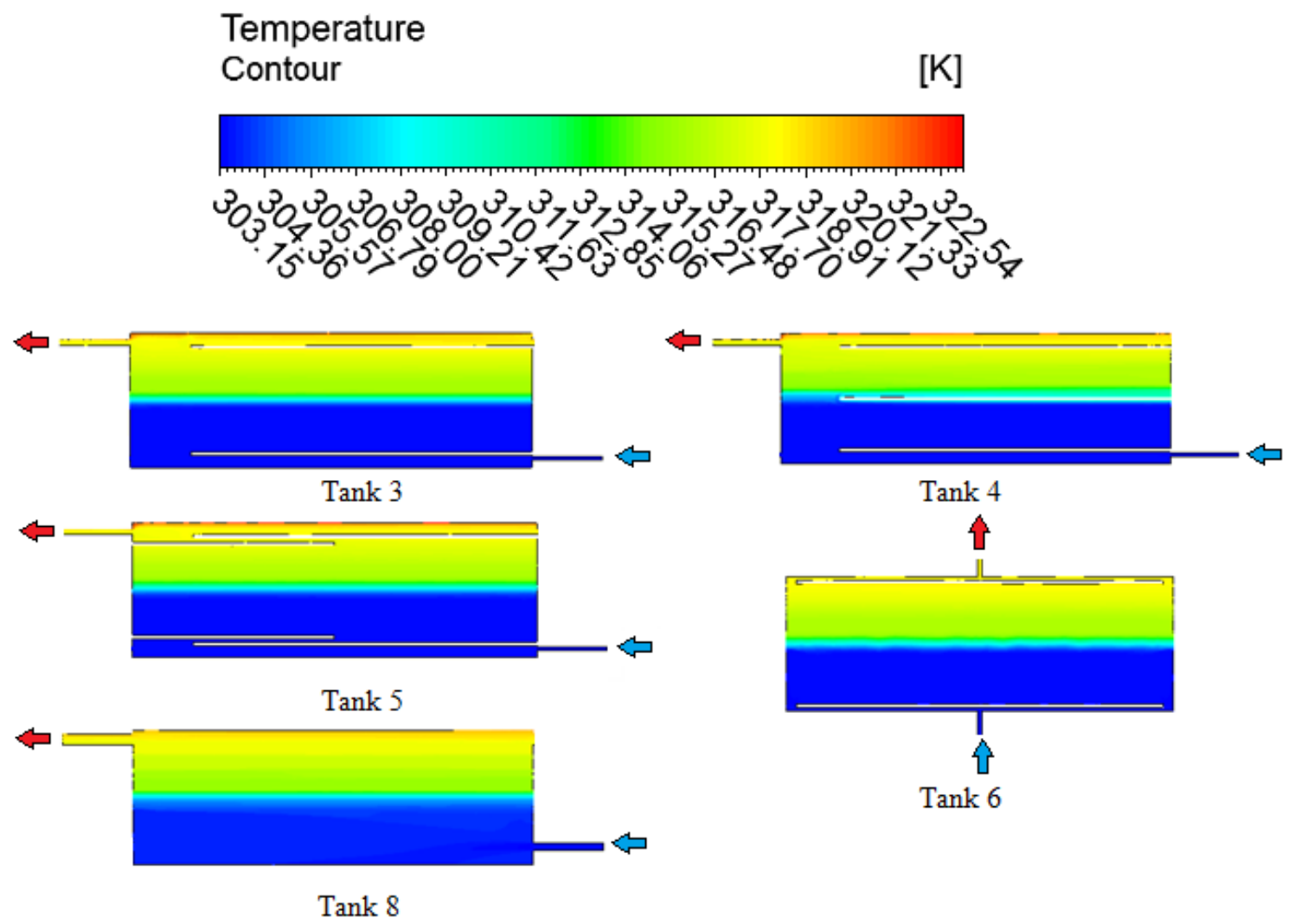

Figure 4.27: Temperature contour plot of 5 different designs 2.9 hours into simulation of Case 3. Essentially stagnant pocket of fluid below the middle baffle of Tank 4 that contributes into the destratification of the tank. 


\section{Temperature}

Contour $\quad[K]$

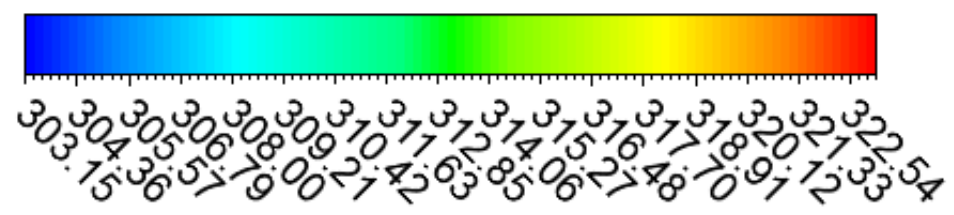

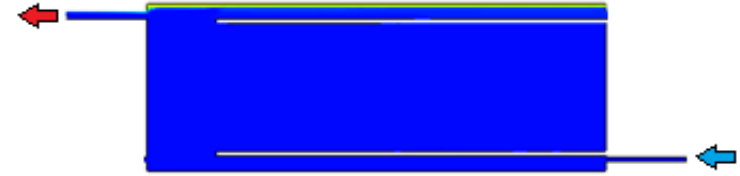

Tank 3

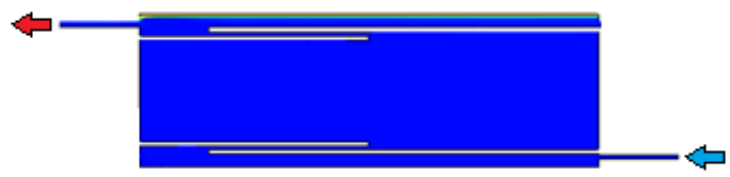

Tank 5

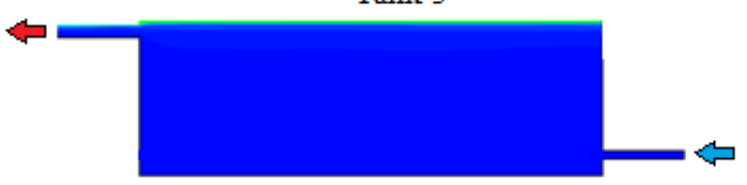

Tank 8

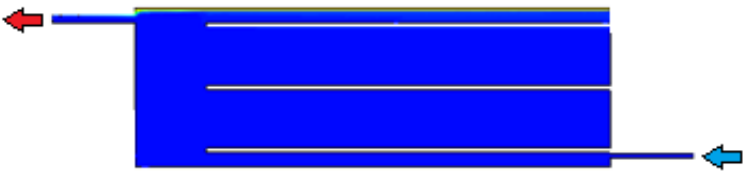

Tank 4

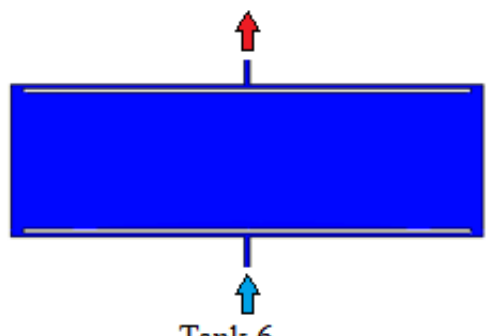

Tank 6

Figure 4.28: Temperature contour plot of 5 different designs 7 hours into simulation of Case 3. Stagnant fluid at the top of all tanks except for Tank 6 that is not easily accessed that contributes into the destratification of the tank.

Figure 4.25 presents the Huhn's efficiency for the five different designs during discharging a pre-stratified tank. It was expected that since the tank temperature and the inlet temperature will be closer, then the buoyancy forces will be weaker and more mixing will take place within the tank. However, as clearly shown in Figure 4.25, Huhn's efficiency for all designs is very high because when mixing occurs in the tank at the beginning of the simulation, the cold inlet jet is mixing with cooler fluid resulting in less destruction of exergy (high quality energy), as demonstrated in Figure 4.26. This leads to better performance than discharging a fully charged hot tank. This is 
confirmed by the drop in the Huhn's efficiency at the beginning of Case 1 to $10 \%$ for Tanks 3 to 5 and 8 while for Case 3 Huhn's efficiency drop to only $60 \%$. It should be noted that Huhn's efficiency of Tank 3 and Tank 5 overlap.

Figure 4.24 presents the top outlet temperature of the fluid leaving the tank for the five different designs during discharging a pre-stratified tank. Figure 4.24 clearly show that the best performing tank is Tank 6 because it has the highest outlet temperature for the longest duration and the sharpest thermocline. This is a result of the reduction of the mixing volume at the bottom of the tank, as shown in Figure 4.26 by moving the bottom baffle closer to the bottom of the tank, and the elimination of stagnant fluid at the top of the tank, as shown in Figure 4.28 by placing the outlet at the top of the tank. This is confirmed by Huhn's efficiency which shows that Tank 6 outperforms the other tanks by about 3\%. Yet, there is still a drop in the performance of Tank 6 around 2 hours and 5.6 hours resulting from stagnant pocket of fluid underneath the top baffle which mixes the fluid layers and reduces the level of stratification. Furthermore, the graph of the outlet temperature shows that Tanks 3 to 5 have a better level of stratification than Tank 8 and this is confirmed by Huhn's efficiency. This result is similar to the previous case because the bottom baffle help spread the inlet jet while restricting it from spreading in the vertical direction. Tank 4 and Tank 5 have the similar performance as Tank 3. It should be noted that the middle baffle drops Huhn's efficiency slightly at around 2.9 hours into the simulation and this is due to the nearly stagnant pocket of fluid that is present below the middle baffle, as displayed in Figure 4.27. Lastly, Tank 8 shows a significant amount of mixing at the beginning of the simulation but by the end of the simulation, the tank has a very close level of stratification as the other designs. 
Therefore, the best performing design is again Tank 6 , and this is due to its prolonged high outlet temperature and the sharp thermocline shown in Figure 4.24. Huhn's efficiency showed that the tank designs performed better than expected and this is due to the presence of cooler fluid at the bottom of the tank that mixed with the inlet jet resulting in less destruction of exergy.

\subsubsection{Case 4: Simultaneous Charging and Discharging of a Pre-stratified Tank with Constant Charging Inlet Tem- perature}

In order to closely consider a more realistic condition that takes place within a real tank, a case where the tank experiences charging and discharging simultaneously was studied. From this investigation it is expected to gain a better understanding of the mixing patterns that occur during simultaneous charging and discharging, and more importantly if more mixing occurs in this situation. It is expected that more mixing takes place within the tank because there is a higher overall mass flow rate in and out of the tank.

The locations of the bottom outlets for Tanks 3 to 5 were relocated to be on the same side as the inlet. This is expected to increase the fluid mixing underneath the bottom baffle leading to the elimination of stagnant fluid at the bottom of the tank. This is expected to enhance the performance of Tanks 3 to 5 .

As shown in Figure 4.29, the tank being studied is the hot tank at the DLSC, where the tank is charging from the solar collector loop and the discharging to the space heating loop. The tank being studied is initially pre-stratified with a linearly decreasing temperature of $70^{\circ} \mathrm{C}$ at the top of the tank and $55^{\circ} \mathrm{C}$ at the bottom of 
the tank. The gradient is an approximation of the gradient experienced by the hot STTS tank at DLSC based on the three temperature sensors. The initial conditions are typical temperatures experienced by the hot STTS tanks at the DLSC. The inlet charging temperature is $80^{\circ} \mathrm{C}$ with a flow rate of $14 \mathrm{~L} / \mathrm{s}$, the discharging mass flow rate is $6 \mathrm{~L} / \mathrm{s}$. This simulation will only consider the hot tank. The flow rates chosen are the largest achievable flow rates, which will generate the most mixing within the tank. Since there is only one inlet and two outlets in this tank, the top outlet is set to the mass flow rate of $6 \mathrm{~L} / \mathrm{s}$ and the bottom outlet is set to an average outlet pressure of zero. The total simulation time is 5 hours; tank turn over time is about 4.5 hours.

The tanks selected to be tested for this case are Tanks 3 to 6 and 8 . Tank 3 to 6 are top performers in Case 1 and Tank 8 has a very close performance to the top performing designs while employing no complicated baffle arrangement.

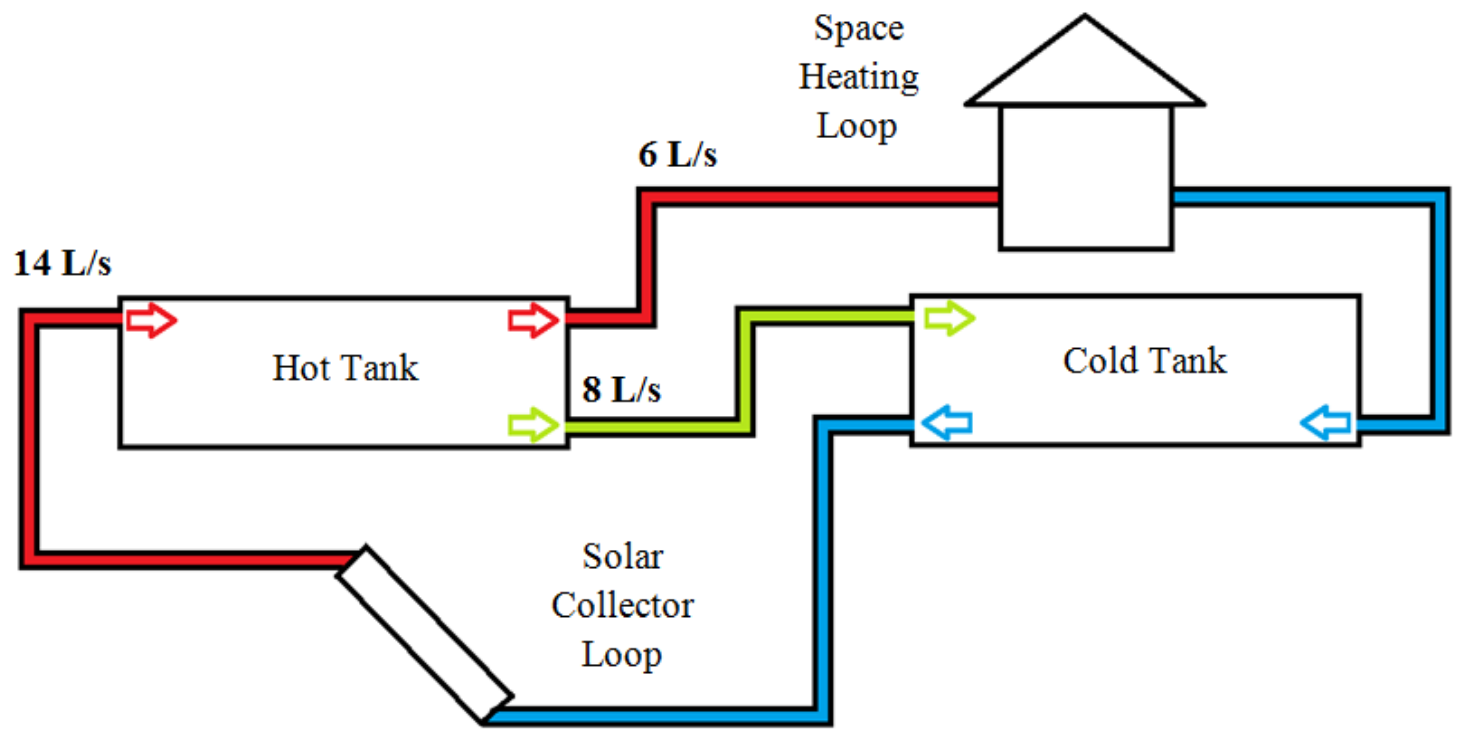

Figure 4.29: Schematic of the tanks at Drake Landing Solar Community showing that the hot tank has multiple outlets but only one inlet for our specific case of simultaneous charging and discharging from the solar collector to space heating 


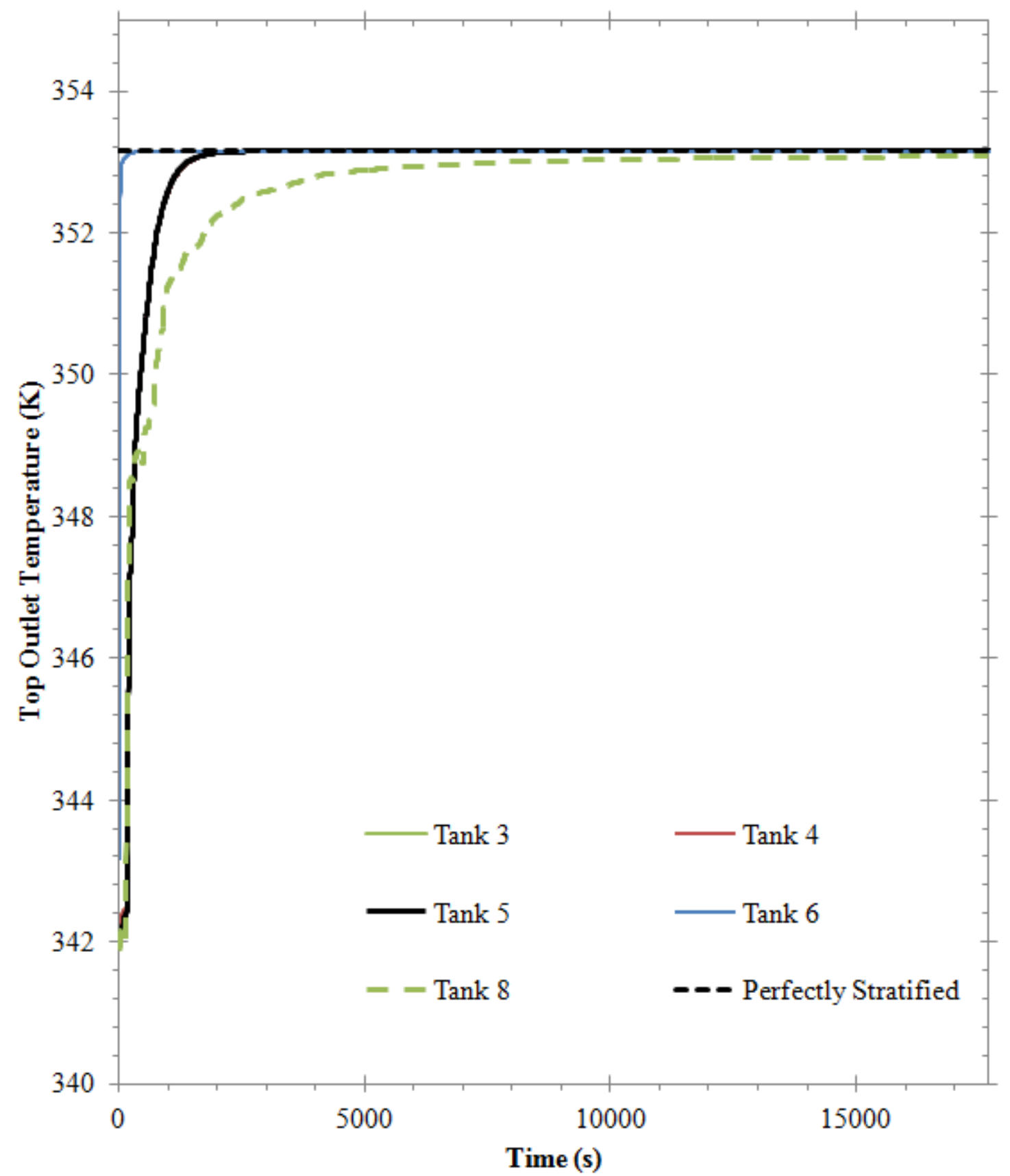

Figure 4.30: Transient temperature of fluid leaving the top of the tank for 5 different designs during simulation of Case 4 . Note: the transient outlet temperature curves for Tanks 3 to 5 overlap. 


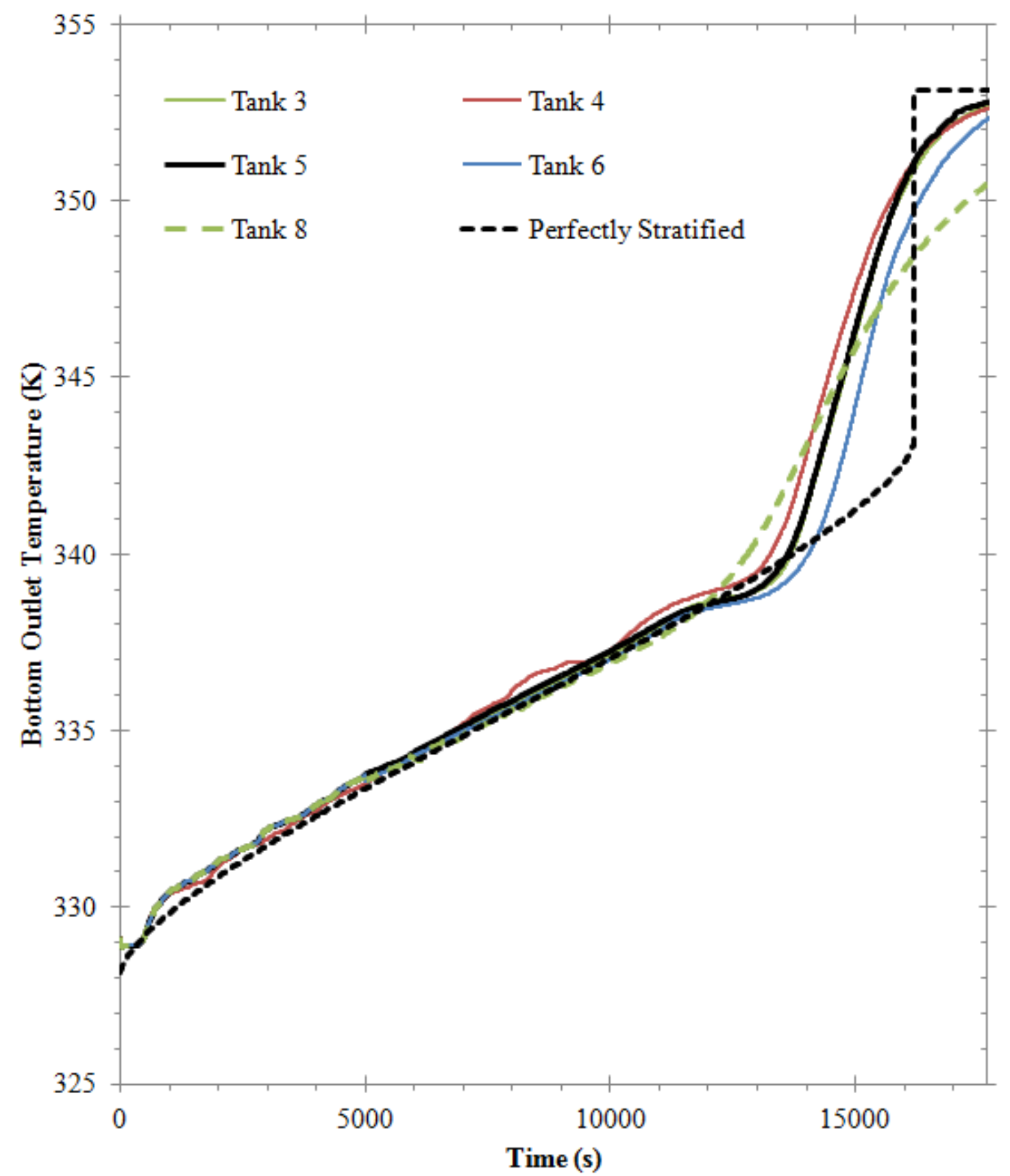

Figure 4.31: Transient temperature of fluid leaving the bottom of the tank for 5 different designs during simulation of Case 4 . Note: the transient outlet temperature curves for Tanks 3 and 5 overlap. 


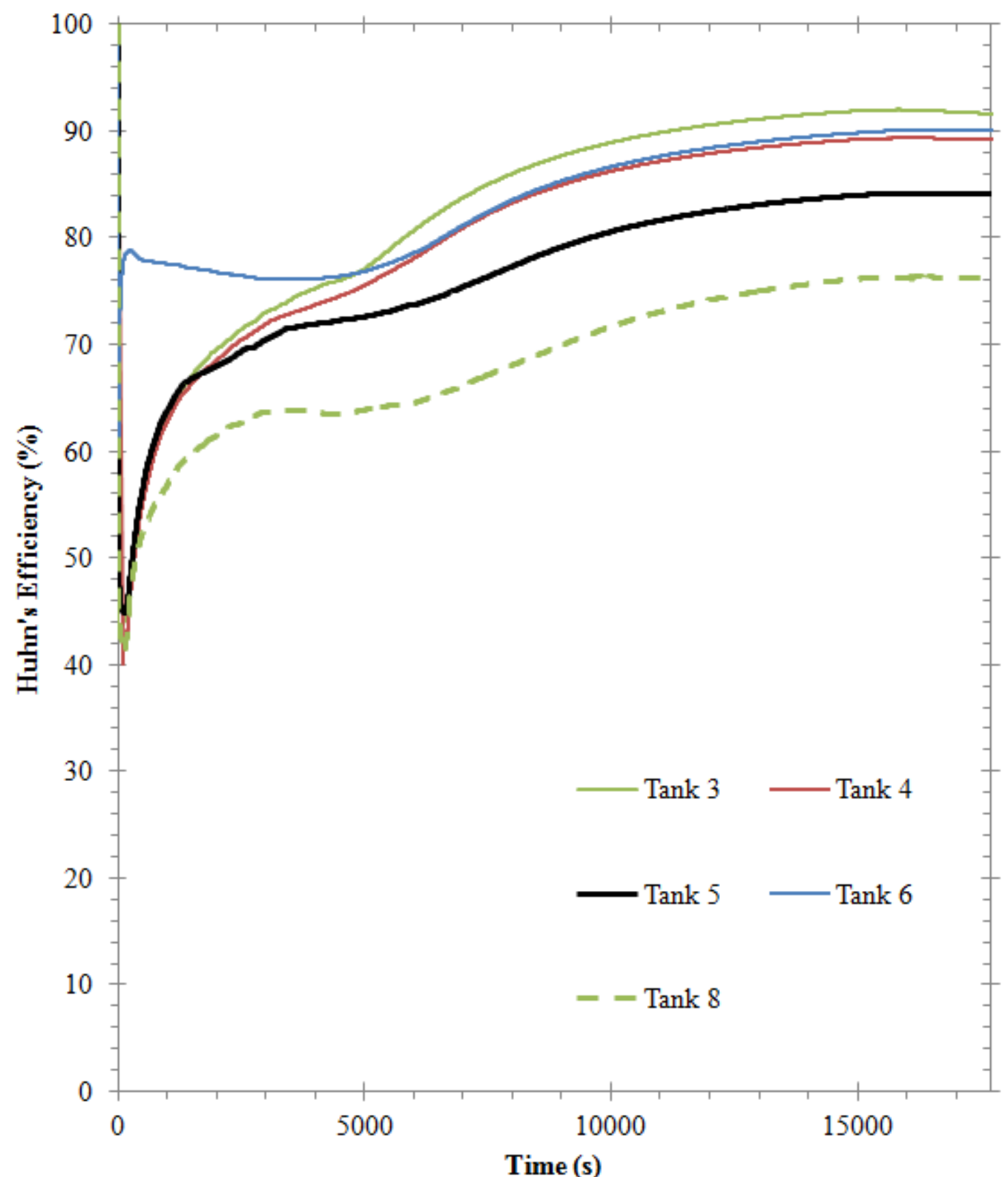

Figure 4.32: Huhn's efficiency for 5 different designs during simulation of Case 4 


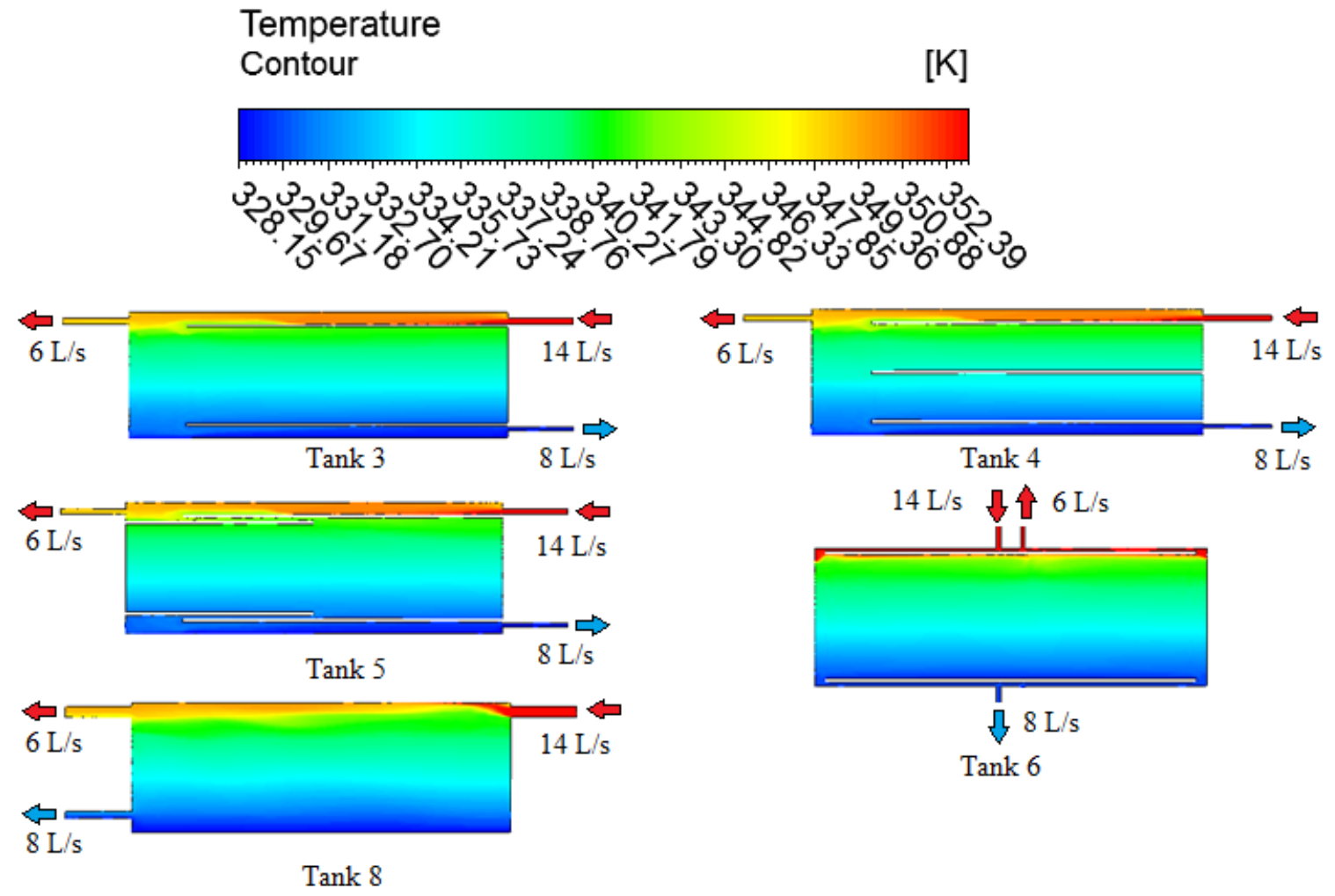

Figure 4.33: Temperature contour plot of 5 different designs 5 minutes into simulation of Case 4. Inlet jet mixing taking place at the top of the tank degrading the level of stratification. 


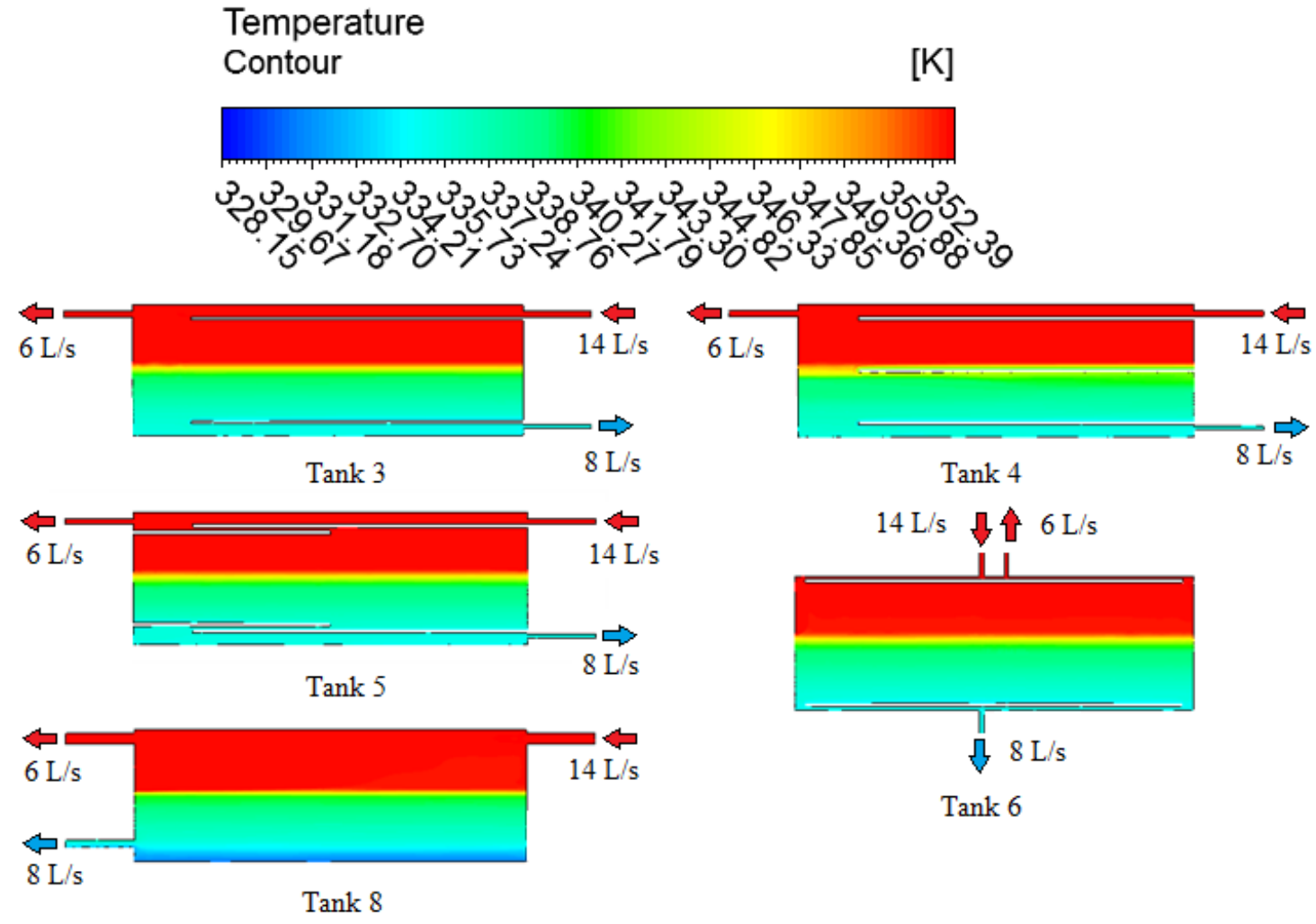

Figure 4.34: Temperature contour plot of 5 different designs 2 hours into simulation of Case 4. Essentially stagnant pocket of fluid above the middle baffle of Tank 4 contributes to the tank destratification. 


\section{Temperature}

Contour

$[\mathrm{K}]$
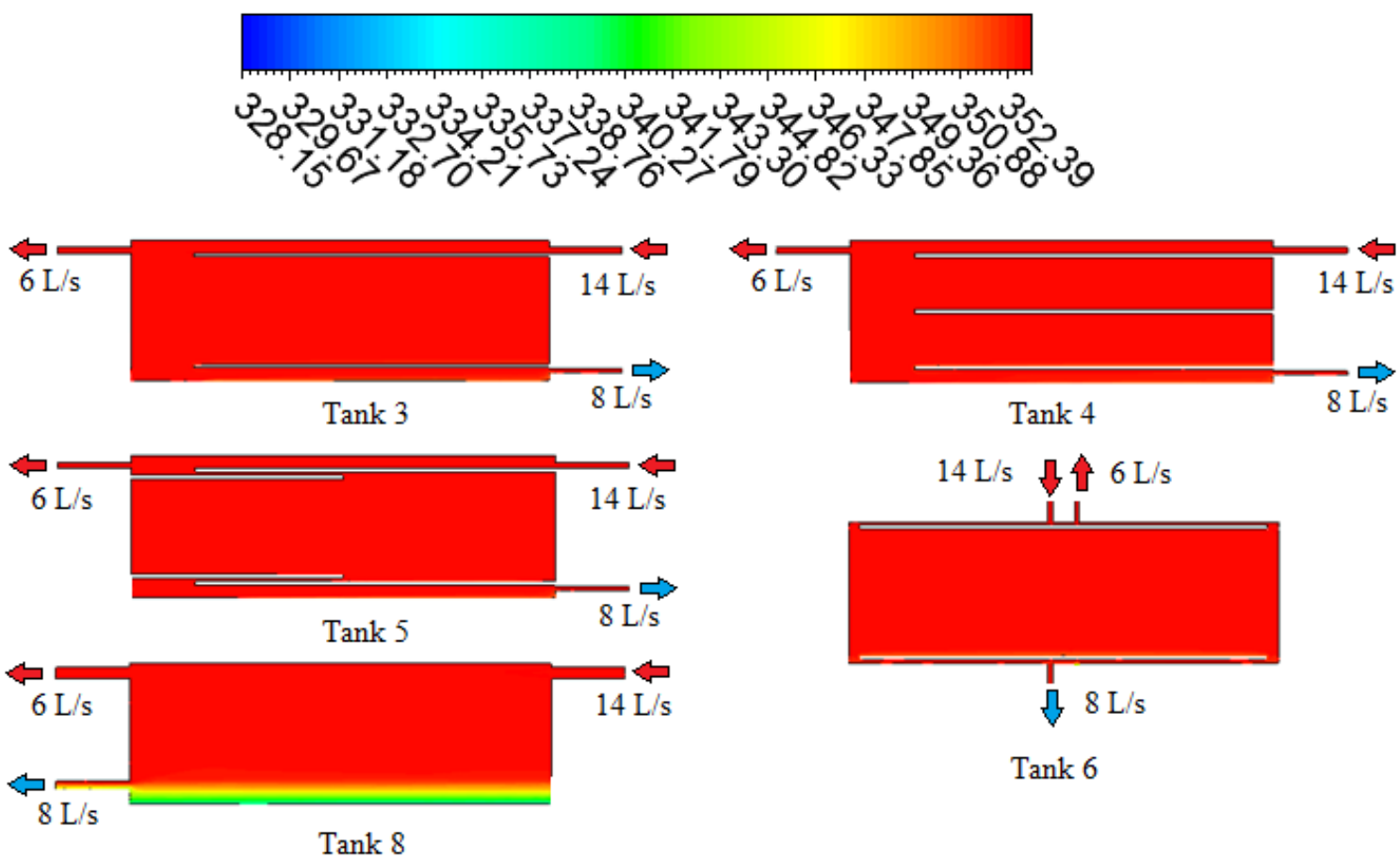

Tank 6

Figure 4.35: Temperature contour plot of 5 different designs 5 hours into simulation of Case 4. Stagnant cold fluid at the bottom of the tank that is not accessible and degrades tank performance.

Figure 4.30 presents the transient top outlet temperature of the tank during discharging and clearly shows that the best performing tank is Tank 6 . Tank 6 shows a very early sharp rise in the top outlet temperature in order to closely resemble the perfectly stratified tank. This was easily achieved because of the very close proximity of the charging inlet and the discharging outlet as seen in Figure 4.33.

It should be noted that Tanks 3 to 5 have the same transient top outlet temperature which leads to all curves overlapping on top of each other. This suggests that the transient top outlet temperature is related to the transit time for fluid from the inlet to the outlet. The transit time is related to the inlet velocity and the physical 
distance between the charging inlet and the discharging outlet. Since Tank 8 has the lowest inlet velocity, this contributes to the slower rise time. Tank 8 also does not employ any device to reduce the mixing caused by the inlet jet, leading to a significant amount of mixing that occurs at the top of the tank thus increasing the rise time of the top outlet temperature.

Figure 4.31 presents the transient bottom outlet temperature of the different tanks during simultaneous charging and discharging. The figure clearly shows that Tanks 3 to 6 have a similar performance and there is a marginal difference between the designs. However, it is clear that Tank 8 experiences the most mixing because the bottom outlet temperature rises the earliest out of all designs with a reduced slope compared to the other tank designs. This is confirmed by Huhn's efficiency presented in Figure 4.32, where it shows that Tank 8 has the lowest efficiency out of all designs. According to Figure 4.32 all tanks experienced excessive mixing at the beginning of the simulation except for Tank 6, which experiences mixing but not as intensely as all other designs. This is expected due to the use of the baffle that restricts the inlet from excessive mixing and the lack of cold fluid to mix with. All designs have about the same efficiency of about $85 \%$, similar to the efficiency achieved in Case 2. It should be noted that Tank 8 underperforms all other designs by about 15\%. Tank 5 underperforms all other designs by about $5 \%$, this is a negligible difference because it may be within the simulation error. According to Figure 4.34, Tank 4 suffered again from the presence of the middle baffle because it created nearly stagnant pocket of fluid above it, mixing the fluid layers which degrades the level of stratification. Lastly, unlike all previous cases, Figure 4.35 clearly shows that there is no fluid stagnant at the bottom of Tanks 3 to 5 . This can be attributed to the relocation of the outlet to 
be on the same side as the inlet, and it is evident that the bottom baffles assisted in increasing the mixing at the bottom of the tank which helped discharge the fluid at the bottom of the tank.

It is concluded from this case that simultaneous charging and discharging introduces excessive mixing at the beginning of the test and the level of stratification is comparable to an initially fully mixed discharged tank under charging conditions. The best performing designs are Tanks 3, 4, and 6 which have approximately the same level of stratification. Tank 8 underperforms the best performing tanks by about $15 \%$. The simulations show that the closer the proximity of the top inlet and outlet, the faster the response of the top outlet temperature and better agreement with the perfectly stratified top outlet temperature. Moreover, relocating the outlet in the tank from across of the bottom baffle to underneath the bottom baffle eliminated the stagnant fluid at the bottom of the tank. Lastly, it should be noted that a tank experiencing simultaneous charging and discharging is very similar to a tank experiencing only charging in which the charging inlet mass flow rate is slightly lower and the response is slower.

\subsubsection{Case 5: Charge a Pre-stratified Tank with Decreasing Charging Inlet Temperature}

The charging inlet temperature experienced by the tanks at the DLSC continuously changes throughout the charging cycle. From morning to noon, the incident solar radiation on the solar collectors increases, resulting in an increase in the charging inlet temperature. The opposite happens later in the day when the incident solar radiation on the solar collectors decreases resulting in a decrease in the charging 
inlet temperature. From our previous understanding of the main factors that destroy stratification within a tank, it is expected that the plume entrainment generated by the decreasing inlet temperature during the later hours of the day will have a more pronounced impact on the level of stratification within the tank. As a result, it is essential to gain a better understanding of the transient temperature profile and fluid flow within the tank when the tank experiences a decreasing inlet temperature.

As shown in Figure 4.17, the charging simulation is focused on the hot tank. The tank being studied is initially pre-stratified with a linearly decreasing temperature of $70^{\circ} \mathrm{C}$ at the top of the tank and $55^{\circ} \mathrm{C}$ at the bottom of the tank. The inlet charging temperature is linearly decreasing from $80^{\circ} \mathrm{C}$ to $60^{\circ} \mathrm{C}$ within the first two hours of the simulation with a constant flow rate of $14 \mathrm{~L} / \mathrm{s}$. The inlet charging temperature is set to $60^{\circ} \mathrm{C}$ and a mass flow rate of $14 \mathrm{~L} / \mathrm{s}$ from 2 hours into the simulation till the end. The total simulation time is 3 hours; tank turn over time is about 2.58 hours.

It is expected that the tank will experience slightly more mixing than usual within the first hour because the inlet temperature is decreasing which mixes with the warmer fluid that was previously injected into the tank. After about 60 minutes from the beginning of the simulation, it is expected that the tank will experience excessive mixing because the temperature of the inlet fluid is lower than the temperature of the fluid at the top of the tank, which leads to plume entrainment. Plume entrainment is expected to mix the entire tank volume, because stratifiers are not employed in the simulation to help deliver the inlet fluid to the correct fluid layer.

The tanks chosen to be tested for this case are Tanks 1 to 4,6 and 8. Tank 1 and 2 are investigated in this case because it is expected that a middle baffle can have an effect on the level of stratification within the tank when the inlet temperature 
is decreasing since the middle baffle will restrict the mixing to a fewer temperature layers. Tank 5 is not considered in this case because from previous simulations it was concluded that the performance of Tanks 3 and 5 are very similar.

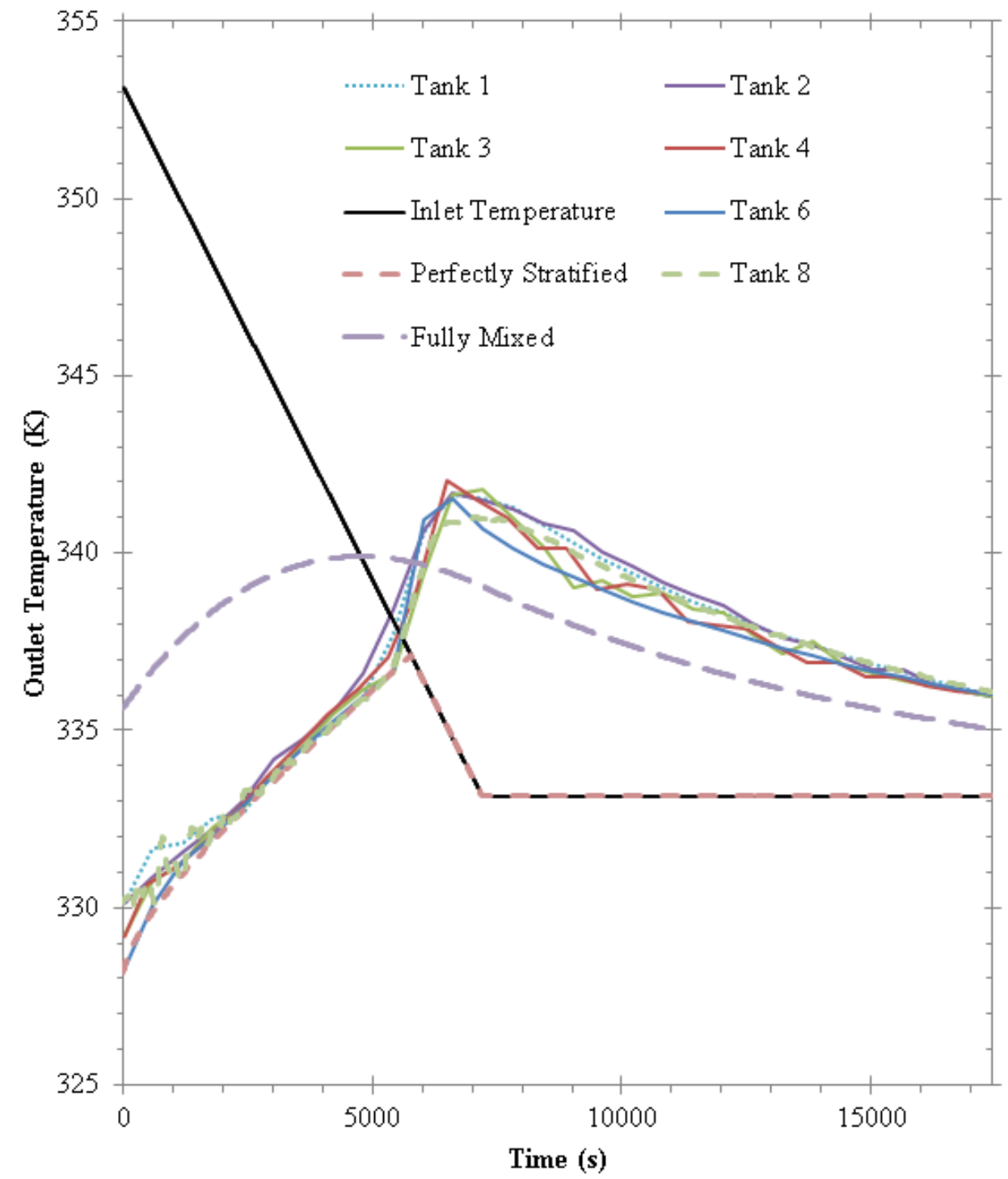

Figure 4.36: Transient temperature of fluid leaving the bottom of the tank for 6 different designs during simulation of Case 5 


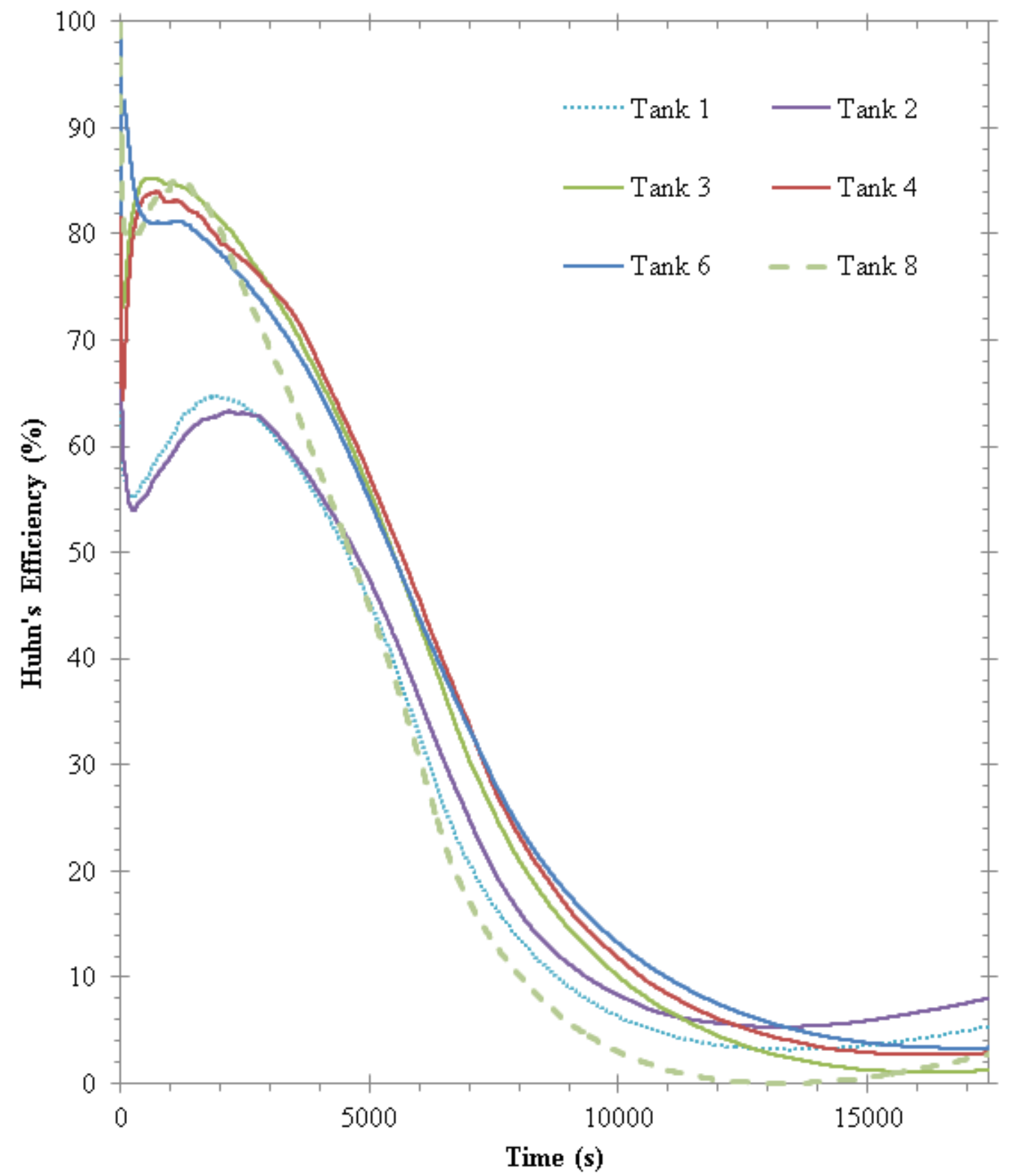

Figure 4.37: Huhn's efficiency for 6 different designs during simulation of Case 5 


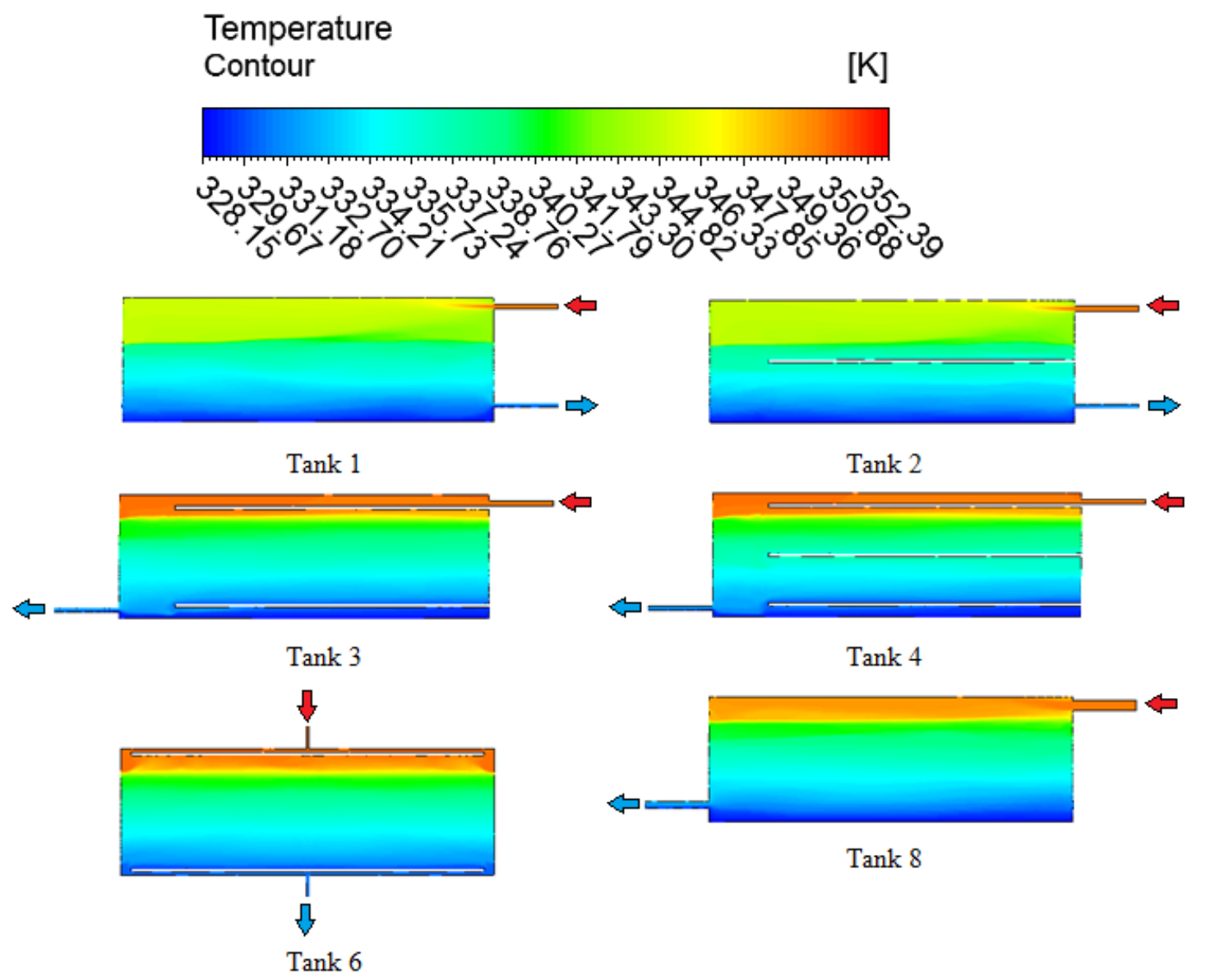

Figure 4.38: Temperature contour plot of 6 different designs 15 minutes into simulation of Case 5. Inlet jet mixing taking place at the top of the tank degrading the level of stratification. 


\section{Temperature}

Contour $\quad[\mathrm{K}]$
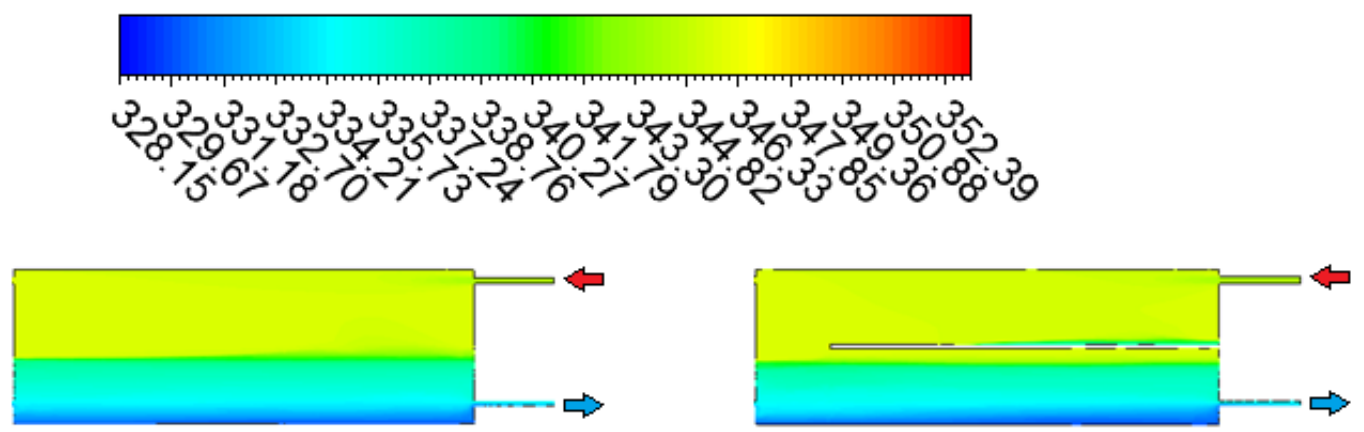

Tank 1

Tank 2

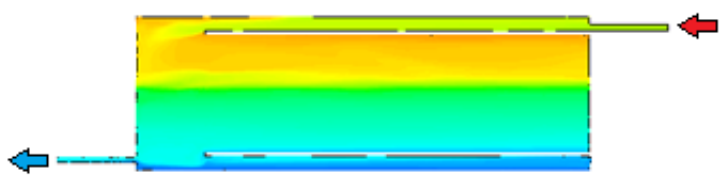

Tank 3

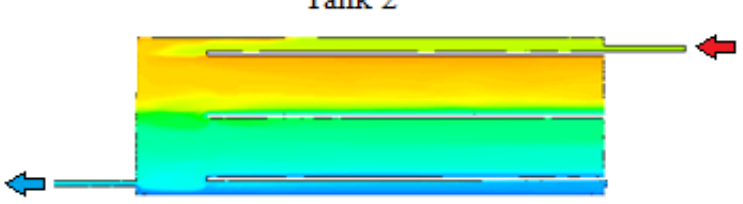

Tank 3

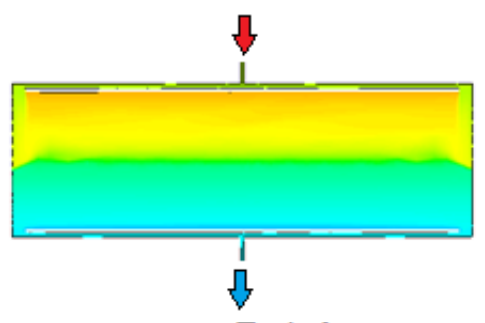

Tank 4

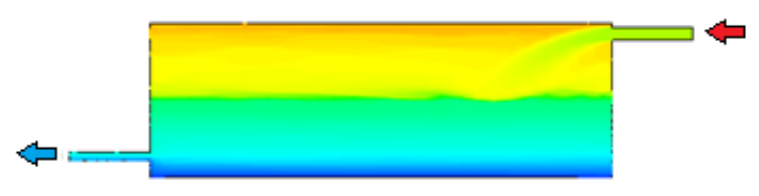

Tank 8

Tank 6

Figure 4.39: Temperature contour plot of 6 different designs 55 minutes into simulation of Case 5. Plume entrainment resulting in excessive mixing. 
Temperature Contour [K]
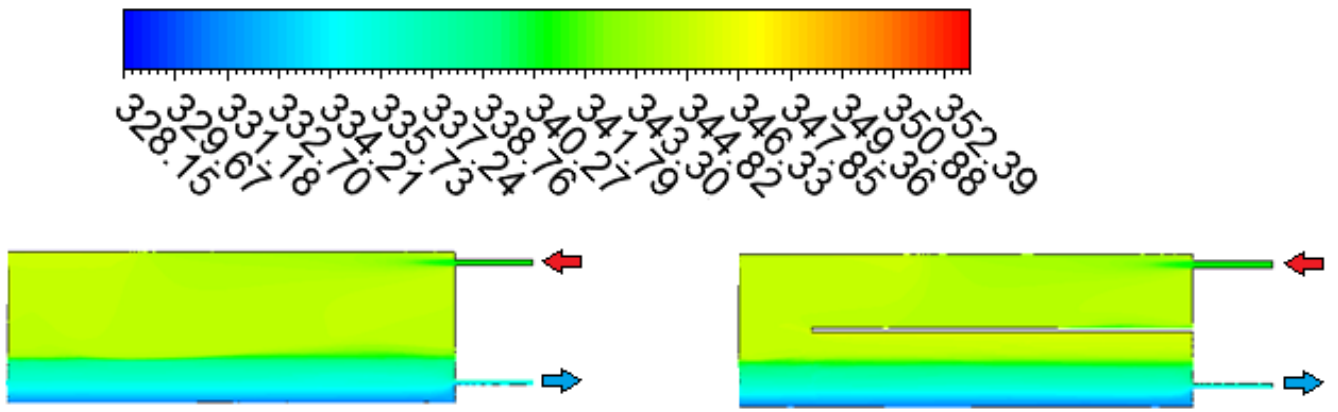

Tank 1

Tank 2

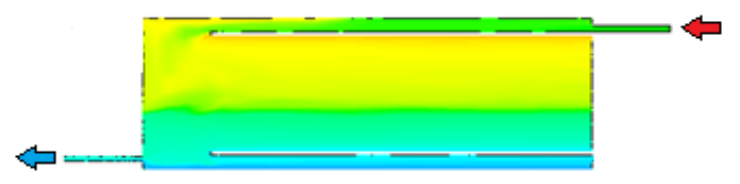

Tank 3
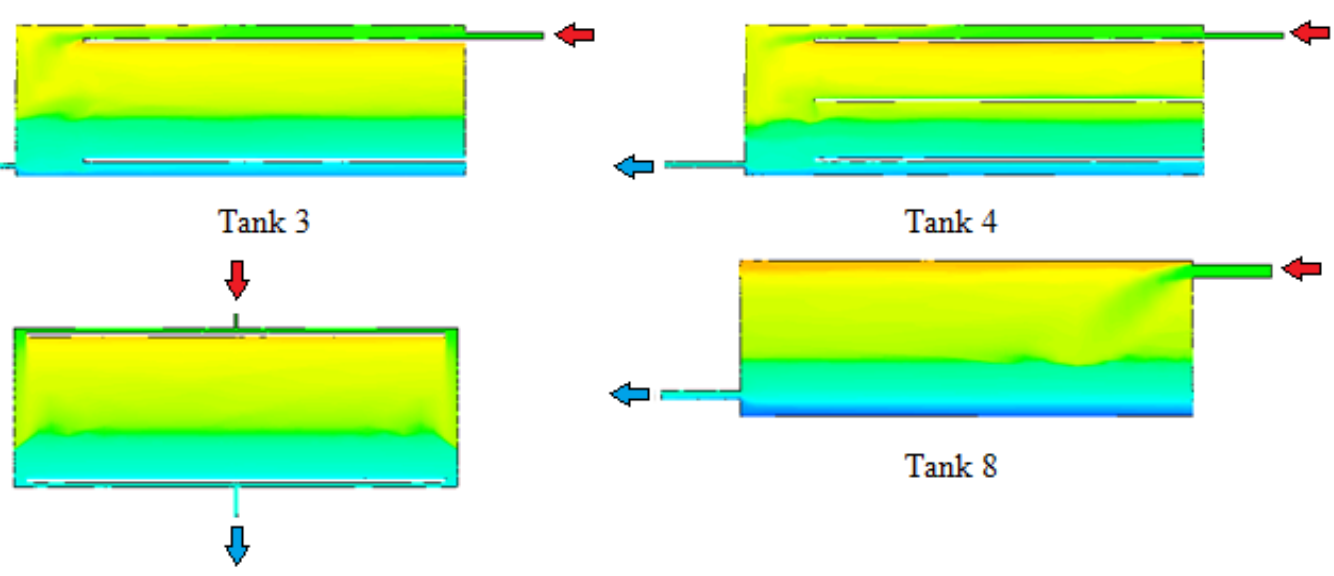

Tank 4

Tank 6

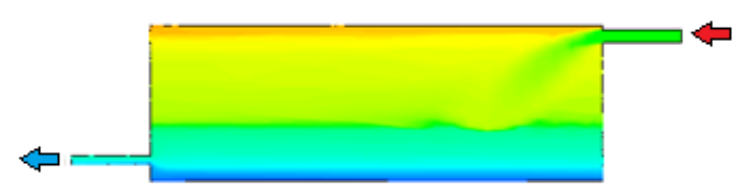

Tank 8

Figure 4.40: Temperature contour plot of 6 different designs 1.25 hours into simulation of Case 5. The inability for the middle baffle to reduce the damage generate from plume entrainment. 
Temperature

Contour

$[\mathrm{K}]$

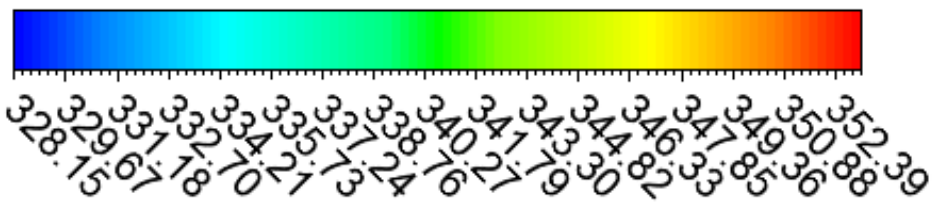

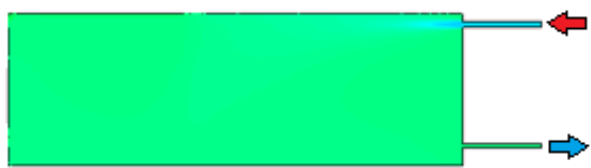

Tank 1

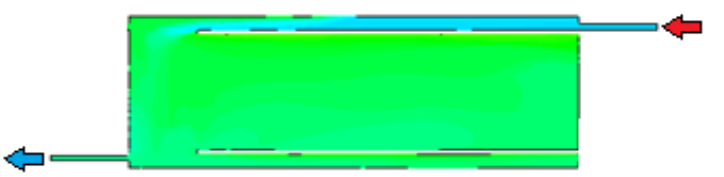

Tank 3

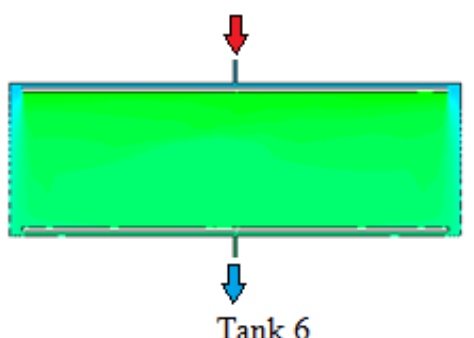

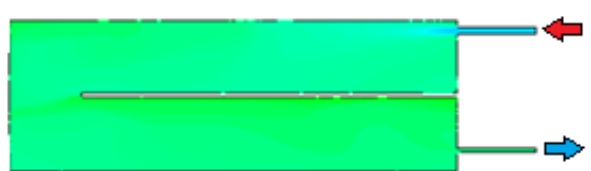

Tank 2

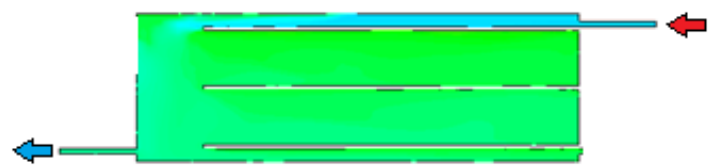

Tank 4

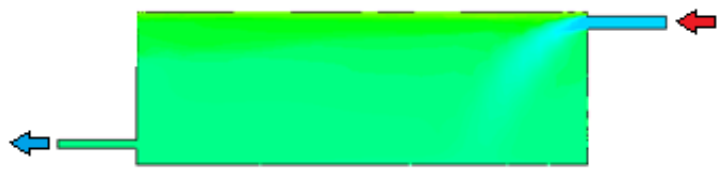

Tank 8

Figure 4.41: Temperature contour plot of 6 different designs 3 hours into simulation of Case 5. Plume entrainment completely mixes the tank.

Figure 4.36 presents the transient outlet temperature of the tank during charging a pre-stratified tank with decreasing charging inlet temperature and clearly shows that all the tank designs result in similar transient outlet temperature. In addition, all tanks have a performance very close to a perfectly stratified tank up to 1.7 hours and then divert far away from a perfectly stratified solution. This is confirmed by Figure 4.37, where Huhn's efficiency for all the different tank designs drops dramatically starting from around 50 minutes into the simulation. This agrees with our 
expectations that after 60 minutes from the start of the simulation, the tank inlet temperature will be lower than the temperature at the top of the tank leading to the initiation of plume entrainment. According to Figure 4.39, this drop is a result of the plume entrainment that causes more mixing as time progresses because the inlet temperature is decreasing within the first two hours. Huhn's efficiency in Figure 4.37 clearly shows that the tanks become almost fully mixed because the efficiency is approaching zero. This is evident in the difference between Figure 4.39 and Figure 4.40 (about 30 minutes apart), the tank experienced a significant amount of mixing leading to the loss of the top hot temperature layers. Moreover, Figure 4.41 confirms that by the end of the simulation all tanks are fully mixed. Furthermore, Figure 4.37 shows that initially the tank experiences some mixing and this is due to the inlet jet, shown in Figure 4.38. However the rate of exergy destruction drops dramatically for all tanks between 17 to 34 minutes and this can be attributed to the hot inlet jet mixing with warmer fluid and this is responsible for the increase in Huhn's efficiency.

As a result, all tank designs have the same performance for a case where the inlet charging temperature decreases over time. As the temperature starts to decrease, the tanks start to approach a fully mixed tank solution. It can be concluded that all tanks have very poor performance, and in order to help sustain the level of stratification during a decreasing charging inlet temperature, the tank must be equipped with a stratifier which would deposit the inlet fluid at approximately the correct level in the tank to maintain stratification. 


\subsubsection{Case 6: Simultaneous Charging and Discharging a Pre- stratified Tank with Decreasing Charging Inlet Tem- perature}

It was understood that charging with a decreasing inlet temperature will lead to excessive mixing, and eventually a fully mixed STTS tank. However, at DLSC, the tank is always under simultaneous charging and discharging, therefore, it is necessary to study the effect of simultaneous charging and discharging while experiencing a decreasing inlet temperature. This case is expected to provide a better understanding of the mixing patterns that occur during simultaneous charging and discharging.

As shown in Figure 4.29, the tank being studied is the hot tank at the DLSC, where the tank is charging from the solar collector loop and the discharging to the space heating loop. The tank is initially pre-stratified with a linearly decreasing temperature of $70^{\circ} \mathrm{C}$ at the top of the tank and $55^{\circ} \mathrm{C}$ at the bottom of the tank. The inlet charging temperature is linearly decreasing from $80^{\circ} \mathrm{C}$ to $60^{\circ} \mathrm{C}$ within two hours from the start of the simulation with a constant flow rate of $14 \mathrm{~L} / \mathrm{s}$. The discharging mass flow rate is $6 \mathrm{~L} / \mathrm{s}$. The total simulation time is 5 hours; tank turn over time is about 4.5 hours.

Similar to Case 5, it is expected that the tank will experience excessive mixing after about 60 minutes from the beginning of the test. This can be attributed to plume entrainment. Plume entrainment is expected to mix the entire tank volume, because as the inlet fluid sinks to the correct fluid temperature, it will mix all the fluid above it leading to a fully mixed tank.

The tanks chosen to be investigated for this case are Tanks 1 to 4,6 and 8 . 


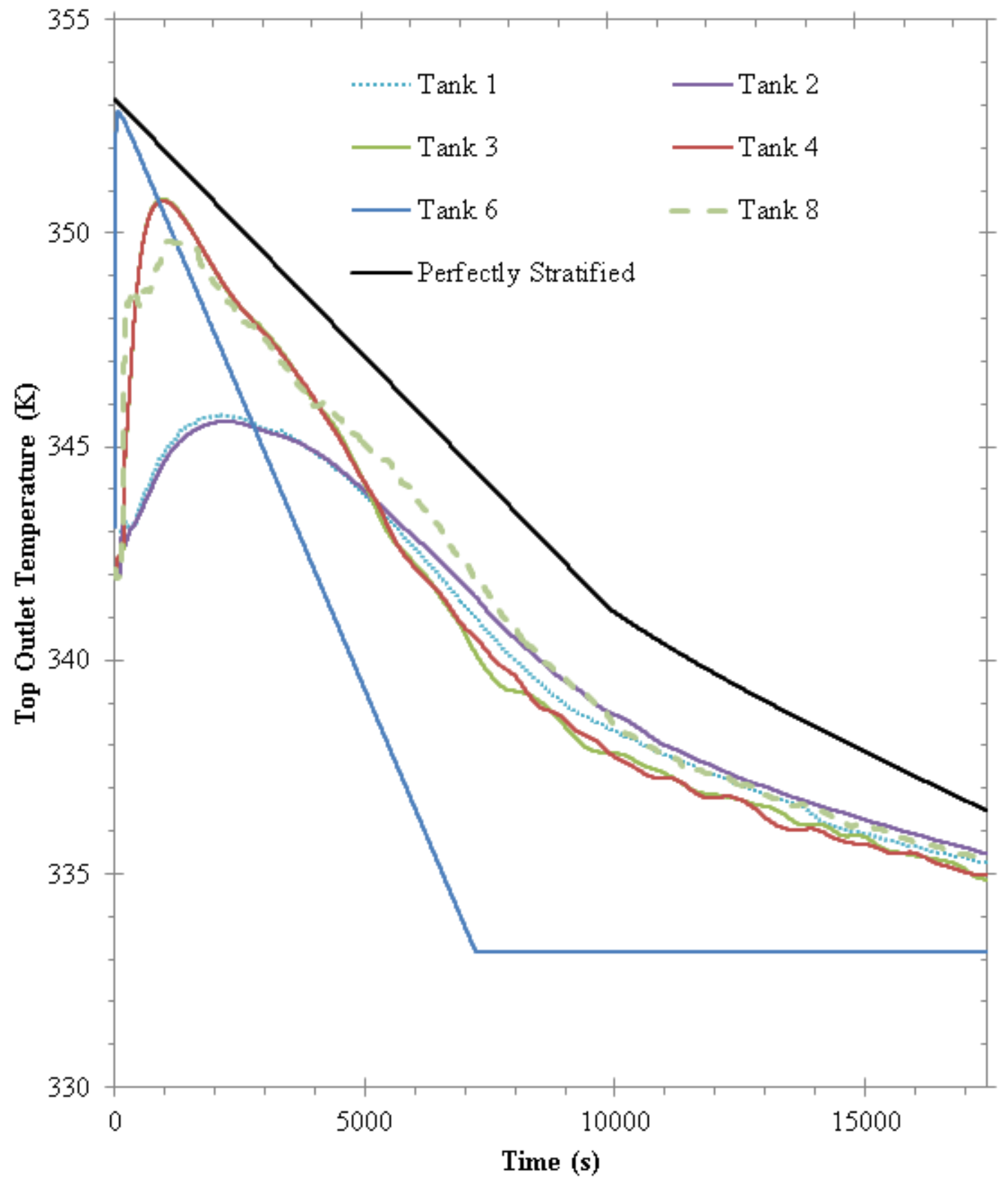

Figure 4.42: Transient temperature of fluid leaving top of the tank for 6 different designs during simulation of Case 6 


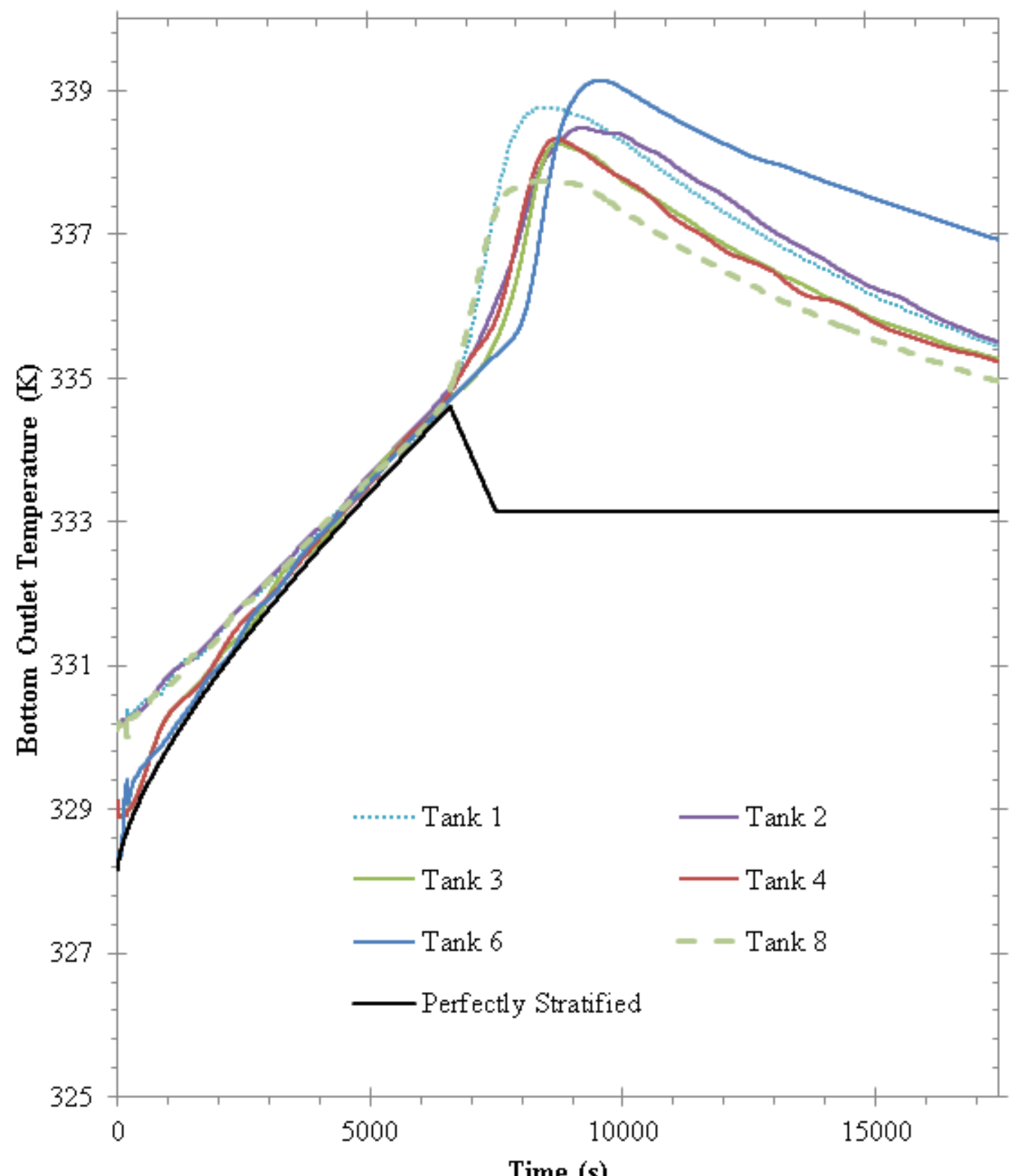

Figure 4.43: Transient temperature of fluid leaving bottom of the tank for 6 different designs during simulation of Case 6 


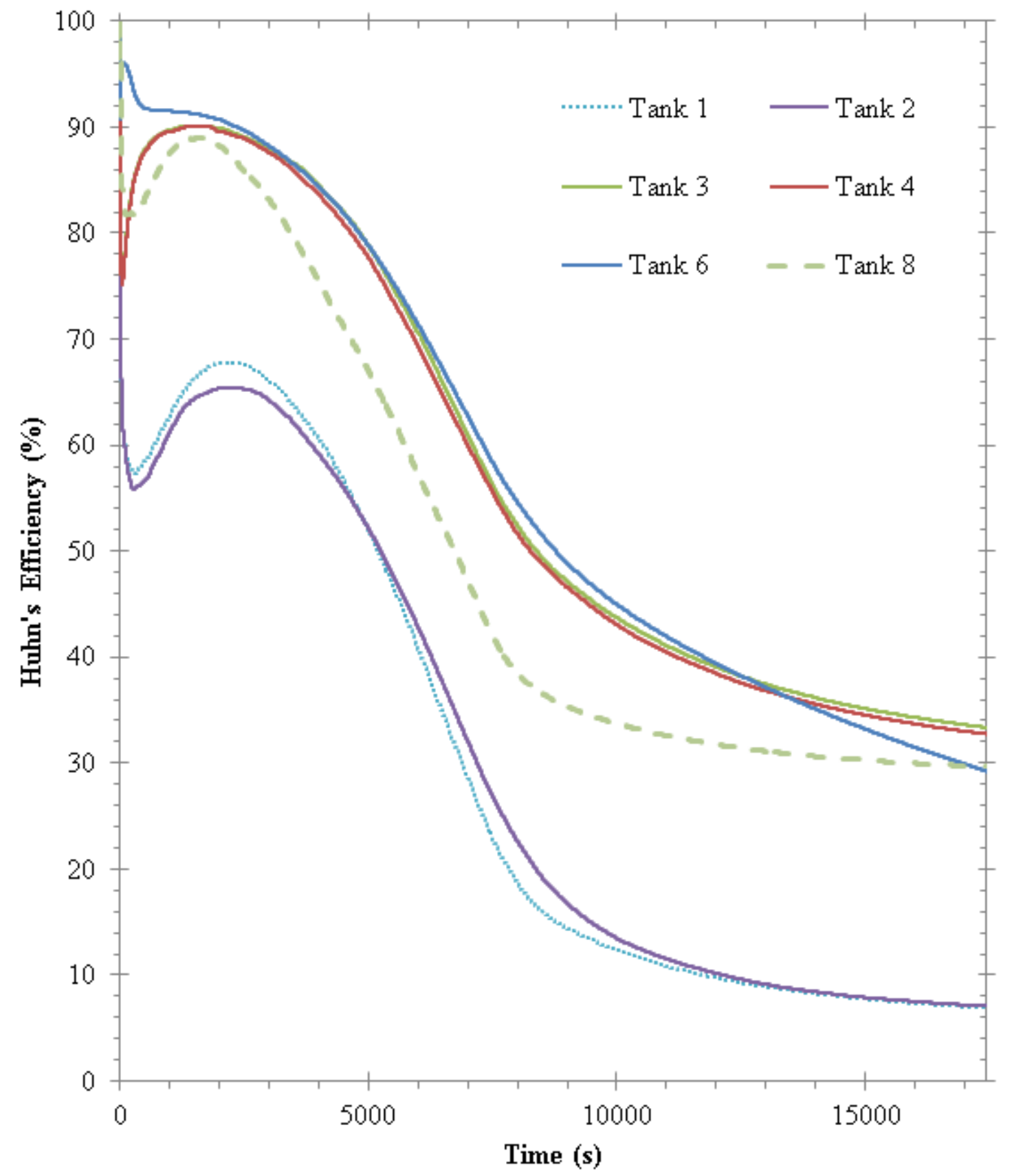

Figure 4.44: Huhn's efficiency for 6 different designs during simulation of Case 6 


\section{Temperature}

Contour

\section{$[\mathrm{K}]$}

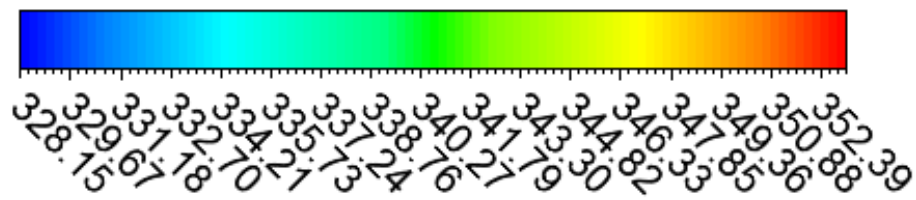

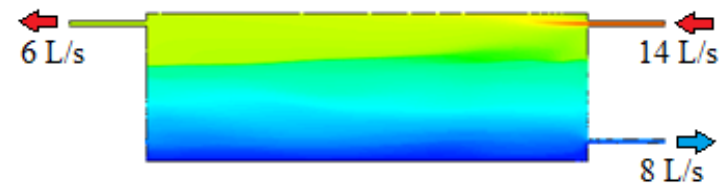

Tank 1

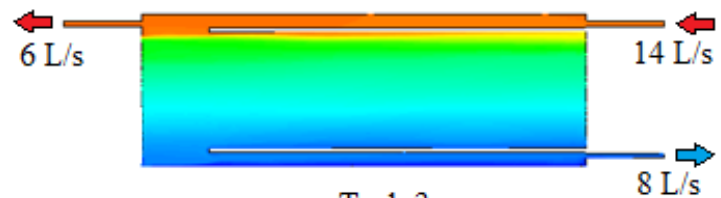

Tank 3

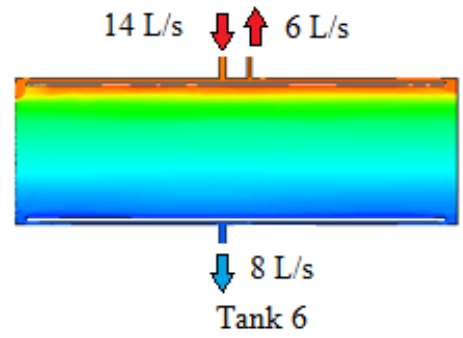

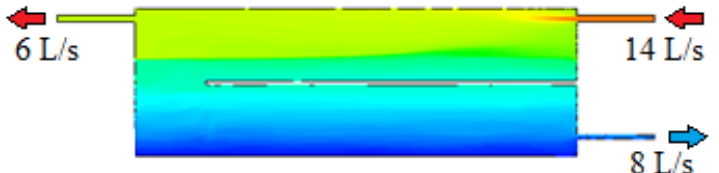

Tank 2

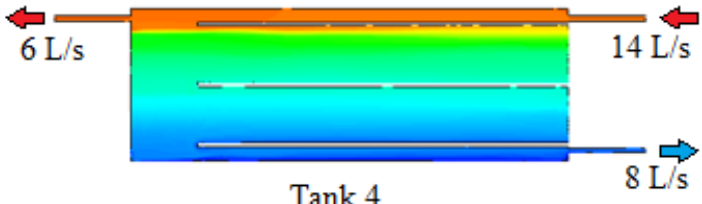

Tank 4

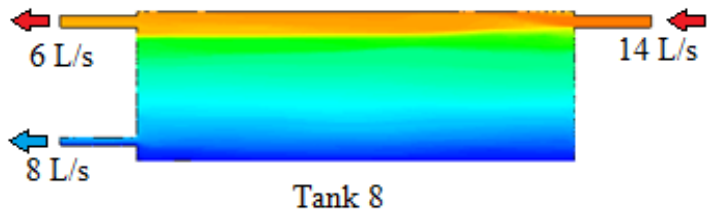

Figure 4.45: Temperature contour plot of 6 different designs 15 minutes into simulation of Case 6. Inlet jet mixing taking place at the top of the tank which contributes to the destratification of the tank. The curves for Tank 3 and 4 overlap. 


\section{Temperature}

Contour

$[\mathrm{K}]$
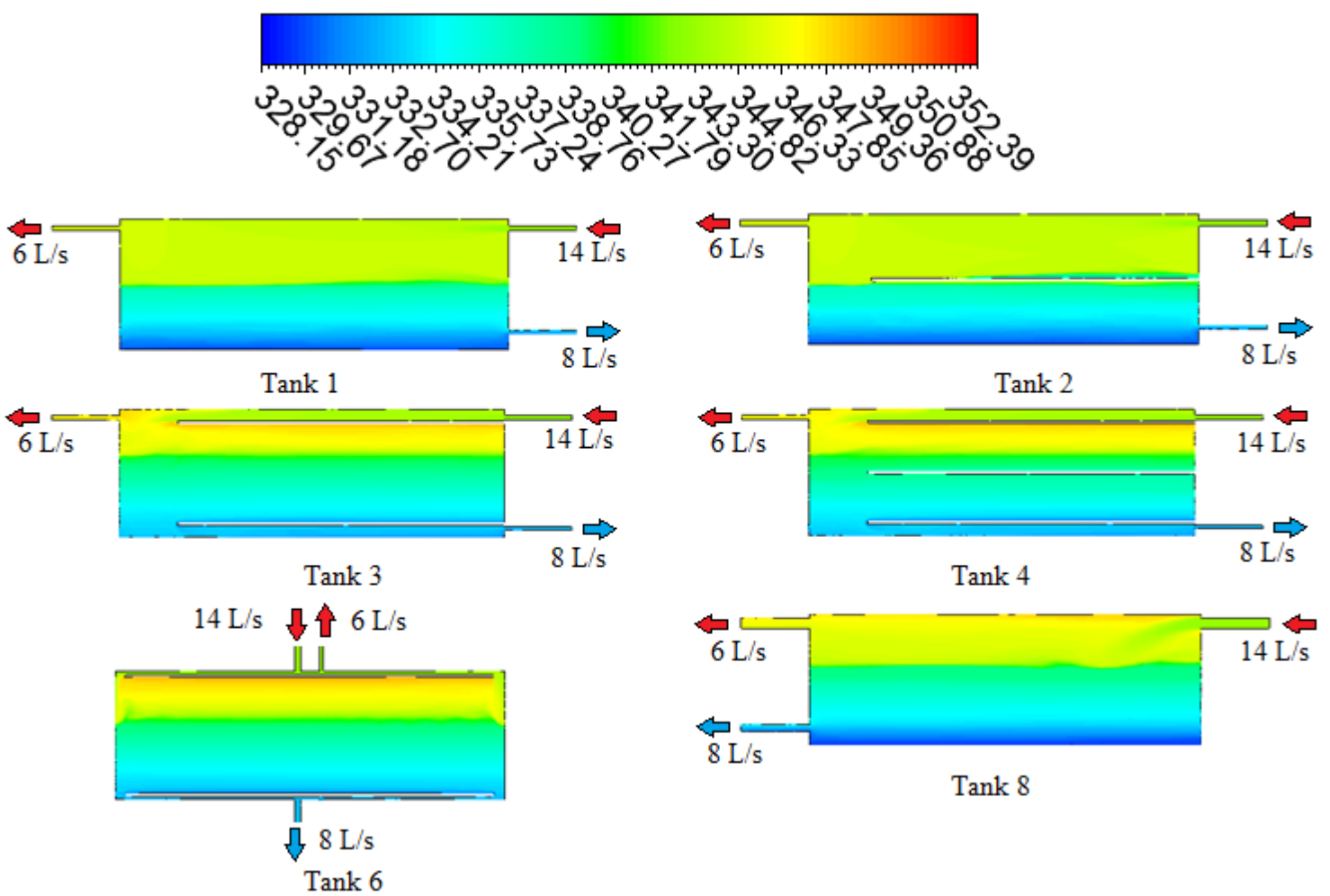

Figure 4.46: Temperature contour plot of 6 different designs 1 hour into simulation of Case 6. Plume entrainment resulting in excessive mixing at the top of the tank. 


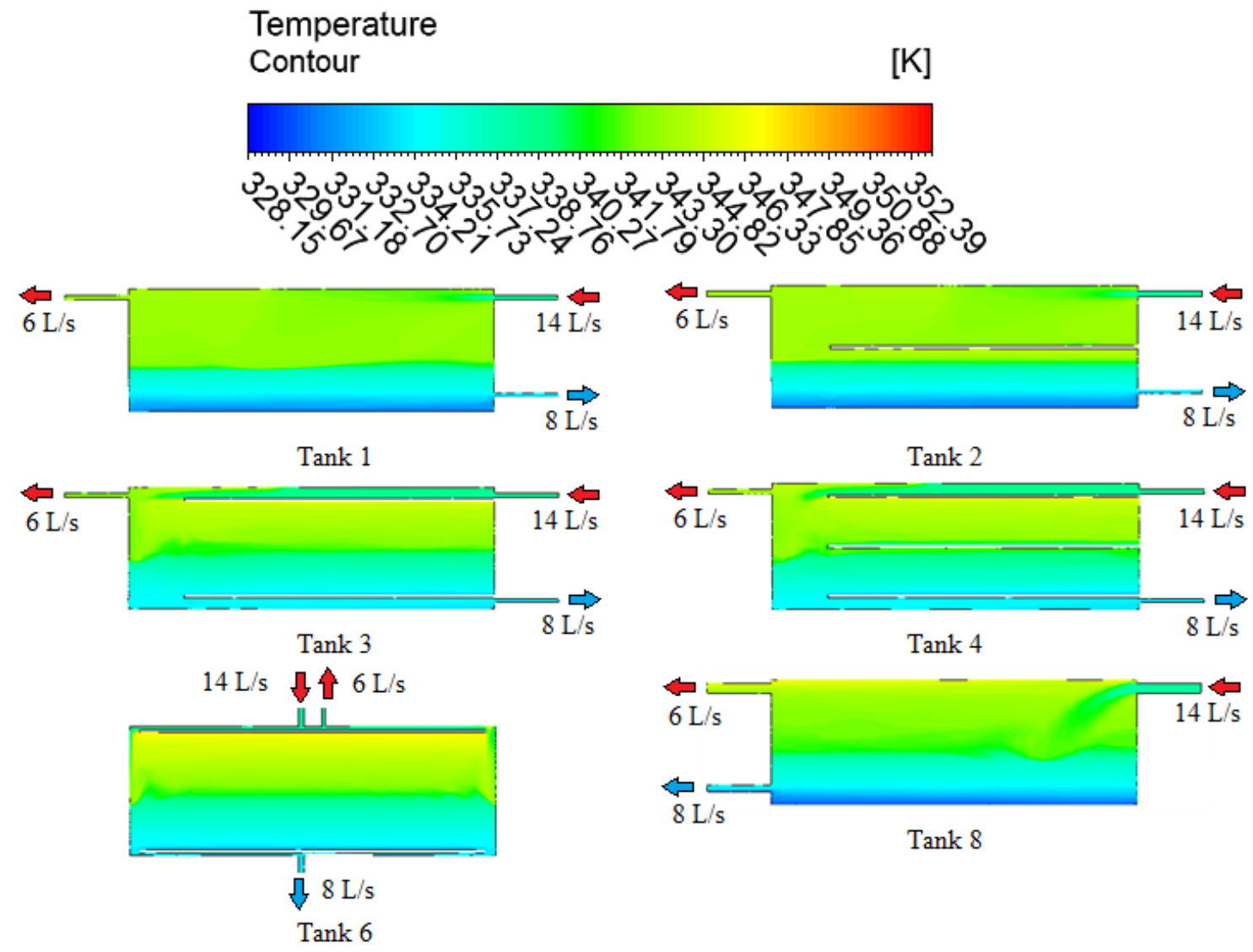

Figure 4.47: Temperature contour plot of 6 different designs 1.5 hours into simulation of Case 6. The middle baffle of Tank 2 is ineffective in reducing the damaging effect of plume entrainment. 


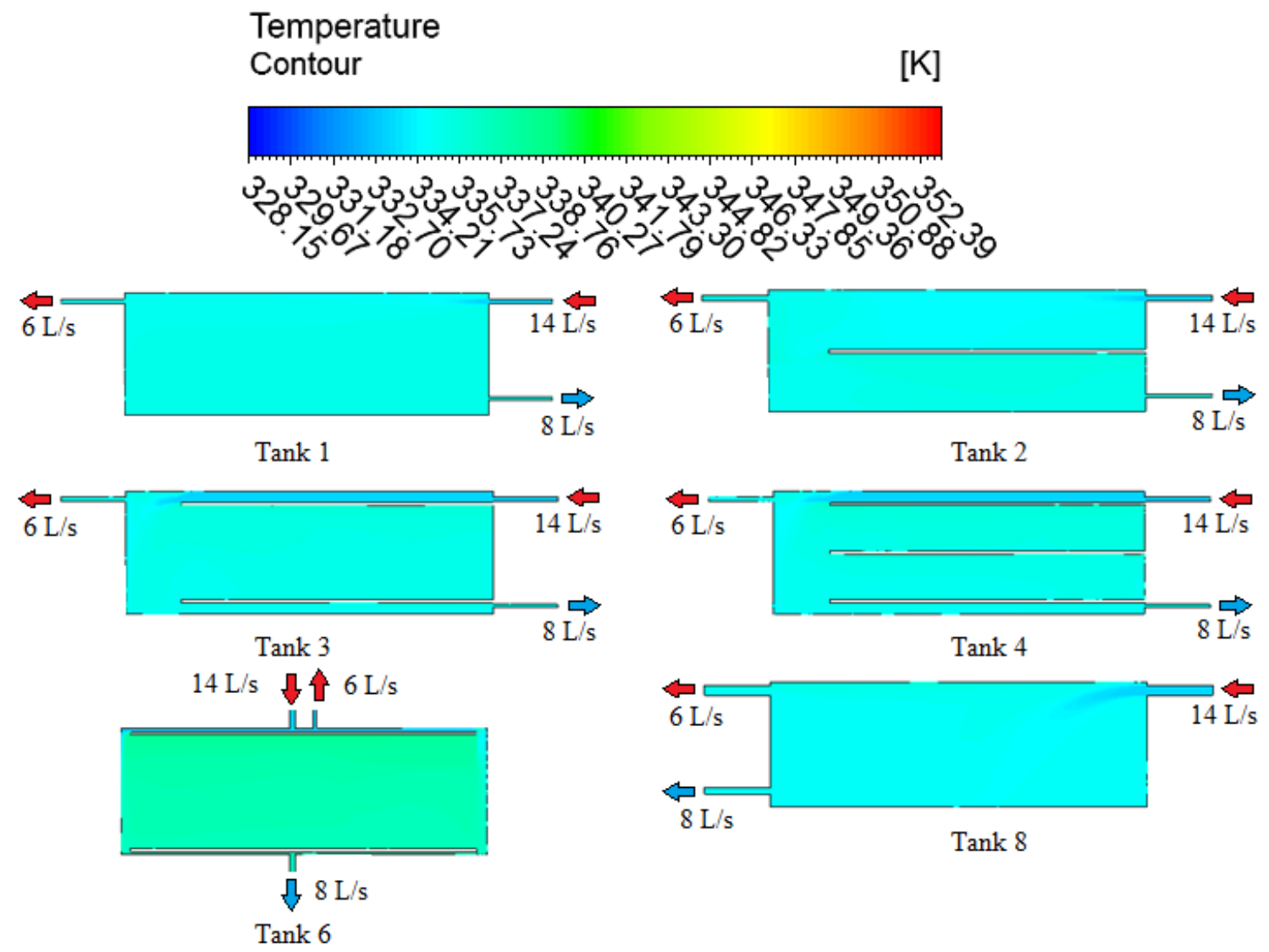

Figure 4.48: Temperature contour plot of 6 different designs 5 hours into simulation of Case 6. The tanks are all completely mixed by the end of the simulation.

Figure 4.42 displays the top outlet temperature of the tank and it shows that all tanks have a performance far away from the perfectly stratified tank. It should be noted that the curves for Tanks 3 and 4 overlap. The furthest tank from a perfectly stratified solution is Tank 6 . This is due to the very close proximity between the inlet jet and the top outlet, so the fluid short circuits between the charging inlet and the top outlet leading to the sharp decrease in the outlet temperature. Tanks 3, 4, and 8 have a similar performance, and they provide the best performance out of all designs. This can be attributed to the location of the top inlet and outlet that are 
far from each other which allows the inlet jet to spread properly and allows for some stratification to occur. The top outlet temperature of Tank 1 and Tank 2 are very similar. They slightly underperform Tanks 3 and 4 , this is due to the lack of baffles that help spread the inlet fluid without creating excessive mixing. Tanks 1 and 2 underperform Tank 8 because of the small inlet diameter that introduces a very fast jet into the tank leading to more mixing.

Figure 4.43 presents the bottom outlet temperature of the tank and it shows that all tanks have a performance very close to the perfectly stratified tank up to about 1.5 hours and then divert far away. It should be noted that Tanks 3 and 4 have almost the same performance and the transient bottom outlet temperatures overlap. Tanks 1, 2, and 8 start far from a perfectly stratified tank and this is due to the location of the bottom outlet being considerably higher from the bottom of the tank, which makes it harder for the outlet to access the cold fluid present below the outlet. Tanks 3 , and 4 have the bottom outlets located lower in the tank and these tanks employ baffles that help extract the cold fluid present below the bottom outlet. Tank 6 follows the perfectly stratified solution closely because of the location of the bottom outlet being at the bottom of the tank, which eliminates stagnant fluid and can discharge the tank layer by layer. After 1.5 hours, the tanks cannot follow the perfectly stratified tank because the perfectly stratified tank short circuits the top inlet and the bottom outlet. This is attributed to the inlet fluid being cooler than all the fluid stored within the tank. However, the designs simulated cannot follow the perfectly stratified profile because as the plume sinks inside the tank to the correct temperature level, it mixes with the fluid above it creating a fully mixed tank.

Figure 4.44 demonstrates Huhn's efficiency and it shows that Tanks 3, 4, 6, and 8 
have a performance of about $40 \%$ while Tanks 1 and 2 have a performance of about 10\%. It should be noted that Tanks 3 and 4 have the same performance and their efficiencies overlap. This suggests that adding a middle baffle does not improve the level of stratification within the tank. This is confirmed by Figure 4.47 where it is clear that there is no notable difference between Tanks 3 and 4 . It was expected that adding a middle baffle will confine the mixing in the tank to a fewer number of temperature layers leading to better stratification within the tank, but the tank did not perform as expected.

All tanks experience an initial drop in the efficiency from the start of the simulation to about 8 minutes and then experience a sharp drop at about 40 minutes. The initial small drop in efficiency is related to the introduction of the fast inlet jet into the tank which creates some mixing, shown in Figure 4.45. The second drop occurs when the inlet jet temperature is colder than the top of the tank, causing it to sink within the tank leading to significant mixing as shown in Figure 4.46. It should be noted that Tank 6 has the best performance until the second sharp drop in efficiency. It starts with a considerably higher efficiency due to its ability to deliver higher top outlet temperature up to 25 minutes, and as time progresses, the top outlet temperature diverts dramatically from the perfectly stratified solution. Tank 3 and Tank 4 experience a larger initial drop than Tank 6 because the inlet jet created a considerable amount of mixing in the beginning of the simulation. These tanks were able to later outperform Tank 6 because of their ability to discharge warmer fluid out of the top outlet. Tank 8 experiences an initial drop in efficiency due to the mixing introduced by the inlet jet and its inability to discharge hot fluid from the top outlet quickly. In addition, it experiences a sharper decrease in the second drop in 
efficiency, and this is due to the lack of baffles because the baffles allow the tank to store warmer fluid under the baffle away from the excess mixing that occurs within the tank. However, since the tank lacks baffles, the plume can then penetrate through all the top temperature layers and create more mixing within the tank. However, it is important to note that the difference in performance is small, about $5 \%$ from the best performing tank. Tanks 1 and 2 have very poor performance compared to the other tanks; this is due to the very fast unconstrained inlet jet that creates more mixing initially. Similarly to Tank 8, the lack of baffles creates more mixing within the tank due to the plume penetration through all the top temperature layers. A general observation is that the tank that experiences more initial mixing has a delayed onset of the second sharp decline in efficiency because when a tank experiences excessive mixing, the top layers of the tank are cooler than a perfectly stratified tank resulting in a delay of the plume entrainment. Again, by the end of the simulation, all tanks are almost fully mixed and there is no sign of stratification, this is clearly displayed in Figure 4.48.

The closer together the charging inlet and the discharging top outlet, the more likely the tank will short circuit resulting in a degradation of the level of stratification in the case of a decreasing charging inlet temperature. The middle baffle adds no significant improvement to the stratification. Tanks $3,4,6$ and 8 have almost the same performance and again this proves that the simple solution of increasing the inlet diameter will have a comparable performance to highly complicated tank designs. The best performing tanks are Tanks 3 and 4 followed by Tank 6 and 8 , the worst performing designs are Tanks 1 and 2. It should be noted that all tanks are fully mixed by the end of the simulation suggesting that a stratifier must be employed in 
order to help maintain the stratification within these tanks.

\subsection{Conclusion}

This chapter introduced nine different tank designs and they were rigorously tested under six different cases. The summary of the cases is provided in Table 4.4. It is

\begin{tabular}{|l|l|l|l|l|l|l|l|l|l|}
\hline Rank & $\# 1$ & $\# 2$ & $\# 3$ & $\# 4$ & $\#$ 5 & $\#$ 6 & $\#$ 7 & $\#$ 8 & $\#$ 9 \\
\hline $\begin{array}{l}\text { Case 1: Discharging a fully } \\
\text { mixed hot tank }\end{array}$ & 6 & 5 & 4 & 3 & 9 & 8 & 7 & 1 & 2 \\
\hline $\begin{array}{l}\text { Case 2: Charging a fully } \\
\text { mixed cold tank }\end{array}$ & 6 & 3 & 5 & 4 & 8 & & & & \\
\hline $\begin{array}{l}\text { Case 3: Discharge a pre- } \\
\text { stratified tank }\end{array}$ & 5 & 3 & 6 & 4 & 8 & & & & \\
\hline $\begin{array}{l}\text { Case 4: Simultaneous } \\
\text { charging and discharging of } \\
\text { a pre-stratified tank }\end{array}$ & 3 & 6 & 4 & 5 & 8 & & & & \\
\hline $\begin{array}{l}\text { Case 5: Charging a pre- } \\
\text { stratified tank with decreas- } \\
\text { ing charging inlet tempera- } \\
\text { ture }\end{array}$ & 6 & 4 & 3 & 2 & 1 & 8 & & & \\
\hline $\begin{array}{l}\text { Case 6: Simultaneous } \\
\text { charging and discharging of } \\
\text { a pre-stratified tank with } \\
\text { decreasing charging inlet } \\
\text { temperature }\end{array}$ & 3 & 4 & 8 & 6 & 1 & 2 & & & \\
\hline
\end{tabular}

Table 4.4: Summary of results of the performance of nine different design undergoing six different test cases

clear that the best performing designs are Tank 6 , Tank 3 and its enhanced versions Tanks 4 and 5. Tank 6 has the best performance because the outlets are moved to the top and the bottom of the tank in order to eliminate stagnant fluid that is not easily discharged. In addition, Tank 6 has reduced the distance between the baffle and the ports. This decreased the volume that can be mixed when the inlet jet 
is introduced into the tank. Tank 3 and its enhanced versions are among the best performing designs because they employ horizontal baffles that allow the inlet jet to spread horizontally but not vertically which helps reduce the jet speed while reducing the mixing that takes place within the tank. Tank 5 had slightly better performance than Tank 3 because the redirecting baffles help the fluid turn inside the tank which help reduce the mixing that occurs. However, the addition of the redirecting baffles did not contribute to a notable improvement in the performance. As a result, it is recommended to use Tank 3 instead of Tank 5 due to its simplicity. Tank 4 slightly underperformed Tank 3, and this is attributed to the middle baffle that stagnated a pocket of fluid around it, destroying the layering of the water, leading to a reduction in the level of stratification of the tank. Tanks 8 and 9 slightly underperformed the best performing designs, but it should be recognized that these designs are the simplest to implement. Tank 7 did not perform as expected and was not able to spread the fluid along the baffle and created excessive mixing within the tank. Tanks 1 and 2 had a similar performance, and they are the poorest performing tanks. This suggests that the addition of a middle baffle into a tank has little to no effect on the level of stratification within the tank.

It can also be concluded that the tank that is enhanced for charging will be enhanced for discharging because the same mechanisms are in use for both cases. It should be noted that this is only applicable for a case where the Richardson number during charging and discharging are similar, such as the cases that were investigated. In addition, simultaneous charging and discharging with constant charging inlet temperature is very similar to only charging but with a lower inlet velocity. The performance of the tanks is closely related to the proximity of the top inlet and the top 
outlet due to short circuiting that might occur if the inlet and outlet are very close. Most importantly, it is observed that none of the designs considered were able to maintain its level of stratification when experiencing a decreasing inlet temperature, and all tank designs were fully mixed by the end of the simulation. This suggests that further investigations need to be conducted in order to improve the stratification of the tank during decreasing charging inlet temperature. 


\section{Chapter 5}

\section{Conclusion and Future Work}

Due to the mismatch between the availability of solar energy and the demand, there is a need for effective thermal energy storage. Previous research has shown that a highly stratified tank can act to increase overall system efficiency since stratification allows for high temperature water to be available to the load and cold water to be sent to the collector. This thesis has been concerned with a CFD study of the thermal performance of large horizontal tanks. It is motivated by the system at DLSC which includes two large STTS tanks.

\subsection{Performance of the Large Horizontal STTS Tank Designs}

A three dimensional CFD model was generated for nine different tank designs, three of which were previously existing designs and six were new designs. The nine tanks 
designs are shown in Figure 5.1. These designs were rigorously tested during discharging, charging, simultaneous charging and discharging, discharging a prestratified tank, charging with decreasing inlet temperature and simultaneous charging and discharging with a decreasing charging inlet temperature. The best performing designs are Tank 6, and Tank 3. Tank 6, which is a new design, relocated the ports to the top and the bottom of the tank in order to eliminate stagnant fluid that is not easily discharged. The design also incorporated horizontal baffles close to the inlet and outlet ports. The baffles acted to confine the mixing by the inlet jet. Tank 3, recommended by Rysanek [6], used horizontal inlets and outlets together with horizontal baffles. It was found that the tanks experience excessive mixing near the inlet jet and always have stagnant fluid below the outlet during charging or above the outlet during discharging. The stagnant fluid is eliminated when the outlet location was moved from across the baffle to above the top baffle or below the bottom baffle. Tanks 4 and 5 incorporated a middle baffle and redirecting baffles respectively have a similar performance to Tank 3. As a result, Tank 3 is determined to be a better option because of its relative simplicity due to the implementation of fewer baffles. Tanks 8 and 9 are tanks without baffles with horizontal inlets and outlets, discharging inlet diameters are $200 \mathrm{~mm}$ and $400 \mathrm{~mm}$ respectively. They slightly underperformed the best performing designs, but it should be recognized that these designs are the simplest to implement due to the lack of baffles. Tank 7 is a tank with horizontal inlets and outlets and with two vertical baffles. The inlet fluid impinges on the vertical baffle, allowing the inlet jet to spread while confining the mixing within the tank. The tank did not perform as expected and created excessive mixing within the tank. Tank 1 does not contain baffles and has horizontal inlets and outlets, and Tank 2 has 
horizontal inlets and outlets and a baffle located in the middle of the tank. Tank 2 is the current STTS tank at DLSC. Tanks 1 and 2 have a similar behaviour, and they are the poorest performing designs. Since Tanks 1 and 2, and Tanks 3 and 4 have a similar performance, this suggests that adding a middle baffle to a tank has little to no effect on the level of stratification.

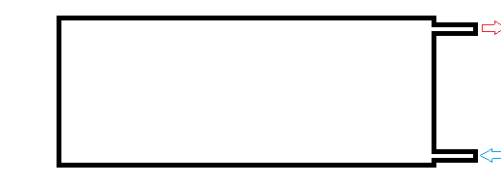

Tank 1

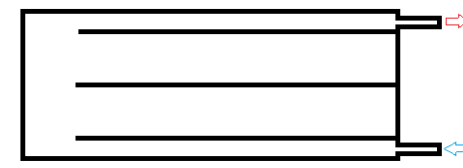

Tank 4

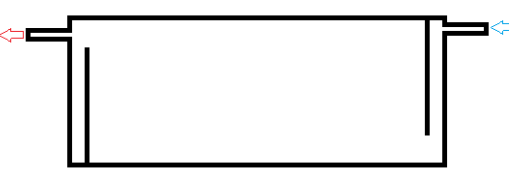

Tank 7

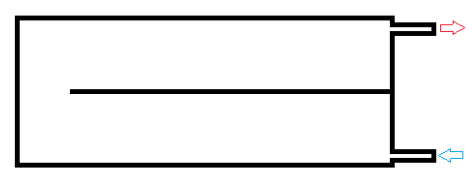

Tank 2

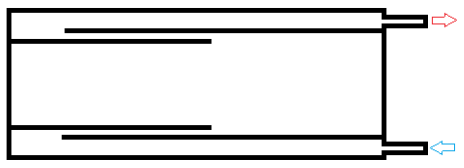

Tank 5

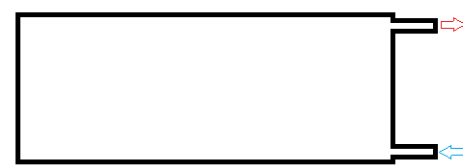

Tank 8

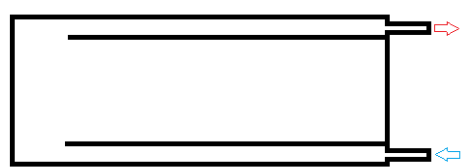

Tank 3
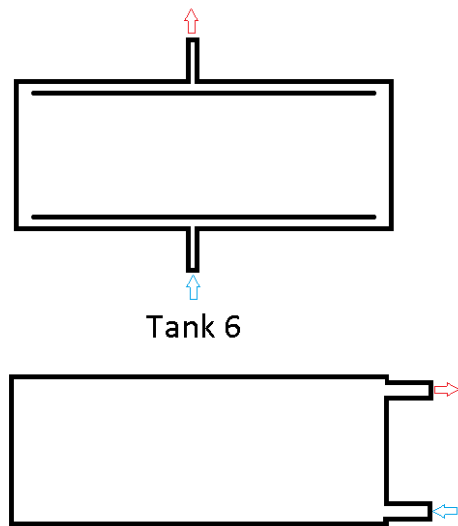

Tank 9

Figure 5.1: Summary of all tanks investigated (Not to scale)

\subsection{Analysis of the Cases Utilize to Test the STTS Tank Designs}

Simulations of the discharging of a fully charged tank confirms that the current tank at the DLSC experiences excessive mixing during discharging. This is mainly caused by the inlet jet spreading in the vertical direction and entraining hot fluid into the 
cold jet stream.

The performance of the tanks for both charging and discharging was similar. This was a result of the similarity of the flow rates and hence similar Richardson numbers.

The performance of the tank experiencing simultaneous charging and discharging at constant temperature is very similar to a tank experiencing only charging in which the charging inlet mass flow rate is slightly lower and the tank response is slower. The simulations also show that the closer the proximity of the top inlet and outlet to each other, the faster the response of the top outlet temperature. This is because the fluid will essentially "short circuit" the tank. This yields better agreement with the perfectly stratified tank.

The most challenging case for stratification was when the inlet charging temperature decreased with time. This situation can occur in the afternoon when solar energy irradiation is reduced. Simulations predicted that none of the tanks are able to sustain the initial level of stratification when the inlet charging temperature drops below the temperature at the top of the tank. Plume entrainment mixes the tank and by the end of the simulation, all the tanks approached a fully mixed tank solution. Moreover, when this condition was applied for simultaneous charging and discharging, it was seen that the close proximity of the top inlet and outlet ports, results in cooler water exiting the tank as a result of short circuiting. Thus the short circuiting was beneficial when the inlet temperature was high, but resulted in lower outlet temperatures when the inlet temperature dropped below the highest tank temperature. 


\subsection{Recommendations for Future Work}

- Investigating the use of baffles or diffusers in order to help stratify the tank when charging with a decreasing inlet temperature

- Investigating the best location of inlet or outlet ports for simultaneous charging and discharging.

- Obtain an adaptive structured mesh that is refined at the thermocline and coarsened away from the thermocline

- Test the impact of adding multiple baffles in the middle of the tank on stratification during charging with a decreasing inlet temperature

- Test the impact of the length of the baffle and the distance from the top or bottom of the tank on the level of stratification, for Tank 6 geometry

- Test the impact of changing the inlet diameter to $200 \mathrm{~mm}$ for Tanks 3 and 6 on the level of stratification 


\section{Bibliography}

[1] R. Perez. A Way to the Most Abundant Energy, 2013. URL http://www.scientificamerican.com/article/a-way-to-the-most-abundant-energy/.

[2] Energy Efficiency Trends in Canada, 1990 to 2009, 2012. URL http://oee.rncan.gc.ca/publications/statistics/trends11/chapter3.cfm?attr=0.

[3] McClenahan-D. Djebbar R. Thornton J. Wong B. Carriere J. Sibbitt, B. and J. Kokko. The Performance of a High Solar Fraction Seasonal Storage District Heating System-Five Years of Operation. Energy Procedia, 30:856-865, 2012.

[4] Statistics Canada. Table 3-2: Household energy use, by fuel type and by province, 2011 Average energy use, 2013. URL http://www. statcan.gc.ca/pub/11-526-s/2013002/t004-eng.htm.

[5] A Numerical Study of Thermal Stratification in Solar Energy Storage Tanks,. Master's thesis.

[6] A.M. Rysanek. Second Law Performance Analysis of a Large Thermal Energy Storage Vessel Using CFD. 2009.

[7] B. Sibbitt. Private communication, 2012. 
[8] K.G.T. Hollands and M.F. Lightstone. A Review of Low-Flow, Stratified-Tank Solar Water Heating Systems. Solar Energy, 43(2):97-105, 1989.

[9] Morad-S. Ratzon Y. Ziskind G. Aviv, A. and R. Letan. Experimental and Numerical Study of Mixing in a Horizontal Hot-Water Storage Tank. Journal of Solar Energy Engineering, 131(3):031004, 2009.

[10] L.J. Shah and S. Furbo. Entrance Effects in Solar Storage Tanks. Solar Energy, 75(4):337-348, 2003.

[11] Danish Jalal Nizami. Computational Fluid Dynamics Study and Modelling of Inlet Jet Mixing in Solar Domestic Hot Water Tank Systems. Master's thesis, McMaster University, 2010.

[12] Z. Lavan and J. Thompson. Experimental Study of Thermally Stratified Hot Water Storage Tanks. Solar Energy, 19(5):519-524, 1977.

[13] Mech-A.R. Sliwinski, B.J. and T.S. Shih. Stratification in Thermal Storage During Charging. In 6th International Heat Transfer Conference, Toronto, volume 4, pages 149-154, 1978.

[14] Holzer-J.C. Gari H.N. Loehrke, R.I. and M.K. Sharp. Stratification Enhancement in Liquid Thermal Storage Tanks. Journal of Energy, 3(3):129-130, 1979.

[15] Y.H. Zurigat, P.R. Liche, and A.J. Ghajar. Influence of Inlet Geometry on Mixing in Thermocline Thermal Energy Storage. International Journal of Heat and Mass Transfer, 34(1):115-125, 1991.

[16] A.J. Ghajar and Y.H. Zurigat. Numerical Study of the Effect of Inlet Geometry 
on Stratification in Thermal Energy Storage. Numerical Heat Transfer, 19(1): 65-83, 1991.

[17] L.P. Chauvet, S.D. Probert, and D.J. Nevrala. Thermal-Energy Stores for Supplying Domestic Hot-Water and Space-Heating. Applied energy, 48(2):163-190, 1994.

[18] Ghajar-A.J. Zurigat, Y.H. and P.M. Moretti. Stratified Thermal Storage Tank Inlet Mixing Characterization. Applied Energy, 30(2):99-111, 1988.

[19] A Zachar, I Farkas, and F Szlivka. Numerical Analyses of the Impact of Plates for Thermal Stratification Inside a Storage Tank With Upper and Lower Inlet Flows. Solar Energy, 74(4):287-302, 2003.

[20] Arslan-M. Ozceyhan V. Altuntop, N. and M. Kanoglu. Effect of Obstacles on Thermal Stratification in Hot Water Storage Tanks. Applied thermal engineering, 25(14):2285-2298, 2005.

[21] Altuntop-N. Ozceyhan V. Arslan, M. and M. Kanoglu. Optimum Dimensions of an Obstacle Placed in a Hot Water Tank for Thermal Stratification. Energy, Exploration \&3 Exploitation, 23(5):357-373, 2005.

[22] A.A. Hegazy. Effect of Inlet Design on the Performance of Storage-Type Domestic Electrical Water Heaters. Applied Energy, 84(12):1338-1355, 2007.

[23] Cho-S.H. Chung, J.D., C.S. Tae, and H. Yoo. The Effect of Diffuser Configuration on Thermal Stratification in a Rectangular Storage Tank. Renewable Energy, 33 (10):2236-2245, 2008. 
[24] Thomas J.P. Van Koppen, C.W.J. and W.R. Veltkamp. The Actual Benefits of Thermally Stratified Storage in a Small and a Medium Size Solar System. In Sun II, volume 1, pages 576-580, 1979.

[25] Andersen E. Shah, L.J. and S. Furbo. Theoretical and Experimental Investigations of Inlet Stratifiers for Solar Storage Tanks. Applied Thermal Engineering, 25(14):2086-2099, 2005.

[26] Zurigat Y.H. Abu-Hamdan, M.G. and A.J. Ghajar. An experimental study of a stratified thermal storage under variable inlet temperature for different inlet designs. International Journal of Heat and Mass Transfer, 35(8):1927-1934, 1992.

[27] Furbo S. Andersen, E. and J. Fan. Multilayer Fabric Stratification Pipes for Solar Tanks. Solar Energy, 81(10):1219-1226, 2007.

[28] J.H. Davidson and D.A. Adams. Fabric stratification manifolds for solar water heating. Journal of Solar Energy Engineering, 116(3):130-136, 1994.

[29] E. Andersen and S. Furbo. Fabric Inlet Stratifiers for Solar Tanks With Different Volume Flow Rates. 2006.

[30] K. Lorenz. Storage Vessel for Thermal Storage of Energy in a Liquid, Apparatus and Method for Feeding Liquid to a Storage Vessel, January 29 2004. URL https://www.google.com/patents/W02004010057A1?cl=en. WO Patent App. PCT/SE2003/001,227.

[31] Marty H. Vogelsanger, P. and M. Cinelli. Experiments With Vertical Plates for Temperature Stratification in a Heat Storage Tank. D2 of Subtask D of IEA-SHC 
Task 32, International Energy Agency-Solar Heating and Cooling Programme (IEA-SHC), 2007.

[32] Cruickshank C.A. Streicher W. Harrison S.J. Haller, M.Y., E. Andersen, and S. Furbo. Methods to Determine Stratification Efficiency of Thermal Energy Storage Processes-Review and Theoretical Comparison. Solar Energy, 83(10): 1847-1860, 2009.

[33] W.P. Bahnfleth and J. Song. Constant Flow Rate Charging Characteristics of a Full-Scale Stratified Chilled Water Storage Tank With Double-Ring Slotted Pipe Diffusers. Applied thermal engineering, 25(17):3067-3082, 2005.

[34] R.J. Shyu and C.K. Hsieh. Unsteady Natural Convection in Enclosures With Stratified Medium. Journal of solar energy engineering, 109(2):127-133, 1987.

[35] I. Diner and M.A. Rosen. Energy and Exergy Analyses of Thermal Energy Storage Systems, pages 233-334. John Wiley \& Sons, Ltd, 2010. ISBN 9780470970751. doi: 10.1002/9780470970751.ch6. URL http://dx.doi.org/10.1002/9780470970751.ch6.

[36] L. Wu and R. Bannerot. Experimental Study of the Effect of Water Extraction on Thermal Stratification in Storage. Journal of Solar Energy Engineering, 109, 1987.

[37] M.A. Abdoly and D. Rapp. Theoretical and Experimental Studies of Stratified Thermocline Storage of Hot Water. Energy Conversion and Management, 22(3): 275-285, 1982. 
[38] P.S. Chan, A.M.C. Smereka and D. Giusti. A Numerical Study of Transient Mixed Convection Flows in a Thermal Storage Tank. Journal of Solar Energy Engineering, 105(3):246-253, 1983.

[39] Kreider J.F. Tran, N. and P. Brothers. Field Measurements of Chilled Water Storage Thermal Performance. ASHRAE Transactions, 95:1106-1112, 1989.

[40] M.A. Rosen. Appropriate Thermodynamic Performance Measures for Closed Systems for Thermal Energy Storage. Journal of Solar Energy Engineering, 114 (2):100-105, 1992.

[41] V. Panthalookaran, W. Heidemann, and H. Müller-Steinhagen. A New Method of Characterization for Stratified Thermal Energy Stores. Solar Energy, 81(8): 1043-1054, 2007.

[42] J. Van Berkel. Thermocline Entrainment in Stratified Energy Stores. 1997.

[43] R. Huhn. Beitrag zur thermodynamischen analyse und bewertung von wasserwärmespeichern in energieumwandlungsketten. 2006.

[44] E. Hahne and Y. Chen. Numerical Study of Flow and Heat Transfer Characteristics in Hot Water Stores. Solar Energy, 64(1):9-18, 1998.

[45] D.J. Close. A Design Approach for Solar Processes. Solar Energy, 11(2):112-122, 1967.

[46] J.A. Duffie and W.A. Beckman. Solar Engineering of Thermal Processes. John Wiley \& Sons, 2013. 
[47] R.L. Cole and F.O. Bellinger. Thermally Stratified Tanks. In Presented at the ASHRAE Natl. Meeting, Toronto, 27 Jun. 1982, volume 1, 1982.

[48] Ghajar A.J. Oppel, F.J. and P.M. Moretti. Computer Simulation Of Stratified Heat Storage. Applied Energy, 23(3):205-224, 1986.

[49] F.J. Ghajar and A.J. Oppel. A Numerical and Experimental Study of Stratified Thermal Storage.

[50] R.A. Pate. A Thermal Energy Storage Tank Model for Solar Heating. Utah State University, 1977. URL http://books .google.ca/books?id=sShqnQEACAAJ.

[51] Brunger A.P. Hollands K.G.T. Csordas, G.F. and M.F. Lightstone. Plume Entrainment Effects in Solar Domestic Hot Water Systems Employing VariableFlow-Rate Control Strategies. Solar Energy, 49(6):497-505, 1992.

[52] Vonfuchs G.F. Kuhn, J.K. and A.P. Zob. Developing and Upgrading of Solar System Thermal Energy Storage Simulation Models. NASA STI/Recon Technical Report N, 81:14422, 1980.

[53] B.J. Newton. Modeling of Solar Storage Tanks. PhD thesis, University of Wisconsin-Madison, 1995.

[54] M.S. Shin, Jang D.S. Lee S.N. Lee Y.S. Kim, H.S., and H.G. Yoon. Numerical and Experimental Study on the Design of a Stratified Thermal Storage System. Applied Thermal Engineering, 24(1):17-27, 2004.

[55] Rejane De Césaro Oliveski, Arno Krenzinger, and Horácio A Vielmo. Comparison Between Models for the Simulation of Hot Water Storage Tanks. Solar Energy, 75(2):121-134, 2003. 
[56] El-Amin M.F. Heidemann W Panthalookaran, V. and H. Müller-Steinhagen. Calibrated Models for Simulation of Stratified Hot Water Heat Stores. International Journal of Energy Research, 32(7):661-676, 2008.

[57] ICEM-CFD Ansys. 12.0 user manual. Ansys, Canonsburg, PA, 2009.

[58] Yunus A Çengel and Afshin Jahanshahi Ghajar. Heat and Mass Transfer: Fundamentals $\& 3$ Applications. McGraw-Hill, 2011.

[59] B. Rezaie, B. Reddy, and M.A. Rosen. Seasonal Stratified Thermal Energy Storage Exergy Analysis. In ESim 2012: Building Simulation Conference, May 1-4, 2012, Halifax, NS, Canada, pages 352-365, 2012. 


\section{Appendix A}

\section{Justification of Assumptions used in the Numerical Solution}

\section{A.1 Heat Loss from Tank by Natural Convection}

This section explores the implications of neglecting the heat losses from the tank walls to the ambient air.

The analysis assumes that the tank does not have insulation on the inside or the outside of the tank wall, the surface temperature is $60^{\circ} \mathrm{C}$, and the ambient temperature is $20^{\circ} \mathrm{C}$. Then heat loss to the ambient can be calculated by determining the natural convection around the tank.

\section{A.1.1 Heat Loss From the Horizontal Cylinder}

The tank can be split into two parts, the horizontal cylinder and the sides. Firstly, the Rayleigh number must be calculated in order to use the correct correlation that 
describes the heat loss from a horizontal cylinder through natural convection.

$$
R a_{D}=\frac{g \beta\left(T_{s}-T_{\infty}\right) D^{3}}{v^{2}} \operatorname{Pr}
$$

where $g$ is the acceleration due to gravity, $\beta$ is the thermal expansion, $T_{s}$ is the surface temperature, $T_{\infty}$ is the temperature of the ambient, $v$ is the kinematic viscosity, $\operatorname{Pr}$ is the Prandtl number and $D$ is the tank diameter. All these quantities must be evaluated at the film temperature $\left(T_{f}\right)$ which is the average temperature between the ambient and the surface.

$$
\begin{gathered}
T_{f}=\frac{T_{\text {surface }}+T_{\text {ambient }}}{2} \\
T_{f}=\frac{60^{\circ} \mathrm{C}+20^{\circ} \mathrm{C}}{2} \\
T_{f}=40^{\circ} \mathrm{C}=313.15 \mathrm{~K}
\end{gathered}
$$

Air properties at $40^{\circ} \mathrm{C}$ are as follows: $\rho=1.127\left(\frac{\mathrm{kg}}{\mathrm{m}^{3}}\right), c_{p}=1005\left(\frac{\mathrm{J}}{\mathrm{kg} \cdot \mathrm{K}}\right)$ $k=0.0271\left(\frac{W}{m . K}\right), v=16.97 \times 10^{-6}\left(\frac{m^{2}}{s}\right), \operatorname{Pr}=0.711$

The thermal expansion $(\beta)$ is defined as:

$$
\begin{gathered}
\beta=\frac{1}{T_{f}} \\
\beta=\frac{1}{313.15 K}
\end{gathered}
$$

Then the Rayleigh number, presented in Equation A.2 becomes:

$$
R a_{D}=\frac{\left(9.81 \frac{m}{s^{2}}\right)\left(\frac{1}{313.15 K}\right)\left(60^{\circ} \mathrm{C}-20^{\circ} \mathrm{C}\right)(3.8 \mathrm{~m})^{3}}{\left[16.97 \times 10^{-6}\left(\frac{m^{2}}{s}\right)\right]^{2}} \times 0.711
$$




$$
R a_{D}=4.47 \times 10^{10}
$$

Since the Rayleigh number is less than $10^{12}$, then the Nusselt number for a horizontal cylinder is defined as follows [58]:

$$
\begin{gathered}
N u=\left[0.6+\frac{0.387 R a_{D}^{1 / 6}}{\left(1+\left(\frac{0.559}{P r}\right)^{9 / 16}\right)^{8 / 27}}\right]^{2} \\
N u=\left[0.6+\frac{0.387\left(4.47 \times 10^{10}\right)^{1 / 6}}{\left(1+\left(\frac{0.559}{0.711}\right)^{9 / 16}\right)^{8 / 27}}\right]^{2} \\
N u=390
\end{gathered}
$$

Calculating the heat transfer coefficient

$$
\begin{gathered}
N u=\frac{h D}{k} \\
h=\frac{N u k}{D} \\
h=\frac{390\left(0.0271\left(\frac{W}{m K}\right)\right)}{(3.8 m)} \\
h=2.78\left(\frac{W}{m^{2} K}\right)
\end{gathered}
$$


Energy lost from the horizontal cylinder surface

$$
\dot{Q}_{\text {cylinder }}=h A\left(T_{\text {surface }}-T_{\text {ambient }}\right)
$$

Where $A$ is the surface area of the horizontal cylinder

$$
\begin{gathered}
A=\pi D L \\
A=\pi \times 3.8 m \times 11.42 m \\
A=136 m^{2}
\end{gathered}
$$

Calculating the energy lost from the horizontal cylinder using Equation A.7

$$
\begin{gathered}
\dot{Q}_{\text {cylinder }}=2.78\left(\frac{W}{m^{2} K}\right) 136\left(m^{2}\right)\left(60^{\circ} \mathrm{C}-20^{\circ} \mathrm{C}\right) \\
\dot{Q}_{\text {cylinder }}=15.2 \mathrm{~kW}
\end{gathered}
$$

\section{A.1.2 Heat Loss Through the Sides of the Tank}

In order to obtain a natural convection heat transfer coefficient for the sides of the tank, it is required to assume that the ends of the tank are vertical plates. Since, the Rayleigh number was calculated earlier to be between $10^{10}-10^{13}$, then the Nusselt number of the vertical plate is defined as follows [58]:

$$
\begin{gathered}
N u=0.1 R a_{L}^{1 / 3} \\
N u=0.1 \times\left(4.47 \times 10^{10}\right)^{1 / 3}
\end{gathered}
$$




$$
N u=355
$$

The heat transfer coefficient is calculated using Equation A.1.2

$$
\begin{gathered}
h=\frac{355\left(0.0271\left(\frac{W}{m K}\right)\right)}{(3.8 m)} \\
h=2.53\left(\frac{W}{m^{2} K}\right)
\end{gathered}
$$

The surface area of the two sides of the tank is calculated as follows:

$$
\begin{gathered}
A=2\left(\frac{\pi}{4}\right) D^{2} \\
A=2\left(\frac{\pi}{4}\right)(3.8 m)^{2} \\
A=22.7 m^{2}
\end{gathered}
$$

The energy lost through the sides of the tank is calculated using Equation A.7

$$
\begin{gathered}
\dot{Q}_{\text {sides }}=2.78\left(\frac{W}{m^{2} K}\right) 22.7\left(m^{2}\right)\left(60^{\circ} \mathrm{C}-20^{\circ} \mathrm{C}\right) \\
\dot{Q}_{\text {Sides }}=2.30 \mathrm{~kW}
\end{gathered}
$$

\section{A.1.3 Total Energy Loss Through Tank}

Total energy loss from the tank is equal to the heat loss through the horizontal cylinder in addition to the heat loss through the two sides.

$$
\dot{Q}_{\text {lost }}=\dot{Q}_{\text {cylinder }}+\dot{Q}_{\text {sides }}
$$




$$
\dot{Q}_{\text {lost }}=17.5 \mathrm{~kW}
$$

\section{A.1.4 Energy Leaving the Tank During Discharging}

The energy leaving the tank during discharging must be calculated in order to properly gauge the error introduced into the simulation by assuming that the heat loss to the ambient is negligible. As seen in Case 1, the tank is fully charged at $60^{\circ} \mathrm{C}$ and the inlet temperature is $30^{\circ} \mathrm{C}$ and the mass flow rate is $6 \mathrm{~L} / \mathrm{s}$.

The energy leaving the tank can be calculated as follows:

$$
\begin{gathered}
\dot{Q}_{\text {out }}=\dot{m} c_{p}\left(T_{\text {out }}-T_{\text {in }}\right) \\
\dot{Q}_{\text {out }}=6 \frac{L}{\mathrm{~s}} \frac{\mathrm{m}^{3}}{1000 L} 997 \frac{\mathrm{kg}}{\mathrm{m}^{3}} 4181.7 \frac{\mathrm{J}}{\mathrm{kg} \cdot \mathrm{K}}\left(60^{\circ} \mathrm{C}-30^{\circ} \mathrm{C}\right) \\
\dot{Q}_{\text {out }}=750.4 \mathrm{~kW}
\end{gathered}
$$

\section{A.1.5 Error Introduced by Assuming No Heat Loss from Tank}

$$
\begin{gathered}
\text { Error }(\%)=\frac{\dot{Q}_{\text {lost }}}{\dot{Q}_{\text {out }}} \times 100 \% \\
\text { Error }(\%)=\frac{17.5 \mathrm{~kW}}{750.4 \mathrm{~kW}} \times 100 \% \\
\operatorname{Error}(\%)=2.33 \%
\end{gathered}
$$

Since the error introduced into the simulation for the case of the tank without insulation is small, relative to the error of the validation results, then assuming that there is no heat loss to the ambient is a valid assumption. 


\section{A.2 Heat Conduction Through Tank Wall}

Lightstone [5] conducted a numerical simulation comparing a tank with a steel wall with regular wall conductivity and another tank with wall conductivity one order of magnitude higher. It was found that the hot fluid above the thermocline is slightly cooler and the bottom fluid below the thermocline is slightly warmer. However, these effects are very small. As a result, it was decided that assuming heat conduction through the tank wall has a negligible effect on stratification within the tank.

\section{A.3 Heat conduction Through Baffles}

Conduction only occurs when there is a temperature gradient along the baffle. A temperature gradient occurs across a baffle when the thermocline is going through the baffle. The thermocline of a perfectly startified tank moves up within the tank very quickly, a maximum of $12 \mathrm{~mm}$ per minute and a minimum of about $1 \mathrm{~mm}$ per minute during Case 1 as shown in Figure A.1. Since the baffle is very thin, about 10 $\mathrm{mm}$ in thickness, then conduction will take place within the tank for 10 minutes over a 7 hour simulation. This leads to the conclusion that the error introduced from this momentary conduction is negligible. 


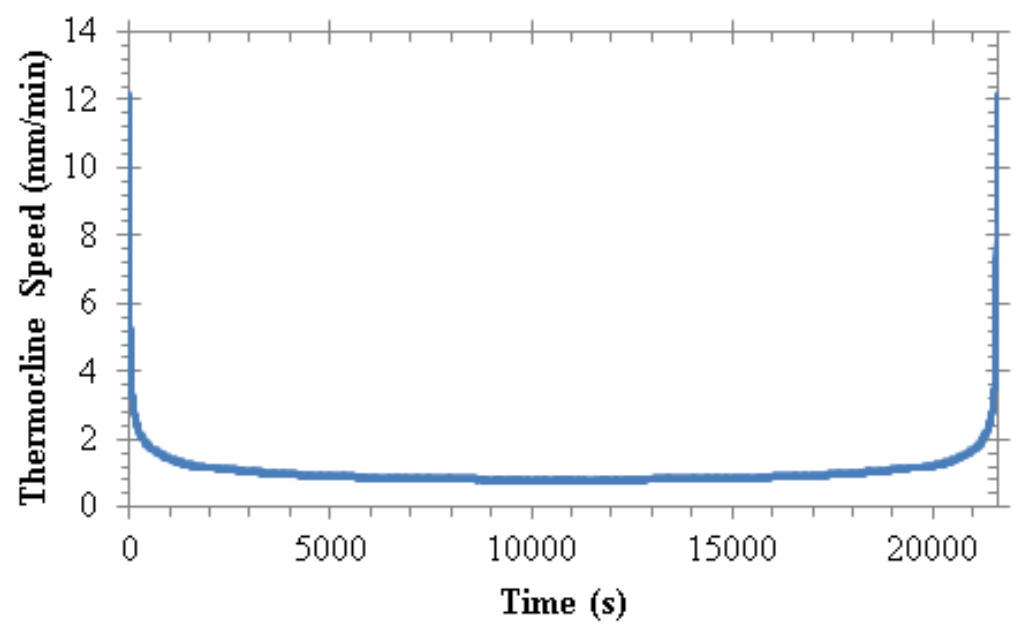

Figure A.1: Speed of the thermocline within a tank during a discharging cycle similar to Case 1 


\section{Appendix B}

\section{TES Analysis}

In order to quantify the level of stratification within the tank that is numerically tested, its performance must be compared to a tank that is fully mixed and a tank that is perfectly stratified. This section describes the equations employed to analyze the numerical solutions.

\section{B.1 Fully Mixed Tank Temperature}

This section describes the steps followed to obtain the transient average temperature profile of a fully mixed tank. 


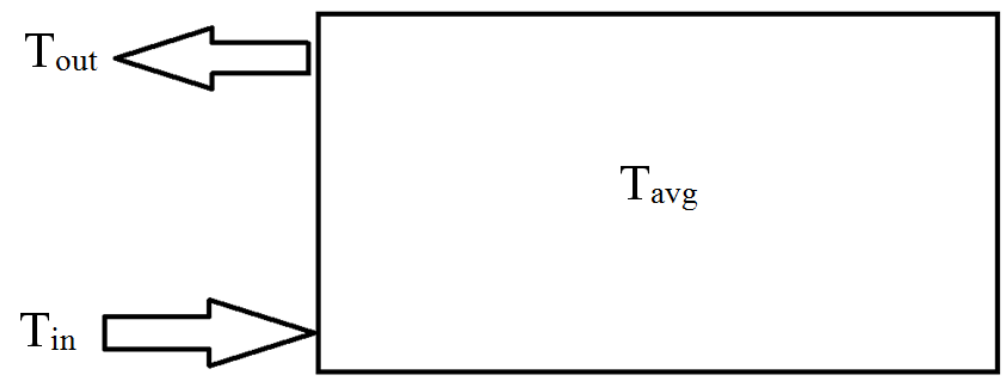

Figure B.1: Illustration of a fully mixed tank

The energy balance on the system shown in Figure B.1 is as follows:

$$
\begin{gathered}
m_{\text {store }} c_{p} \frac{\partial T_{\text {avg }}(t)}{\partial t}=\dot{m} c_{p}\left(T_{\text {out }}-T_{\text {in }}\right) \\
\frac{\partial T_{\text {avg }}(t)}{\partial t}=\frac{\dot{m}}{m_{\text {store }}}\left(T_{\text {out }}-T_{\text {in }}\right) \\
T(t)=C_{1} \exp \left(-\frac{\dot{m}}{m_{\text {store }}} t\right)+T_{\text {in }}
\end{gathered}
$$

Since,

$$
T(0)=T_{\text {initial }}
$$

Then,

$$
\begin{gathered}
T(0)=C_{1}+T_{i n}=T_{\text {initial }} \\
C_{1}=T_{\text {initial }}-T_{\text {in }}
\end{gathered}
$$

Therefore, the final fully mixed equation is:

$$
T(t)=\left(T_{\text {initial }}-T_{\text {in }}\right) \exp \left(-\frac{\dot{m}}{m_{\text {store }}} t\right)+T_{\text {in }}
$$




\section{B.2 Energy}

This section describes the energy balance on the tank and details the energy introduced, energy extracted and energy stored in the tank. Energy balance for a thermal system can be written as [59]:

$$
\text { Energy In - Energy Out = Energy Accumulated }
$$

where energy in, energy out and energy accumulated are defined respectively as follows:

$$
\begin{gathered}
\text { Energy In }=\dot{m} c_{p} t T_{\text {in }} \\
\text { Energy Out }=\dot{m} c_{p} t T_{\text {out }} \\
\text { Energy Accumulated }=m_{\text {store }} c_{p}\left(T_{\text {final }}-T_{\text {initial }}\right)
\end{gathered}
$$

\section{B.3 Exergy}

This section describes the exergy analyses incorporated to analyze a TES system for thermal stratification. Exergy balance for a thermal system can be written as [59]:

$$
\text { Exergy In - Exergy Destruction = Exergy Accumulated }
$$




\section{B.3.1 TES Charging}

For charging, the exergy in, exergy accumulated and exergy destruction are defined respectively as follows:

$$
\text { Exergy In }=\dot{m} c_{p} t\left(T_{\text {in }}-T_{\text {out }}-T_{0} \ln \frac{T_{\text {in }}}{T_{\text {out }}}\right)
$$

Where $T_{\text {ambient }}$ is the reference environment temperature

$$
\text { Exergy Accumulated }=m_{\text {store }} c_{p}\left(T_{\text {final }}-T_{\text {initial }}-T_{0} \ln \frac{T_{\text {final }}}{T_{\text {initial }}}\right)
$$

$$
\text { Exergy Destruction }=\text { Exergy In }- \text { Exergy Accumulated }
$$

\section{B.3.2 TES Discharging}

The exergy balance can be redefined as follows:

$$
\text { Exergy Recovered - Exergy Destruction = Exergy Accumulated }
$$

For discharging, the exergy recovered, exergy accumulated and exergy destruction are defined respectively as follows:

$$
\begin{gathered}
\text { Exergy Recovered }=\dot{m} c_{p} t\left(T_{\text {out }}-T_{\text {in }}-T_{0} \ln \frac{T_{\text {out }}}{T_{\text {in }}}\right) \\
\text { Exergy Accumulated }=m_{\text {store }} c_{p}\left(T_{\text {final }}-T_{\text {initial }}-T_{0} \ln \frac{T_{\text {final }}}{T_{\text {initial }}}\right)
\end{gathered}
$$

Exergy Destruction $=-$ Exergy Recovered - Exergy Accumulated 


\section{B.4 Huhn's Efficiency}

According to Haller et al. [32], the best method for quantifying stratification is the stratification efficiency proposed by Huhn because it is in qualitative agreement with entropy production and is applicable to variable inlet temperatures and mass flows.

$$
\text { Huhn's Efficiency }=\left(1-\frac{\text { Exergy Destruction Simulated }}{\text { Exergy Destruction Fully Mixed }}\right) * 100 \%
$$

\section{B.5 Tank Turn Over Time}

The tank turn over time is an important measure that has been referred to multiple times in order to help determine the appropriate simulation time for the tank. This measure basically determines the time required for the inlet fluid to replace the entire tank volume. It is calculated as follows:

$$
\text { Tank Turn Over Time }=\frac{\text { Total Tank Volume }}{\text { Volume Flow Rate In or Out of Tank }}
$$




\section{Appendix C}

\section{Detailed Drawings and Meshes of Nine Designs Tested}

C.1 Design 1: Tank Without Baffles

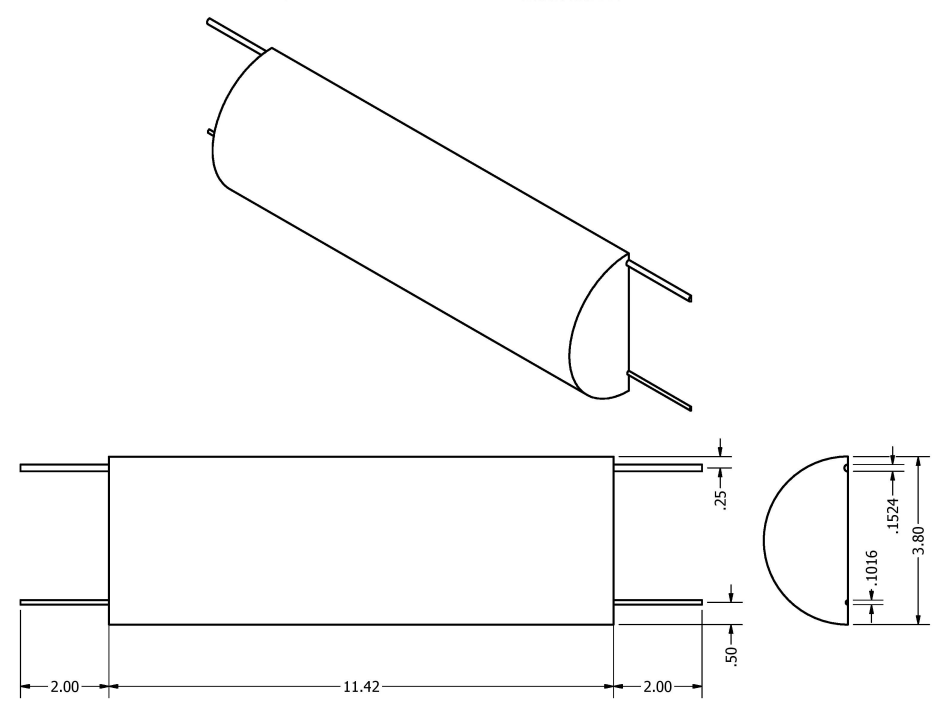

Figure C.1: Detailed drawing of Design 1 (tank without baffles) 


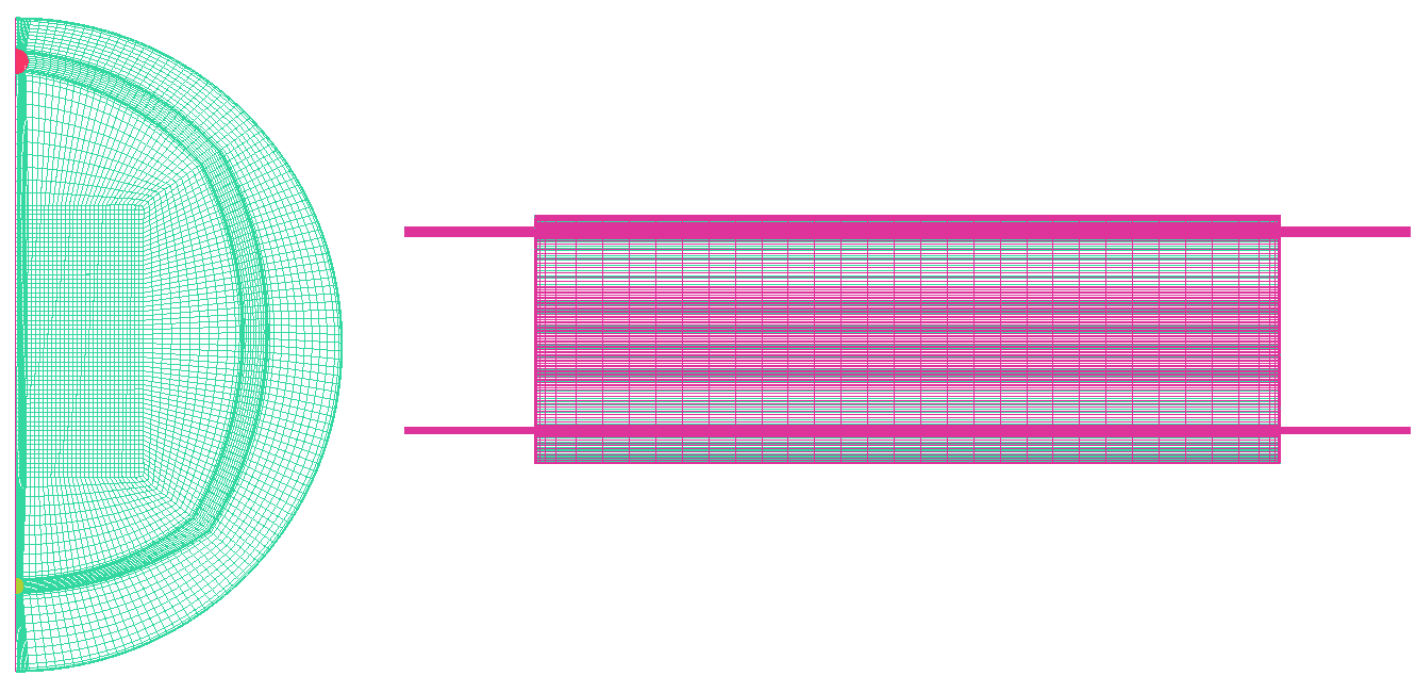

Figure C.2: Mesh for Design 1 (tank without baffles) 


\section{C.2 Design 2: Current Tank at DLSC}

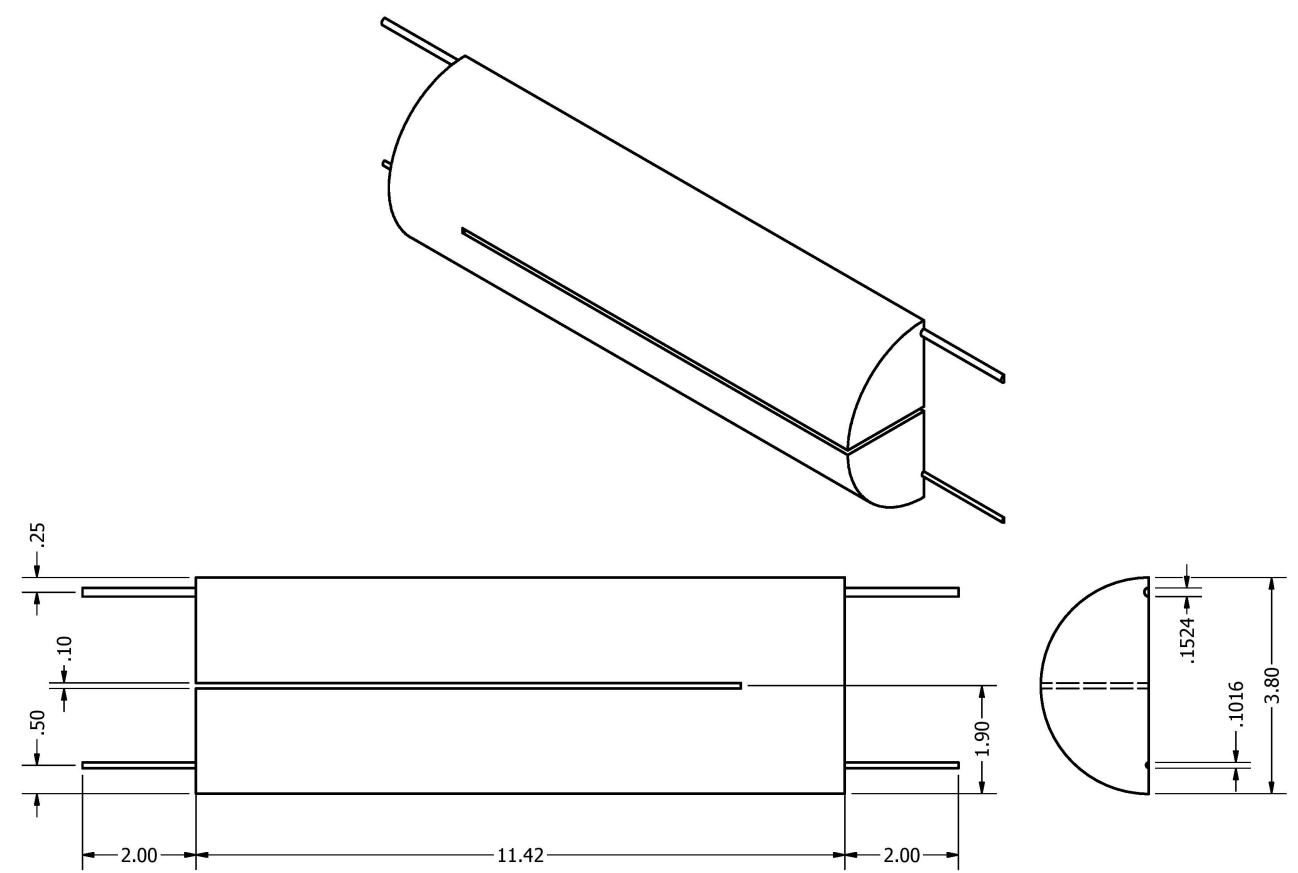

Figure C.3: Detailed drawing of Design 2 (current tank at DLSC)
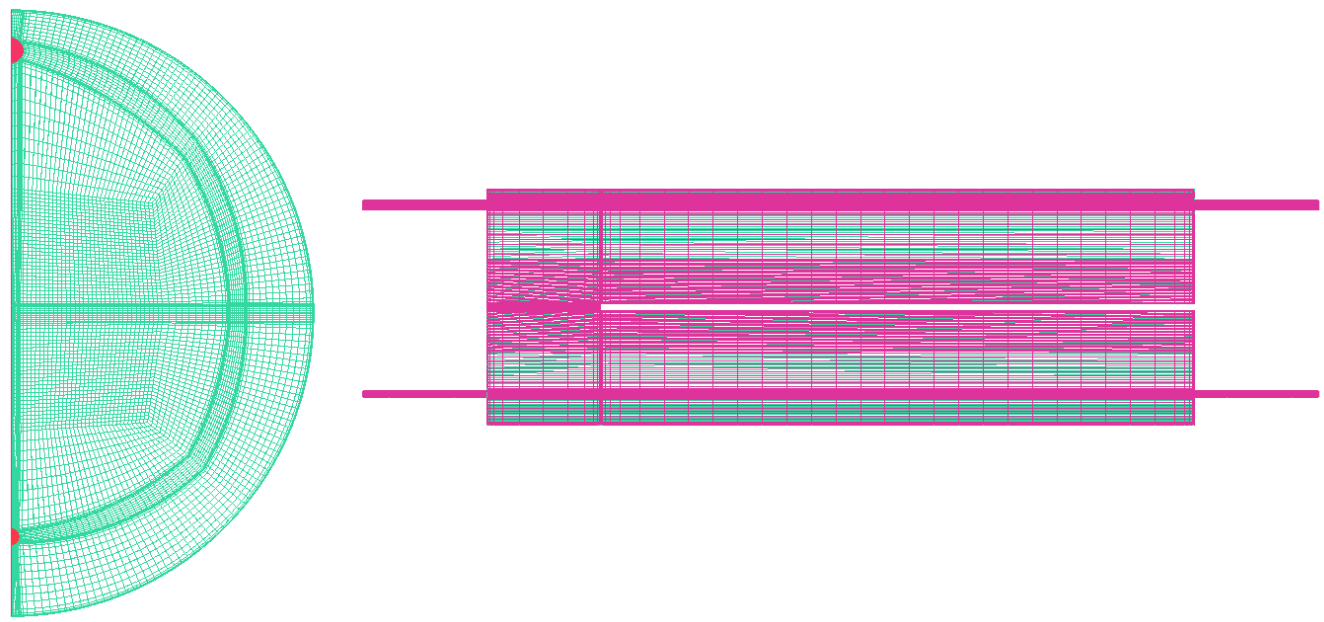

Figure C.4: Mesh for Design 2 (current tank at DLSC) 


\section{C.3 Design 3: Rysanek's Best Performing Tank}

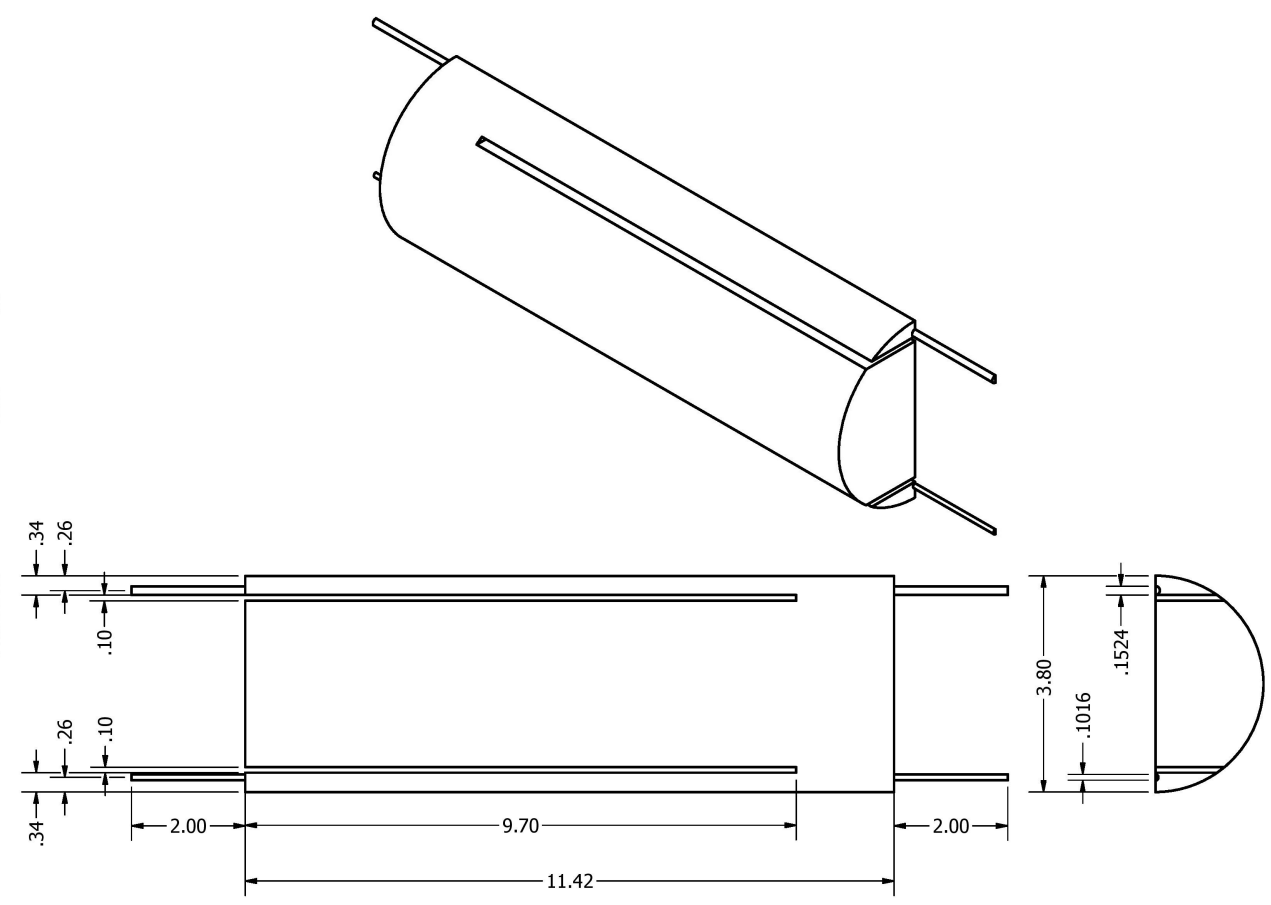

Figure C.5: Detailed drawing of Design 3 (Rysanek's best performing tank)
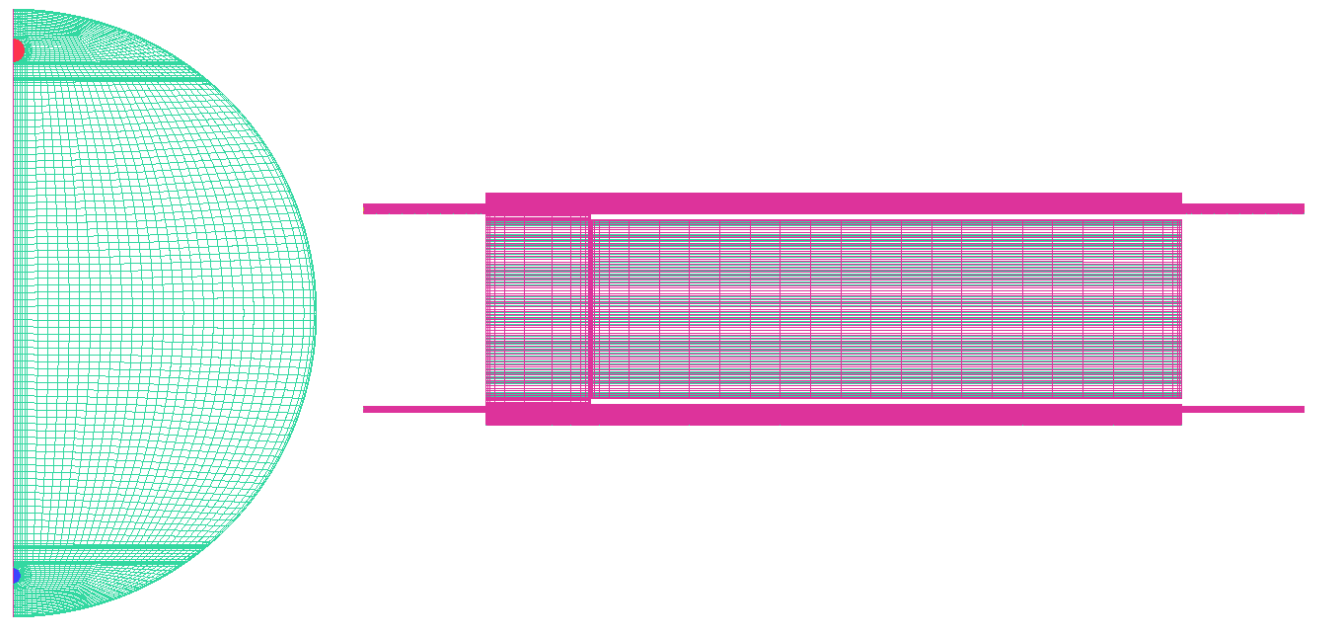

Figure C.6: Mesh for Design 3 (Rysanek's best performing tank) 


\section{C.4 Design 4: Rysanek's Tank with Middle Baffle}

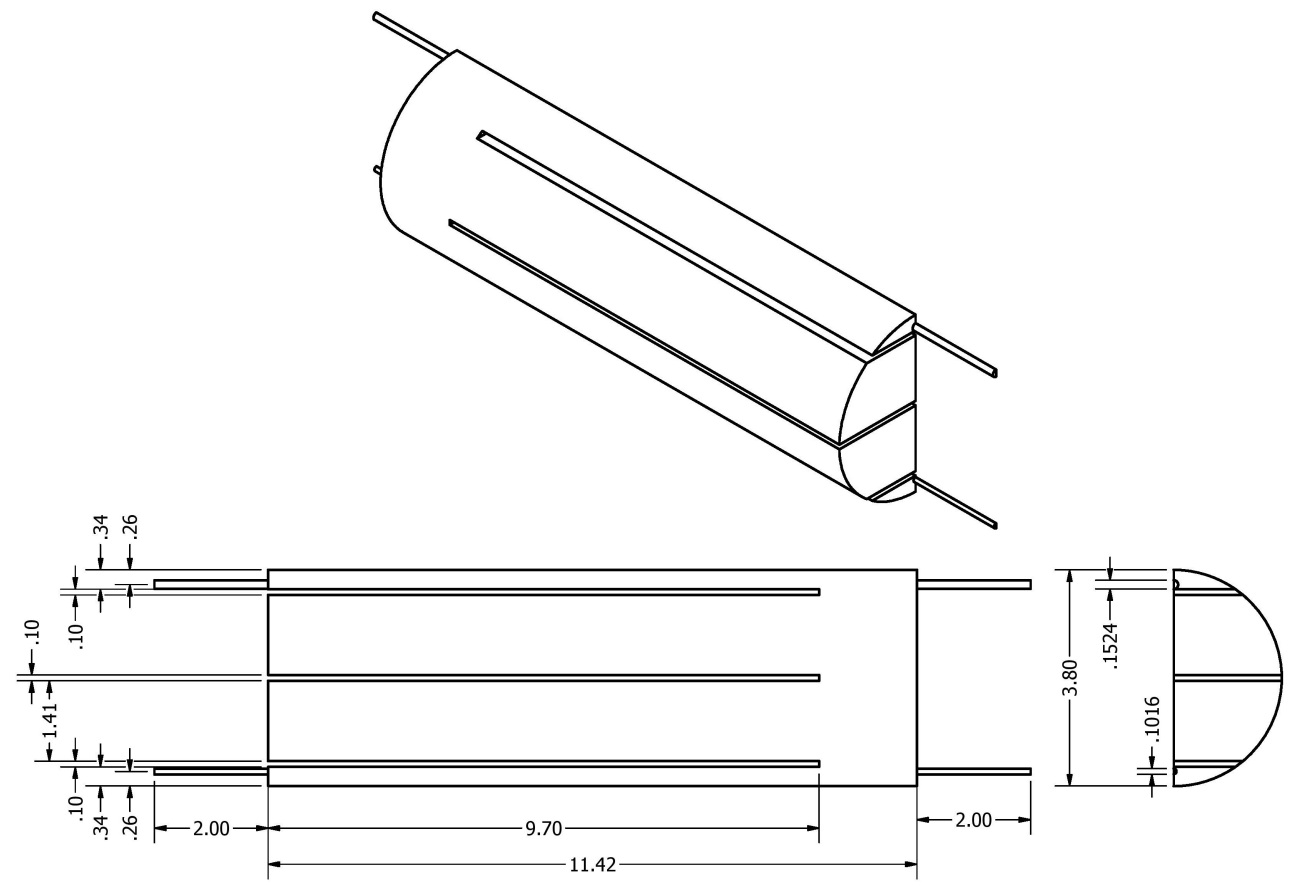

Figure C.7: Detailed drawing of Design 4 (Rysanek's tank with a middle baffle)
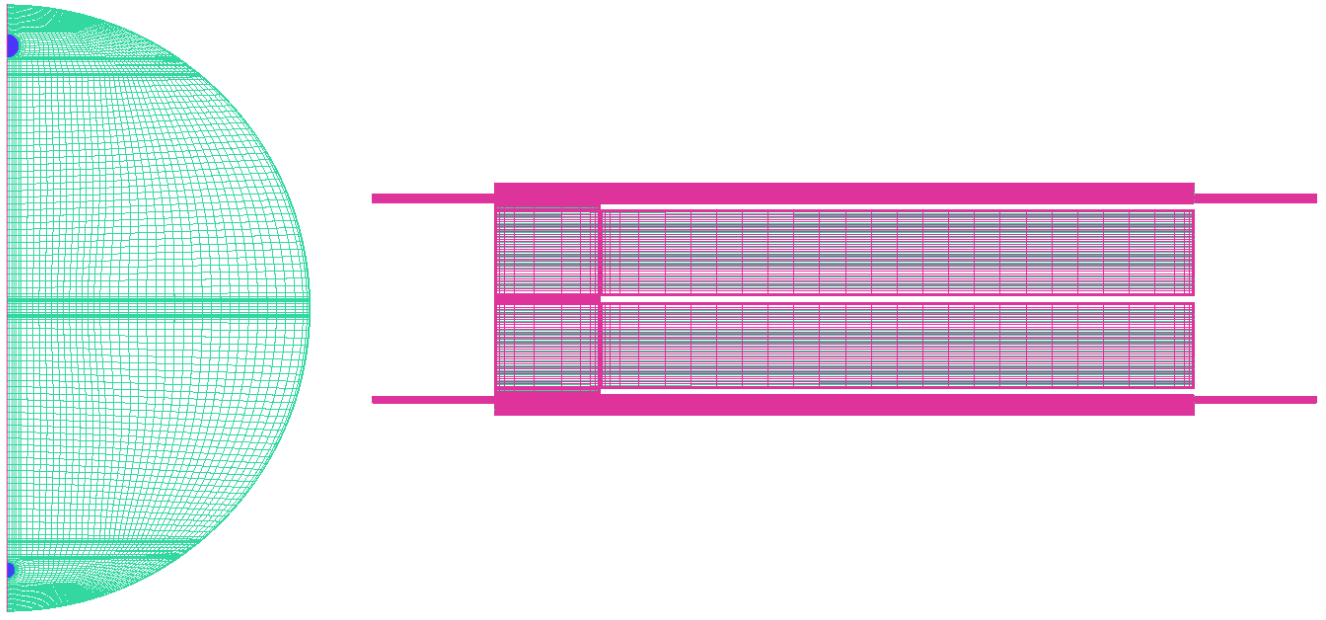

Figure C.8: Mesh for Design 4 (Rysanek's tank with a middle baffle) 


\section{C.5 Design 5: Rysanek's Tank with Redirecting Baffles}

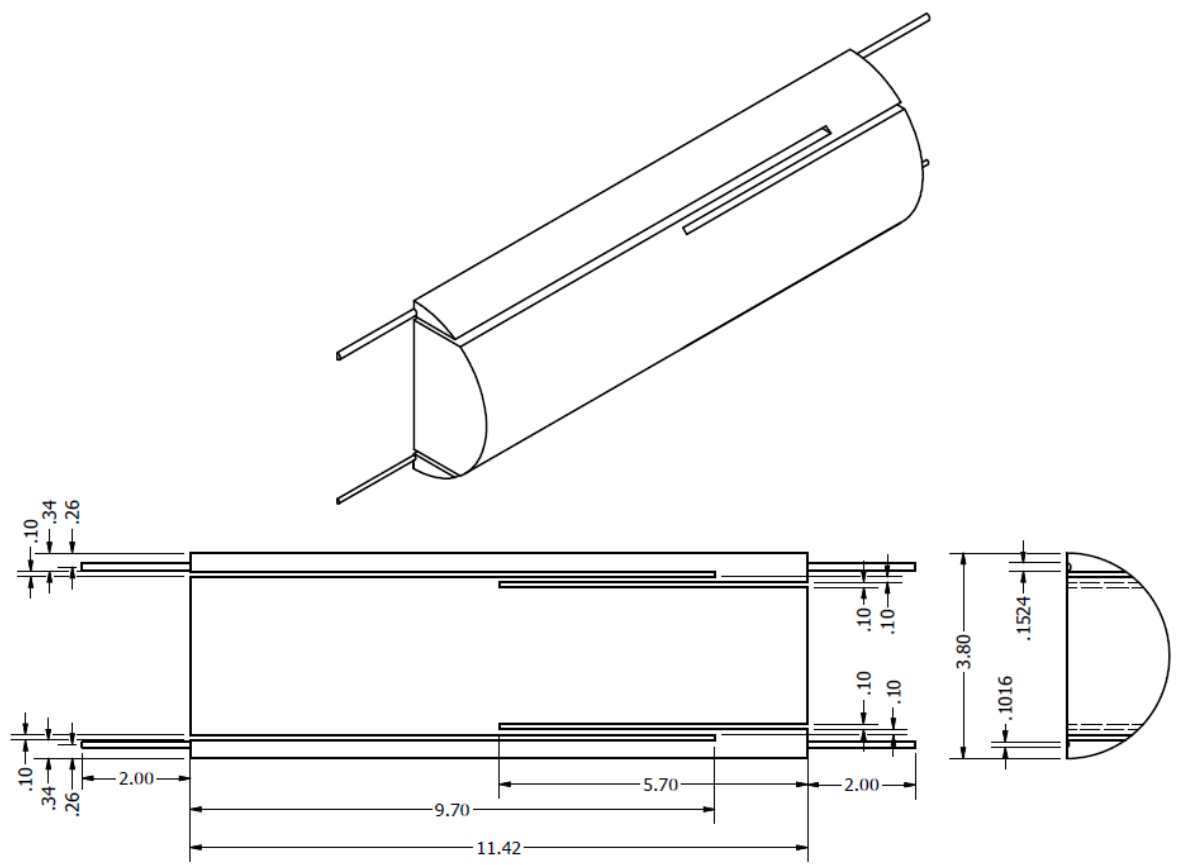

Figure C.9: Detailed drawing of Design 5 (Rysanek's tank with redirecting baffles)
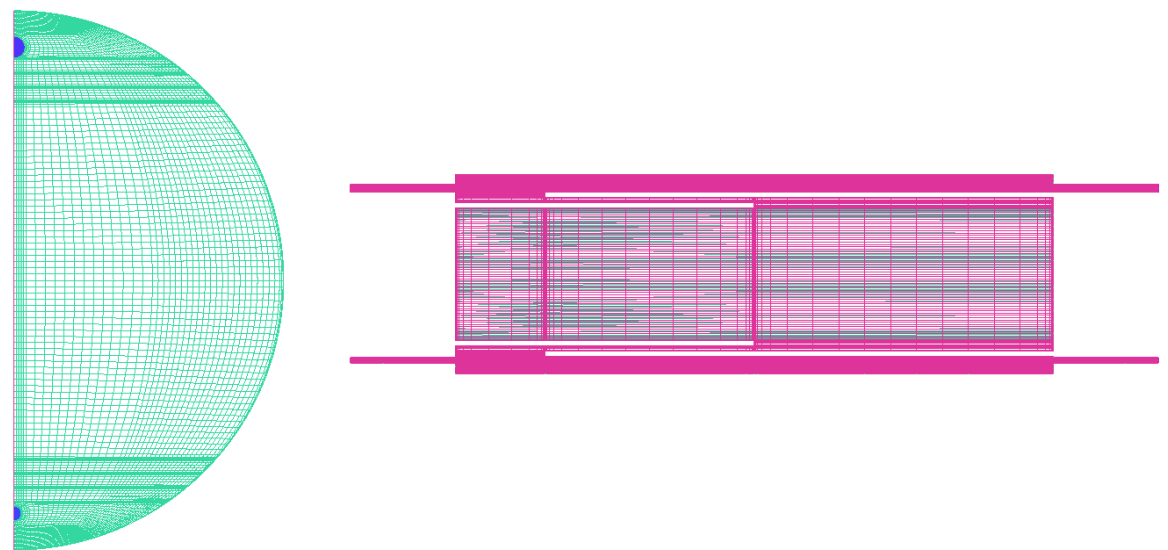

Figure C.10: Mesh for Design 5 (Rysanek's tank with redirecting baffles) 


\section{C.6 Design 6: Tank with Top and Bottom Inlet and Outlet}

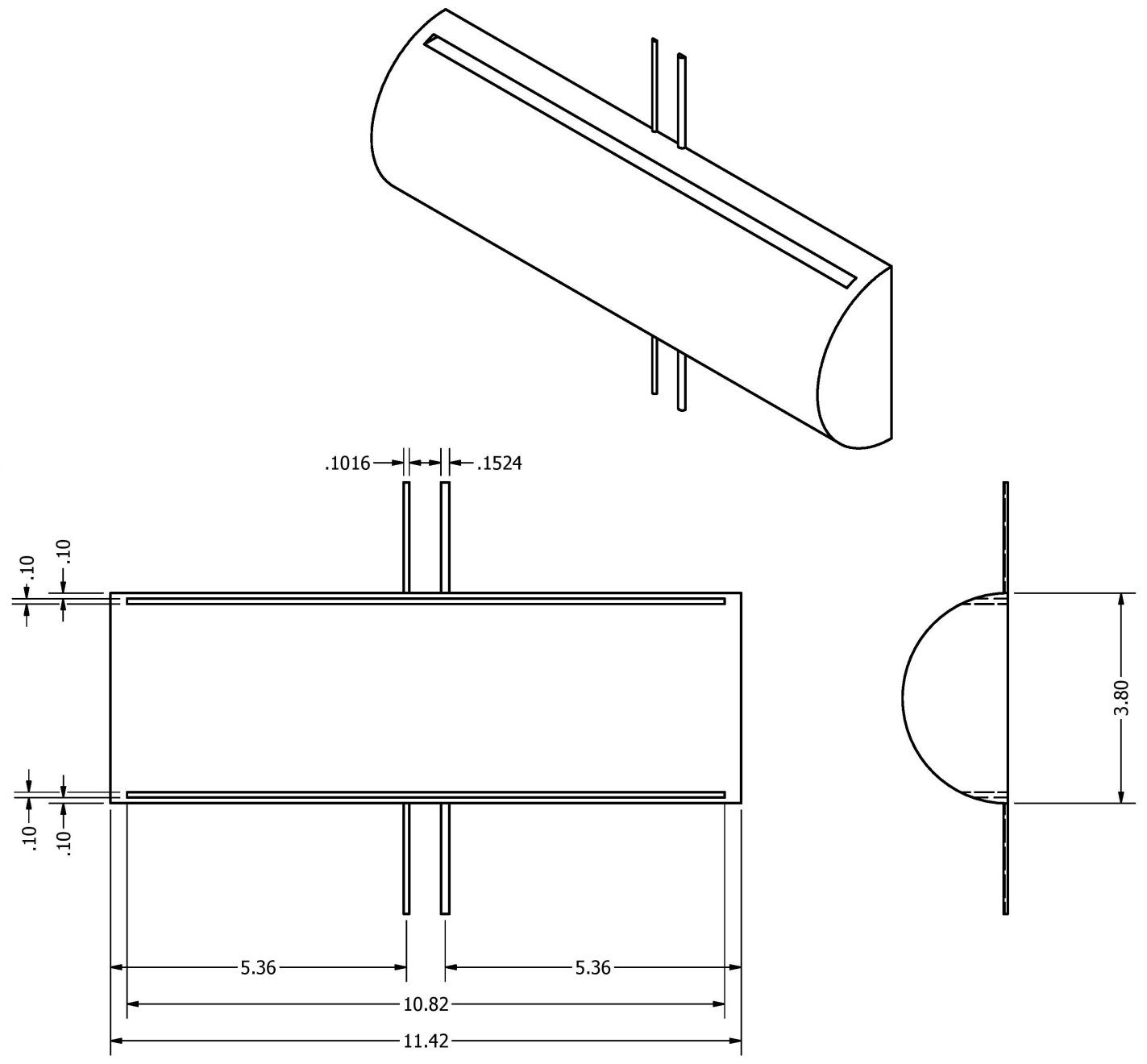

Figure C.11: Detailed drawing of Design 6 (tank with top and bottom inlet and outlet) 

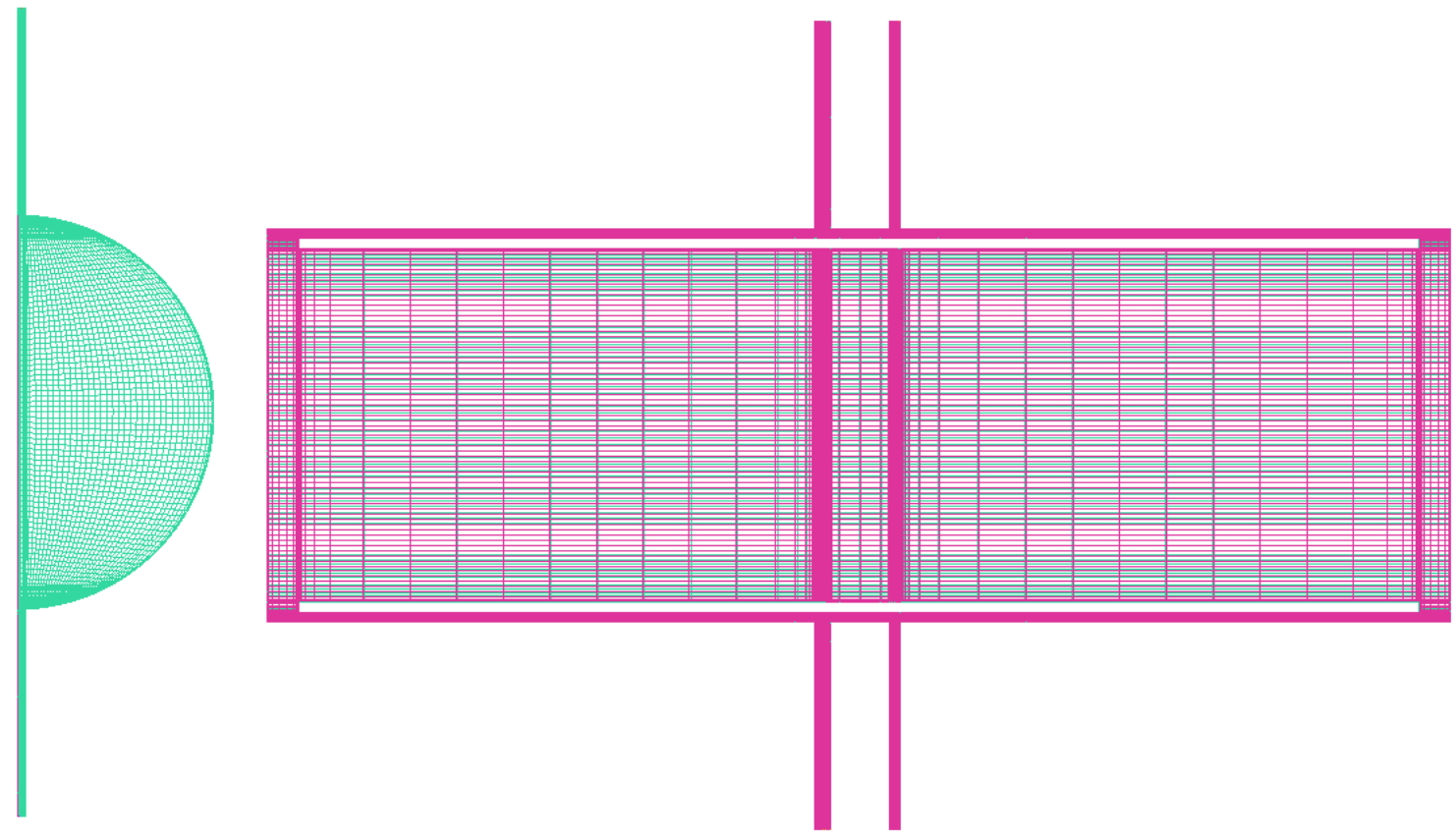

Figure C.12: Mesh for Design 6 (tank with top and bottom inlet and outlet) 


\section{C.7 Design 7: Tank with Vertical Baffles}

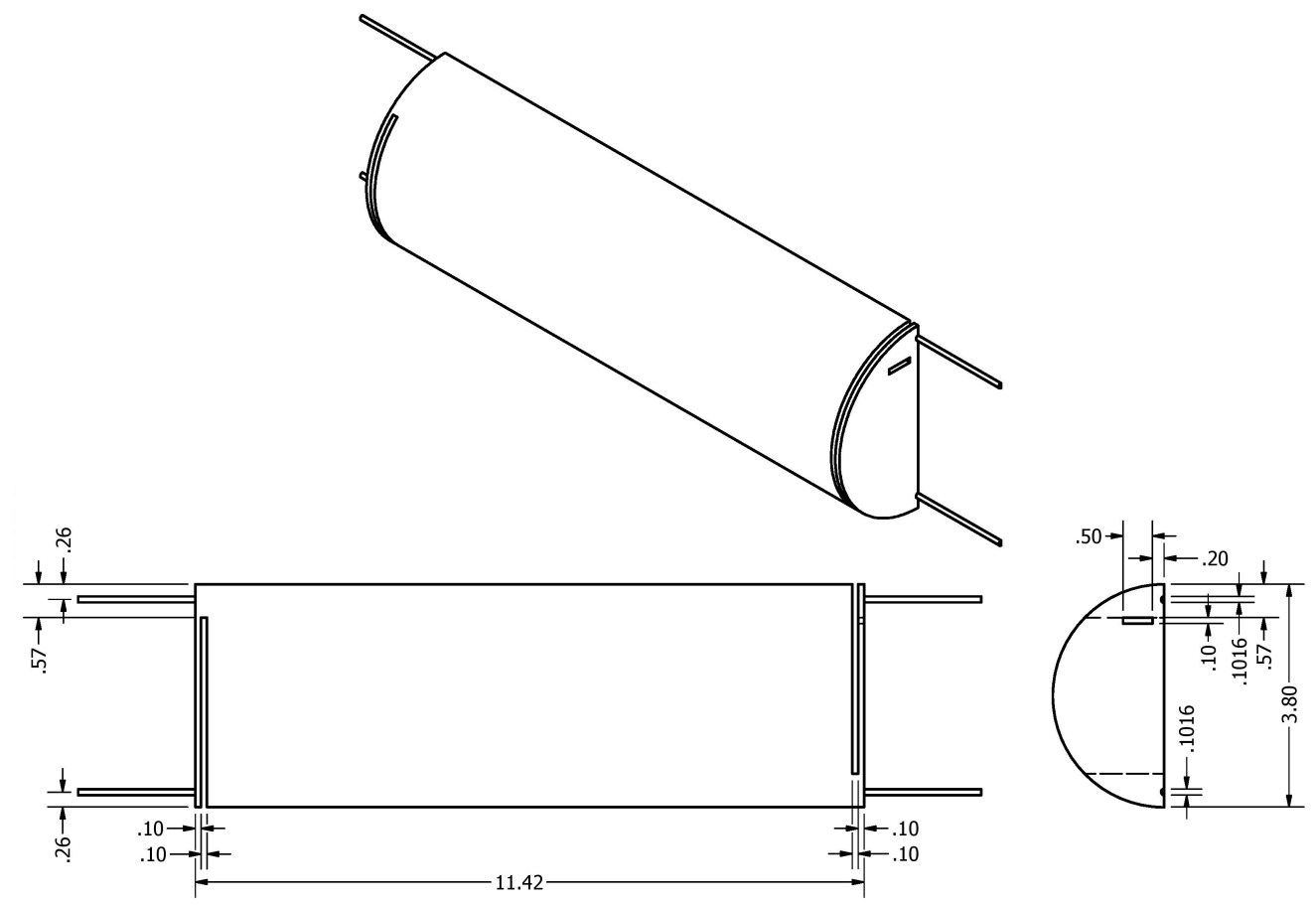

Figure C.13: Detailed drawing of Design 7 (tank with vertical baffles)
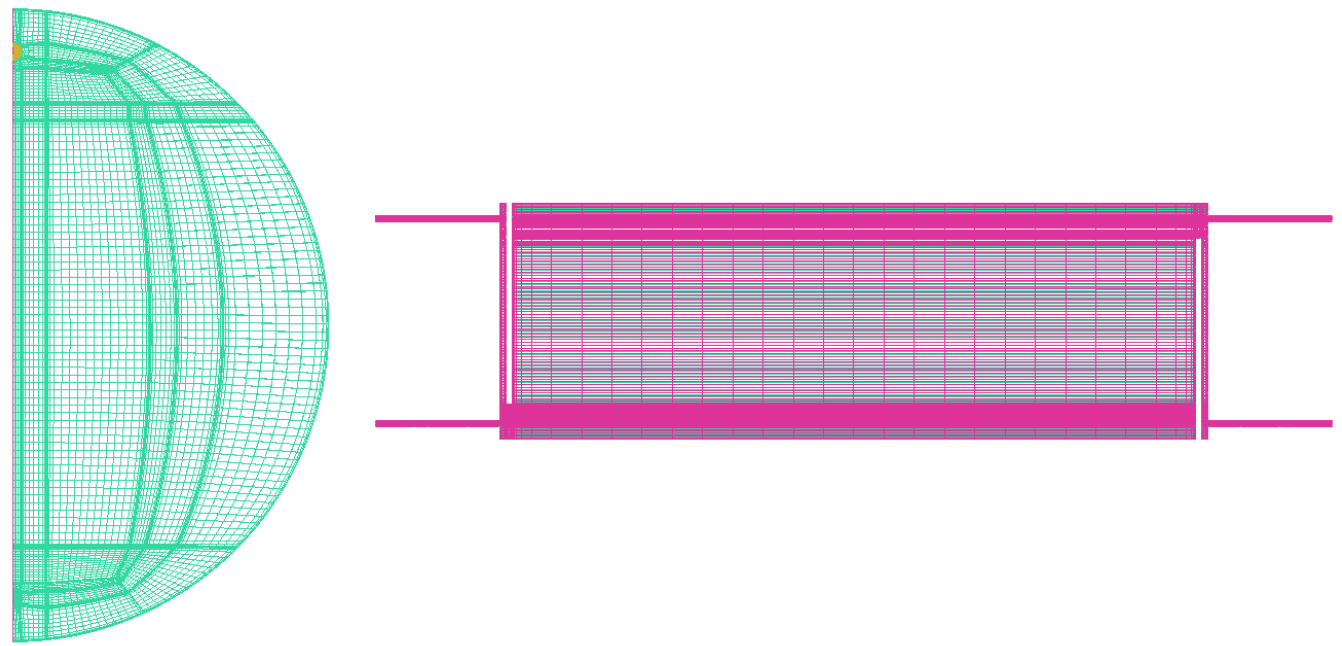

Figure C.14: Mesh for Design 7 (tank with vertical baffles) 


\section{C.8 Design 8: Tank Without Baffles and a Dis- charge Inlet of $200 \mathrm{~mm}$}

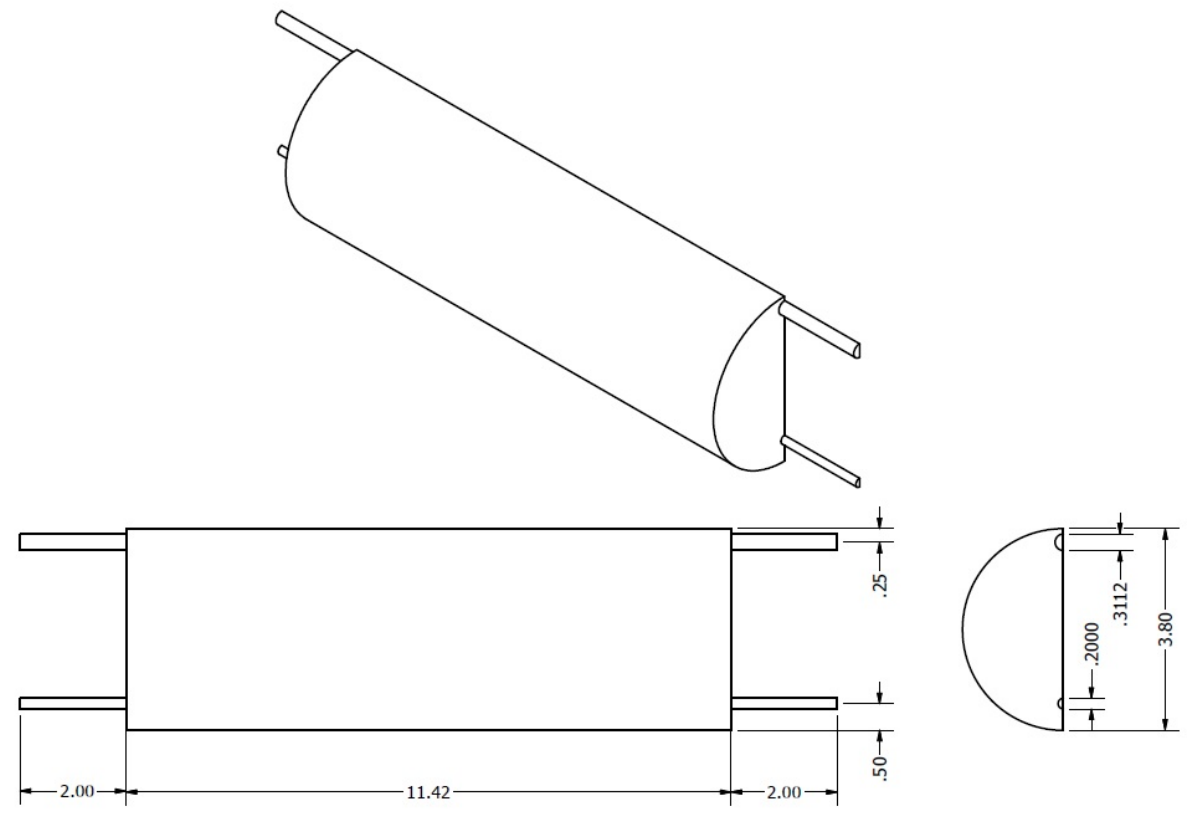

Figure C.15: Detailed drawing of Design 8 (tank without baffles and a discharge inlet of $200 \mathrm{~mm}$ )

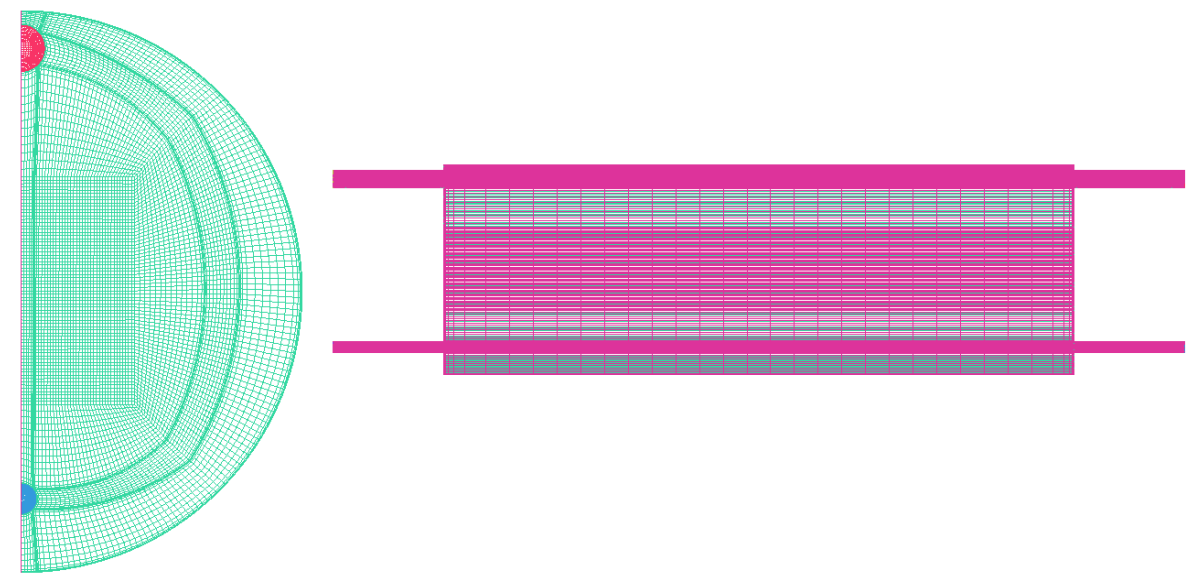

Figure C.16: Mesh for Design 8 (tank without baffles and a discharge inlet of 200 $\mathrm{mm})$ 


\section{C.9 Design 9: Tank Without Baffles and a Dis- charge Inlet of $400 \mathrm{~mm}$}

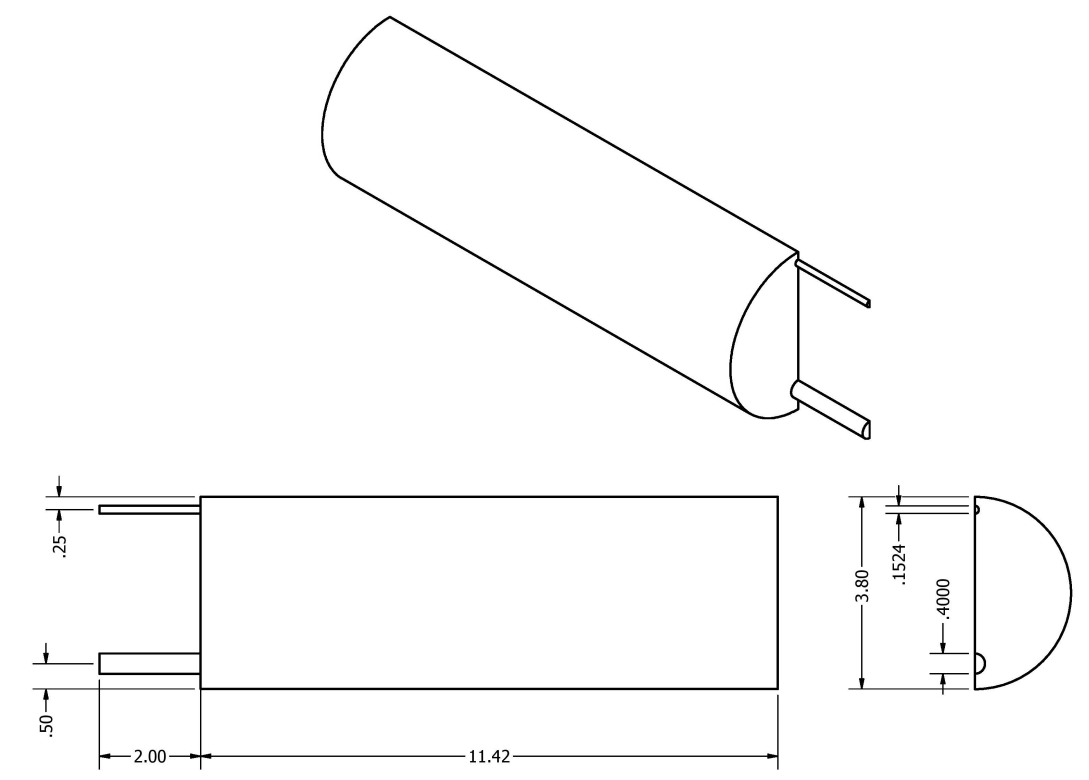

Figure C.17: Detailed drawing of Design 9 (tank without baffles and a discharge inlet of $400 \mathrm{~mm}$ ) 

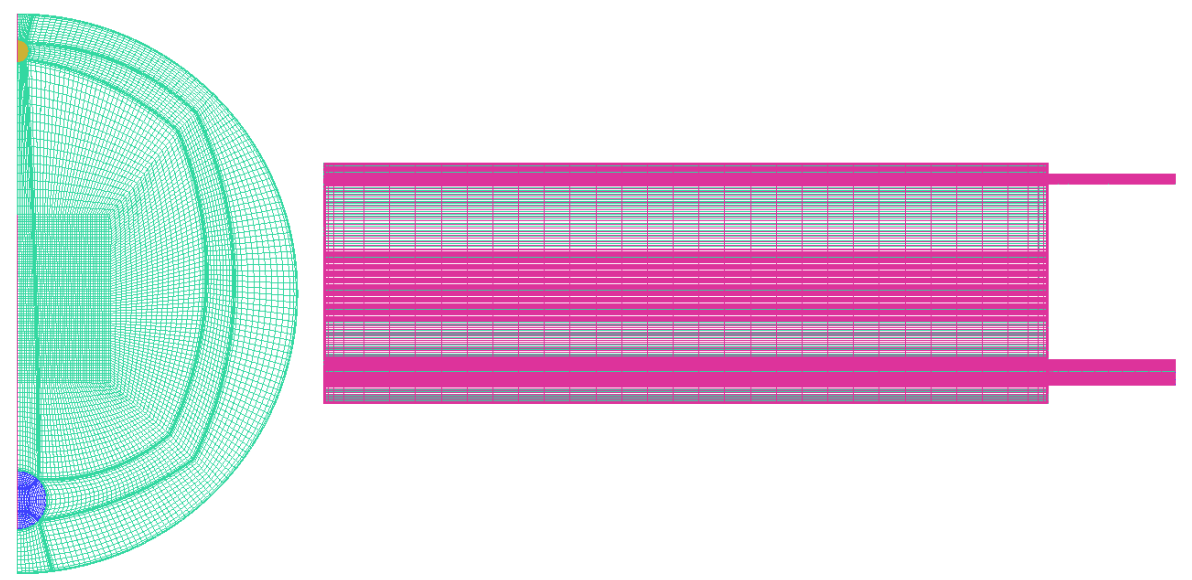

Figure C.18: Mesh for Design 9 (tank without baffles and a discharge inlet of 400 $\mathrm{mm})$ 


\section{Appendix D}

\section{Grid Independence Test for Tank 6}

It is important to verify that the grid independence test seen in Chapter 3 can be applied to all other tank designs. This motivated the grid independence test for Tank 6 , where one grid was 300,000 nodes and the other was 1,200,000 nodes. Information about geometry of Tank 6 is available in Appendix C. The test is conducted for a tank that is initially charged at $60^{\circ} \mathrm{C}$ and is discharged by fluid with a mass flow rate of $6 \mathrm{~L} / \mathrm{s}$ and temperature of $30^{\circ} \mathrm{C}$.

It should be noted that the coarse grid takes about one week to compute, but the fine grid takes about four weeks to compute. 


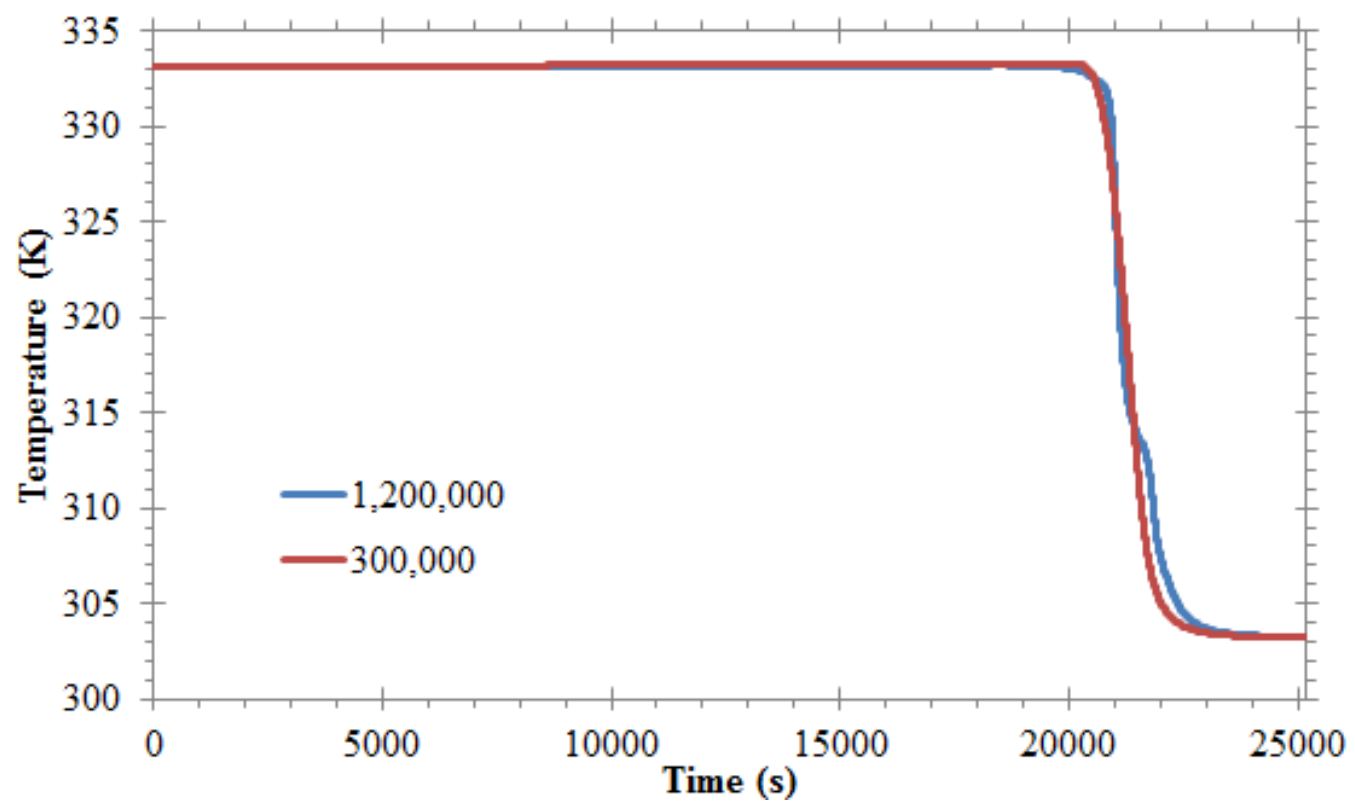

Figure D.1: Transient top outlet temperature of an initial hot tank during discharging showing the difference between a 300,000,1,200,000 nodes grids

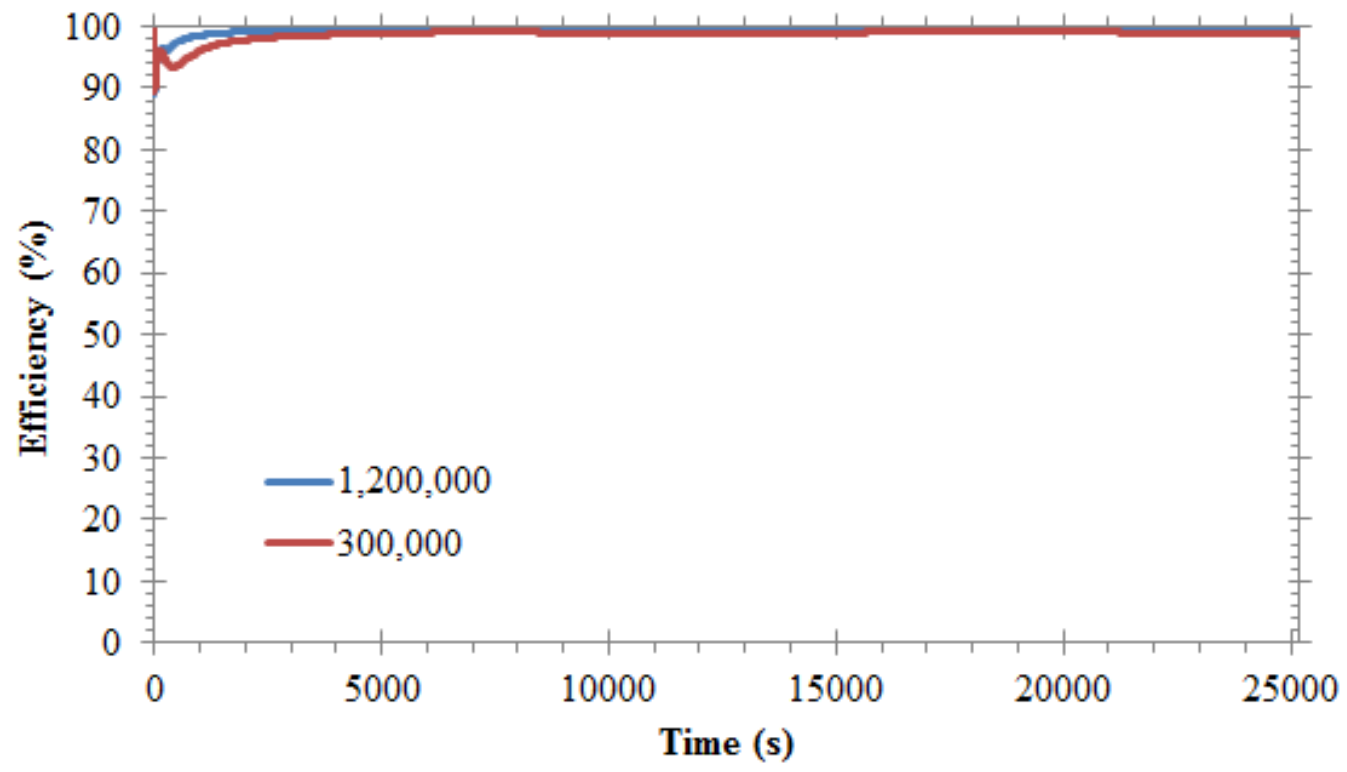

Figure D.2: Huhn's efficiency of an initially hot tank during discharging showing the difference between a 300,000, 1,200,000 nodes grids 
Figure D.1 presents the transient top outlet temperature of a initially hot tank during discharging. The results show that the curves for the two grid intensities are very similar. The coarse mesh underestimates the thickness of the thermocline, but the time when the temperature sharply drops is accurately simulated. Since, the thickness of the thermocline does not have a significant effect on the analysis of the tank, therefore, it can be concluded that the coarse grid has acceptable accuracy. Figure D.2 presents Huhn's efficiency of the tank. Huhn's efficiency for the two grids overlap, except at the beginning of the simulation where the finer grid predicts a higher Huhn's efficiency. As a result, it can be concluded that the coarser mesh predicts conservative solutions.

In conclusion, the coarse grid was able to make a significant saving in computational time while predicting similar solutions to the fine grid, therefore the analysis is grid independent. As a result, it is safe to assume that the other tank geometries with similar grids will be grid independent. 


\section{Appendix E}

\section{Tank 3 without Buoyancy}

In order to better understand the role of buoyancy for discharging conditions, a simulation was performed with the buoyancy force excluded. The conditions studied are for an initially fully charged tank at $60^{\circ} \mathrm{C}$ with a discharging inlet flow rate of 6 $\mathrm{L} / \mathrm{s}$ and temperature of $30^{\circ} \mathrm{C}$.

Figure E.1 shows temperature contours of a tank with buoyancy activated and another with buoyancy deactivated at a range of times up to 175 minutes which is about half the tank turnover time. The inlet is located at the bottom right side of the tank and exits at the top left. As shown in Figure E.1, the tank with buoyancy deactivated becomes almost fully mixed at half the tank turn over time (6 hours) while the tank with activated buoyancy has little mixing taking place. It is clear that 25 minutes into the discharging simulation that most of the mixing in the tank without buoyancy is a product of the inlet jet that had to make a very sharp turn into the tank when it reached the end of the bottom baffle. This penetration introduced significant mixing within the center of the tank, leading to almost all fluid in that region to be fully mixed. The fluid that stayed hot after 125 minutes is where the 
fluid was essentially stagnant and therefore not easily accessed. In contrast, the fluid in the tank with buoyancy was moving in the tank as a plug, except the first 25 minutes of the simulation where the bottom of the tank appears to be almost fully mixed.

Therefore, it was learned that most of the mixing that takes place in Tank 3 (Rysanek's recommended tank) is initiated from the sharp turn that the fluid makes when it reaches the end of the bottom baffle. Additionally, the tank with buoyancy has significant mixing at the bottom of the tank in the first 25 minutes of the simulation. 


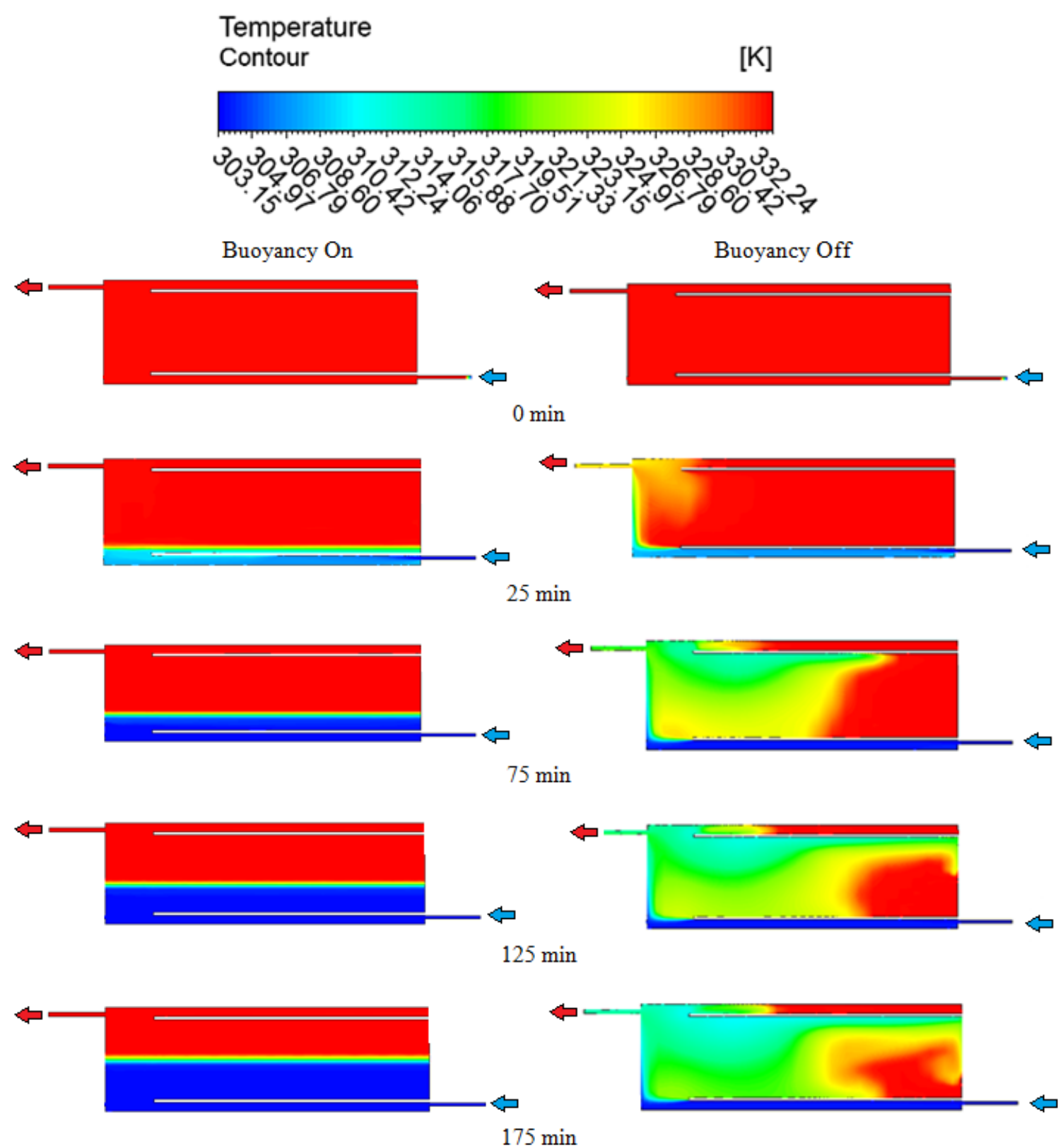

Figure E.1: Transient temperature contour plots of Tank 3. Left: tank with buoyancy activated, Right: tank without buoyancy The tank inlet is located at the bottom right of the tank while the outlet is located at the top left 